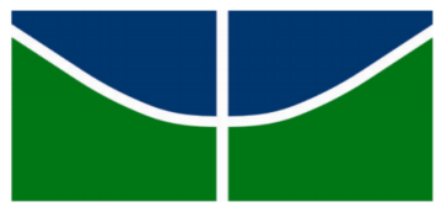

Universidade de Brasília

Instituto de Psicologia

Departamento de Psicologia Clínica

Programa de Pós-Graduação em Psicologia Clínica e Cultura

Efeito de Programas de Preparação para Aposentadoria:

Um Estudo Experimental

CRISTINEIDE LEANDRO-FRANÇA

Brasília-DF

Junho de 2016 


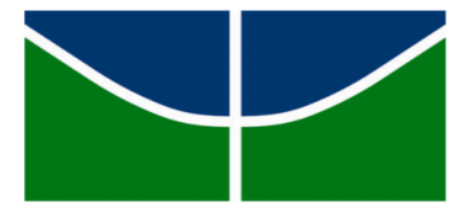

Universidade de Brasília

Instituto de Psicologia

Departamento de Psicologia Clínica

Programa de Pós-Graduação em Psicologia Clínica e Cultura

\section{Efeito de Programas de Preparação para Aposentadoria: Um Estudo Experimental}

CRISTINEIDE LEANDRO-FRANÇA

Tese apresentada ao Programa de Pós-Graduação em Psicologia Clínica e Cultura da Universidade de Brasília como requisito parcial à obtenção do título de Doutora.

Orientadora: Prof ${ }^{a}$. Dra. Sheila Giardini Murta

Brasília-DF

Junho de 2016 


\section{Efeito de Programas de Preparação para Aposentadoria: Um Estudo Experimental}

BANCA EXAMINADORA

Prof. a Dra. Sheila Giardini Murta

Universidade de Brasília - UnB

Presidente da Banca

Prof. a Dra. Lucia Helena de Freitas Pinho França Universidade Salgado de Oliveira - UNIVERSO Membro Titular

Prof. a Dra. Janaína Bianca Barletta Universidade Paulista - Unip. Membro Titular

Prof. ㄹ Dra. Margô Gomes de Oliveira Karnikowsk Universidade de Brasília - UnB Membro Titular

Prof. ${ }^{a}$ Dra. Eliane Maria Fleury Seidl Universidade de Brasília - UnB

Membro Titular

Prof. ․ Dra. Isolda de Araújo Gunther Universidade de Brasília - UnB Membro Suplente 
Dedico este trabalho ao meu marido Antônio, a nossa filha Ingrid e a minha orientadora Sheila Murta que tanto me apoiaram nessa jornada, incentivando-me a vencer os desafios e abrir novas e afortunadas portas... 
Se você abre uma porta, você pode ou não entrar em uma nova sala. Você pode não entrar e ficar observando a vida. Mas se você vence a dúvida, o temor, e entra, dá um grande passo: nesta sala vive-se! Mas, também, tem um preço... São inúmeras outras portas que você descobre. Às vezes curtem-se mil e uma. O grande segredo é saber quando e qual porta deve ser aberta. A vida não é rigorosa, ela propicia erros e acertos. Os erros podem ser transformados em acertos quando com eles se aprende. Não existe a segurança do acerto eterno.

A vida é generosa, a cada sala que se vive, descobrem-se tantas outras portas. $\mathrm{E}$ a vida enriquece quem se arrisca a abrir novas portas. Ela privilegia quem descobre seus segredos e generosamente oferece afortunadas portas. Mas a vida também pode ser dura e severa. Se você não ultrapassar a porta, terá sempre a mesma porta pela frente. É a repetição perante a criação, é a monotonia monocromática perante a multiplicidade das cores, é a estagnação da vida... Para a vida, as portas não são obstáculos, mas diferentes passagens!

(Içami Tiba) 


\section{AGRADECIMENTOS}

À minha querida orientadora Sheila Murta por partilhar seu admirável conhecimento, pelo apoio constante, pela parceria em projetos, livros, artigos, congressos, por me motivar e empoderar a cada dia. Nos últimos seis anos, nós caminhamos juntas, trabalhamos intensamente no mestrado e doutorado, com alegria e leveza, contribuindo para a ciência e acima de tudo construindo uma relação de amizade e respeito. Suas orientações, sabedoria e suporte me motivaram a ir além, a aumentar minha autoeficácia e resiliência, a alcançar sonhos, para mim outrora inatingíveis, como realizar um doutorado sanduíche no exterior. Sheila, eu sou muito grata a você pela pesquisadora que me tornei. A você, todo o meu afeto e apreço!

Aos meus coorientadores holandeses, Prof. Dr. Kene Hénkens e Dra. Hanna van Solinge, (Netherlands Interdisciplinary Demographic Institute - Nidi) pelo respeito ao meu trabalho e aprendizagem que me proporcionaram. Ao Prof. Dr. Douglas Hershey (Oklahoma State University) pela oportunidade de trabalho conjunto na Holanda e por compartilhar gentilmente seus conhecimentos.

Aos professores doutores, membros da minha banca de qualificação e de defesa, Áderson Costa, Eliane Seidl, Fábio Iglesias, Isolda Gunther, Janaína Barletta, Lúcia França e Margô Karnikowsk pela disponibilidade, sugestões para aprimoramento do meu trabalho e participação no momento mais significativo da minha trajetória profissional.

Ao meu esposo Antonio e a minha filha Ingrid, pelo incentivo e apoio incondicional às minhas escolhas e decisões. Obrigada meus amores pela paciência, carinho e atenção. Vocês são minhas preciosas e melhores conquistas. Sou grata a Deus por tê-los colocado em minha vida. Filha querida, que este trabalho possa te inspirar de alguma forma, seja na vida profissional ou pessoal.

Aos meus pais, Carmelita e Francisco, pelas orações e ensinamentos éticos e morais os quais procuro carregar sempre comigo em minhas decisões e ações. Aos meus irmãos César, Cristina, João Dehon, Cealys, Clevane (in memoriam), sobrinhos (as), tios (as), cunhados (as), primo (as) pelo carinho e palavras de apoio, mesmo à distância. À minha irmã Christiane pelo apoio e por estar sempre ao meu lado nas horas que mais preciso.

À minha sogra Neusa pelas mensagens diárias que me fortaleceram enquanto estive fora do Brasil e a minha cunhada Mônica. Minha gratidão por cuidarem da minha filha enquanto estive ausente.

À Tereza Marques, minha querida professora de inglês que pacientemente ajudou-me a superar limitações e insegurança com relação à língua, lembrando-me sempre que errar é humano, que cometer "micos" é normal, me motivando a crer que o céu é o limite para quem quer vencer!

À Joyce Santos, Karen Weizenmann, Soraya Waquim, Jully Angel e Aline Dutra pelo auxílio na coleta e transcrição de dados. Ao Prof. Dr. Fabio Iglesias, Daniel Barbosa e Leonardo Barbosa pelo suporte na análise dos dados e pelas sugestões para aprimoramento do texto.

A CAPES, pelos investimentos em minha formação acadêmica no exterior. 
Aos colegas do Grupo de Estudo em Prevenção e Promoção da Saúde no Ciclo da Vida GEPPSVida, pelo apoio, trocas acadêmicas, amizade e pela oportunidade em refletir sobre questões teóricas e metodológicas relacionadas ao meu objeto de estudo.

À Juliana Seidl pela amizade e parceria em projetos, escrita de artigos, congressos e em especial na organização e escrita de nosso primeiro livro "Programas de Educação para Aposentadoria: Como Planejar, Implementar e Avaliar".

Aos amigos Angela Ferreira, Meirelane Naves e Marcelo Peixoto pela amizade, carinho, pelas palavras de incentivo e pelas trocas de experiências profissionais e de vida.

À Rose Marie Schenkels e Josie Scholten, meus fatores de proteção durante meu doutorado sanduíche na Holanda. Obrigada pelos momentos de descontração, pela atenção, receptividade, apoio, pelos passeios, por me apresentarem à cultura holandesa e por me receberem com hospitalidade à brasileira.

À Prof ${ }^{a}$. Dra. Lucia França pelas orientações na escolha da Instituição e coorientadores para o meu doutorado sanduíche. A ela, aos Professores Dr. José Carlos Zanelli, Dra. Dulce Helena Pena Soares e Dr. Mo Wang pelas respostas às minhas solicitações de informações sobre a literatura na área.

Ao grupo de pesquisadores e administradores do Netherlands Interdisciplinary Demographic Institute (Nidi) pelo reconhecimento ao meu trabalho, pela atenção às minhas demandas profissionais e pessoais, enquanto estive na Holanda, em especial Dra. Ellen Dingemans, Prof. Dr. Frans van Poppel e Jeannette van der Aar.

Aos queridos (as) colegas psicólogos, assistentes sociais, enfermeiros, médicos, nutricionistas, administradores, secretários e auxiliares que integram à equipe de profissionais da Diretoria de Saúde, Segurança e Qualidade de Vida da UnB, pelo carinho, amizade e apoio.

Ao Programa de Pós-Graduação em Psicologia Clínica e Cultura (PPG PsiCC), representado por renomados professores, em especial ao Prof. Dr. Maurício Naubem e Prof ${ }^{a}$. Dra. Inês Gandolfo, pelo apoio ao meu doutorado sanduíche e outras demandas. À querida Thamires Rodrigues, pela receptividade, empenho e auxílio em resolver as minhas solicitações encaminhadas a essa secretaria.

Ao Ministério do Planejamento e ao Centro de Educação a Distância (CEAD/UnB), em especial ao Carlos Cezar Soares Batista e à Prof ${ }^{a}$. Wilza Ramos, pela parceria e apoio na realização do Curso Educação para Aposentadoria, que posssibilitou a coleta parcial de dados da minha pesquisa.

À Universidade de Brasília-UnB, a qual eu tenho o imenso prazer de trabalhar e que tem me proporcionado muitas alegrias no decorrer da minha trajetória profissional e pessoal.

Aos participantes desta pesquisa, em especial aos servidores da UnB, Fiocruz, Icmbio, $C G U$ e INEP que colaboraram com este estudo em suas diferentes etapas. Desejo um dia encontrá-los e saber que estão realizando ações que favoreçam suas aposentadorias e um envelhecimento ativo e que estejam felizes com suas escolhas. Que vocês tenham todos (as) uma aposentadoria bem-sucedida! 


\section{SUMÁRIO}

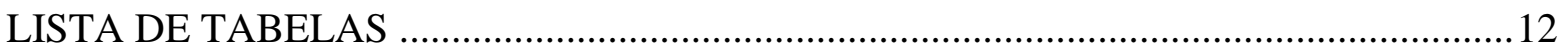

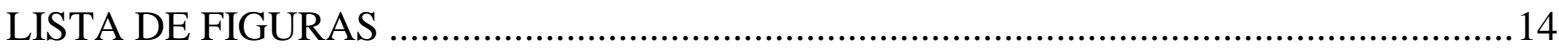

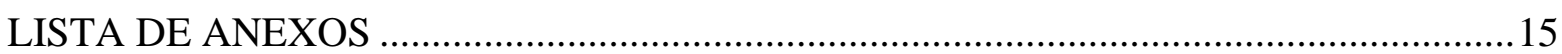

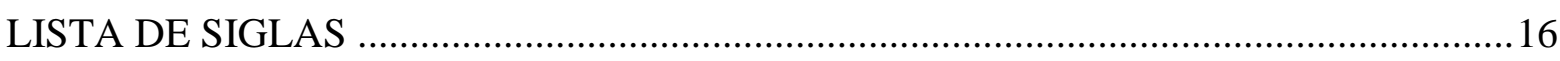

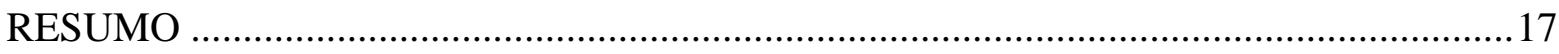

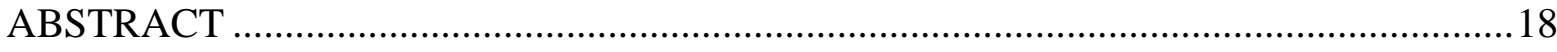

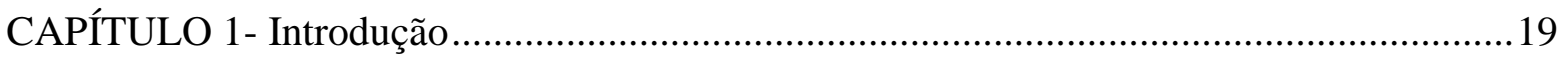

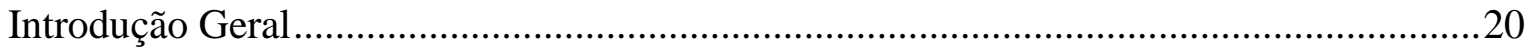

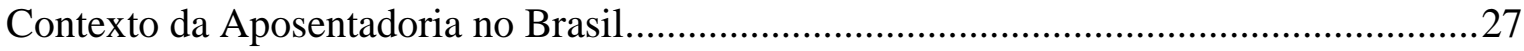

Regras para Concessão da Aposentadoria no Brasil........................................................32

Regime Geral da Previdência Social - RGPS .............................................................32

Regime Próprio da Previdência Social dos Servidores Públicos - RPPS ........................34

Programas de Preparação para Aposentadoria (PPA) ........................................................38

Fundamentação Teórica da Tese ................................................................................4

Modelo Transteórico de Mudança ...........................................................................43

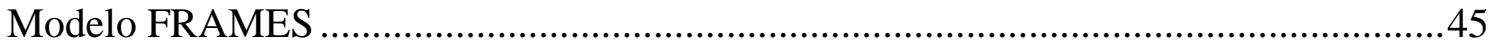

Modelo Perspectiva de Tempo Futuro - PTF...............................................................46

Modelo Perspectiva Dinâmica baseada em Recursos .........................................................47

Aprovação do Comitê de Ética.....................................................................................4

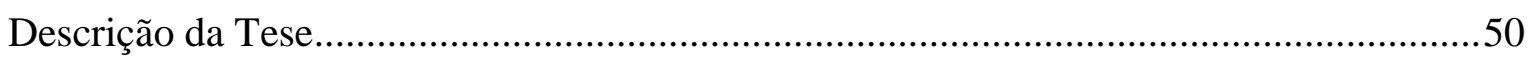

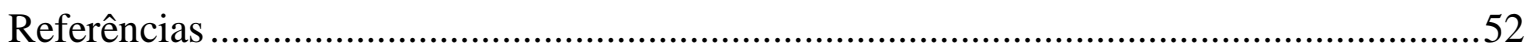

CAPÍTULO 2- Prevenção e promoção da saúde mental no envelhecimento: Conceitos e

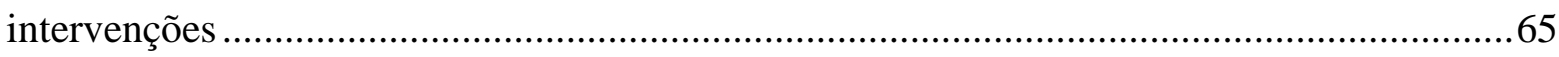

Resumo

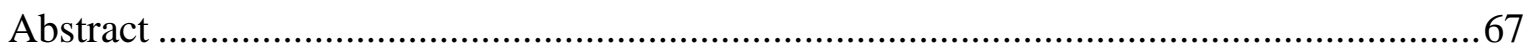



Envelhecimento Ativo: Conceito, Fatores Determinantes e de Risco ..................................71

Prevenção e Promoção à Saúde: Aspectos Históricos e Conceituais .....................................73

Focos de Intervenções na Prevenção e Promoção de Envelhecimento Ativo........................76

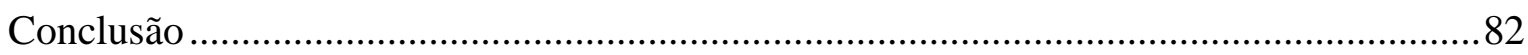

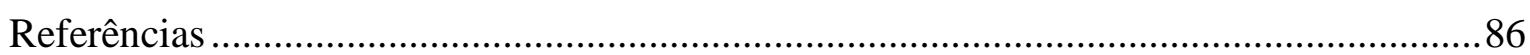

CAPÍTULO 3- Aposentadoria: Crise ou liberdade?............................................................90



Condições Associadas à Aposentadoria como Crise...........................................................92 
Condições Associadas à Aposentadoria como Liberdade..... .97

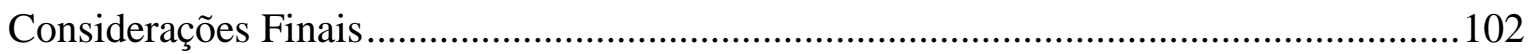

Referências

CAPÍTULO 4 - Evaluation of retirement planning programs: A qualitative analysis of

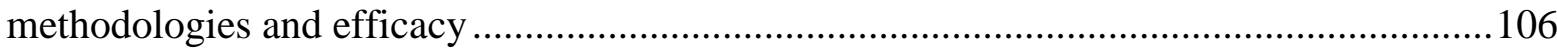

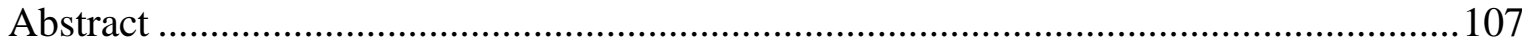

Methodological Aspects of Retirement Programs ..........................................................109

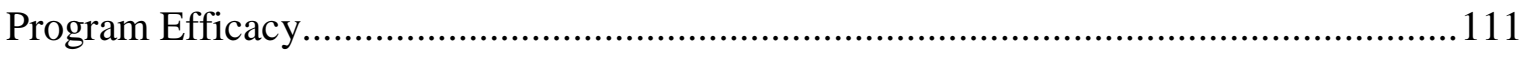

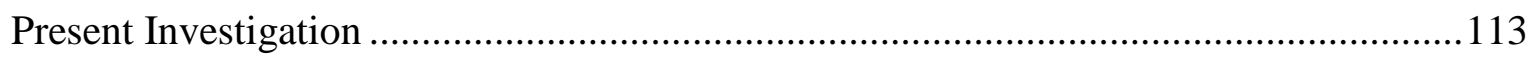



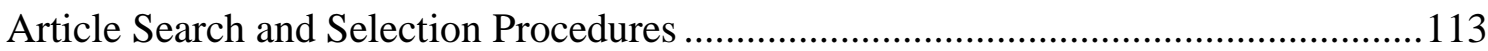

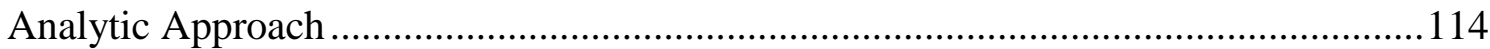

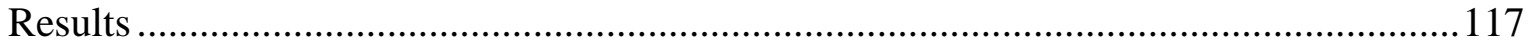

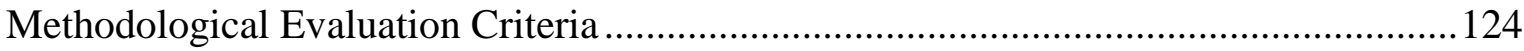

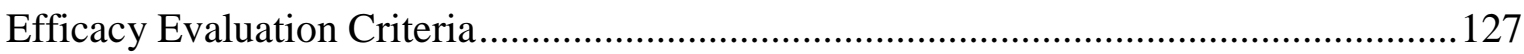

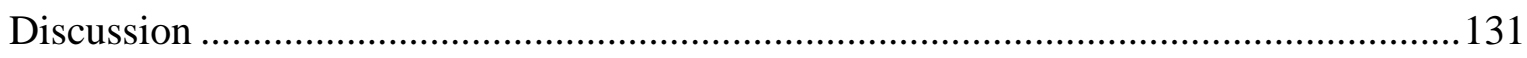

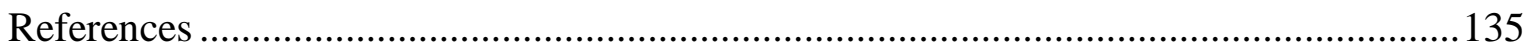

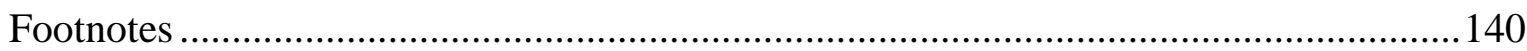

CAPÍTULO 5- Escala de perspectiva de tempo futuro relativa à aposentadoria: Evidências de validade

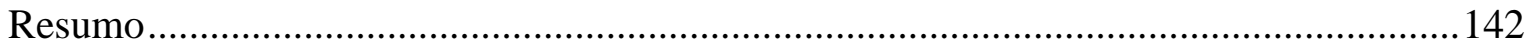

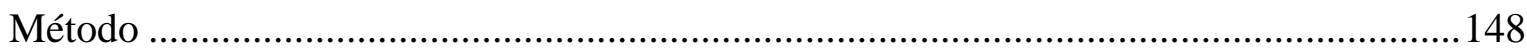

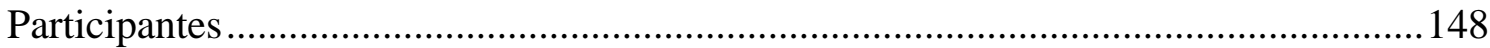

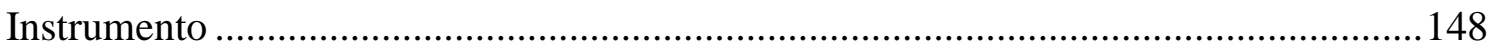

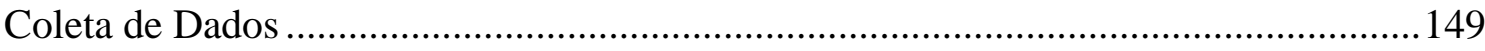



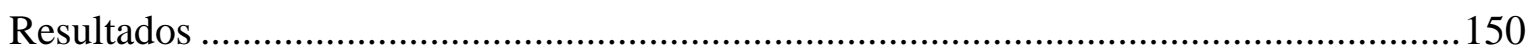

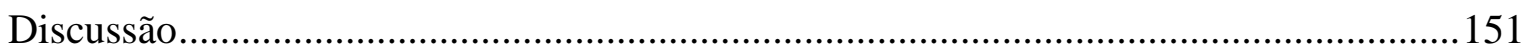

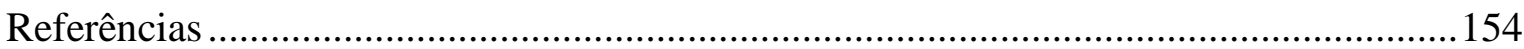

CAPÍTULO 6 - Evidências de eficácia e validade social de programas de preparação para





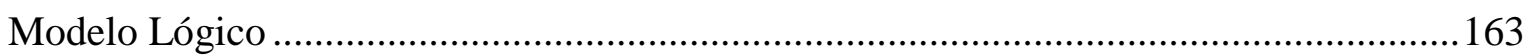

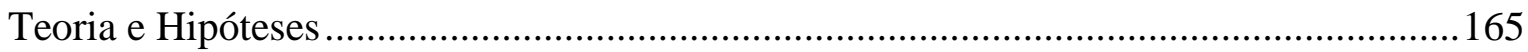

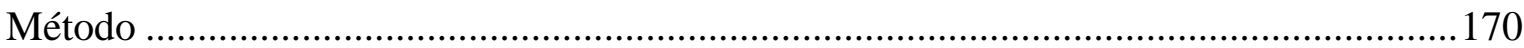

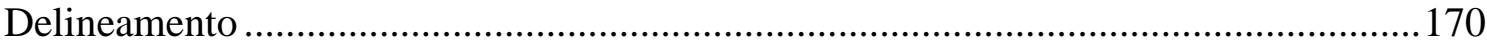






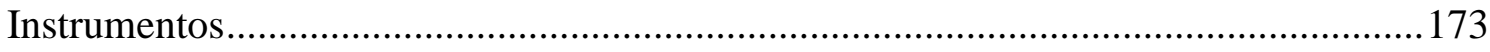

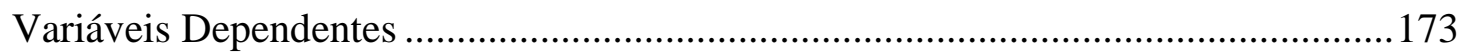

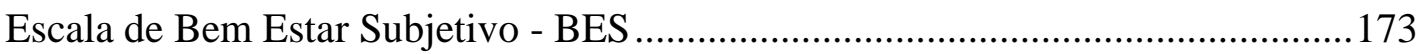

Escala de Perspectiva de Tempo Futuro relativa à Aposentadoria- EpersTFA ......173

Escala de Mudança em Comportamento de Planejamento para Aposentadoria .....174

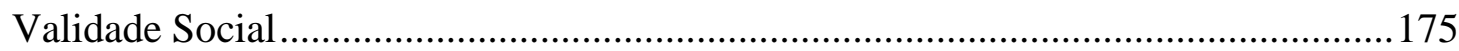

Questionário de Satisfação do Cliente ..............................................................175

Roteiro de Entrevista para Avaliação de Processo de Mudança ..............................176

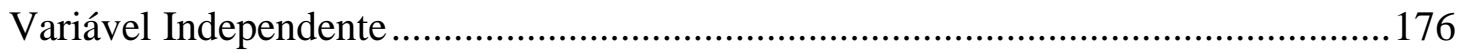

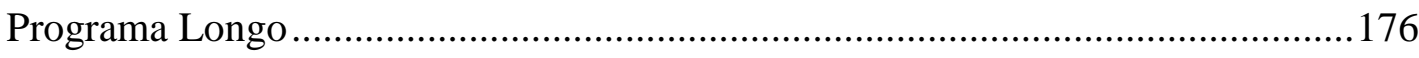

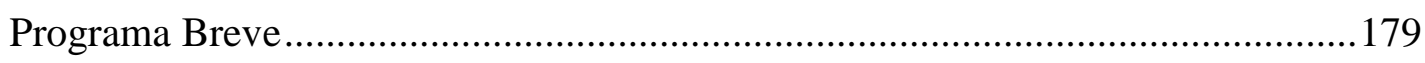

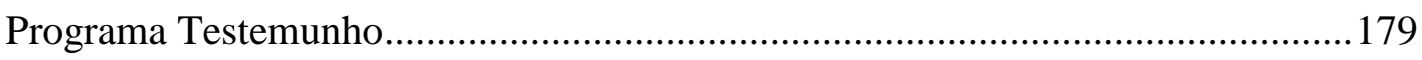



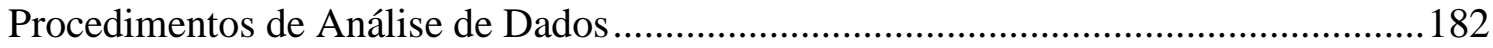

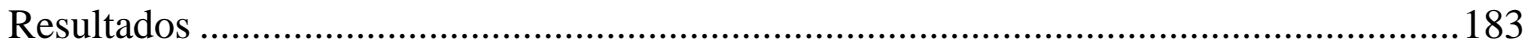

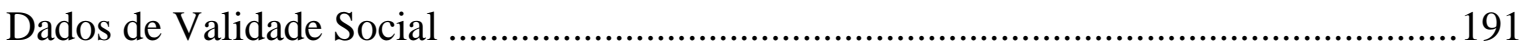

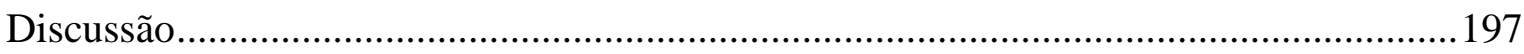

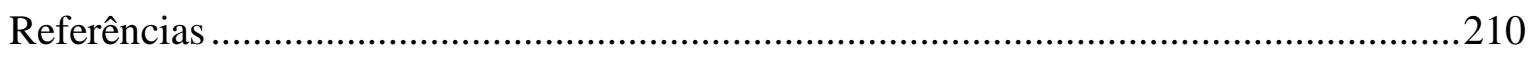

CAPÍTULO 7 - Effects of hree types of retirement preparation program: A qualitative study

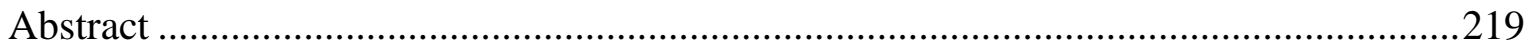

Retirement Context in Brazil................................................................................22

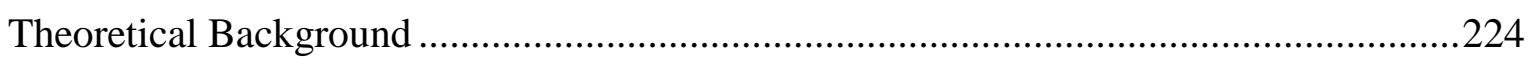

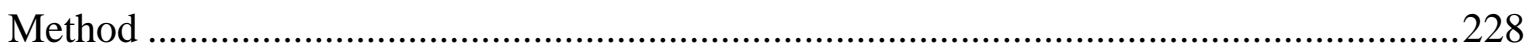

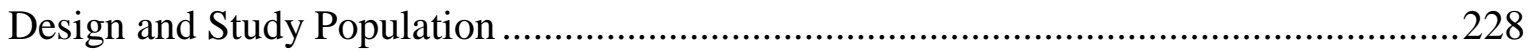

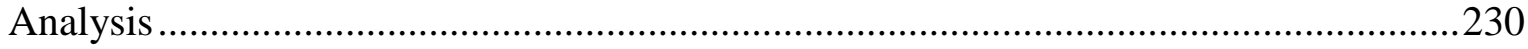

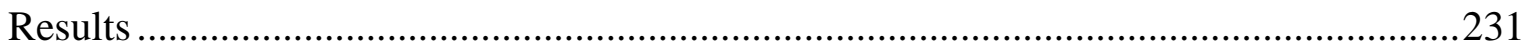

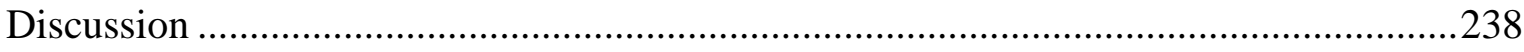

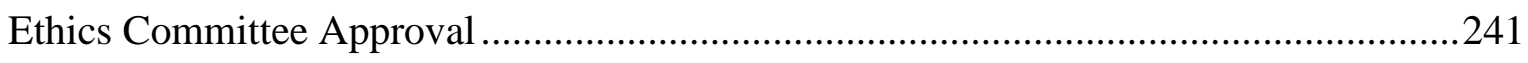

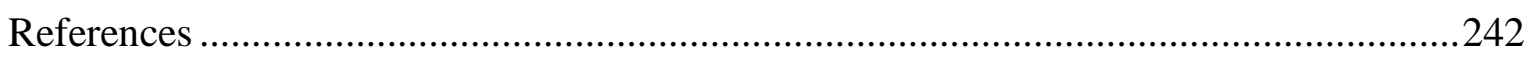

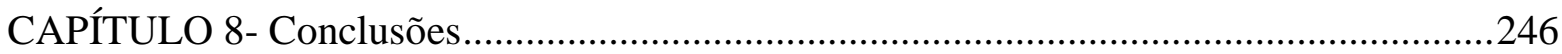

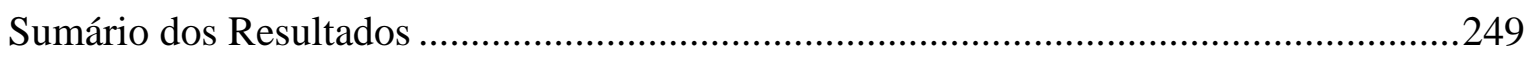

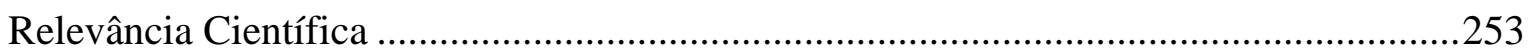

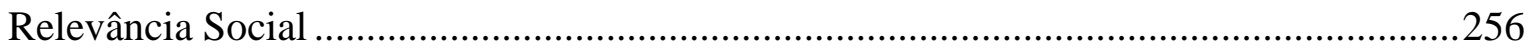

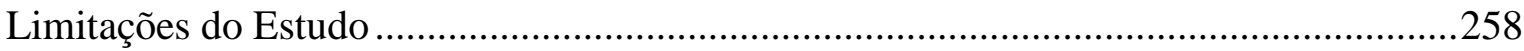

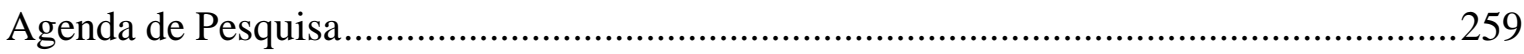




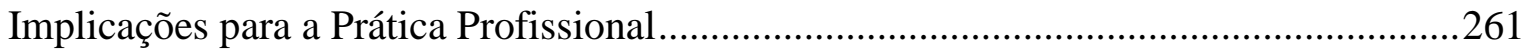



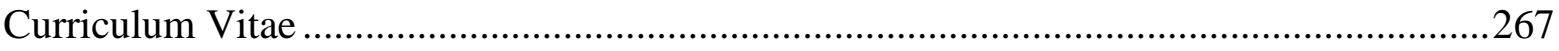

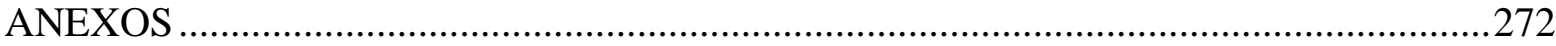




\section{LISTA DE TABELAS}

Capítulo 3 - Aposentadoria: Crise ou liberdade?

Tabela 1. Estratégias que Facilitam a Adaptação e Promovem a Qualidade de Vida na Aposentadoria

Capítulo 4 - Evaluation of retirement planning programs: A qualitative analysis of methodologies and efficacy

Table 1. Definition of Methodological Criteria used to Evaluate Intervention Studies .......115

Table 2. Definition of Efficacy Criteria used to Evaluate the Intervention Studies .............116

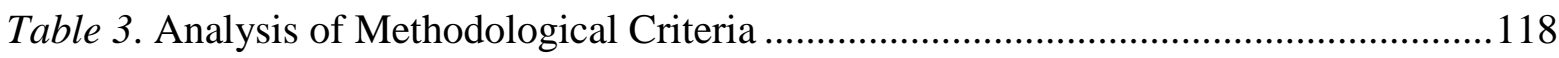

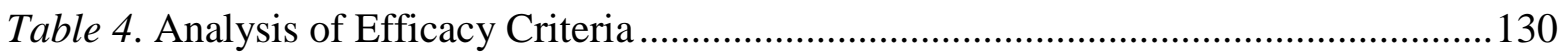

Capítulo 5 - Escala de perspectiva de tempo futuro relativa à aposentadoria: Evidências de validade

Tabela 1. Média e Desvio Padrão e Matriz Unifatorial dos Itens da Escala Perspectiva de Tempo Futuro Relativo à Aposentadoria.

Capítulo 6 - Evidências de eficácia e validade social de programas de preparação para aposentadoria: Um estudo experimental

Tabela 1. Características Demográficas da Amostra........................................................172

Tabela 2. Descrição de Temas, Objetivos e Técnicas utilizadas no Programa Longo .........178

Tabela 3. Descrição das Etapas, Objetivos e Atividades Realizadas na Intervenção Breve 179

Tabela 4. Descrição e Objetivos das Etapas da Intervenção Testemunho 180

Tabela 5. Valores de Estatísticas Descritivas Intra e Entre Grupos para as Variáveis

Dependentes, comparando Resultados do Pré-Teste e Follow-up.

Tabela 6. Valores de Significância Entre Grupos para as Variáveis Dependentes, conforme Condição Experimental, do Pré-Teste e Follow-up. 188

Tabela 7. Valores de Significância Intragrupos para as Variáveis Dependentes, conforme

Condição Experimental, comparando Resultados do Pré-Teste e Follow-up. 189

Tabela 8. Categorias, Frequência (F) e Relatos dos Participantes do Grupo Controle. 190 
Tabela 9. Frequência (F) e Percentual (\%) de Respostas ao Questionário de Satisfação. ...192 Tabela 10. Frequência (F) e Categorias das Perguntas "O Que Você Mais Gostou no Programa?"

Tabela 11. Frequência (F) e Categorias da Pergunta "O Que Você Menos Gostou no Programa?" 195

Capítulo 7 - Effects of hree types of retirement preparation program: A qualitative study

Table 1. Transtheoretical Model Applied to the Retirement Preparation Process 226

Table 2. Characteristics of the Programs for Retirement Planning .227

Table 3. Descriptive Results of the Coding of the Interviews $(\mathrm{N}=20)$ 


\section{LISTA DE FIGURAS}

Capítulo 1 - Introdução

Figura 1. Esperança de vida ao nascer segundo projeção populacional, para ambos os sexos, por unidades de federação brasileira - Ano 2016

Figura 2. Hipóteses de pesquisa.

Figura 3. Idade média anual dos servidores públicos federais civis do poder executivo por sexo e tipo de aposentadoria.

Figura 4. Principais pilares dos Programas de Preparação/Educação para Aposentadoria ...41

Figura 5. Estágios de mudança do comportamento segundo o Modelo Transteórico. 44

Figura 6. Princípios ativos da Intervenção Breve .46

Figura 7. Ilustração do Modelo Perspectiva Dinâmcia baseada em Recursos. 49

Capítulo 2 - Prevenção e promoção da saúde mental no envelhecimento: Conceitos e intervenções

Figura 1. Fatores determinantes do envelhecimento ativo

Capítulo 3 - Aposentadoria: Crise ou liberdade?

Figura 1. Aposentadoria como crise. .93

Figura 2. Aposentadoria como liberdade. .98

Capítulo 6 - Evidências de eficácia e validade social de programas de preparação para aposentadoria: Um estudo experimental

Figura 1. Modelo Lógico: Programas de Preparação para Aposentadoria 164

Figura 2. Fluxograma de participantes, randomização e desistências.

Figura 3. Média dos fatores que compõem as variáveis dependentes deste estudo, em cada condição experimental, nas avaliações de pré-teste e follow-up. 186

Figura 4. Relatos dos participantes e frequência de respostas (F) para aprimoramento da qualidade dos programas

Capítulo 7 - Effects of hree types of retirement preparation program: A qualitative study

Figure 1. Flow Chart of Participants and Dropouts 


\section{LISTA DE ANEXOS}

Anexo A. Autorização do Comitê de Ética .........................................................................22

Anexo B. Termo de Consentimento Livre e Esclarecido ......................................................22

Anexo C. Escala de Mudança em Comportamento de Planejamento para Aposentadoria...278

Anexo D. Carta Convite - Validação da Escala Perspectiva de Tempo Futuro relativa à Aposentadoria - EPersTFA (enviada via email) ..........................................................279

Anexo E. Escala de Mudança em Comportamento de Planejamento para Aposentadoria ...280

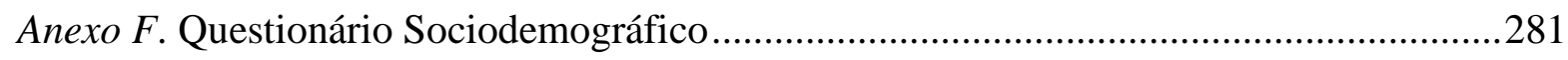

Anexo G. Escala de Bem - Estar Subjetivo (EBES) ..........................................................282

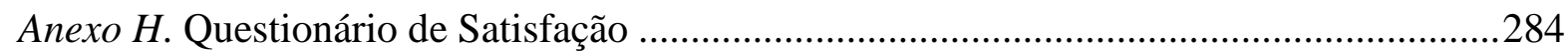

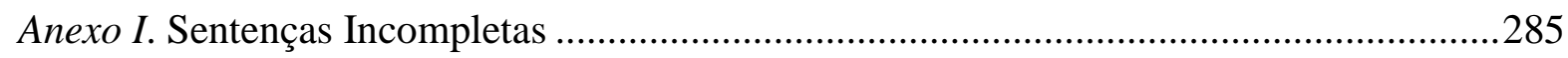

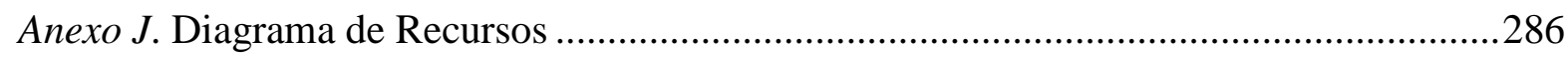

Anexo K. Técnica de Completamento de Frases...............................................................287

Anexo L. Apresentação de objetivos e principais técnicas aplicadas na intervenção longa .288

Anexo M. Roteiro de Entrevista para Avaliação de Processo de Mudança ..........................291 


\section{LISTA DE SIGLAS}

BVS - Biblioteca Virtual em Saúde

CQS-8 - Client Satisfctaion Questionnaire

EBES - Escala de Bem-Estar Subjetivo

EMCPA - Escala de Mudança de Comportamento em Planejamento para Aposentadoria EPersTFA - Escala de Perspectiva de Tempo Futuro relativa à Aposentadoria

FRAMES - Feedback, Responsability, Advice, Menu of options, Empathy e Self-efficacy

IB - Intervenção Breve

ICMBio - Instituto Chico Mendes de Conservação da Biodiversidade

IEA - Institute of Economics Affairs

INEP - Instituto Nacional de Estudos e Pesquisas Educacionais Anísio Teixeira

IPEA - Instituto de Pesquisa Econômica Aplicada

MPOG - Ministério do Planejamento Orçamento e Gestão

NIDI - Netherlands Interdisciplinary Demographic Institute

PIAE - Plano Internacional de Ação sobre o Envelhecimento

PPA - Programa de Preparação para Aposentadoria

PTF- Perspectiva de Tempo Futuro

SEBRAE - Serviço Brasileiro de Apoio às Micro e Pequenas Empresas

SENAI- Serviço Nacional de Aprendizagem Industrial

SPR - Society for Prevention Research

TCLE - Termo de Consentimento Livre e Esclarecido

TC - Terapia Comunitária

WHO - World Health Organization 


\section{RESUMO}

Os programas de preparação para aposentadoria se apresentam como estratégias potenciais de promoção de bem-estar e prevenção a problemas de saúde no envelhecimento. Neste sentido, o objetivo central desta tese é saber em que extensão três diferentes programas de preparação para a aposentadoria, longo, breve e testemunho (variável independente), promovem maior bem-estar subjetivo, melhor perspectiva de tempo futuro relativa à aposentadoria e mudanças em comportamento de planejamento para aposentadoria (variáveis dependentes). Esta tese tem como principal abordagem teórica o Modelo Transteórico de Mudança e é composta por seis estudos. O primeiro estudo trata-se de uma revisão narrativa que descreve aspectos históricos, conceituais e intervenções sobre prevenção e promoção à saúde mental da pessoa idosa. O segundo estudo, também revisão narrativa, identifica as condições associadas à percepção e à vivência da aposentadoria como favorecedora de crise ou bem-estar. O terceiro estudo é uma revisão integrativa que avalia a qualidade dos programas de planejamento para aposentadoria, considerando critérios metodológicos e de eficácia dos programas. Resultados mostraram fragilidades em critérios metodológicos e de eficácia, nos estudos analisados, apontando ausência de delineamento experimental ou quase-experimental, escassez de instrumentos previamente validados, de avaliações longitudinais dos programas e de procedimentos mais robustos para análise de dados. O quarto estudo testa evidências de validade de uma escala que investiga perspectiva de tempo futuro relativa à aposentadoria numa amostra de servidores públicos $(n=141)$. A análise fatorial da escala mostrou uma estrutura unifatorial, índice de consistência interna aceitável $(\alpha=0,74)$ e propriedades psicométricas satisfatórias. O quinto é um estudo empírico, com métodos mistos, que avalia a eficácia de três programas de preparação para aposentadoria (longo, breve e testemunho), em uma amostra de servidores públicos $(n=30)$, e tem como objetivos comparar resultados entre essas modalidades e um grupo controle, antes e seis meses após suas realizações e investigar a validade social desses programas. Os programas longo e breve adotaram estratégias dialogadas, informativas e vivenciais, e o programa testemunho contou com depoimento de uma servidora aposentada. Os instrumentos utilizados para coleta de dados foram entrevistas, questionário demográfico, escalas de mudança em comportamentos de planejamento para aposentadoria, de bem-estar subjetivo, de perspectiva de tempo futuro relativa à aposentadoria e questionário de satisfação do cliente. Os dados quantitativos foram analisados por estatística não paramétrica e descritiva e os dados qualitativos pela análise de conteúdo. Resultados desse estudo mostraram que não houve diferença estatisticamente significativa entre os grupos, no follow-up, quanto às variáveis dependentes. Uma possível explicação para isto é o reduzido tamanho da amostra, que limitou o poder estatístico. No entanto, na comparação entre grupos, resultados da estatística descritiva demonstraram eficácia das três intervenções com relação à variável bem-estar subjetivo em comparação aos resultados do grupo controle. Os dados revelaram ainda validade social elevada dessas intervenções no que se refere à relevância dos objetivos, aceitabilidade dos procedimentos e importância social de seus efeitos. O sexto é um estudo empírico, qualitativo, que apresenta os efeitos dos três programas, referidos no estudo anterior, sobre servidores públicos $(n=20)$. O foco da análise desse estudo foi estabelecer se os participantes apresentaram alterações cognitivas, motivacionais e/ou comportamentais e verificar o progresso dos participantes através dos estágios do Modelo Transteórico de Mudança durante o período de follow-up. Para análise dos dados, utilizou-se o software WeftQDA. Os resultados apontaram que o programa longo promoveu três tipos de mudanças (cognitivas, motivacionais e comportamentais), o programa breve possibilitou dois tipos de mudanças (cognitiva e motivacional) e o programa testemunho apenas um tipo de mudança (cognitiva). Os participantes do programa longo progrediram em mais estágios de mudança (contemplação, preparação, ação e manutenção), quanto à mudança de comportamento no planejamento da aposentadoria, do que os participantes do programa breve e testemunho. A principal contribuição desta pesquisa é preencher lacunas na literatura quanto ao uso de delineamento experimental para investigar os efeitos desses programas. Espera-se que resultados do presente estudo encorajem uma agenda de pesquisa em prevenção de riscos, promoção da saúde, bem-estar e qualidade de vida na aposentadoria.

Palavras-Chave: aposentadoria; envelhecimento; estudos de intervenção; eficácia. 


\begin{abstract}
Retirement preparation programs present themselves as potentials strategies to health and wellbeing promotion and of prevention of health problems in aging. The main goal of this research is to know to what extent three different retirement preparation programs in long, short and testimony (independent variable) formats, promote greater subjective well-being, better perspectives of the future during retirement and changes in behavior in planning for retirement (dependent variables). This research has as main theoretical approach the Transtheoretical Model Change and consists of six studies. The first study, a narrative review, describes the historical and conceptual frameworks and interventions in prevention and promotion of mental health of the elderly. The second study, a narrative review, identifies the conditions associated with the perception and experience of retirement as either a crisis situation or a well-being one. The third study, a integrative review, evaluates the quality of retirement planning programs considering methodological and efficacy criteria of programs. Results showed weaknesses in the methodological and efficacy criteria in the studies analyzed, indicating the absence of experimental or quasi-experimental design, shortage of validated instruments, longitudinal evaluations and robust procedures to data analysis. The fourth study tests evidence of validity of a scale that investigates perspectives of the future concerning the retirement of civil servants in a sample $(\mathrm{n}=141)$. Factor analysis showed one-factor structure, acceptable internal consistency $(\alpha=0.74)$ and satisfactory psychometric properties. The fifth is an empirical study that evaluates the efficacy of three retirement preparation programs (long, short and testimony), in civil servants sample $(\mathrm{n}=30)$, comparing results between long, short and testimony intervention and a control group in pretest and in a follow-up of six months. Moreover, the social validity of these programs was investigated. Long and short programs used educational activities and group discussion technique; and the testimony program included the testimony of an experienced retired civil servant. The instruments used for data collection were interviews, demographic questionnaire, scales of change in behavior of planning for retirement, scale of subjective well-being, scale of perspectives of the future during retirement and customer satisfaction questionnaire. Quantitative data were analyzed by non-parametric and descriptive statistics and qualitative data through content analysis. Results of the fifth study showed there were not statistically significant differences between the groups in terms of dependent variables. One possible explanation for this is the small sample size, which limited the statistical power. Descriptive statistical results showed the efficacy of three interventions on the subjective wellbeing variable comparing with results of the control group. The data also showed a high social validity of these interventions in social significance of goals, acceptability of procedures and social importance of interventions outcomes. The sixth study is a qualitative study, which shows the effects of the three programs mentioned in the fifth study on civil servants sample $(n=20)$. The focus of the analysis of this study was to establish whether the participants had cognitive, motivational and/or behavioral changes in retirement planning and check the progress of participants through Transtheoretical Model stages of change during the follow-up of six months. For data analysis, we used the WeftQDA software. The results showed that the long program promoted three types of changes (cognitive, motivational and behavioral changes), brief program promoted two types of changes (cognitive and motivational changes) and the testimony program promoted only one type of change (cognitive change). The main contribution of this research is to fill gaps in the literature on the use of experimental design to investigate the effects of the retirement preparation programs. Finally, it is expected that results of this study encourage a research agenda in risk prevention, health promotion, well-being and quality of life in retirement.
\end{abstract}

Keywords: retirement; aging; intervention studies; efficacy. 


\section{CAPítUlo 1}

Introdução 


\section{Introdução Geral}

Indicadores de longevidade no Brasil demonstram que governo e sociedade civil devem se preparar para o envelhecimento da população que conta, atualmente, com 23,5 milhões de pessoas com mais de 65 anos. Segundo o Instituto de Pesquisa Econômica Aplicada - IPEA (2013), a longevidade da população brasileira está em rápida ascensão. A esperança de vida do brasileiro cresceu em média 11,24 anos entre 1980 e 2010, com aumento significativo nas regiões Norte e Nordeste.

Em 2012, a expectativa de vida foi de 74,6 anos de idade aumentando para 74,9 anos em 2013. Em 2014, esse índice subiu para 75,2 anos, com estimativa de alcançar, em 2030, 79,53 anos (Região Sul) e 76,64 anos (Região Nordeste), para ambos os sexos, segundo dados da Tábua Completa da Mortalidade brasileira que é publicada, anualmente, pelo Instituto Brasileiro de Geografia e Estatística - IBGE. Os dados dessas tábuas são utilizados pelo Ministério da Previdência para calcular aposentadorias e a vida média para cada idade. A Figura 1 apresenta uma estimativa sobre a expectativa de vida ao nascer da população brasileira, por algumas unidades de federação, no ano de 2016.

A perspectiva de vida dos brasileiros se amplia na medida em que melhora a qualidade de vida da população. Logo, os fatores determinantes da longevidade no Brasil estão associados às melhores condições de saneamento, aos avanços médicos, farmacológicos, ao acesso à informação, à implementação de políticas públicas e benefícios sociais. Por outro lado, esses indicadores de desenvolvimento da qualidade de vida podem impactar a política atual de previdência pública, tornando iminentemente necessária uma mudança no sistema previdenciário, como forma de prevenir um desequilíbrio financeiro e garantir direitos à aposentadoria das gerações futuras (IPEA, 2013).

Além dos ajustes na legislação previdenciária, a implantação de políticas públicas e o desenvolvimento de estratégias que auxiliem o trabalhador a lidar com as mudanças 
decorrentes da aposentadoria apresentam-se como medidas favoráveis à promoção de um envelhecimento ativo, bem-estar e qualidade de vida na aposentadoria.

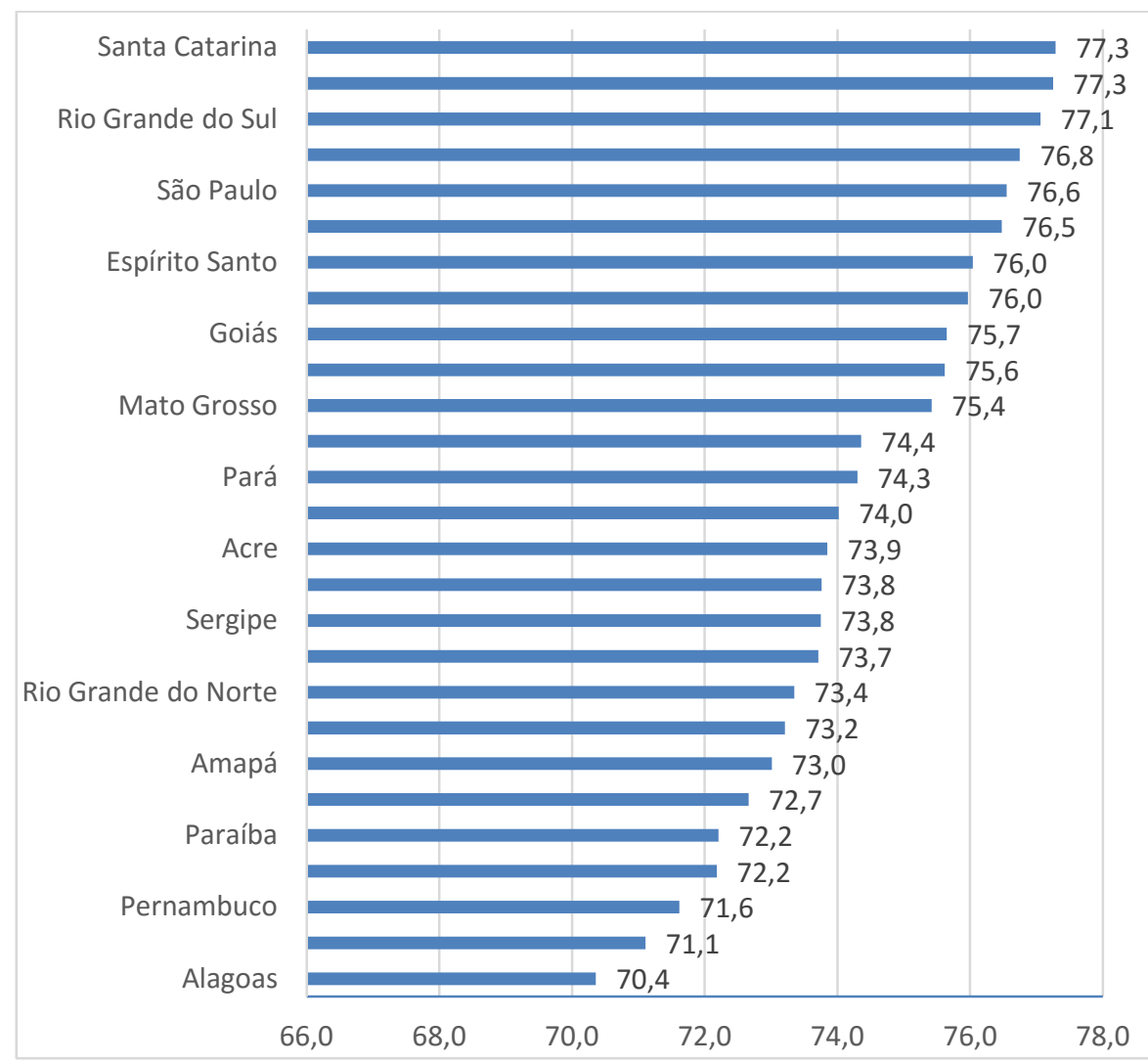

Figura 1. Esperança de vida ao nascer segundo projeção populacional, para ambos os sexos, por unidades de federação brasileira - Ano 2016

Nota: Instituto Brasileiro de Geografia e Estatística (IBGE) $)^{1}$

Políticas públicas internacionais, como o Plano Internacional de Ação para o Envelhecimento - PIAE (World Health Organization - WHO, 2002), e nacionais, como a Política Nacional do Idoso (Lei 8.842/1994), Estatuto do Idoso (Lei 10/741/2003) e a Política de Atenção à Saúde e Segurança no Trabalho do Servidor Público Federal - PASS (MPOG, Portaria Normativa SRH n $1.261 / 2010$ e no 3/2013) enfatizam a importância de implementação de programas com foco no bem-estar, qualidade de vida, envelhecimento ativo e preparação para aposentadoria (Leandro-França \& Murta, 2014b).

\footnotetext{
${ }^{1}$ Retirado de http://www.ibge.gov.br/home/presidencia/noticias/imprensa/ppts/0000000243.pdf
} 
As normatizações nacionais que orientam sobre a implementação de programas de preparação para aposentadoria são citadas abaixo, com destaque, respectivamente, para a Política Nacional do Idoso (Art.10, Inciso IV, Alínea c), o Estatuto do Idoso (Art. 28, Inciso II) e a Política de Atenção à Saúde e Segurança no Trabalho do Servidor Público Federal - PASS (Portaria SRH nº 1.261, Seção I, Parágrafo XV e nº 3, Art. 11, IV).

Art. 10. Na implementação da política nacional do idoso, são competências dos órgãos e entidades públicos:

IV - na área de trabalho e previdência social:

c) criar e estimular a manutenção de programas de preparação para aposentadoria nos setores público e privado com antecedência mínima de dois anos antes do afastamento;

Art. 28. O Poder Público criará e estimulará programas de:

II - preparação dos trabalhadores para a aposentadoria, com antecedência mínima de 1 (um) ano, por meio de estímulo a novos projetos sociais, conforme seus interesses, e de esclarecimento sobre os direitos sociais e de cidadania;

\section{Seção I}

\section{Quanto à Promoção de Saúde}

$X V$ - incentivar na Administração Pública Federal a implantação de Programas de Preparação à Aposentadoria - PPA;

Art. 11. No intuito de viabilizar o cuidado em saúde e aumentar o impacto dos programas e ações de promoção da saúde, priorizam-se os seguintes temas de interesse:

IV - envelhecimento ativo, educação e preparação para a aposentadoria;

Nas últimas duas décadas, tem aumentado consideravelmente a atenção dos pesquisadores sobre as modalidades de preparação/educação para aposentadoria, principalmente sobre as intervenções de longa duração. Entretanto, evidências sobre a 
eficácia desses programas são escassas. Assim, o uso de métodos mais robustos para avaliação desses programas mostra-se necessário.

Desse modo, o objetivo principal desta tese é avaliar o efeito de três programas (longo, breve e testemunho) de planejamento ou preparação para aposentadoria, em uma amostra de servidores públicos federais, e comparar resultados entre essas modalidades e um grupo controle, antes e seis meses após suas realizações.

Mais especificamente, a questão de pesquisa é compreender em que extensão três diferentes programas ou intervenções de preparação para a aposentadoria promovem maior bem-estar subjetivo, melhor perspectiva de tempo futuro relativa à aposentadoria e mudanças em comportamento de planejamento para aposentadoria?

Como objetivo secundário, busca-se verificar a validade social desses programas, considerando a relevância social dos objetivos, aceitabilidade dos procedimentos e importância social dos efeitos.

Para responder a questão de pesquisa, três hipóteses foram elaboradas:

H1: Os participantes do programa longo demonstrarão maior bem-estar subjetivo, melhor perspectiva de tempo futuro relativa à aposentadoria e mudanças em planejamento para aposentadoria, no follow-up, em comparação aos participantes do programa breve, testemunho e grupo controle.

H2: Os participantes do programa breve e testemunho apresentarão resultados similares, no follow-up, em bem-estar subjetivo, perspectiva de tempo futuro relativa à aposentadoria e mudanças em comportamentos de planejamento para aposentadoria.

H3: Os participantes do programa breve e testemunho demonstrarão um maior bem-estar subjetivo, melhor perspectiva de tempo futuro relativa à aposentadoria e mudanças em comportamentos de planejamento para aposentadoria, no follow-up, em comparação aos participantes do grupo controle.

Figura 2. Hipóteses de pesquisa

Nesta tese, o termo programa e intervenção são empregados como sinônimos. Por intervenção, entende-se qualquer programa, serviço, política ou produto que tem como objetivo influenciar ou mudar as condições organizacionais, ambientais e sociais das 
pessoas, como também suas escolhas, atitudes, crenças e comportamentos (Bowen et al., 2009; Gottfredson et al., 2015). Embora o conceito de intervenção seja mais amplo e inclua diversas práticas de ajuda, similares às experiências vivenciadas em intervenções de preparação para aposentadoria, para melhorar saúde, bem-estar e redução de problemas (Gottfredson et al., 2015), optou-se por empregar o temo "programa" neste estudo por se tratar de uma terminologia usual por profissionais que realizam tais ações em organizações brasileiras.

Esta pesquisa sobre eficácia de Programas de Preparação para Aposentadoria mostra-se importante por algumas razões. Primeiro, mesmo se revelando como área em ascenção, as ações com foco no planejamento da aposentadoria são pouco avaliadas, a julgar pela escassez de publicações (Murta, Leandro-França, \& Barbosa, 2014). A eficácia de programas de planejamento para aposentadoria tem sido difícil de alcançar nessa área tendo em vista a não especificação dos métodos de amostragem, de amostras randomizadas, da ausência de medidas pré e pós-intervenção e de follow-up, de estudos piloto, da falta de grupo controle e da escassez de instrumentos validados a essa população (Leandro-França, Murta, Hershey, \& Barbosa, 2016; Murta et al., 2014; Hershey, Mowen, \& Jacobs-Lawson, 2003). A inclusão desses critérios como métodos de avaliação de programas de preparação para aposentadoria mostra-se importante para oferecer à sociedade práticas baseadas em evidências. Avaliações de eficácia e efetividade são essenciais para assegurar a disseminação ou difusão de práticas eficientes (Flay et al., 2005, Gottfredson et al., 2015).

A definição de eficácia de uma intervenção está relacionada aos efeitos benéficos resultantes de um programa, projeto ou política específica, sob condições ideais de implementação. Ao avaliar a eficácia de uma intervenção ou programa, busca-se saber se o alcance das metas propostas nessas ações foi causado pelas estratégias adotadas e não 
decorrentes de variáveis aleatórias (Flay et al., 2005; Murta et al., 2014). Quanto maior a segurança em se atribuir os resultados às estratégias adotadas e não a explicações alternativas, maior a validade interna do estudo. Por outro lado, a avaliação de efetividade busca encontrar os efeitos produzidos pelas intervenções, no contexto natural, quando essas ações são aplicadas por multiplicadores capacitados pela equipe especialista, desenvolvedores da intervenção original. Quanto maior a segurança em se inferir que os resultados obtidos se aplicam a novas populações, maior a validade externa do estudo (Murta et al., 2014).

A priori, para testar e assegurar efeitos positivos da efetividade de uma intervenção é necessário conduzir uma avaliação de eficácia e, posteriormente, sendo esses critérios atendidos, prosseguir com a disseminação ou difusão da ação (Flay et al., 2005; Gottfredson et al., 2015, Murta et al., 2014). Assim, ao fazer uso de um delineamento experimental e mais robusto quanto às ameaças à validade interna, espera-se que o presente estudo ofereça evidências relativas à eficácia ou limitações de intervenções em planejamento para aposentadoria e contribua para preencher a lacuna da literatura quanto ao uso desse tipo de delineamento nas avaliações de programas dessa natureza.

A segunda contribuição refere-se à investigação da validade social das intervenções em planejamento para aposentadoria, descritas nesta pesquisa. Existe uma rica literatura sobre a história, os conceitos e os componentes da validade social no campo da saúde pública e da psicologia comportamental (Francisco \& Butterfoss, 2007; Lane \& BeebeFrankenberger, 2004). No entanto, o uso de avaliações de validade social ainda não foi registrado na literatura sobre programas de preparação para aposentadoria. Ao investigar a validade social das intervenções ou programas, procura-se conhecer como a intervenção pode afetar a vida dos participantes e se a qualidade de vida foi melhorada em função da intervenção. A validade social tem como componentes a relevância social referente aos 
objetivos da intervenção, a aceitabilidade dos procedimentos para alcançar esses objetivos e a avaliação da importância social dos efeitos da intervenção (Francisco \& Butterfoss, 2007; Kazdin, 1977; Lane \& Beebe-Frankenberger, 2004).

Em suma, os componentes da validação social foram originalmente desenvolvidos para investigar a aceitabilidade dos procedimentos e efeitos das intervenções comportamentais entre clientes e consumidores. Para acessar essas informações, métodos mistos de análises, quantitativas e qualitativas, podem ser empregados. De acordo com Francisco e Butterfoss (2007), nos estudos de saúde pública e pesquisas com a participação da comunidade, basear-se somente no teste de significância estatística pode resultar perder importantes dimensões sociais como, por exemplo, o impacto da intervenção na vida dos participantes e efeitos na comunidade. Logo, verificar a validade social dos programas realizados nesta pesquisa suprirá a lacuna na literatura da área, no que se refere a esse tipo de avaliação, como também acessará os efeitos dessas intervenções ampliando a análise dos resultados além da significância estatística.

Terceiro, a avaliação e divulgação de resultados comparativos de três modalidades de intervenção aplicadas à população em transição para aposentadoria poderá encorajar a implementação de ações similares em organizações públicas e privadas, como previsto na legislação brasileira. Embora recentes na administração pública brasileira, avaliações de programas públicos realizadas de forma sistemática e contínua são essenciais para se alcançar resultados eficazes, possibilitar um melhor uso e controle dos recursos públicos, fornecer dados importantes para implementar políticas mais consistentes e auxiliar os gestores de programas na tomada de decisão, resultando em uma gestão pública eficiente (Costa \& Castanhar, 2003).

Para uma compreensão abrangente do objeto de pesquisa desta tese, serão abordados ainda nesta seção introdutória: (1) panorama histórico da aposentadoria no 
Brasil, destacando as principais leis e regras para sua concessão, no âmbito privado e público; (2) formatos dos programas de preparação para aposentadoria; (3) principais considerações teóricas e conceituais que embasam os estudos desta tese; (4) considerações éticas da pesquisa e, por fim, (5) breve apresentação da tese e estudos realizados.

\section{Contexto da Aposentadoria no Brasil}

A palavra aposentadoria está etimologicamente associada a duas ideias: (1) a de retirar-se aos aposentos ou recolhimento ao espaço de não trabalho e (2) de jubilamento. A primeira é muitas vezes associada ao status de inatividade, abandono e finitude. A segunda possui uma concepção de otimismo, recompensa e contentamento (Soares \& Costa, 2011). Os trabalhadores possuem formas diferentes de entender e vivenciar esse processo. Se de um lado alguns percebem a aposentadoria como uma situação de crise, de outro existe a espera ansiosa por sua chegada, como tempo de liberdade e júbilo (Santos, 1990).

Apesar dessas diferenças individuais, o direito à aposentadoria sempre esteve presente como pauta de lutas e conquistas da classe trabalhadora (Soares \& Costa, 2011). Na história do Brasil, muitas mudanças ocorreram ao longo do tempo quanto à consolidação desses direitos. Uma das principais conquistas foi a criação do Ministério da Previdência Social ${ }^{2}$, em 1974, o qual define previdência como um seguro que garantirá benefícios financeiros aos trabalhadores na aposentadoria. A previdência social tem como proposta reconhecer e conceder direitos aos seus segurados. A receita proveniente da previdência social é utilizada para substituir a renda do trabalhador contribuinte, quando ele perde a capacidade de trabalho, seja pela doença, invalidez, idade avançada, morte, desemprego involuntário ou mesmo maternidade e reclusão.

\footnotetext{
${ }^{2}$ Fonte: Ministério da Previdência Social disponível em http://www1.previdencia.gov.br/
} 
No Brasil, os primeiros benefícios de previdência social foram previstos na Constituição Imperial de 1824, que promulgou o direito de proteção social com o uso de casas de socorros públicos (artigo 179, XXXI). Em 1835, surgiu o sistema mutualista de cobertura de riscos para servidores do Estado (Montepio Geral dos Servidores do Estado) a primeira entidade previdenciária de caráter privado a funcionar no país. Por meio desse sistema, vários associados contribuíam com um fundo financeiro para a cobertura de risco e os encargos eram divididos com todos os beneficiários (Ribeiro, Galdino, Martins, \& Ribeiro, 2015; Silva 2007).

O modelo Bismarkiano, com origem na Alemanha em 1883, durante o governo do Chanceler Otto Von Bismarck, foi o primeiro regime de previdência social que influenciou as regras de aposentadoria existentes no Brasil. No regime Bismarkiano, inicialmente, promulgou-se a Lei de Seguridade Social que garantia direitos para o trabalhador como o seguro-doença. De acordo com esse modelo, a concessão dos benefícios era de responsabilidade tripartite, ou seja, por meio do empregado, empregador e estado, similar ao adotado no Brasil nos dias atuais (Ribeiro et al., 2015; Serra-Gurgel, 2008; Silva 2007).

Dando seguimento ao contexto histórico, em 1884, criou-se uma lei que previa benefícios em caso de acidentes no trabalho e, posteriormente, com a promulgação da primeira Constituição da República brasileira (1888) foi regulamentado um montepio obrigatório (tipo de previdência privada) para os funcionários dos Correios (Decreto $\mathrm{n}^{\mathrm{o}}$ 9.212/1889). Em seguida, a Constituição de 1891, primeira a incluir o nome aposentadoria em suas normas, estabeleceu em suas declarações de direitos (Secção II, art. 75) a concessão da aposentadoria para servidores públicos em caso de invalidez:

Art. 75. A aposentadoria só poderá ser dada aos funcionários públicos em caso de invalidez no serviço da Nação. 
Outras leis importantes também foram promulgadas como, por exemplo, o Código Comercial (1850), que previa o direito de manutenção do salário por três meses na hipótese de acidente imprevisto e inculpado, e o Decreto $\mathrm{n}^{\mathrm{o}} 2.711$ (1860) que regulamentava o custeio dos montepios e das sociedades de socorros mútuos. Contudo, o marco da aposentadoria no Brasil ocorreu com o decreto $n^{\circ} 4.682 / 1923$ ou Lei Eloy Chaves. Esta lei decretou a criação das caixas de aposentadorias e pensões para ferroviários em situações de doenças, invalidez, velhice e morte de familiares (Ribeiro et al., 2015; Silva 2007).

Após a promulgação da Lei Eloy Chaves, o governo de Getúlio Vargas, iniciado em 1930, propôs mudanças importantes no regime trabalhista e previdenciário como, por exemplo, a criação do Ministério do Trabalho, Indústria e Comércio (decreto $\mathrm{n}^{\mathrm{o}}$ 19.433/1930) e da Consolidação das Leis do Trabalho - CLT, em 1943. Na esfera trabalhista destaca-se a criação do salário mínimo, a jornada diária de 8h de trabalho, o direito a férias anuais remuneradas, o descanso semanal e a regulamentação do trabalho do menor e da mulher. No campo previdenciário, a mudança mais significativa da era Vargas ocorreu com a reestruturação do sistema de Caixas de Aposentadorias e Pensões (CAP) que eram organizadas em geral por empresas e empregados.

Ainda na era Vargas, as CAP foram substituídas por Institutos de Aposentadorias e Pensões (IAP). Os IAP eram considerados autarquias vinculadas ao governo federal e entidades de proteção social de diferentes categorias profissionais como comerciários, bancários, industriários, ferroviários e dos servidores do estado. Posteriormente, os IAP foram transformados no Instituto Nacional da Previdência Social- INPS (Serra-Gurgel, 2008; Silva, 2007).

Em meados de 1960, o segundo modelo que provocou mudanças no sistema da seguridade social e previdência do Brasil foi um modelo originado da Inglaterra conhecido 
como "Plano Beveridge". A proposta desse modelo era unificar os seguros sociais existentes, determinar a universalidade de proteção social para todos os cidadãos, estabelecer a tríplice forma de contribuição e custeio, com predominância de custeio estatal (Ribeiro et al., 2015; Serra-Gurgel, 2008; Silva, 2007).

Influenciados por esses modelos, em 1960, governistas criaram a Lei Orgânica da Previdência Social (Lei no 3.807). Em 1966, surgiu o Instituto Nacional de Previdência Social (INPS) e, em 1969, criou-se o FGTS (Fundo de Garantia por Tempo de Serviço), com expansão da cobertura previdenciária para empregados domésticos, trabalhadores rurais e profissionais autônomos (Couto, 2000). Com base nessa Lei Orgânica, os trabalhadores rurais começaram a ter seus direitos assegurados e os benefícios como auxílio reclusão, maternidade e funeral foram regulamentados (Ribeiro et al., 2015).

Outro marco importante na historia da previdência social no Brasil ocorreu com a promulgação da Constituição de 1988, denominada Constituição Cidadã. Nesta, a aposentadoria foi inclusa como direito fundamental e de ordem social (Capítulo II, art. 6 e 7, Título VII):

Art. $6^{\circ}$ São direitos sociais a educação, a saúde, a alimentação, o trabalho, a moradia, o transporte, o lazer, a segurança, a previdência social, a proteção à maternidade e à infância, a assistência aos desamparados, na forma desta Constituição.

Art. $7^{o}$ São direitos dos trabalhadores urbanos e rurais, além de outros que visem à melhoria de sua condição social:

VIII - décimo terceiro salário com base na remuneração integral ou no valor da aposentadoria;

Ainda como normas gerais da Constituição Federal de 1988 (Ordem Social: Título VIII, Capítulo II, Seção, I, art. 194), consta a organização por parte do poder público das 
regras de seguridade social que é composta pelos pilares: saúde, previdência e assistência social:

Art. 194. A seguridade social compreende um conjunto integrado de ações de iniciativa dos Poderes Públicos e da sociedade, destinadas a assegurar os direitos relativos à saúde, à previdência e à assistência social.

Em 1988, foi também criado o Instituto Nacional de Seguridade Social - INSS. Trata-se de uma autarquia, vinculada ao Ministério da Previdência Social, que substituiu o Instituto Nacional de Previdência Social - INPS, responsável pelo pagamento da aposentadoria, pensão por morte, auxílio-doença, auxílio-acidente e outros benefícios para as pessoas que contribuíram e adquiriram o direito, como previsto em lei.

A partir desse panorama histórico, observa-se que as leis que regem a aposentadoria no Brasil são extensas e deveras complicadas, tendo em vista as modificações e inclusões de várias Emendas Constitucionais ao longo da história. Logo, na maioria das vezes, a aquisição desse benefício por parte dos trabalhadores é analisada caso a caso, considerando, por exemplo, idade, tempo de contribuição, tipo de serviço, regime institucional (serviço público, contrato, terceirização) dentre outros critérios.

A seguir, são apresentadas, resumidamente, as regras gerais para concessão da aposentadoria no Brasil para os trabalhadores e funcionários públicos celetistas (regidos pelo Regime Geral da Previdência Social- RGPS/INSS) e mais especificamente as dos servidores públicos federais, público-alvo deste estudo, regidos pelo Regime dos Servidores Civis - RPPS. Esses regimes possuem orçamentos e legislação específicos e são admitidos fundos de previdência complementar para ambos (Silva, 2007). 


\section{Regras para Concessão da Aposentadoria no Brasil ${ }^{3}$}

\section{Regime Geral da Previdência Social - RGPS}

As regras para concessão da aposentadoria no Brasil seguem alguns critérios préestabelecidos relacionados à (1) idade, (2) tempo de contribuição e (3) tipo de trabalho ou incapacidade adquirida durante a vida laboral e (4) aposentadoria especial. Aposentadoria, em regra geral, é concedida por idade aos homens com 65 anos e às mulheres com 60 anos. Os trabalhadores rurais do sexo masculino se aposentam por idade aos 60 anos e as mulheres, aos 55 anos. Contudo, mesmo que o(a) trabalhador(a) tenha alcançado a regra geral de aposentadoria por idade esta não é um direito garantido, pois para solicitar esse benefício é necessário que o(a) trabalhador(a) tenha contribuído por no mínimo 15 anos, que equivalem a 180 meses de contribuições. Esta regra é válida para todos os trabalhadores inscritos após 25 de julho de 1991. Para os que começaram a contribuir antes dessa data são necessárias 144 contribuições (Ribeiro et al., 2015).

Para adquirir a aposentadoria por tempo de contribuição é necessário possuir 35 anos de contribuição para o trabalhador do sexo masculino e 30 anos para as mulheres, como regra geral. Entretanto, algumas categorias como, por exemplo, professores da educação infantil, ensino fundamental e ensino médio têm um tempo de contribuição diferenciado (30 anos para os homens e 25 para as mulheres). Outra modalidade por contribuição é aposentadoria por tempo de contribuição proporcional, sendo exigida a idade mínima de 48 para mulheres com 25 anos de contribuição e 53 anos de idade para homens e 30 anos de contribuição, com no mínimo 180 contribuições. Entretanto, essa modalidade de aposentadoria foi retirada do texto constitucional pela emenda 20 , de 16/12/1998. No regime geral de previdência social administrado pelo INSS só tem direito a essa modalidade quem já contribuía até 16/12/1998.

\footnotetext{
${ }^{3}$ Fonte: Portal Brasil disponível em http://www.brasil.gov.br/economia-e-emprego/2014/05/confira-os-tiposde-aposentadoria-existentes-no-brasil.
} 
A aposentadoria por invalidez é concedida após laudo da perícia médica do INSS quando este considerar a pessoa totalmente incapaz para o trabalho, por motivo de doença ou acidente. Existe ainda a aposentadoria especial, destinada aos trabalhadores que comprovarem além do tempo de trabalho, efetiva exposição aos agentes nocivos à saúde, sejam físicos, químicos ou biológicos.

Recentemente, foi aprovada no Brasil uma nova regra de cálculo das aposentadorias denominada "Regra 85/95 Progressiva" (Medida Provisória n ${ }^{\circ}$ 676, publicada em 18 de junho de 2015). Esta medida pressupõe a soma de pontos (idade e tempo de contribuição) para fazer o pedido de aposentadoria, sendo 85 anos para mulheres e 95 anos para homens. Contudo, é obrigatório ter no mínimo 30 anos de contribuição para mulheres e 35 para homens.

Exemplos ${ }^{4}:$

Se uma mulher tem 55 anos de idade e 30 anos de contribuição, ela pode se aposentar porque a soma dos dois valores dá $85(55+30)$.

No caso de um homem, ele poderia se aposentar, se tivesse, por exemplo, 60 anos de idade e 35 anos de contribuição $(60+35=95)$.

Os trabalhadores que conseguirem atingir essa regra até dezembro de 2016 receberão o benefício de forma integral sem a aplicação do fator previdenciário ${ }^{5}$. O número de pontos evolui a partir de 2017 até 2022, para acompanhar a transição demográfica no Brasil.

\footnotetext{
${ }^{4}$ Retirado de http://economia.uol.com.br/empregos-e-carreiras/noticias/redacao/2015/07/04/entenda-comofunciona-a-regra-8595.htm

${ }^{5}$ Fator previdenciário (Lei 9.876/99) é uma fórmula matemática complexa que tem o objetivo de reduzir os benefícios de quem se aposenta antes da idade mínima de 60 anos para mulheres e 65 anos para homens e incentivar o contribuinte a trabalhar por mais tempo. Quanto menor a idade no momento da aposentadoria, maior é a redução do benefício. O Fator Previdenciário continua em vigor. Entretanto, não incidirá na aposentadoria de quem completar o patamar mínimo de pontos exigidos pela regra $85 / 95$.
} 
O cálculo de idade e tempo vai aumentando até 2027, quando atingirá a regra 90/100 conforme estimativa citada abaixo:

- 2015 a 2018: 85 para mulheres / 95 para homens;

- 2019 a 2020: 86 (mulheres) / 96 (homens);

- 2021 a 2022: 87 (mulheres) / 97 (homens);

- 2023 a 2024: 88 (mulheres) / 98 (homens);

- 2025 a 2026: 89 (mulheres) / 99 (homens);

- 2027: 90 (mulheres) / 100 (homens).

\section{Regime Próprio da Previdência Social dos Servidores Públicos - RPPS}

A partir da promulgação da Constituição Federal de 1988, muitas alterações ocorreram nas regras para concessão de aposentadorias e pensões dos servidores públicos brasileiros, titulares de cargo efetivo, destacando-se as Emendas Constitucionais de números 20/1998, 41/2003 e 47/2005 e a Lei 12.618 de 2012 (artigo 30) que institui o regime de previdência complementar para servidores públicos federais titulares de cargo efetivo.

Diante de tantas mudanças, entender todas as regras e critérios para aposentar-se é uma tarefa complexa. Logo, não é objetivo desta seção descrever todas as leis e emendas referentes ao assunto, mas, especificar apenas as regras gerais. As regras gerais para a aposentadoria dos servidores públicos estão descritas no artigo 40 da Constituição Federal de 1988. Além dessas regras, existem ainda as regras transitórias aplicadas para cálculo de aposentadoria apenas dos servidores que já atuavam no serviço público antes das emendas 20/1998, 41/2003 e 47/2005 entrarem em vigor.

O regime de previdência social destinado aos servidores públicos do Brasil é vinculado à administração direta. Os servidores públicos são regidos pelo regime jurídico estatutário regulamentado pela lei 8.112 de 1990, excluindo-se os empregados das 
empresas públicas. Em regra geral, os tipos de aposentadoria no serviço público dividemse em (1) voluntária, (2) por invalidez permanente e (3) compulsória.

Para obtenção da aposentadoria voluntária com proventos integrais é necessário que o servidor comprove o tempo de contribuição de 35 anos para homens e 30 para mulheres (no cargo, na carreira, no serviço público) e a idade de 65 anos para homens e 60 para mulheres. De acordo com as emendas 20/1998 e 41/2003 é necessário ainda possuir 5 anos no cargo e 10 anos no serviço público. A aposentadoria por invalidez permanente ocorre quando o servidor, por motivo de saúde, fica impossibilitado de realizar suas atividades laborais, necessitando de avaliação de junta médica oficial.

A aposentadoria compulsória é uma imposição legal que obriga o(a) servidor(a) a se afastar do cargo ou serviço público quando atinge a idade máxima prevista em lei (Murta et al., 2010). Conforme a CF/1988, a idade limite para homens e mulheres é 70 anos de idade. No entanto, recentemente, a Lei Complementar n. 152, de 3 de dezembro de 2015 alterou o dispositivo do artigo 40 da CF/1988 e aumentou o limite de idade para 75 anos:

Art. $2^{\circ}$ Serão aposentados compulsoriamente, com proventos proporcionais ao tempo de contribuição, aos 75 (setenta e cinco) anos de idade:

I - os servidores titulares de cargos efetivos da União, dos Estados, do Distrito

Federal e dos Municípios, incluídas suas autarquias e fundações;

II - os membros do Poder Judiciário;

III - os membros do Ministério Público;

IV - os membros das Defensorias Públicas;

$V$ - os membros dos Tribunais e dos Conselhos de Contas.

O aumento no limite da idade para se aposentar vem acontecendo em vários países, em razão do envelhecimento da população e dificuldades em manter a sustentabilidade de seus sistemas previdenciários. Na Holanda, por exemplo, desde a promulgação da Lei de 
pensões "General Old Age Act" ou em Holandês "Algemene Ouderdomswet" (AOW), de 1957, as pessoas que viveram ou trabalharam nos Países Baixos entre as idades de 15 e 65 têm direito a receber aposentadoria do Estado. Logo, desde essa data, a idade oficial (compulsória) para aposentadoria da população é 65 anos, independente do vínculo empregatício. Entretanto, poucos trabalhadores (menos de 10\%) aposentam com essa idade, ou seja, grande parte dos trabalhadores holandeses se aposenta precocemente (Dammam, Henkens, \& Kalmijn, 2011; Hershey \& Henkens, 2014).

Nos anos de 2001 a 2007, a idade média de aposentadoria dos trabalhadores holandeses foi em torno de 61 anos. A partir de 2007, a idade média da aposentadoria aumentou, alcançando 63 anos, em 2011. Assim como no Brasil, iniciativas políticas têm elevado progressivamente a idade limite da aposentadoria na Holanda de 65 para 67 anos até 2020 (65a em 2015, 66a em 2018, 67a em 2020). A partir de 2020, a idade mínima para aposentar será vinculada aos índices de expectativa de vida dessa população (Dammam et al., 2011). Tais mudanças foram necessárias, pois a expectativa de vida do holandês após 65 anos de idade continuará crescendo, com previsão de um aumento de 24 anos de vida para homens e 26 anos de vida para mulheres em 2060 (Dingemans, 2016).

No Brasil, a idade média da aposentadoria de servidores públicos em 2005 era 59 anos para homens e 57 para mulheres, elevando até 2015 para 62 anos (homens) e 59 anos (mulheres), segundo dados do Sistema Integrado de Administração de Recursos Humanos - SIAPE $^{6}$ apresentados na Figura 3:

\footnotetext{
${ }^{6}$ Retirado de http://www.planejamento.gov.br/assuntos/gestao-publica/arquivos-e-publicacoes/BEP
} 


\begin{tabular}{|c|c|c|c|c|c|c|}
\hline \multirow{2}{*}{ Ano } & \multicolumn{3}{|c|}{ Integral } & \multicolumn{3}{|c|}{ Proporcional } \\
\hline & Masculino & Feminino & Ambos & Masculino & Feminino & Ambos \\
\hline 2005 & 59 & 57 & 58 & 62 & 58 & 60 \\
\hline 2006 & 60 & 58 & 59 & 62 & 59 & 60 \\
\hline 2007 & 60 & 58 & 59 & 62 & 58 & 60 \\
\hline 2008 & 60 & 58 & 59 & 62 & 58 & 60 \\
\hline 2009 & 61 & 58 & 60 & 62 & 61 & 62 \\
\hline 2010 & 61 & 58 & 60 & 58 & 56 & 57 \\
\hline 2011 & 62 & 58 & 60 & 63 & 60 & 62 \\
\hline 2012 & 61 & 58 & 60 & 61 & 59 & 60 \\
\hline 2013 & 62 & 59 & 60 & 61 & 58 & 60 \\
\hline 2014 & 62 & 59 & 61 & 62 & 59 & 61 \\
\hline 2015 & 62 & 59 & 61 & 62 & 59 & 60 \\
\hline
\end{tabular}

Figura 3. Idade média anual dos servidores públicos federais civis do poder executivo por sexo e tipo de aposentadoria.

Considerando o aumento na expectativa de vida dos brasileiros, esses dados demonstram que os servidores públicos têm aposentado em idade considerada ativa. O mesmo acontece com os trabalhadores aposentados pelas regras do Regime Geral da Previdência Social (The Economist, 2012; Veras, 2012). Posto isso, o medo do futuro, insegurança na tomada de decisão quanto a se aposentar, perda da identidade, do prestígio, do convívio social no trabalho são percepções da aposentadoria como situação de crise (Santos, 1990; Leandro-França, 2014) e podem ser vivenciadas com mais intensidade em trabalhadores que se aposentam cedo. Pesquisas apontam ainda que a aposentadoria é um fator de risco ao suicídio em pessoas idosas. Isto ocorre em função da vivência da 
aposentadoria como crise, vinculada à depressão, isolamento social, conflitos conjugais e solidão (Minayo \& Cavalcante, 2012).

Desse modo, tais fatores potencializam a importância do planejamento da aposentadoria, por meio dos Programas de Preparação para Aposentadoria- PPA, como medida de prevenção aos problemas que ocorrem nessa fase da vida. Esses programas oferecem um espaço de escuta, diálogo, reflexão sobre perdas e ganhos com a aposentadoria, sobre alternativas de trabalho remuneradas ou não (França, L. 2002; França, C., 2012), ou seja, favorecem a troca de informações entre pessoas que se encontram em situações semelhantes, mas com perspectivas de futuro diferenciadas, produzindo assim mudanças cognitivas, motivacionais e comportamentais (França, Murta, Negreiros, Pedralho, \& Carvalhedo, 2013).

\section{Programas de Preparação para Aposentadoria (PPA)}

Os programas de preparação para aposentadoria são reconhecidos na literatura nacional e estrangeira como alternativas vantajosas ao trabalhador uma vez que auxiliam na adaptação à aposentadoria, geram mudanças positivas em saúde, qualidade de vida, atitudes e hábitos (Ogunbameru \& Sola, 2008; Wang, Henkens, \& van Solinge, 2011), promovem menos objeções à aposentadoria compulsória (Glamser \& DeJong, 1975), melhoram a satisfação com a vida após a aposentadoria (Glamser, 1981), ajudam os trabalhadores a conquistarem mais independência na aposentadoria, diminuem a apreensão com essa fase da vida e auxiliam na elaboração de projetos para o futuro (Makino, 1994).

Os programas de preparação para aposentadoria surgiram em meados de 1950 nos Estados Unidos da América (Glamser, 1981; Leandro-França et al., 2016; Muniz, 1996; Salgado, 1980 citado por Zanelli, 2000). No entanto, as publicações que descrevem tais programas começam a aparecer na literatura a partir da década de 1970, como observado 
em estudos clássicos de Beck (1984), Glamser e DeJong (1975); Glamser (1981), Heather (1996), Makino (1994), Marcellini, Sensoli, Barbini e Fioravanti (1997), Wolfe e Wolfe (1975) e Wotherspoon (1995).

No Brasil, conforme relato de especialistas e pesquisadores dessa área, algumas empresas como a Petrobrás, na década de 1980, e a Universidade Federal de Santa Catarina - UFSC, em 1993, já desenvolviam programas de preparação para aposentadoria (França et al., 2014). Além da Petrobras e da UFSC, um dos primeiros programas de preparação para aposentadoria do Brasil foi realizado por Magnani, Mendes, Melo, Barbosa e Bueno, em 1993, no Serviço Social do Comércio de São Paulo (Muniz, 1996; Seidl, Leandro-França, \& Murta, 2014). Estudos sobre os programas de preparação para aposentadoria começaram a ser divulgados na literatura na década de 1990 (França 1992; Muniz, 1996; Zanelli, 1994). No entanto, a experiência de um PPA realizada na Petrobras, de 1992 a 1996, nomeado como "Programa de Preparação para o Amanhã", é o primeiro programa a ser descrito na literatura nacional, que se tem conhecimento (Muniz, 1996; Seidl et al., 2014).

Apesar de serem consideradas práticas relevantes pelos gestores, e respaldadas em leis, os programas de preparação para aposentadoria não são amplamente realizados nas organizações brasileiras. Estudo de França et al. (2014) sobre a percepção dos gestores brasileiros de organizações públicas e privadas em relação aos programas de preparação para aposentadoria revelou que $82,5 \%$ dos gestores participantes $(\mathrm{N}=207)$ considera entre importante e muito importante a implantação dessas práticas. Todavia, somente $23 \%$ das organizações envolvidas na pesquisa realizam esses programas.

As organizações brasileiras que mais realizam PPA estão no setor público. Algumas instituições têm se destacado na implantação dessas ações, como Petrobrás, Furnas, Vale, Serpro e governos estaduais, por exemplo, o estado da Bahia com o 
Programa Prepare-se (França et al., 2014). As universidades públicas também têm um papel relevante no pioneirismo e continuidade dessas ações como a UFSC, que iniciou o PPA há mais de três décadas, atualmente o programa é intitulado Aposentação (Soares \& Costa, 2011), e mais recentemente, em 2010, a Universidade de Brasília com o Programa Viva Mais! (França et al., 2014; Murta et al., 2014).

Os tipos de programas se diferenciam em relação aos objetivos, número de encontros, duração, temas abordados e técnicas utilizadas. Usualmente, essas modalidades são intervenções que contemplam módulos informativos (conteúdo em forma de palestras sobre temas relacionados aos preditores de bem-estar e qualidade de vida e que possam auxiliar na decisão de aposentar) em conjunto com o uso de estratégias vivenciais (exposição dialogada e atividades interativas) (França 2002; França \& Carneiro; 2009; Glamser \& DeJong, 1975; Muniz, 1996; Murta, Caixeta, Souza, \& Ribeiro, 2008; Seidl et. al, 2014; Soares \& Costa, 2011).

Em geral, o conteúdo abordado em ações longas ou breves envolvem recursos que podem ser estruturados em três dimensões: (a) saúde e autonomia (atividade física, alimentação saudável, sexualidade, planejamento financeiro, legislação previdenciária, resiliência, autopercepção e projeto de vida); (b) ocupação e pós-carreira (trabalho, identidade e trajetória profissional, planos para o futuro, empreendedorismo, descoberta de novas habilidades, lazer, organização do tempo livre e ócio criativo); e (c) apoio social (relação conjugal, vínculos familiares, amizades, laços sociais, espiritualidade, afeto e intimidade, voluntariado) (Glamser \& DeJong, 1975; Seidl et al., 2014). Os principais pilares ou temas dos encontros de um PPA são apresentados resumidamente na Figura 4. 


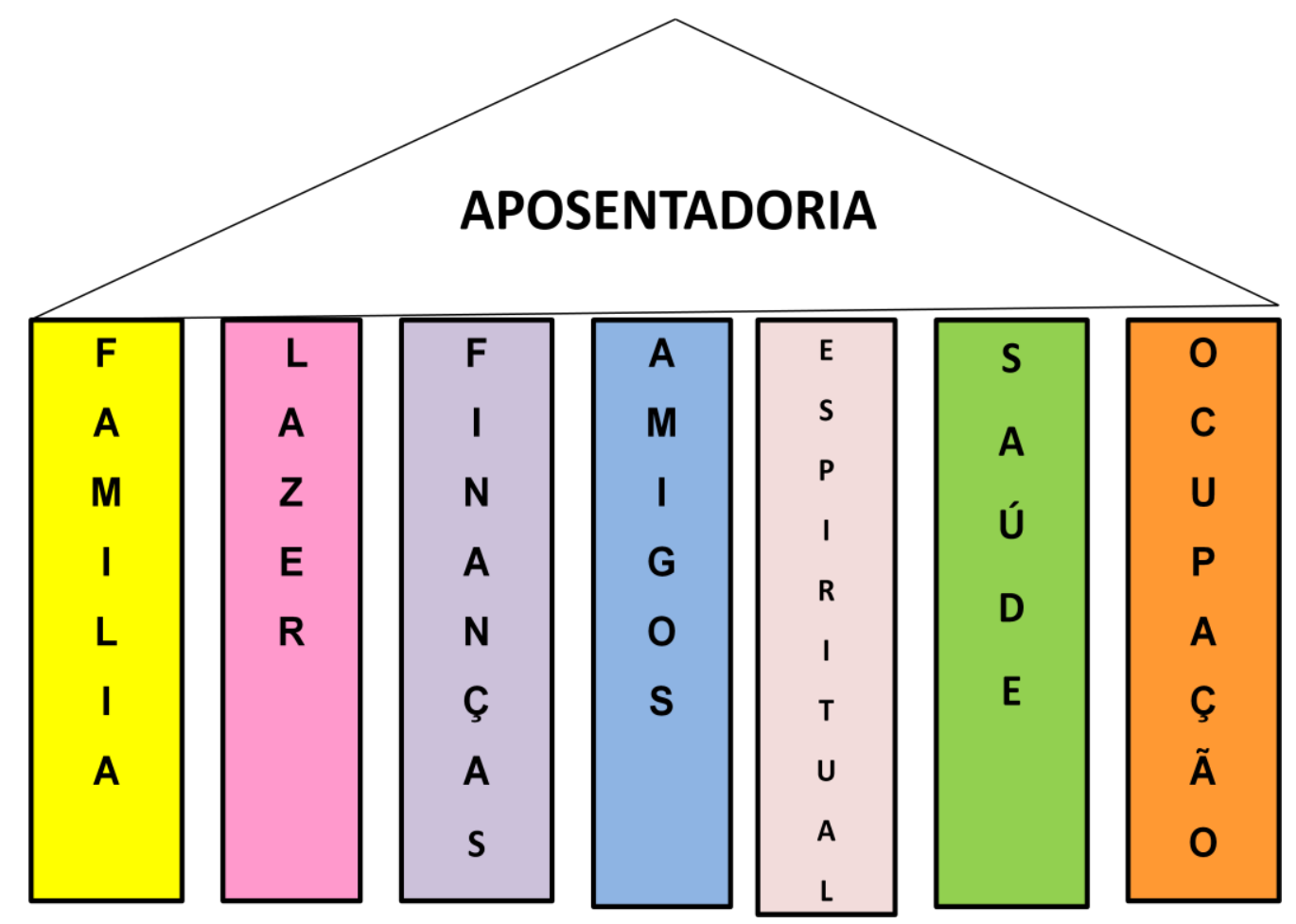

Figura 4. Principais pilares dos Programas de Preparação/Educação para Aposentadoria $^{7}$

O programa longo, especificado na literatura internacional como abrangente e na literatura nacional como continuado ou extensivo (Seidl et al., 2014; Soares \& Costa, 2011), resulta em sessões estruturadas, em grupo, aproximadamente de oito a 20 encontros, organizados em um período maior de tempo, com frequência semanal, quinzenal ou mensal (França, 2002; Glamser \& DeJong, 1975; Murta et al., 2014; Seidl et al., 2014; Soares \& Costa, 2011). O programa no formato breve ocorre em encontro único, com duração de 3 a 4 horas, de maneira individual ou em grupo, em apenas um período do dia. Considera-se, também, como formato breve as palestras ou seminários de sensibilização realizados ocasionalmente, com duração de uma a duas horas. Outro formato de programa com esse foco, usual em organizações brasileiras, é o tipo intensivo que se destaca pela sua característica de imersão, semelhante a workshop, no qual o conteúdo e as técnicas vivenciais e informativas, como as apresentadas no formato

\footnotetext{
${ }^{7}$ Figura elaborada pela autora da Tese.
} 
continuado, são distribuídos em períodos mais curtos e consecutivos como, por exemplo, em dois, três dias, ou em uma semana (Seidl et al., 2014).

Na presente tese, investigou-se um programa no formato longo denominado Viva Mais! descrito na literatura por Murta et al. (2014), outro no formato breve como proposto por França et al. (2013) e um denominado testemunho (depoimento de uma servidora aposentada), desenvolvido para uso nesta pesquisa, ainda que comumente praticado nas organizações. A descrição sobre conteúdo e estratégias utilizadas no programa longo estão no Anexo L.

Experiências com programas longos e breves incluindo diversas categorias profissionais são citadas na literatura (França, L., Menezes, \& Siqueira, 2012; França, C. et al., 2013; Glamser \& DeJong, 1975; Hershey, Walsh, Brougham, Carter, \& Farrel, 1998; Hershey et al., 2003; Laughlin \& Cotten, 1994; Muniz, 1996; Murta et al., 2014; Pereira \& Guedes, 2012; Soares, Costa, Rosa, \& Oliveira, 2007; Soares, Luna, \& Lima, 2010; Taylor-Carter, Cook, \& Weinberg, 1997; Zanelli, 2000). Entretanto, nota-se que são inexistentes as publicações sobre a modalidade testemunho com foco no planejamento para aposentadoria, embora essa seja uma abordagem usual no campo prático de planejamento para aposentadoria.

Testemunho, abordagem advinda do campo da pesquisa em saúde, é uma intervenção narrativa ou depoimento real, com detalhes emocionais sobre situações que evoquem imagens e sentimentos sobre uma determinada doença ou problema. Exemplo de intervenção testemunho na área da saúde é o depoimento de uma pessoa sobre a sua experiência pessoal com o câncer (Lemal \& van den Bulck, 2010). Muitos pesquisadores têm se perguntado quando, como e por que os testemunhos estimulam a percepção de riscos e a mudança de comportamentos (Busselle \& Bilandzic, 2008; Green, 2006). Uma variedade de fatores pode responder essas questões, incluindo possibilidades como (a) 
identificação com a situação-problema por meio da empatia, (b) perceber-se em situação similar, (c) perceber a história como uma representação realista do mundo e (d) ser absorvido ou transportado para dentro da narrativa (Busselle \& Bilandzic, 2008).

\section{Fundamentação Teórica da Tese}

Quatro modelos teóricos incorporados da área de saúde, psicologia e sociologia fundamentam os estudos que compõem esta tese:

\section{Modelo Transteórico de Mudança}

Primeiro, o modelo Transteórico de Mudança desenvolvido por Prochaska e DiClemente (1982), nos Estados Unidos na década de 1980, embasou os estudos centrais desta tese (Capítulos 6 e 7). A proposta deste modelo é entender como as pessoas modificam seus comportamentos ao longo do tempo, progredindo em direção à adoção e à manutenção de comportamentos saudáveis e pró-ativos por meio de estágios (Gunther \& Borges, 2014).

Os estágios de mudança se dividem em: pré-contemplação (indivíduos não consideram qualquer possibilidade de mudança de comportamento), contemplação (indivíduos estão conscientes da necessidade de mudar seus comportamentos), preparação (indivíduos pretendem tomar iniciativa para agir), ação (ocorrência real de mudança), manutenção (quando a mudança de comportamento acontece há pelo menos seis meses) e término ou finalização (quando o indivíduo segue realizando o comportamento adquirido, por pelo menos cinco anos). O término é considerado por alguns autores como a saída do ciclo de mudança (Prochaska, Norcross, \& DiClemente, 1994), ou seja, quando o indivíduo acredita ser "capaz de continuar com o novo comportamento sem sentir-se tentado a engajar-se no antigo padrão de resposta" (Gunther \& Borges, 2014, p. 46). 
Em adição a esse modelo, comportamentos de retrocessos ou recaídas podem acontecer e são considerados comportamentos típicos durante o processo de mudança (Gunther \& Borges, 2014; Leandro-França, Murta, \& Villa, 2014). A Figura 5 ilustra os estágios de mudança do comportamento segundo o Modelo Transteórico.

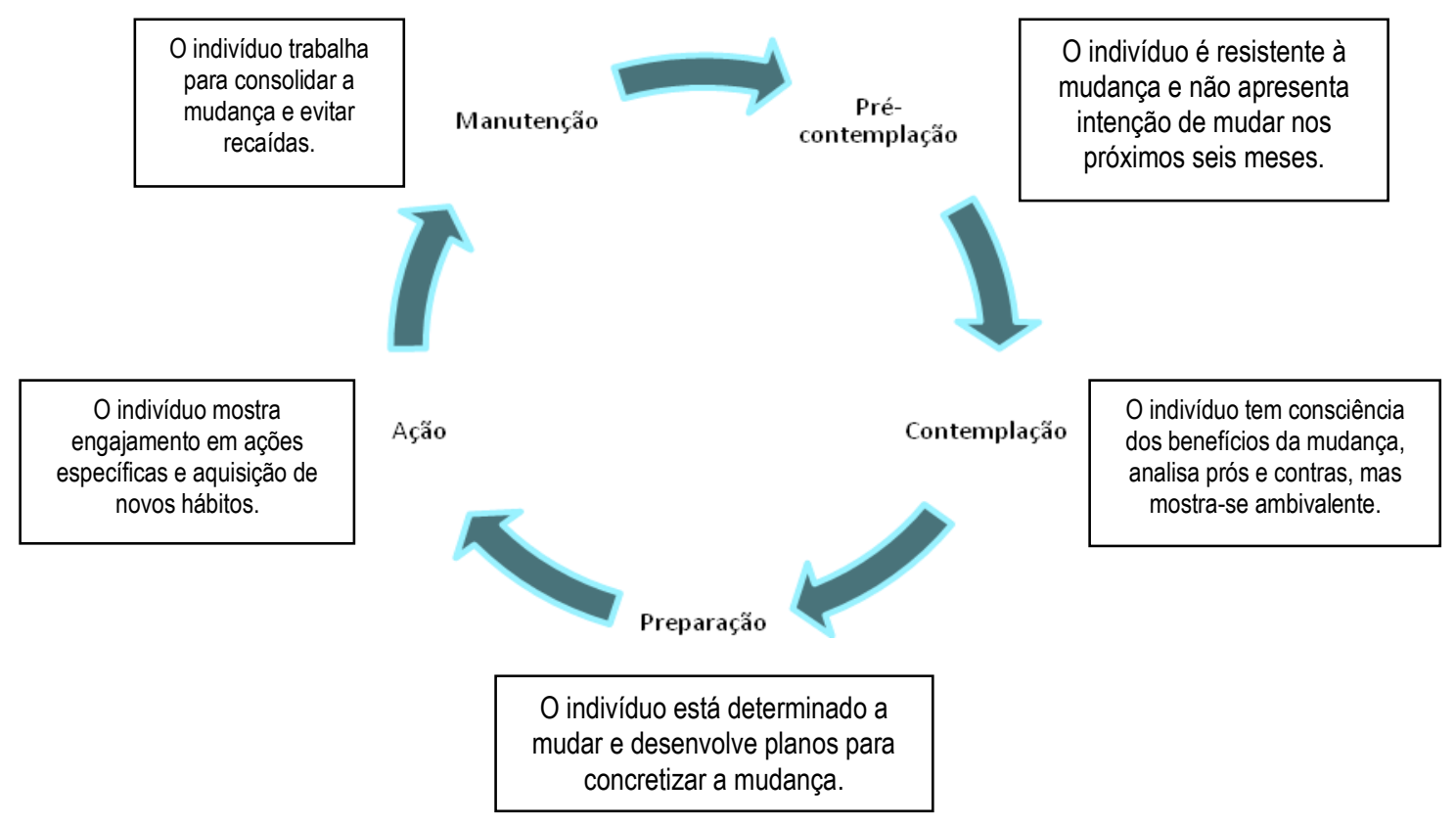

Figura 5. Estágios de mudança do comportamento segundo o Modelo Transteórico. Nota: Leandro-França, Barletta, Murta e Tavares (2015).

O modelo transteórico de mudança tem sido investigado e aplicado especialmente na área da saúde em situações como cessação do tabagismo, controle do peso e promoção de atividade física (Prochaska \& DiClemente, 1983). Recentemente, essa abordagem teórica, tem sido utilizada para fundamentar estudos sobre planejamento para aposentadoria e a construção de medida com esse foco como observado em estudos de França (2012); França et al. (2013), Leandro-França et al. (2014), Leandro-França, Murta e Iglesias (2014). Para Leandro-França et al. (2014), informações sobre os estágios de mudança são úteis a profissionais que coordenam os programas de preparação para aposentadoria, pois podem "subsidiar a tomada de decisão acerca de procedimentos mais 
apropriados para a intervenção, quando devem ser utilizados e quais comportamentos precisam ser promovidos" (p. 258).

\section{Modelo FRAMES}

O segundo modelo teórico desta tese está associado a fatores que promovem a efetividade das intervenções breves. Miller e Sanchez (1994) foram os primeiros a descrever este modelo na literatura, enfatizando os elementos motivacionais e estratégias terapêuticas encontradas em práticas breves de intervenções bem sucedidas (LeandroFrança et al., 2015).

Esses elementos compõem o acróstico FRAMES (do inglês Feedback, Responsability, Advice, Menu of Option, Empathy, Self-eficacy), apresentados na Figura 6. Feedback refere-se à retroalimentação por meio de uma avaliação prévia, responsabilidade significa autonomia e compromisso com as mudanças desejadas, aconselhamento são as orientações fornecidas pelo terapeuta ou facilitador, menu de opções é um catálogo de estratégias que estimulem à ação, empatia é a postura empática do terapeuta ou facilitador e autoeficácia é a confiança nos recursos pessoais (Leandro-França et al., 2014; Marques \& Furtado, 2004; Miller \& Rollnick, 2001).

Intervenções breves como ação na preparação para aposentadoria, compostas pelos elementos FRAMES, são consideradas pela literatura (França et al., 2013; Leandro-França et al., 2014) uma abordagem propícia à promoção de mudanças cognitivas, motivacionais e comportamentais favoráveis ao ajustamento à aposentadoria (França et al., 2013; Miller \& Rollnick, 2001). No presente estudo, utilizou-se na íntegra um modelo de intervenção breve desenvolvido e avaliado por França (2012). 


\begin{tabular}{|c|l|}
\hline $\mathbf{F}$ & $\begin{array}{l}\text { Feedback sobre comportamentos específicos e/ou } \\
\text { devolução de resultados com base em instrumentos } \\
\text { fidedignos }\end{array}$ \\
\hline $\mathbf{R}$ & $\begin{array}{l}\text { Autonomia e liberdade de escolha quanto à mudança } \\
\text { Compromisso pessoal com a mudança }\end{array}$ \\
\hline $\mathbf{A}$ & $\begin{array}{l}\text { Orientações e recomendações fornecidas pelo } \\
\text { profissional ao cliente sem julgamento de valor }\end{array}$ \\
\hline $\mathbf{M}$ & $\begin{array}{l}\text { Uso de estratégias e recursos como guias, folhetos, } \\
\text { vídeos oferecidos pelo profissional ao cliente }\end{array}$ \\
\hline $\mathbf{E}$ & $\begin{array}{l}\text { Atitude do profissional por meio de uma escuta } \\
\text { respeitosa e compreensiva }\end{array}$ \\
\hline $\mathbf{S}$ & $\begin{array}{l}\text { Confiança do cliente em suas habilidades e } \\
\text { potencialidades. }\end{array}$ \\
\hline
\end{tabular}

Figura 6. Princípios ativos da Intervenção Breve

Nota: Leandro-França et al. (2015).

\section{Modelo Perspectiva de Tempo Futuro - PTF}

O terceiro modelo refere-se ao construto PTF, o qual é conceituado como uma característica cognitiva motivacional da personalidade e investigado, desde a década de 1930, como uma dimensão temporal do futuro por teóricos como Kurt Lewin. Contudo, Joseph Nuttin (1909-1988) e Willy Lens, seu principal colaborador, foram os que mais contribuíram para desenvolver os conceitos que embasam este constructo na contemporaneidade (Schmitt, 2010).

Em geral, PTF é utilizada para investigar a orientação do indivíduo quanto ao alcance de metas futuras e pressupõe a capacidade de antecipar resultados futuros com base no comportamento presente. PTF é denominada ainda como um processo que tem como finalidade o alcance de um objetivo em curto (PTF restrita) ou longo prazo (PTF extensa) (Lens, Paixão, Herrera, \& Grobler, 2012; Schmitt, 2010). Indivíduos com PTF extensa ou aprofundada possuem objetivos claros para o futuro em longo prazo (ex. cinco 
anos a partir do presente), demonstram mais motivação e perseverança para alcançar os objetivos elaboram planos ou projetos com estruturas comportamentais sólidas, duradouras e equilibradas em relação aos que possuem uma PTF restrita (Lens et al., 2012; Schmitt, 2010).

No contexto da preparação ou planejamento da aposentadoria, compreender a perspectiva de tempo futuro pode ser útil na elaboração de planos sobre o que fazer na aposentadoria, pois, segundo este modelo teórico, pessoas que possuem objetivos claros para o futuro podem experimentar maiores níveis de satisfação pessoal e de vida. Logo, metas claras e específicas proporcionam o estabelecimento de intenções futuras e orientam a realização de comportamentos desejados (Stawski, Hershey, \& Jacobs-Lawson, 2007).

\section{Modelo Perspectiva Dinâmica baseada em Recursos}

O quarto e último referencial teórico que fundamenta os estudos desta tese tem como base elementos que integram uma perspectiva dinâmica baseada em recursos desenvolvida por Wang et al. (2011). Para esses pesquisadores, uma boa adaptação à aposentadoria está aliada ao investimento em mudanças comportamentais, respaldadas em recursos cognitivos, motivacionais, emocionais, financeiro, ocupacional-social, autonomia e bem-estar (Barbosa, Monteiro, \& Murta, 2016; Leandro-França et al., 2014; van Solinge \& Hénkens, 2008; Wang et al., 2011). São exemplos de recursos que promovem uma aposentadoria satisfatória, ter saúde e estabilidade financeira (Kim \& Moen, 2002; Richardson \& Kilty, 1991), possuir uma boa relação conjugal (Price \& Joo, 2005), ter vínculos conscientes, valorosos e prazerosos com a família, comunidade e amigos (van Solinge \& Henkens, 2008), forte autoestima e autoeficácia (Reitzes \& Mutran, 2004; van Solinge \& Henkens, 2008).

Segundo Wang et al. (2008), a adapatação à aposentadoria é um processo longitudinal no qual o nível de ajustamento a essa fase da vida pode mudar em função dos 
recursos que o indivíduo possui. Logo, esses recursos podem aumentar, diminuir ou permanecer inalterados ao longo dos anos. Na perspectiva desse modelo, as pessoas que possuem recursos valorizados por elas e que atendem suas necessidades terão menos dificuldade em se adaptar à aposentadoria. Em contrapartida, a diminuição de tais recursos provocará efeitos adversos sobre a adaptação à aposentadoria (Wang et al., 2011).

Percebe-se que os programas de preparação para aposentadoria existentes no Brasil adotam essa perspectiva dinâmica baseada em recursos ao abordarem em seus encontros os preditores para uma aposentadoria bem-sucedida como, por exemplo, cuidados com a saúde, investimentos financeiro e em atividades de ocupação pós-carreira. No entanto, a literatura da área ainda não fez uso desse aporte teórico para fundamentar esses programas em seus formatos longo ou breve. Por esse motivo, este modelo foi um dos selecionados para fundamentar o presente estudo. Em resumo, esta perspectiva dinâmica baseada em recursos pode ser aplicada para identificar fatores que influenciam a qualidade no ajustamento ou adaptação à aposentadoria. A Figura 7 mostra uma variedade de fatores antecedentes que podem interferir de forma positiva ou negativa nesse processo de ajustamento, incluindo variáveis do nível macro, organizacional, trabalho, familiar e individual. 


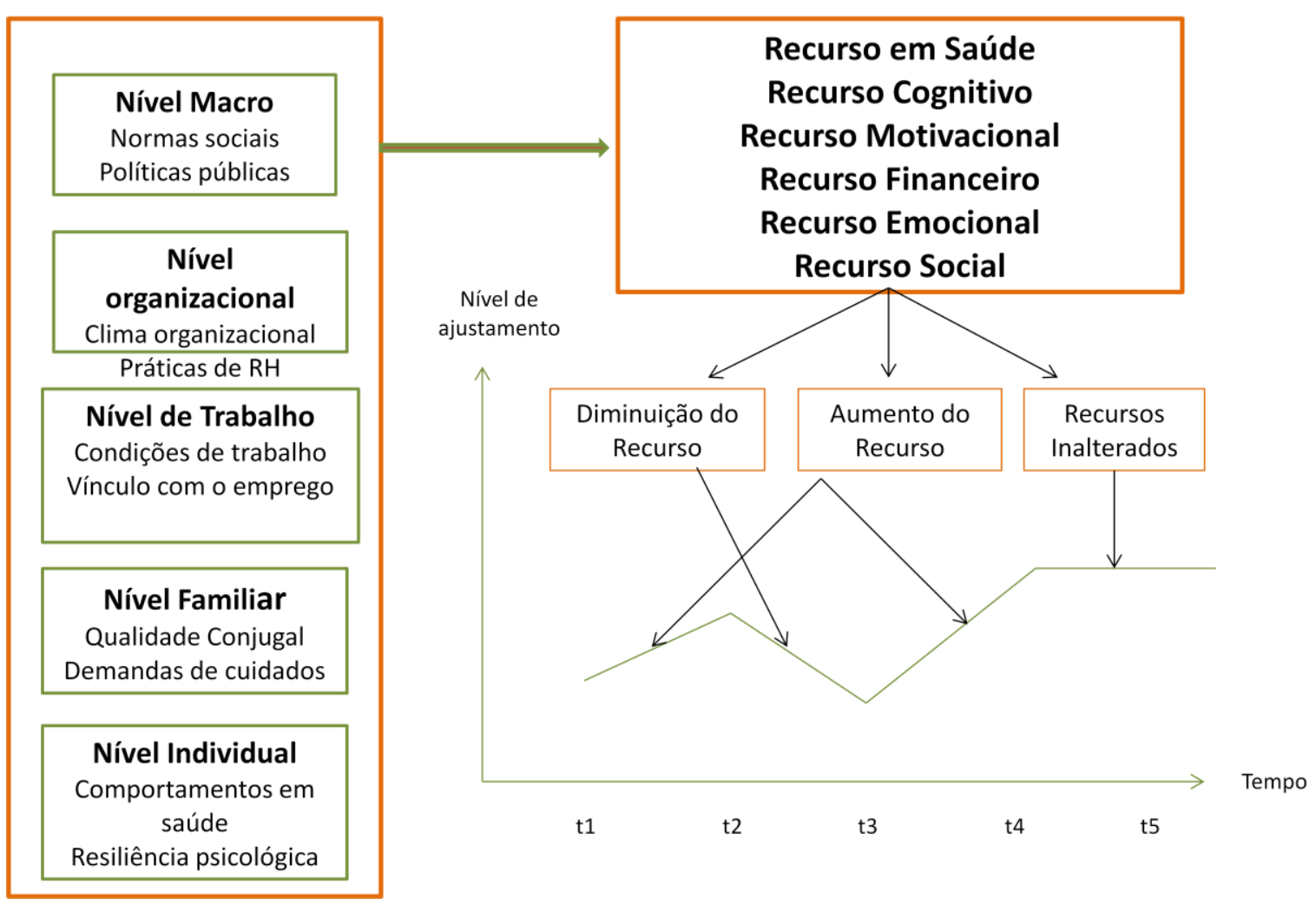

Figura 7. Ilustração do Modelo Perspectiva Dinâmcia baseada em Recursos Nota: Wang, Henkens \& van Solinge (2011)

\section{Aprovação do Comitê de Ética}

A aprovação ética para esta pesquisa foi concedida pelo Comitê de Ética do Instituto de Ciências Humanas da Universidade de Brasília (Registro 707.387), como apresentada no Anexo A. Para proteger o anonimato e a privacidade dos participantes, nomes de usuário e outros detalhes de identificação foram excluídos das análises. 


\section{Descrição da Tese}

Além do capítulo introdutório (Capítulo 1), esta tese engloba mais sete capítulos, incluindo duas revisões narrativas, uma revisão integrativa, um estudo empírico com métodos mistos de avaliação, um estudo empírico com análises qualitativas, e, por fim, um capítulo de conclusão, como descritos a seguir:

O Capítulo 2 consiste numa revisão narrativa sobre a concepção de envelhecimento no contexto mundial atual, considerando aspectos históricos e conceituais sobre prevenção e promoção à saúde mental da pessoa idosa e focos de intervenção.

O Capítulo 3 é uma revisão narrativa que tem como foco identificar na literatura as condições associadas à percepção e a vivência da aposentadoria como favorecedora de crise ou bem-estar.

O Capítulo 4 trata-se de uma revisão integrativa de estudos empíricos que tem como objetivo avaliar a qualidade dos programas de planejamento para aposentadoria, considerando critérios metodológicos e de eficácia dos programas.

O Capítulo 5 descreve evidências de validade de um instrumento que investiga o constructo perspectiva de tempo futuro relativo à aposentadoria.

O Capítulo 6 refere-se a um estudo empírico, com uso de métodos mistos, que avalia a eficácia de três programas (longo, breve e testemunho) de planejamento ou preparação para aposentadoria, em uma amostra de servidores públicos federais $(n=30)$, e compara resultados entre essas modalidades e um grupo controle, antes e seis meses após suas realizações. Como pergunta central deste estudo, busca-se saber em que extensão três diferentes programas de preparação para a aposentadoria promovem maior bem-estar subjetivo, melhor perspectiva de tempo futuro relativo à aposentadoria e mudanças em comportamento de planejamento para aposentadoria. O objetivo secundário deste estudo é 
avaliar a validade social dos programas considerando a relevância dos objetivos, aceitabilidade dos procedimentos e importância social das intervenções.

O Capítulo 7, um estudo qualitativo, com uso de entrevistas semiestruturadas, apresenta os efeitos de três programas de preparação aposentadoria (longo, breve e testemunho), de curta e longa duração, sobre servidores públicos brasileiros $(n=20)$. O foco da análise foi estabelecer se os participantes apresentaram alterações cognitivas, motivacionais e/ou comportamentais no período após o programa e em que medida os resultados são diferentes para os vários programas. Além disso, verificou-se o progresso dos participantes através dos estágios do Modelo Transteórico de Mudança (précontemplação, contemplação, preparação, ação, manutenção) durante o período de followup de 06 meses após finalização dos programas. A principal pergunta deste estudo é saber em que extensão três diferentes programas facilitam o planejamento da aposentadoria e auxiliam os trabalhadores a se prepararem para esssa fase da vida.

No Capítulo 8, referente às conclusões, são sumarizados os principais achados dos capítulos teóricos e empíricos, as limitações, discutidas as contribuições científicas e sociais desta tese e proposta uma agenda de pesquisa para estudos futuros. 


\section{Referências}

Albuquerque, A. \& Tróccoli, B. (2004) Desenvolvimento de uma escala de bem-estar subjetivo. Psicologia: Teoria e Pesquisa, 20, 153-164.

Armstrong-Stassen, M. (2008). Organizational practices and the post-retirement employment experience of older workers. Human Resource Management Journal, 18, 36-53. doi: 10.1111/j.1748-8583.2007.00057.x

Barbosa, L., Monteiro, B., \& Murta, S. (2016). Retirement adjustment predictors: A systematic review. Work, Aging and Retirement, 2, 262-280, doi:10.1093/workar/waw008.

Bardin, L. (2011). Análise de conteúdo. São Paulo: Edições 70.

Beck, S. (1984). Retirement preparation programs: Differentials in opportunity and use. Journal of Gerontology, 39, 596-602.

Bowen, D.J., Kreuter, M., Spring, B., Cofta-Woerpel, L., Linnan, L., Weiner, C... \& Fernandez, M. (2009). How we design feasibility studies. American Journal of Preventive Medicine, 36, 452-457

Brasil. Ministério do Planejamento, Orçamento e Gestão (2010). Portaria Normativa SRH n. 1261/2010. Institui os princípios, diretrizes e ações em saúde mental dos servidores da administração pública federal.

Brasil. Ministério do Planejamento, Orçamento e Gestão (2013). Portaria Normativa SRH n. 3/2013. Institui as diretrizes gerais de promoção da saúde do servidor público federal, que visam orientar os órgãos e as entidades do Sistema de Pessoal Civil da Administração Federal - SIPEC.

Busselle, R., \& Bilandzic, H. (2008). Fictionality and perceived realism in experiencing stories: A model of narrative comprehension and engagement. Communication Theory, 18, 255-280. 
Campbell, D. T., \& Stanley, J. C. (1963). Experimental and quasi-experimental designs for research on teaching. In N. L. Gage (Ed.) Handbook of research on teaching (pp. 1176). Chicago: Rand McNally.

Constituição da República Federativa do Brasil (1988). Brasília, Brasil. Retirado de http://www.planalto.gov.br/ccivil_03/constituicao/constituicao.htm

Corcoran, K. \& Fischer, J. (2000). Measures for clinical practice: A sourcebook. New York:The Free Press, 3a edição.

Costa, F., \& Castanhar, J. C. (2003). Avaliação de programas públicos: Desafios conceituais e metodológicos. RAP - Revista de Administração Pública, 37, 969-992.

Couto, B. (2000). O Direito social e a assistência social brasileira: Uma equação possível? 8a . ed. São Paulo: Cortez.

Damman, M., Henkens, K., \& Kalmijn, M. (2011). The impact of midlife educational, work, health and family experiences on men's early retirement. Journal of Gerontology, 66, 617-627.

Dingemans, E.A.A. (2016). Working after retirement; determinants and consequences of bridge employment. Doctoral dissertation. University of Groningen, Holanda. doi:10.1093/workar/waw008

Field A. (2013). Discovering statistics using IBM SPSS statistics. New York: Sage.

Flay, B., Biglan, A., Boruch, R., Castro, F., Gottfredson, D., Kellam, S... Ji, P. (2005). Standards of evidence: Criteria for efficacy, effectiveness and dissemination. Prevention Science, 6, 151-175. doi: 10.1007/s11121-005-5553-y

Francisco, V., \& Butterfoss, F. (2007) Social validation of goals, procedures, and effects in public health. Health Promotion Practice, 8, 128-133. 
França, C. (2012). Modelo de uma intervenção breve para planejamento da aposentadoria: Desenvolvimento e avaliação. Dissertação de Mestrado, Universidade de Brasília, Brasília, DF.

França, C., Murta, S., Negreiros, J., Pedralho, M., \& Carvalhedo, R. (2013). Intervenção breve na prepração para aposentadoria. Revista Brasileira de Orientação Profissional, 14, 99-110.

França, L. H. (1992). Terceira idade: O trabalho social com idosos no SESC e os programas de preparação para aposentadoria nas empresas. Revista de Administração Pública, 26, 174-181.

França, L. H. (2002). Repensando a aposentadoria com qualidade: Um manual para facilitadores de programas de educação para aposentadoria em comunidades. CRDE UnATI UERJ.

França, L. H., \& Carneiro, V. L. (2009). Programas de preparação para a aposentadoria: Um estudo com trabalhadores mais velhos em Resende (RJ). Revista Brasileira de Geriatria e Gerontologia, 12, 429-447.

França, L. H., Menezes, G., \& Siqueira, A. (2012). Planejamento para aposentadoria: A visão dos garis. Revista Brasileira de Geriatria e Gerontologia, 15, 733-745.

França, L. H., Menezes, G., Bendassolli, P., \& Macedo, L. (2013). Aposentar-se ou continuar trabalhando? O que influencia essa decisão? Psicologia: Ciência e Profissão, 33, $548-563$.

França, L. H., Nalin, C., Siqueira-Brito, A., Amorim, S., Rangel, T., \& Ekman, N.C. (2014). A percepção dos gestores brasileiros sobre os programas de preparação para aposentadoria. Estudos interdisciplinares sobre o envelhecimento, 19, 879898. 
Glamser, F., \& DeJong, G. (1975). The efficacy of preretirement preparation programs for industrial workers. Journal of Gerontology, 30, 595-600.

Glamser, F. (1981). The impact of preretirement programs on the retirement experience. Journal of Gerontology, 36, 244-250.

Green, M. C. (2006). Narratives and cancer communication. Journal of Communication, $56,5163-5183$

Gottfredson, D., Cook, T., Gardner, F., Gorman-Smith, D., Howe, G., Sandler, I., \& Zafft, K. (2015). Standards of evidence for efficacy, effectiveness, and scale- up research in prevention science: Next generation. Prevention Science, 16, 893926. doi 10.1007/s11121-015-0555-x.

Gunther, I., \& Borges, L. (2014). Modelos teóricos que fundamentam os programas de educação para aposentadoria. In S. Murta, C. Leandro-França \& J. Seidl. Programas de preparação para aposentadoria: como planejar, implementar e avaliar. (pp. 84-113). Novo Hamburgo: Editora Sinopsys.

Heather, N. (1996). The public health and brief interventions for excessive alcohol consumption: The British experience. Addictive Behaviors, 21, 857-868

Hershey, D. A., Walsh, D. A., Brougham, R., Carter, S., \& Farrell, A. H. (1998). Challenges of training pre-retirees to make sound financial planning decisions. Educational Gerontology, 24, 447-470.

Hershey, D. A., Mowen, J. C., \& Jacobs-Lawson, J. M. (2003). An experimental comparison of retirement planning intervention seminars. Educational Gerontology, 29, 339-359. doi: 10.1080 $=03601270390180271$

Hershey, D. A., Jacobs-Lawson, J. M., McArdle, J. J., \& Hamagami, A. (2007). Psychological foundations of financial planning for retirement. Journal of Adult Development, 14, 26-36. 
Hershey, D. A., Henkens, K., \& van Dalen, H. (2010). Aging and financial planning for retirement: Interdisciplinary influences viewed through a cross-cultural lens. International Journal of Aging and Human Development, 70, 1-38.

Hershey, D., \& Henkens, K. (2014). Impact of different types of retirement transitions on perceived satisfaction with life. The Gerontologist, 54, 232-244.

Instituto Brasileiro de Geografia e Estatística - IBGE (2016). Retirado de http://www.sidra.ibge.gov.br/bda/emprego/

Instituto de Pesquisa Econômica Aplicada - IPEA (2013). Atlas do Desenvolvimento Humano no Brasil. Retirado de http://atlasbrasil.org.br/2013/destaques/destaque2

Kazdin, A. E. (1977). Assessing the clinical or applied importance of behavior change through social validation. Behavior Modification, 1, 427-452.

Kim, J. E., \& Moen, P. (2002). Retirement transitions, gender and psychological wellbeing: A life course ecological model. Journal of Gerontology, 57B, 212-222. doi: $10.1348 / 096317905 \times 68204$

Lane, K. L., \& Beebe-Frankenberger, M. (2004). School-based interventions: The tools you need to succeed. Boston : Pearson

Laughlin, C., \& Cotten, P.D. (1994). Efficacy of a pre-retirement planning intervention for ageing individuals with mental retardation. Journal of Intellectual Disability Research, 38, 317-328.

Leandro-França, C. (2014). Aposentadoria: Crise ou liberdade. In Murta, S., LeandroFrança, C., \& Seidl. J. (Eds.). Programas de educação para aposentadoria: Como planejar, implementar e avaliar (pp. 54-65). Novo Hamburgo: Sinopsys.

Leandro-França, C., \& Murta, S. (2014a). Fatores de risco e de proteção na adaptação à aposentadoria. Revista Psicologia Argumento, 32, 33-43. doi:10.7213/psicol.argum.32.076.DS03. 
Leandro-França, C., \& Murta, S. (2014b). Prevenção e promoção da saúde mental no envelhecimento: Conceitos e intervenções. Psicologia: Ciência e Profissão, 34, 318329. doi:10.1590/1982-3703001152013

Leandro-França, C., Murta, S., \& Iglesias, F. (2014). Planejamento da aposentadoria: Uma escala de mudança de comportamento. Revista Brasileira de Orientação Profissional, 15, 75-84.

Leandro-França, C., Murta, S., \& Villa, M. (2014). Efeitos de uma intervenção breve no planejamento da aposentadoria. Revista Psicologia: Organizações e Trabalho, 14, 257-270.

Leandro-França, C., Santos, J., \& Pedralho, M. (2015). Planejamento para aposentadoria: Relato de intervenção em um grupo de homens de meia-idade. In S., Murta, C., Leandro-França, K., Santos, \& L., Polejack (Eds.). Prevenção e promoção em saúde mental: Fundamentos, planejamento e estratégias de intervenção (pp. 823843). Novo Hamburgo: Sinopsys.

Leandro-França, C. Barletta, J. Murta, S. \& Tavares, T. (2015). Intervenções breves aplicadas à prevenção e promoção em saúde mental. In S., Murta, C., LeandroFrança, K., Santos, \& L., Polejack (Eds.). Prevenção e promoção em saúde mental: Fundamentos, planejamento e estratégias de intervenção (pp. 341-367). Novo Hamburgo: Sinopsys.

Leandro-França, C., Murta, S., Hershey, D., \& Barbosa, L. (2016). Evaluation of retirement planning programs: A qualitative analysis of methodologies and Efficacy. Educational Gerontology, 42, 497-512.

doi: $10.1080 / 03601277.2016 .1156380$ 
Leandro-França, C.,van Solinge, H., Henkens, K., \& Murta, S. (2016). Effects of three types of retirement preparation program: A qualitative study of civil servants in Brazil. Educational Gerontology, 42, 388-400. doi:10.1080/03601277.2016.1139969

Leandro-França, C., Seidl, J., \& Murta, S. (2016). Intervenção breve como estratégia de planejamento para aposentadoria: Transformando intenções em ações, Psicologia em Estudos, 20, 543-553. doi: 10.4025/psicolestud.v20i4.27413.

Lei $n^{\circ}$ 10.741. (2003, $1^{\text {o }}$ de outubro). Estatuto do Idoso, Diário Oficial da União, Brasil. Retirado de http://www.planalto.gov.br/ccivil_03/leis/2003/L10.741.htm

Lei no. 8.842, de 04 de janeiro de 1994 (1994). Dispõe sobre a Política Nacional do Idoso. Retirado de http://www.planalto.gov.br/ccivil_03/leis/L8842.htm

Lemal, M., \& van den Bulck, J. (2010). Testing the effectiveness of a skin cancer narrative in promoting positive health behavior: A pilot study. Preventive Medicine, 51, 178181. doi: 10.1016/j.ypmed.2010.04.019

Lens, W., Paixao, M. P., Herrera, D., \& Grobler, A. (2012). Future time perspective as a motivational variable: Content and extension of future goals affect the quantity and quality of motivation. Japanese Psychological Research, 54, 321-333.

Magnani, L. A. C., Mendes, M. B., Mello, P. M. de, Barbosa, S. A., \& Bueno, K. C. D. (1993). Programas de Preparo para a Aposentadoria (PPA): Sua importância e necessidade na sociedade brasileira contemporânea. Curitiba: Faculdade de Direito de Curitiba.

Makino, N. (1994). Preretirement education and life planning programs in Japan. Educational Gerontology, 20, 503-510.

Marcellini, F., Sensoli, C., Barbini, N., \& Fioravanti, P. (1997). Preparation for retirement: Problems and suggestion of retirees. Educational Gerontology, 23, 377387. doi:10.1080/0360127970230406 
Marques, A. C., \& Furtado, F. E. (2004). Intervenções breves para problemas relacionados ao álcool. Revista Brasileira de Psiquiatra, 26, 28-32.

Menezes, G., \& França, L. H. (2012). Preditores da decisão da aposentadoria por servidores públicos federais. Revista Psicologia, Organizações e Trabalho, 12, 315-328.

Miller, W. R. \& Sanchez, V. C. (1994). Motivating young adults for treatment and lifestyle change. In G. Howard (Ed.). Issues in alcohol use and misuse by young adults. Notre Dame, IN: University of Notre Dame Press.

Miller, W., \& Rollnick, S. (2001). Entrevista motivacional: Preparando as pessoas para a mudança de comportamentos adictivos. São Paulo: Artmed.

Minayo, M. C. \& Cavalcante, F. (2012). Autópsias psicológicas e psicossociais de idosos que morreram por suicídio no Brasil. Ciência \& Saúde Coletiva, 17, 1943-1954.

Muniz, J. A. (1996). PPA: Programa de preparação para o amanhã. Estudos de Psicologia, 2, 198-204.

Murta, S. G., Caixeta, T. D., Souza, K. L., \& Ribeiro, D. C. (2008). Avaliação de um programa de preparo para a aposentadoria e envelhecimento bem sucedido. In S.G Murta (Ed.), Grupos psicoeducativas: Aplicações em múltiplos contextos, (pp. 181196). Goiânia: Porã Cultural.

Murta, S., Oliveira, S., Siqueira, A. L., Carvalhedo, R., Gunther, I., Lira, N., \& Naves, M. (2010). Viva Mais! Programa de preparação para aposentadoria: Guia para participantes. Universidade de Brasília, Brasil.

Murta, S., Abreu, S., França, C.L., Pedralho, M., Seidl, J., Lira, N., ... Gunther, I. (2014). A preparação para a aposentadoria: Implantação e avaliação do programa Viva Mais!. Psicologia: Reflexão e Crítica, 27, 1-9. doi:10.1590/S010279722014000100001 
Murta, S., Leandro-França, C. \& Seidl, J. (2014). Programas de educação para aposentadoria: Como planejar, implementar e avaliar. Novo Hamburgo: Sinopsys.

Murta, S., Leandro-França, C., \& Barbosa, L. (2014). Pesquisa em avaliação de programas de educação para aposentadoria. In S. Murta, C. Leandro-França \& J. Seidl. Programas de preparação para aposentadoria: Como planejar, implementar e avaliar. (pp. 84-113). Novo Hamburgo: Editora Sinopsys.

Murta, S., Leandro-França, C., Santos, K., \& Polejack, L. (2015). Prevenção e promoção em saúde mental: Fundamentos, planejamento e estratégias de intervenção. Novo Hamburgo: Sinopsys.

Ogunbameru, O., \& Sola, A. (2008). Transition to retirement: Effect of participation in preretirement education in Nigeria. Educational Gerontology, 34, 418-427. doi: $10.1080 / 03601270600850867$

Pereira, T., \& Guedes, S. (2012). Novo tempo: A experiência de implantação do programa de preparação para o pós-carreira no IFRN. Hollos, 4, 158-177.

Petkoska, J. \& Earl, J. (2009). Understanding the influence of demographic and psychological variables on retirement planning. Psychology and Aging, 24, 24551. doi: $10.1037 / \mathrm{a} 0014096$

Price, C. A., \& Joo, E. (2005). Exploring the relationship between marital status and women's retirement satisfaction. International Journal of Aging and Human Development, 61, 37-55.

Prochaska, J., \& DiClemente, C. (1982). Transtheoretical therapy: Toward a more integrative model of change. Psychotherapy: Theory, Research \& Practice, 19, 276-288. doi.org/10.1037/h0088437 
Prochaska, J., \& DiClemente, C. (1983). Stages and processes of self-change of smoking: Toward an integrative model of change. Journal of Consulting and Clinical Psychology, 51, 390-395.

Prochaska, J., Norcross, J., \& DiClemente, C. (1994). Changing for good: A revolutionary six-stage program for overcoming bad habits and moving your life positively forward. New York: Morrow.

Reitzes, D. C., \& Mutran, E. J., (2004). The transition to retirement: Stages and factors that influence retirement adjustment. International Journal of Aging and Human Development, 59, 63-84.

Ribeiro, B., Galdino. M. J., Martins, J., \& Ribeiro, R. (2015). Envelhecimento, aposentadoria e previdência social: Reflexões necessárias. Revista Varia Scientia Ciências da Saúde, 2, 180-187.

Richardson, V., \& Kilty, K. M. (1991). Adjustment to retirement: Continuity vs. discontinuity. International Journal of Aging and Human Development, 33, $151-169$.

Santos, F. (1990). Identidade e Aposentadoria. São Paulo: E.P.U.

Schmitt, R. E. (2010). Teoria da perspectiva de tempo futuro: Aplicações preliminares e reflexões voltadas à pesquisa no ensino superior. Revista Educação por Escrito, 1, 516.

Seidl, J., Leandro-França, C., \& Murta, S. (2014) Formatos de programas de educação para aposentadoria. In S. Murta, C. Leandro-França \& J. Seidl. (Eds.). Programas de educação para aposentadoria: Como planejar, implementar e avaliar (pp. 84-113). Novo Hamburgo: Sinopsys.

Serra-Gurgel, J. B. (2008). Evolução da previdência social. FUNPREV. Retirado de http://www.anasps.org.br/evolucao_historica_previdencia.pdf 
Shultz, K. S., \& Wang, M. (2011). Psychological perspectives on the changing nature of retirement. American Psychologist, 66, 170-179.

Silva, E.A., \& França, L. H. (2015). Violência contra idosos na cidade do Rio de Janeiro. Estudos e Pesquisas em Psicologia, 15, 155-177.

Silva, I. (2007). O regime de previdência complementar dos servidores públicos federais e a Emenda Constitucional $N^{o}$ 41/2003. Monografia apresentada ao Centro de Estudos Sociais Aplicados da Universidade Federal Fluminense UFF, Niterói.

Soares, D. H., Costa, A., Rosa, A., \& Oliveira, M. L (2007). Aposenta-ação: Programa de preparação para aposentadoria. Estudos interdisciplinares sobre o envelhecimento, $12,143-161$.

Soares, D. H., Luna, I., \& Lima, M. (2010). A arte de aposentar-se: Programa de preparação para aposentadoria com policiais federais. Estudos interdisciplinares sobre o envelhecimento, 15, 293-313.

Soares, D., \& Costa, A. (2011). Aposenta-ação: Aposentadoria para ação. $1^{\mathrm{a}}$ Ed, São Paulo:Vetor.

Stawski, R. S., Hershey, D. A., \& Jacobs-Lawson, J. M. (2007). Goal clarity and financial planning activities as determinants of retirement savings contributions. International Journal of Aging and Human Development, 64, 13-32.

Taylor-Carter, M.A., Cook, K., \& Weinberg, C. (1997). Planning and expectations of the retirement experience. Educational Gerontology, 23, 273-288.

The Economist. Brazil's pension system: Tick, tock (March, 24th, 2012). Retirado de http://www.economist.com/node/21551093 
van Solinge, H., \& Henkens, K. (2008). Adjustment to and satisfaction with retirement: Two of a kind? Psychology and Aging, 23, 422-434. doi: 10.1037/08827974.23.2.422

Vansteenkiste, M., Simons, J., Soenens, B., \& Lens, W. (2004). How to become a persevering exerciser? Providing a clear, future intrinsic goal in an autonomy supportive way. Journal of Sport and Exercise Psychology, 26, 232-249.

Veras, R. (2012). Desafio contemporâneo para jovens aposentados: A manutenção da saúde e qualidade de vida. In L. França \& D. Stepansky (Eds.). Propostas multidisciplinares para o bem-estar na aposentadoria (pp. 53-74). Rio de Janeiro: Quartet

Wang, M., Henkens, K., \& van Solinge, H. (2011). Retirement adjustment: A review of theoretical and empirical advancements. American Psychologist, 66, 204-213. doi: $10.1037 / \mathrm{a} 0022414$

Wolfe, B., \& Wolfe, G. (1975). Exploring retirement in a small group. Social Work, 20, 481-484.

World Health Organization - WHO. (2002). Active ageing: A policy framework. Madrid: World Health Organization.

World Health Organization, WHO. (2014). "Ageing well" must be a global priority. Retirado de http://www.who.int/mediacentre/news/releases/2014/lancet-ageingseries/en/

Wotherspoon, C. (1995). Plan now, enjoy later? A study of the use and effectiveness of formal retirement planning programs. Benefits Quarterly, 11, 53-57.

Yalom. I., \& Leszcz, M. (2006). Psicoterapia de grupo: Teoria e prática. Porto Alegre: Artmed. 
Zanelli, J. C. (1994). Aposentadoria: Percepções dos servidores da Universidade Federal de Santa Catarina. Anais do ENANPAD, 10, 26-45.

Zanelli, J. C. (2000). O Programa de preparação para aposentadoria como um processo de intervenção ao final de uma carreira. Revista de Ciências Humanas, edição especial temática, 157-176. 


\section{CAPÍtULO 2}

Publicado em periódico nacional ${ }^{8}$

\section{Prevenção e Promoção da Saúde Mental no Envelhecimento: Conceitos e Intervenções}

\footnotetext{
${ }^{8}$ Leandro-França, C. \& Murta, S. (2014). Prevenção e promoção da saúde mental no envelhecimento: Conceitos e intervenções. Psicologia: Ciência e Profissão, 34, 318-329. doi.org/10.1590/1982-3703001152013
} 


\section{Resumo}

A proposta deste ensaio é descrever a concepção de envelhecimento no contexto atual, considerando aspectos históricos e conceituais sobre prevenção e promoção à saúde mental da pessoa idosa e focos de intervenção. O envelhecimento é um processo que deve ser vivenciado com autonomia, reconhecimento de direitos, segurança, dignidade, bem-estar e saúde. Intervenções de prevenção a transtornos mentais em idosos, escassas na literatura nacional, são essenciais na redução de risco de surgimento de transtornos como depressão, ansiedade e suicídio. Intervenções de promoção à saúde, utilizadas com mais frequência nessa população, são úteis no desenvolvimento de competências como empoderamento, autonomia e autoeficácia. Novas agendas política e de pesquisa devem incluir ações intersetoriais articuladas, com práticas preventivas pautadas no ciclo de pesquisa em prevenção, incluindo estratégias breves e computadorizadas.

Palavras-chave: envelhecimento, saúde mental, prevenção, promoção da saúde, políticas públicas de saúde. 


\begin{abstract}
This essay aims to describe the concept of aging in the current global context, emphasizing historical and conceptual aspects related to mental health's prevention and promotion of the elderly and focus on intervention. Aging is a process that must be experienced with autonomy, recognizing rights, safety, dignity, well-being and health. Preventive interventions on the elderly's mental disorders, scarcely found in Brazilian literature, are essential in order to reduce depression, anxiety and suicide. Interventions on health promotion, most frequently used in this population, are useful develop skills such as empowerment, autonomy and self-efficacy. New policies and research agendas should include intersectoral articulated actions, with preventive practices based on the prevention research cycle, including brief and computerized strategies.

Keywords: aging, mental health, prevention, health promotion, public health policies.
\end{abstract}




\section{Resúmen}

El propósito de este trabajo es describir el conceito de envejecimiento en el contexto actual, teniendo en cuenta los aspectos históricos y conceptuales sobre prevención y promoción de la salud de los ancianos y el enfoque mental de intervención. El envejecimiento es un proceso activo que debe ser experimentado con autonomía, reconocimiento de derechos, seguridad, dignidad, bienestar y salud. Las intervenciones y estudios preventivos para las personas mayores, escasos en la literatura nacional, son esenciales para reducir el riesgo de desarrollar trastornos como la depresión, la ansiedad y el suicidio. Las intervenciones de promoción, de uso más frecuente en esta población, son útiles en el desarrollo de habilidades y recursos tales como responsabilidad, autonomía y auto-eficacia. Nuevas políticas y programas de investigación deben incluir actiones articuladas entre setores, con prácticas preventivas basadas en el ciclo de investigación en materia de prevención, incluidas las estrategias breves y computarizados.

Palabras clave: Envejecimiento, salud mental, prevención, promoción de la salud, las políticas de salud pública. 
É notório nas últimas décadas o crescimento da população com mais de 60 anos, principalmente nos países desenvolvidos. Entre 1970 e 2025 é esperado um aumento de $223 \%$ de pessoas nessa faixa etária em todo o mundo e estima-se que em 2050 haverá 2 bilhões de pessoas idosas, com $80 \%$ delas vivendo nos países mais ricos (World Health Organization, WHO, 2002). Contudo, o envelhecimento da população não é mais uma característica apenas dos países abastados. A expectativa de vida das pessoas vem aumentando rapidamente também em países em desenvolvimento como o Brasil. É previsto que até 2025, o Brasil seja o sexto país com maior quantidade de idosos no mundo (WHO, 2002). Sendo assim, a "revolução da longevidade", termo atualmente utilizado pelos meios de comunicação para discutir o impacto desse fenômeno na saúde, qualidade de vida e economia mundial, requer políticas sólidas e ações urgentes.

No cenário internacional, políticas públicas como o Plano Internacional de Ação sobre o Envelhecimento - PIAE, aprovado em Madrid, pelos países membros da Organização das Nações Unidas (WHO, 2002), estabelecem direções e medidas prioritárias para promover uma velhice saudável. Nesse documento constam alternativas de como inserir o envelhecimento na agenda do desenvolvimento do século XXI, tendo em vista que as ações de prevenção, promoção e assistência têm priorizado o público maternoinfantil e jovem (Xavier, 2012). A declaração política estabelecida pelo PIAE, composta de 19 artigos, recomenda medidas relevantes para modificação desse cenário, tais como (a) reconhecimento da transformação demográfica mundial, (b) celebração do aumento da expectativa de vida em todo mundo como uma grande conquista da humanidade, (c) comprometimento das autoridades governamentais em eliminar a discriminação por motivos de idade, (d) reconhecer que o indivíduo, à medida que envelhece, deve usufruir de uma vida com saúde, segurança e participar de forma ativa na vida econômica, social, 
cultural e política da sociedade, (e) reconhecer a dignidade da pessoa idosa e combater as formas de abandono, abuso e violência.

Com relação à saúde mental da pessoa idosa, esse plano de ação prevê a aplicação de estratégias que favoreçam a prevenção de transtornos mentais, a descoberta precoce, o tratamento dessas doenças, com inclusão de procedimentos de diagnósticos, medicação adequada, psicoterapia e capacitação de profissionais e demais pessoas que atendam esse público. Além disso, está prevista a elaboração de ações que eduquem e conscientizem a população para o alcance de uma velhice com saúde física e mental bem como o fortalecimento de uma rede de cuidados e apoio aos idosos com o envolvimento da família, voluntários e comunidade. Destaca-se ainda nesse plano de ação a importância de realizar pesquisas, baseadas em evidências e indicadores confiáveis, sobre questões relacionadas à idade, como instrumento útil para a formulação de políticas relativas ao envelhecimento.

No contexto nacional, algumas ações marcam a história do Brasil no que se refere às políticas públicas sociais direcionadas à população com mais de 60 anos. Destaca-se a Constituição de 1988, que assegura aos cidadãos brasileiros direitos quanto à seguridade social (Art.194) com medidas destinadas à saúde, à previdência e à assistência social. Inclui-se nesse repertório, a Política Nacional do Idoso, aprovada em 04 de janeiro de 1994 pela Lei no 8.842, que institui o Conselho Nacional do Idoso - CNI e, posteriormente, a elaboração do Estatuto do Idoso, sancionado no dia $1^{\circ}$ de outubro de 2003 pela Lei 10.741 , (Xavier, 2012). Estas normatizações estão em consonância com as políticas internacionais, pois preveem direitos a uma velhice saudável.

Além disso, justificam a necessidade de desenvolver e implantar intervenções de prevenção e promoção à saúde física e mental da pessoa idosa com foco no seu aperfeiçoamento moral, intelectual, espiritual e social, prevalecendo às condições de liberdade, autonomia e dignidade. Neste sentido, este artigo tem por objetivo descrever a 
concepção de envelhecimento no contexto mundial atual, considerando aspectos conceituais de prevenção e promoção à saúde mental da pessoa idosa e focos de intervenções direcionadas a esse público.

\section{Envelhecimento Ativo: Conceito, Fatores Determinantes e de Risco}

As discussões do Plano Internacional de Ação sobre o Envelhecimento - PIAE possibilitaram à WHO (2002) adotar o termo "Envelhecimento Ativo" para englobar a visão da velhice como um processo natural do ciclo de vida que deve ser vivenciado com autonomia, independência, reconhecimento de direitos, segurança, dignidade, bem-estar e saúde. Os fatores determinantes do envelhecimento ativo sofrem influência cultural e de gênero e envolvem a integração de aspectos individuais, econômicos, sociais, físicos, comportamentais, de serviços sociais e de saúde. As características desses fatores são especificadas na Figura 1.

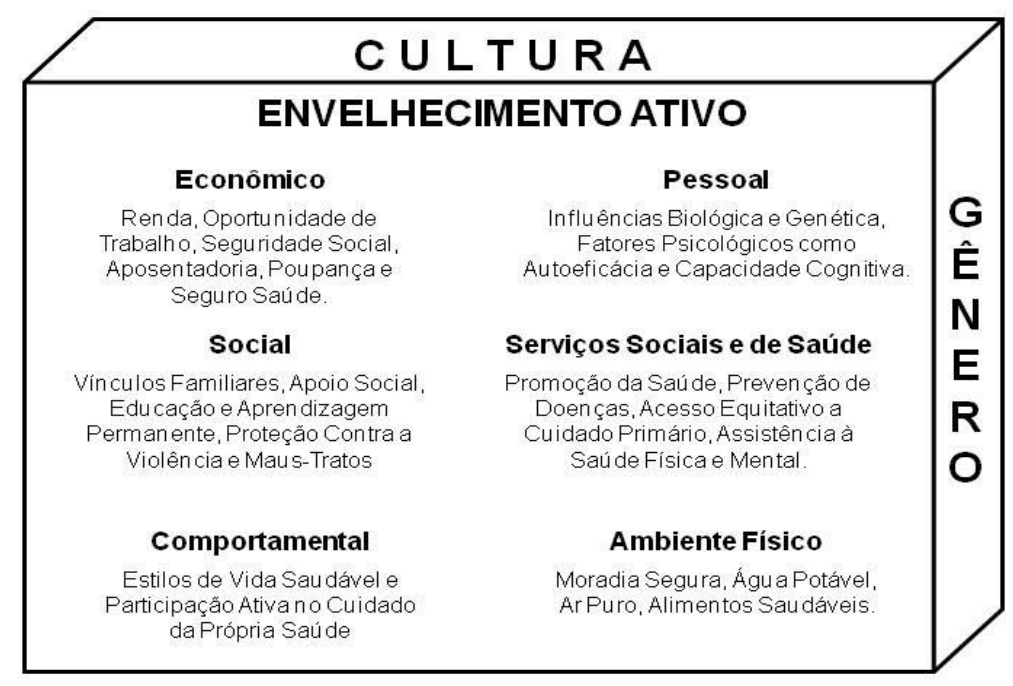

Figura 1. Fatores determinantes do envelhecimento ativo 
No que se refere à saúde mental da pessoa idosa, a aquisição de um envelhecimento ativo encontra desafios, principalmente em função de riscos como, por exemplo, o sofrimento psíquico causado pela depressão. A depressão é considerada pela literatura especializada um grave problema de saúde pública (Muñoz, Cuijpers, Smit, Barrera, \& Leykin, 2010) e um fator de risco ao suicídio (Minayo \& Cavalcante, 2012).

Com o intuito de chamar atenção da população mundial para essa temática, em 10 de outubro de 2012, a depressão foi tema do dia mundial da saúde mental promovido pela WHO (2012). Essa ação teve como finalidade aumentar a consciência da sociedade para os cuidados com esse transtorno e promover a discussão sobre alternativas e investimentos em ações de promoção, prevenção e tratamento. A depressão é uma enfermidade que afeta cerca de 350 milhões de pessoas em todo mundo, sendo as mulheres mais atingidas pela doença do que os homens. Um milhão de pessoas se suicida a cada ano e grande parte delas sofre de depressão severa. O cenário se torna mais grave, pois o acesso à rede de cuidados é difícil na maioria dos países. Em alguns lugares, menos de $10 \%$ das pessoas que sofrem de depressão recebem tratamento (WHO, 2012). Estes dados têm exigido atenção e esforços de gestores, pesquisadores e profissionais da área de saúde para a implantação de ações que combatam esse mal e promovam o bem-estar da população. Ademais, com o aumento acelerado nos índices de envelhecimento e as vulnerabilidades decorrentes dessa época da vida, os idosos são caracterizados como grupo populacional de risco acentuado para a depressão (Pot, Melenhorst, Onrust, \& Bohlmeijer, 2008) e o suicídio (Minayo \& Cavalcante, 2012; Pinto, Pires, Silva, \& Assis, 2012).

Ao analisar 51 casos de suicídio de idosos em dez cidades brasileiras, por meio de autópsias psicológicas, Minayo e Cavalcante (2012) concluíram que doenças graves, transtornos mentais, depressão, conflitos familiares e conjugais formam as principais causas de suicídio nessa época da vida. Sendo assim, nessa faixa etária, os sintomas 
depressivos podem desencadear a crise suicida quando associado às vulnerabilidades socioambientais, psicológicas, familiares e de saúde (Minayo \& Cavalcante, 2012; Barrero, 2012; Pinto et al., 2012). Como fatores de ordem social, destaca-se a aposentadoria, isolamento social, atitude hostil e pejorativa da sociedade e perda de prestígio pessoal. O sentimento de solidão, inatividade, inutilidade, falta de projeto de vida e tendência a reviver o passado refere-se aos fatores psicológicos.

Entre os fatores familiares está a perda dos entes queridos, a viuvez durante o primeiro ano, a mudança forçada de domicílio e situações de desamparo. As enfermidades físicas crônicas, terminais e incapacitantes como, por exemplo, Alzheimer e Parkison, estão relacionados ao comprometimento de saúde. Além disso, o abuso de álcool e outras drogas também são fatores de risco ao suicídio nessa fase da vida (Barrero, 2012). Ao examinar esses fatores, que limitam o alcance de um envelhecimento ativo e saudável, estudiosos dessa temática (Pinto et al., 2012; Pot et al., 2008) sinalizam a importância de ações efetivas de prevenção e de promoção à saúde mental para apoio à pessoa idosa de forma que estas se sintam úteis, ativas e integradas socialmente.

\section{Prevenção e Promoção à Saúde: Aspectos Históricos e Conceituais}

Os limites conceituais entre prevenção e promoção à saúde ainda geram controvérsias na literatura especializada e confusões por muitos profissionais da área que desconhecem o real significado desses termos (Heidmann, Almeida, Boehs, Wosny, \& Montecelli, 2006; Sícoli \& Nascimento, 2003). Ao delimitar os fundamentos de prevenção e promoção à saúde é relevante considerar aspectos históricos que marcaram os seus princípios e formas de intervenção. $\mathrm{O}$ conceito de prevenção vem sendo revisto no decorrer dos anos (Abreu, 2012). A primeira definição de prevenção foi determinada por Caplan que em 1964 a conceituou como modelos primário, secundário e terciário (Dalton, 
Elias, \& Wandersman, 2007). Na perspectiva tradicional da saúde mental, a prevenção primária tem como objetivo a redução da ocorrência de novos casos e é destinada à população exposta a fatores de risco, mas que ainda não contém o transtorno. A prevenção secundária é focada nos participantes que já apresentam sinais iniciais do transtorno. A prevenção terciária está direcionada aos que possuem um diagnóstico de um transtorno, tendo como objetivo reduzir seus prejuízos e consequências (Abreu, 2012; Murta, 2005).

No decorrer dos anos, o conceito de prevenção em saúde mental foi reorganizado em três níveis de intervenção: universal, seletiva e indicada. Conforme essa nova concepção, a prevenção universal refere-se às ações direcionadas a toda população, sem um alvo específico, a prevenção seletiva tem como alvo a população avaliada como de risco acentuado, mas ainda sem sintomas e a prevenção indicada está focada em indivíduos que apresentam sinais ou sintomas iniciais de algum transtorno, sem diagnóstico definido (Muñoz et al., 2010; Pot et al., 2008).

Embora esse novo modelo de prevenção seja bastante reconhecido pela literatura especializada, uma nova revisão foi proposta. $\mathrm{O}$ atual conceito de prevenção compreende a promoção à saúde como uma área específica da prevenção e ressalta a integração entre prevenção, promoção, tratamento (Abreu, 2012). Nesse novo modelo, essas áreas se complementam em suas atribuições. Deste modo, o foco da promoção à saúde é no desenvolvimento de competências e recursos para o enfrentamento de vulnerabilidades individuais e ambientais. A prevenção tem como objetivo a diminuição dos riscos de surgimento de problemas ou transtornos, avaliados conforme os níveis de exposição ao risco (universal, seletiva e indicada) e o tratamento foca no atendimento assistencial, breve ou prolongado, àqueles que possuem um diagnóstico de um transtorno mental (Abreu, 2012, Weisz, Sandler, Durlak, \& Anton, 2005). Na complementação desse modelo, ações 
de manutenção são essenciais para adesão ao tratamento ao longo do tempo e para prevenção à recaída e reincidência (Weisz et al., 2005).

No que se refere à promoção à saúde, em meados dos séculos XIX e XX, os conceitos sobre essa temática estavam associados a um modelo biomédico, que relacionava à saúde com as condições higiênico-sanitárias de vida. $\mathrm{Na}$ década de 70, com base nas discussões sociais e econômicas de saúde, surge uma nova concepção sobre promoção com foco não apenas na doença. Em maio de 1974, no Canadá, o documento intitulado "Informe Lalonde" introduziu os determinantes da saúde com destaque para o fator "estilo de vida" que propõe uma visão comportamental preventiva da saúde com foco na ação pessoal (Heidmann et al., 2006; Sícoli \& Nascimento, 2003).

Outro marco na história da promoção à saúde ocorreu em novembro de 1986 com a I Conferência Internacional sobre Promoção à Saúde que resultou na "Carta de Otawa". Neste documento constam orientações que fundamentam ações de promoção à saúde em todo o mundo como: (1) implementação de políticas públicas saudáveis, (2) criação de ambientes favoráveis à saúde com foco na proteção do meio ambiente e conservação dos recursos naturais, (3) implantação de serviços de saúde com foco na saúde e não na doença, (4) desenvolvimento de ações de saúde com a participação da comunidade de forma a promover o empoderamento comunitário por meio de suporte pessoal e social, e (5) fortalecimento das habilidades pessoais com uso de estratégias que promovam o aprendizado de novas competências que ajudem o indivíduo a lidar com as adversidades do ciclo da vida (WHO, 2009).

Apesar das dificuldades, o campo da promoção da saúde tem evoluído de forma gradual e contínua por meio de conferências que discutem questões importantes amparadas em dois pilares: mudança comportamental e de estilo de vida e saúde, condições e qualidade de vida (Heidmann et al., 2006). Nesta perspectiva, desde 1948, data da criação da WHO 
(2004), a saúde mental integra o conceito ampliado de saúde como "um estado de completo desenvolvimento físico, mental e bem-estar social e não apenas a ausência de doença ou enfermidade" (p.1). Dessa forma, a WHO (2004) descreve saúde mental como um estado de bem-estar no qual as pessoas acreditem em suas potencialidades e capacidades para lidar com as dificuldades cotidianas, trabalhando de forma produtiva e contribuindo para o crescimento da sua comunidade.

Assim, a implantação de intervenções promotoras de saúde são essenciais para a saúde mental da população mundial (WHO, 2004). A articulação entre as cinco estratégias previstas na Carta de Otawa (políticas públicas, ambientes saudáveis, reorientação do conceito de saúde sem conotação de doença, empoderamento da comunidade e fortalecimento de habilidades individuais) pode promover a saúde mental da população. Entretanto, isso é um grande desafio, principalmente, para países latino-americanos, tendo em vista as diferenças sociais, precariedade nas condições de vida e a ausência de recursos (Heidmann et al., 2006).

\section{Focos de Intervenções na Prevenção e Promoção de Envelhecimento Ativo}

A literatura especializada aponta que intervenções de prevenção de doenças e promoção da saúde mental oferecem excelente potencial em promover o empoderamento (Shearer, Fleury, Ward, \& O' Brien, 2012, Teixeira, 2002), saúde e cidadania (Veras \& Caldas, 2004) planejamento e adaptação à aposentadoria (França, 2012; Soares \& Costa, 2011), em reduzir sintomas de depressão (Pot et al., 2008; Korte, Bohlmeij, Cappeliez, Smit, \& Westerhof, 2012) de ansiedade (Zou et al., 2012) e em prevenir o suícidio (Lapierre et al., 2011).

Entretanto, os estudos sobre intervenções preventivas e de promoção à saúde mental em adultos mais velhos são escassos na literatura, em comparação com outras 
faixas etárias como, por exemplo, intervenções direcionadas a crianças e jovens. Isso mostra que os idosos são alvos menos frequentes de programas de prevenção à doença e promoção à saúde (Richard, Gauvin, Ducharme, Leblanc \& Trudel, 2012).

As intervenções de prevenção de doenças e promoção da saúde mental, no Brasil, tem utilizado na maioria das vezes a abordagem comportamental e cognitivocomportamental (Abreu, 2012). Estas abordagens também são comumente utilizadas em intervenções de prevenção à depressão (Muñoz et al., 2010). Todavia, a abordagem ecológica é considerada um componente-chave do novo movimento de prevenção e promoção da saúde, adotada por entidades como a WHO e por Ministérios de Saúde em todo mundo (Richard et al., 2012).

Essa abordagem tem como foco uma perspectiva ampliada dos fatores determinantes da saúde e qualidade de vida e enfatiza as interações entre indivíduos, grupos e seu meio ambiente (Abreu, 2012). Dessa forma, há um crescente reconhecimento de que os programas mais eficazes na prevenção e promoção da saúde são aqueles que adotam abordagens abrangentes, como a proposta pelo modelo ecológico, que inclui várias estratégias de intervenção, visando não só os determinantes individuais de saúde (comportamento, conhecimentos, habilidades), mas também determinantes sociais como rede de apoio, comunidade, organizações e políticas públicas (Abreu, 2012; Jackson et al., 2007). Entretanto, percebe-se que o foco de intervenções de prevenção de doenças e promoção da saúde mental da pessoa idosa está centrado, em sua maioria, no componente individual. Características desse tipo de intervenção são apresentadas, por exemplo, em estudos de prevenção à depressão (Pot et al., 2008; Korte et al., 2012) e ao suicídio (Lapierre et al., 2011) em adultos mais velhos e idosos.

Intervenções preventivas à depressão em idosos têm utilizado a terapia "life review"como estratégia e avaliação da própria vida. Trata-se de uma abordagem que 
possibilita alternativas para lidar melhor com as perdas e declínios relacioandos à idade e encontrar significado nesta nova fase da vida (Korte et al., 2012). Nessa perpectiva, Pot et al. (2008) realizaram um estudo com condições controle e experimental para avaliar a efetividade clínica e econômica de uma intervenção preventiva indicada (idosos com sintomas depressivos leve e moderado). Participaram da intervenção pessoas acima de 55 anos que não possuíam diagnóstico de depressão maior. A intervenção foi composta de 12 sessões, com 08 integrantes, duas horas de duração e sessões centradas em temas como: seu nome, casas nas quais você viveu, reconhecendo seus recursos, amizades, fotografias, linha da vida, o futuro em mim e identidade. Para condição controle foi utilizada uma intervenção mínima por meio de apresentação de um vídeo educativo de 20 minutos o qual fornecia informações sobre fatores e habilidades que promovem um envelhecimento positivo.

Recentemente, Korte et al. (2012) realizaram um estudo com as mesmas características, utilizando a abordagem de intervenção life review. Os dois estudos usaram instrumentos de medidas da depressão, de ansiedade e de qualidade de vida, com avaliações qualitativas e de follow-up, seis e nove meses, respectivamente. Tais estudos apresentaram como resultados primários a redução dos sintomas da depressão e, secundários, a redução dos sintomas de ansiedade, aumento da satisfação com a vida, da qualidade de vida e fortalecimento positivo da saúde mental de adultos mais velhos.

Uma revisão sistemática sobre programas de prevenção ao suicidio em idosos mostrou que existe uma carência de estudos baseados em evidências nesse campo (Lapierre et al., 2011). Das 490 publicações sobre o suicídio em idosos apenas 19 apresentaram critérios de avaliação empírica de uma intervenção preventiva. Contudo, os resultados obtidos nesta meta-análise apontaram evidências de que esses programas de prevenção (universal, seletiva e indicada) produziram efeitos benéficos sobre esta 
população, principalmente, nas mulheres, por serem estas as que mais utilizavam os recursos sociais e serviços de saúde oferecidos pelos programas. O foco das intervenções na maioria dos estudos foi na redução dos fatores de risco (sintomas depressivos e isolamento) e apenas dois estudos focaram nos fatores de proteção (fortalecimento da resiliência, autoconfiança e habilidades sociais). Os programas utilizaram estratégias como workshops, ações sociais em grupo, com atividades educativas, de recreação, física, voluntariado e uso do telefone como estratégia de aconselhamento e apoio.

Ao abordar as estratégias de intervenções que previnem transtornos mentais em idosos, cabe salientar a escassez no uso de tecnologias computadorizadas como, por exemplo, internet e programas computacionais em ações destinadas a essa clientela. De modo geral, intervenções computadorizadas-customizadas (programas personalizados com foco nas características e interesses do indivíduo), realizadas em países da Oceania e da Europa Ocidental, têm apresentado efeitos promissores em programas de promoção à saúde de idosos como, por exemplo, na adesão e manutenção da prática de atividade física (Stralen \& De Vries, 2011).

Embora escassos, resultados de um estudo realizado por Zou et al. (2012) mostram os benefícios de instrumentos tecnológicos para prevenir a doença mental em idosos. $\mathrm{O}$ estudo teve como propósito avaliar a eficácia e aceitabilidade de um programa breve, via internet, para redução de sintomas moderados de ansiedade, embasado na abordagem cognitiva-comportamental. A intervenção consistiu em cinco encontros que abordavam informações sobre os sintomas e tratamento da ansiedade, instruções sobre mudança de pensamentos disfuncionais, principíos básicos sobre como controlar os sintomas físicos, exposição gradativa e prevenção a recaídas. A participação dos participantes, com idade média de 66 anos, aconteceu por meio de um fórum de discussão mediado por psicólogos clínicos, lembretes automáticos regulares, tarefas de casa, notificações por email e suporte 
telefônico semanal realizado por um psicólogo clínico. Os resultados deste estudo são animadores, pois indicaram melhoras significativas nos sintomas de ansiedade e um alto grau de aceitabilidade desse tipo de intervenção pelos idosos.

No que se refere ao foco de intervenções de promoção à sáude mental de idosos, destacam-se, na literatura nacional e internacional, intervenções para o empoderamento dessas pessoas a partir de encontros em grupos que tem como intuito promover a valorização do envelhecer e a discussão de questões referentes à logenvidade (Teixeira, 2002). Estudiosos dessa temática afirmam que uma abordagem de empoderamento é uma perspectiva de autoeficácia e que esta pode fomentar a participação do idoso nas decisões de saúde e promover resultados positivos para a sua vida (Shearer et al., 2012).

Em uma revisão sistemática sobre intervenções de empoderamento para pessoas idosas Shearer et al. (2012) verificaram que as intervenções incluiam um componente de educação para promover o empoderamento e aumentar o conhecimento para a tomada de decisões em relação à problemas de saúde como diabetes, hipertensão. Como resultado das intervenções na saúde mental, os dados dos estudos mostram que o empoderamento influenciou na redução da depressão e ansiedade e fortaleceu a autoeficácia dos participantes (Shearer et al., 2012).

Intervenções nacionais de promoção à saúde mental em idosos tem considerado o impacto positivo no uso de algumas práticas como Universidade Aberta da Terceira Idade - UnATI (Veras \& Caldas, 2004), Terapia Comunitária - TC ( Rocha et al., 2009) e intervenções de Preparação Para Aposentadoria - PPA (França, 2012; Soares \& Costa, 2011). A proposta da UnATI é promover autoestima, resgatar a cidadania, incentivar a autonomia, o empoderamento e a busca de uma velhice bem-sucedida (Veras \& Caldas, 2004). Além disso, é um programa que possui relevância social por possibilitar a inclusão do idoso na sociedade por meio do convívio com outras gerações. 
Quanto à TC, esta é analisada como uma estratégia coletiva com foco nas histórias de vida pessoais que tem beneficiado grupos de idosos de baixo poder aquisitivo, como demonstrado em estudo realizado por Rocha et al. (2009). Estes pesquisadores adotaram a TC para investigar os problemas mais frequentes e as estratégias de enfrentamento empregadas por um grupo de idosas de uma capital brasileira. Os resultados apontam o estresse (medo da morte, perda do cônjuge, angústia originada pelo desrespeito e mesnoprezo em razão da idade) como o problema mais frequente e a espiritualidade (fé e oração) como a estratégia de fortalecimento mais utilizada por essas mulheres. De acordo com os autores, a TC possibilitou o compartlhamendo dos sofrimentos, sentimentos de igualdade e o processo de empoderamento e resiliência dos participantes.

A transição para aposentadoria é um fenômeno que vem sendo bastante estudado pela literatura nacional, tendo em vista que se trata de uma época de mudanças e readaptações no contexto social, familir e ocupacional. A aposentadoria bem-sucedida está entre os fatores determinantes do envelhecimento ativo (WHO, 2002), pois uma má adaptação a esse novo estilo de vida pode acarretar sofrimento psíquico grave como depressão e suícidio (Minayo \& Cavalcante, 2012; Barrero, 2012; Pinto et al., 2012).

Sendo assim, os Programas de Preparação para Aposentadoria têm se destacado como medidas promissoras na promoção de qualidade de vida e ajustamento à aposentadoria (França, 2012; Soares \& Costa, 2011). A maioria dessas intervenções aborda em seu conteúdo temas como segurança financeira, saúde, promoção da autoeficácia, fortalecimento dos vínculos familiares e sociais. Modalidades terapêuticas de curta duração também têm alcançado resultados positivos quando aplicadas a esse público. Destaca-se o estudo de França (2012) que teve o objetivo de desenvolver e avaliar um modelo de intervenção breve, inovador nessa população, fundamentada no Modelo Transteórico de Mudança. A intervenção foi em grupo, em sessão única, com três horas de 
duração, seguida de três monitoramentos, totalizando onze mezes de follow-up. O foco da intervenção foi promover a aquisição de recursos favoráveis a uma boa aposentadoria. Os resultados revelaram que a intervenção breve mostrou-se útil como estratégia de sensibilização ao tema e motivou os participantes a modificar e adquirir comportamentos adaptativos à aposentadoria. Ademais, favoreceu a autonomia e bem-estar, interação grupal, aquisição de conhecimento e a vivência de emoções positivas.

Ao considerar os resultados positivos desses estudos, percebe-se o potencial dessas intervenções na prevenção de transtornos e promoção à saúde mental dos adultos mais velhos e idosos. Sendo assim, um esforço conjunto entre governos, sociedade e pesquisadores é imprescindível na implantação e disseminação de ações eficazes que priorizem a saúde mental da pessoa idosa, como recomendado pelo Plano Internacional de Ação sobre o Envelhecimento .

\section{Conclusão}

Estudos sobre intervenções preventivas e de promoção à saúde mental da pessoa idosa são escassos na literatura especializada, quando comparados aos estudos sobre intervenções na área infanto-juvenil. A falta de atenção a essa clientela pode estar relacionada à questão de preconceito de idade em decorrência de uma posição capitalista da sociedade que reforçou, por muitos anos, atitudes discriminatórias e de exclusão da população idosa, privilegiando os mais jovens em razão do seu potencial produtivo e de vida útil (Xavier, 2012).

Além disso, as crenças de que a saúde física é o principal determinante da qualidade de vida de adultos mais velhos, percepção tradicional do modelo biomédico, podem limitar o potencial de ações desenvolvidas para essa população (Bennett \& Flaherty-Robb, 2003), inclusive na perspectiva de implementação de uma abordagem 
ecológica (Richard et al., 2012). Desse modo, percebe-se a necessidade de romper com paradigmas obsoletos para que o idoso seja, de fato, inserido na agenda sobre ações de prevenção e promoção à saúde mental.

A literatura nacional acerca do tema em questão aponta fragilidades quanto à realização de práticas baseadas em evidências e no cumprimento das etapas do ciclo de pesquisa em prevenção, em comparação aos estudos internacionais. $\mathrm{O}$ ciclo de pesquisa em prevenção é composto por seis fases: (1) identificação do problema e sua prevalência, (2) identificação e avaliação dos fatores de risco e proteção, (3) realização de estudo piloto, (4) realização de estudos experimentais para avaliar a eficácia da intervenção, (5) implantação da intervenção em condições naturais e (6) difusão, que se refere à transferência da intervenção à comunidade, em larga escala (Abreu, 2012; Dalton et al., 2007).

Nessa perspectiva, estudos nacionais sobre intervenções preventivas à saúde mental do idoso se mantêm nas três primeiras fases desse ciclo. De modo geral, essas informações estão coerentes com um estudo recente sobre o estado da arte da pesquisa em prevenção em saúde mental no Brasil, em todas as etapas do ciclo da vida (Abreu, 2012). Os dados apontam que os programas preventivos brasileiros são caracterizados por delineamentos pré-experimentais, sem follow-up e sem discussão dos seus resultados para as políticas públicas. Neste sentido, considerando o ciclo da prevenção, há um longo caminho a percorrer para se alcançar a etapa de disseminação de intervenções preventivas eficazes à saúde mental da pessoa idosa.

Verifica-se ainda que a maioria das intervenções destinadas à saúde mental de idosos, na literatura nacional, tem como foco a promoção (potencializar competências e recursos para o enfrentamento de eventos estressores) do que a prevenção (reduzir riscos de surgimento de problemas ou transtornos). Mesmo que essas intervenções com foco 
único, em prevenção ou promoção, apresentem benefícios à saúde mental da pessoa idosa, tem-se como hipótese que intervenções integradas, embasadas tanto em critérios de prevenção como de promoção à saúde mental, sejam mais abrangentes e robustas. Ademais, é provável que intervenções com foco apenas na promoção também previnam o surgimento de transtornos mentais. Assim, deve-se considerar nessa argumentação, o atual conceito de prevenção, que compreende a promoção à saúde como área específica da prevenção e enfatiza a integração entre esses dois campos (Abreu, 2012).

Destaca-se ainda no contexto nacional, a necessidade de avaliar essas práticas preventivas ou de promoção à saúde mental de pessoas mais velhas e idosas, com rigor metodológico, baseado em evidências que assegurem a eficácia e efetividade desses programas. Para tanto, são necessárias avaliações contínuas e de monitoramento como, por exemplo, avaliar o impacto de intervenções em adultos mais velhos antes deles se aposentarem e, na velhice, durante a aposentadoria.

De modo semelhante, com relação às políticas de intervenções dirigidas à saúde mental do idoso, observa-se que normatizações, como as recomendadas pela WHO (2004), também estão focadas em ações de promoção. Sendo assim, é relevante incluir na agenda política orientações para a implantação de ações preventivas e de outros temas inovadores como a prática de intervenções breves e uso de estratégias computadorizadas. Práticas preventivas via internet, tem beneficiado a população idosa na redução de sintomas de ansiedade (Zou et al., 2012) com alto grau de aceitabilidade por esse público.

Esses resultados promovem a inclusão digital e desmistificam concepções preconceituosas quanto ao uso de computador nessa faixa etária. Entretanto, são necessárias investigações com a utilização desses instrumentos na população nacional de adultos mais velhos e idosos, considerando a diversidade econômica, educacional e sóciocultural brasileira. Intervenções breves também surgem como alternativas viáveis, tendo 
em vista sua rápida aplicabilidade, baixo custo econômico e perspectiva de atender uma demanda maior de participantes (França, 2012).

Baseado nos resultados desses estudos, recomenda-se que intervenções de prevenção e promoção à saúde mental da população idosa sejam realizadas por meio de ações intersetoriais articuladas, agregando contribuições da ciência, estado, sociedade, famílias, comunidades, profissionais de saúde e entidades públicas e privadas (Heidmann et al., 2006). Dados evidenciados neste ensaio têm implicações para planejamento de uma agenda política e de pesquisa que priorize o idoso, investindo em intervenções eficazes e efetivas de prevenção e promoção à saúde mental dessa população. 


\section{Referências}

Abreu, S. (2012). Prevenção em saúde mental no Brasil na perspectiva da literatura e especialistas da área. Dissertação de Mestrado. Universidade de Brasília, Brasília, DF.

Bennett, J. A., \& Flaherty-Robb, M. K. (2003). Issues affecting the health of older citizens: Meeting the challenges. Online Journal of Issues in Nursing, 8(2). Recuperado em 15 de fevereiro 2013, de http://www.nursingworld.org/default.aspx

Barrero, S. (2012). Factores de riesgo suicida em el anciano. Ciência \& Saúde Coletiva, 17, 2011-2016.

Constituição da República Federativa do Brasil (1988). Brasília, Brasil. Recuperado em 14 de fevereiro 2013, de http://www.planalto.gov.br/ccivil_03/constituicao/constituicao.htm

Dalton, J. H., Elias, M. J., \& Wandersman, A. (2007). Community Psychology: Linking individuals and communities. Thomsom Wadsworth: Belmont, California.

França (2012). Modelo de uma intervenção breve para planejamento da aposentadoria: desenvolvimento e avaliação. Dissertação de Mestrado, Universidade de Brasília, Brasília, DF.

Heidmann, I., Almeida,M.C., Boehs, A., Wosny, A., \& Montecelli, M. (2006). Promoção à saúde: trajetória histórica de suas concepções. Texto \& Contexto, 15, 352-358.

Hinrichsen, G. (2010). Public Policy and the Provision of Psychological Services to Older Adults. Professional Psychology: Research and Practice, 41, 97-103.

Jackson, S. F., Perkins, F., Khandor, E., Cordwell, L., Hamann, S., \& Buasai, S. (2007). Integrated health promotion strategies: A contribution to tackling current and future health challenges. Health Promotion International, 21(S1), 75-83. 
Korte, J, Bohlmeij, E.T., Cappeliez, P., Smit, F. \& Westerhof, G. J. (2012). Life review therapy for older adults with moderate depressive symptomatology: a pragmatic randomized controlled trial. Psychological Medicine, 42, 1163-1173.

Lapierre, S., Erlangsen, A.,Waern, M., De Leo, D.,Oyama, H., Scocco, P. ... Quinnett, P.(2011). A Systematic review of elderly suicide prevention programs. Crisis, 32, $88-98$.

Lei no. 8.842, de 04 de janeiro de 1994 (1994). Dispõe sobre a Política Nacional do Idoso. Recuperado em 13 de fevereiro 2013, de http://www.planalto.gov.br/ccivil_03/leis/L8842.htm

Lei 10.741 , de $1^{\circ}$ de outubro de 2003 (2003). Dispõe sobre o Estatuto do Idoso e dá outras providências. Recuperado em 13 de fevereiro 2013, de http://www.planalto.gov.br/ccivil_03/leis/2003/L10.741.htm

Minayo, M. C., \& Cavalcante, F. (2012). Autópsias psicológicas e psicossociais de idosos que morreram por suicídio no Brasil. Ciência \& Saúde Coletiva, 17, 1943-1954.

Muñoz, R., Cuijpers, P., Smit, F., Barrera, A., \& Leykin, Y. (2010). Prevention of major depression. Annual Review of Clinical Psychology, 6 181-212.

Murta, S. (2005). Aplicações do treinamento em habilidades sociais: análise da produção nacional. Psicologia: Reflexão e Crítica, 18, 283-291.

Pinto, L., Pires, T., Silva, M. \& Assis, S. (2012). Evolução temporal da mortalidade por suicídio em pessoas com 60 anos ou mais nos estados brasileiros, 1980 a 2009. Ciência \& Saúde Coletiva, 17, 1973-1980.

Pot, A., Melenhorst, A.S., Onrust, S., \& Bohlmeijer, E. (2008). (Cost) effectiveness of live review for older adults: Design of a randomized controlled trial. BioMed Central Public Health, 8, 1471-2458. doi: 10.1186/1471-2458-8-211. 
Richard, L., Gauvin, L., Ducharme, F., Leblanc, M.E., \& Trudel, M. (2012). Integrating the Ecological Approach in Disease Prevention and Health Promotion Programs for Older Adults: An Exercise in Navigating the Headwinds. Journal of Applied Gerontology, 31, 101-125. doi: 10.1177/0733464810382526.

Rocha, I., Braga, L., Tavares, L., Andrade, F., Filha., M., Dias., M. \& Silva, A. (2009). A terapia comunitária como novo instrumento de cuidado para saúde mental do idoso. Revista Brasileira de Enfermagem, 62, 687-694.

Shearer, N., Fleury, J.,, Ward, K., \& O’Brien, A.M. (2012). Empowerment interventions for older adults. Western Journal of Nursing Research, 34, 24-51.

Sícoli, J., \& Nascimento, P. R. (2003). Promoção de saúde: Concepções, princípios e operacionalização. Interface, 7, 91-112.

Soares, D., \& Costa, A. (2011). Aposenta-Ação: Aposentadoria para ação. $1^{\mathrm{a}}$ Ed, São Paulo:Vetor.

Stralen, M \& De Vries, H. (2011). The long-term efficacy of two computer-tailored physical activity interventions for older adults: Main effects and mediators. Health Psychology, 30, 442-452.

Teixeira, M. (2002). Empoderamento de idosos em grupos direcionados à promoção da saúde. Dissertação de mestrado. Curso de Pós-Graduação em Psicologia Clínica, Fiocruz, ENESP, Rio de Janeiro, RJ.

Veras, R., \& Caldas, C. (2004). Promovendo a saúde e a cidadania do idoso: o movimento das universidades da terceira idade. Ciência \& Saúde Coletiva, 9, 423-432.

Weisz, J. R., Sandler, I. N., Durlak, J. A., \& Anton, B. S. (2005). Promoting and protecting youth mental health through evidence-based prevention and treatment. American Psychologist, 60, 628-648. 
World Health Organization (WHO). (2012). Depression. Recuperado em 13 de fevereiro 2013, de http://www.who.int/mediacentre/factsheets/fs369/en/index.html

World Health Organization (WHO). (2009). Milestone in health promotion: statements from global conferences. Geneva: World Health Organization.

World Health Organization (WHO). (2004). Promoting Mental Health. Geneva: World Health Organization.

World Health Organization (WHO). (2002). Active ageing: A policy framework. Madrid: World Health Organization.

Xavier, B. F. (2012). Um estudo sobre ações sociais do estado brasileiro direcionadas ao idoso e a contribuição do IFRN alusiva a essa temática. Hollos, 2, 275-283.

Zou, J., Dear, B., Titov, N., Lorian, C., Johnston, L., Spence. ... Sachdev, P. (2012). Brief internet-delivered cognitive behavioral therapy for anxiety in older adults: a feasibility trial. Journal of Anxiety Disorders, 26, 650-655. 


\section{CAPÍTULO 3}

Publicado como capítulo de Livro ${ }^{9}$

\section{Aposentadoria: Crise ou Liberdade?}

${ }^{9}$ Leandro-França, C. (2014). Formatos de programas de educação para aposentadoria. Em Murta, S. Leandro-França, C. \& Seidl, J. Programas de preparação para aposentadoria: como planejar, implementar e avaliar. (pp. 84-113). Brasília, DF: Editora Sinopsys. 


\section{Aposentadoria: Crise ou Liberdade?}

A transição para a aposentadoria é um fenômeno vivenciado de forma heterogênea entre os trabalhadores. Alguns sofrem com o possível rompimento dos laços de amizade, da convivência diária, da rotina estabelecida em anos de dedicação ao trabalho formal e de uma identidade profissional construída ao longo da carreira. Outros se adaptam mais facilmente, não vivenciam o afastamento do trabalho com sofrimento e tampouco o associam a um rompimento.

Santos (1990) define essa dualidade de sentimentos referentes à aposentadoria como crise ou liberdade, ou seja, de um lado estão os que vivenciam esse fenômeno como tensão e, de outro, aqueles que percebem a aposentadoria como uma oportunidade de mudança para uma vida com mais autonomia e prazer. Apesar dessas diferenças individuais, em geral os trabalhadores almejam uma aposentadoria bem-sucedida. Mas o que fazer para se viver uma aposentadoria com qualidade de vida?

Para Wang, Henkens e van Solinge (2011), uma boa adaptação à aposentadoria dependerá de recursos que cada indivíduo possui e da capacidade de aquisição e de mudança destes recursos ao longo da vida. Além disso, planejar-se com antecedência também é requisito fundamental para uma aposentadoria bem-sucedida, pois promove atitudes positivas e aumenta a satisfação com a aposentadoria em comparação aos que não se planejaram. Sendo assim, conhecer quais características diferencia uma aposentadoria com qualidade de vida de uma sem é a melhor forma de adaptar-se a essa fase, além de poder ajudar na decisão de se aposentar e na elaboração de um planejamento eficiente. 


\section{Condições Associadas à Aposentadoria como Crise}

A percepção e a vivência da aposentadoria como situação de crise versus como situação de liberdade foram estudadas por Santos (1990) em uma amostra de 100 aposentados da cidade de Recife, com idade entre 40 e 49 anos e de profissões urbanas. Neste estudo, 51 participantes, que relataram representação negativa e vivência da aposentadoria como crise, foram incluídos em categorias denominadas aposentadoriarecusa (19 participantes) e aposentadoria-sobrevivência (32 participantes).

A primeira categoria relatou comportamentos de não aceitação da condição de aposentado, ausência de projetos de vida fora do trabalho e associação de aposentadoria a velhice, morte, inutilidade e ausência de objetivos em suas vidas. Os aposentados atribuídos a esta categoria tinham um alto padrão econômico e um papel profissional de prestígio que proporcionava ganhos sociais e poder, tornando difícil a desvinculação da identidade profissional e a aceitação da condição de aposentado.

Os participantes atribuídos à segunda categoria eram pessoas de níveis econômicos desfavorecidos e que superinvestiam no papel profissional, tanto por questões financeiras quanto por considerá-lo a única fonte de valorização e de inclusão social. Para estes participantes, o fato de não trabalhar, em consequência da aposentadoria, era vivenciado com sentimentos de fracasso, inutilidade e impotência.

Em se tratando da adaptação à aposentadoria, é comum a literatura especializada (França, L. 2002; França, C., \& Murta, 2014; Zanelli, 2012) conceituar e descrever condições que facilitem ou dificultem tal adaptação com base em aspectos pessoais, psicológicos, sociais e organizacionais. A Figura 1 apresenta algumas condições que podem afetar a qualidade de vida e originar a crise na aposentadoria. 

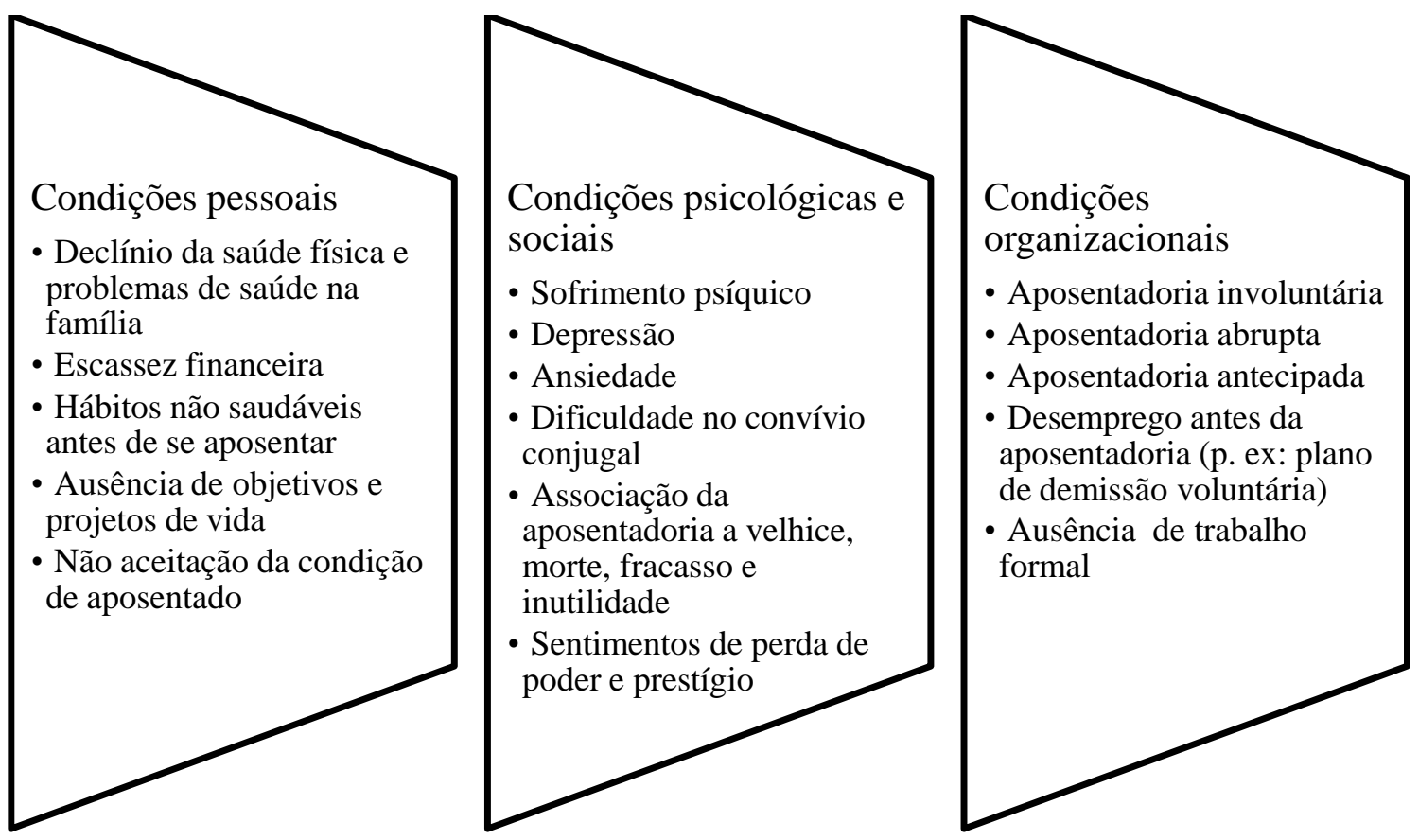

Figura 1. Aposentadoria como crise.

Ao realizar uma revisão da literatura internacional, Wang, Henkens e van Solinge (2011) constataram que filhos dependentes financeiramente, declínio da saúde física, viuvez na transição para a aposentadoria, aposentadoria adiantada em relação ao esperado e problemas de saúde são fatores que podem ocasionar dificuldades na adaptação a esse período da vida. Nesta perspectiva, a proximidade da aposentadoria causa algumas preocupações, principalmente em relação às perdas financeiras. Participantes de programas de educação para aposentadoria costumam relatar dificuldades que podem vir a enfrentar com a redução salarial decorrente desse acontecimento. Percebe-se que este fenômeno afeta principalmente as pessoas que não fizeram uma reserva financeira ao longo da vida, não possuem moradia própria, ajudam financeiramente os filhos e netos ou gastam um percentual significativo do seu salário com medicações para tratamento de alguma doença crônica.

Favorecer a troca de experiências entre os colegas que participam de ações de educação para aposentadoria é muito importante e ajuda as pessoas que passam por tais 
dificuldades a encontrar alternativas para lidar com o problema. Em geral, as propostas do grupo para o manejo dos obstáculos financeiros estão relacionadas ao corte de gastos, à inclusão da família no planejamento financeiro e ao incentivo à autonomia dos filhos, sendo esta última de grande relevância, na medida em que, ao estimular a independência financeira dos filhos, sobrará mais dinheiro para o aposentado investir em sua própria saúde, lazer e qualidade de vida.

O declínio da saúde física, que se agrava com a idade, também pode acarretar consequências negativas na aposentadoria, tendo em vista o impacto financeiro com gastos médicos, com a dependência de terceiros no que diz respeito à locomoção e com os cuidados pessoais. Além disso, segundo Menezes e França (2012), quando o trabalhador percebe que sua saúde está debilitada, fica mais propenso a requerer sua aposentadoria. Tal fato pode ocasionar uma aposentadoria involuntária e, consequentemente, dificuldades para a adaptação a esse estágio da vida.

Assim, quando a aposentadoria ocorre de forma involuntária e abrupta - por exemplo, por motivo de doença pessoal, para acompanhar um familiar que esteja doente ou ainda por conflitos com a chefia ou com colegas de trabalho - ela é considerada um fator de risco. Em situações de conflitos no trabalho, nem sempre o profissional está seguro da decisão e acaba utilizando o ato de se aposentar como uma fuga para evitar lidar com o problema. Desta forma, não percebe que essa decisão precipitada poderá trazer consequências desastrosas para sua vida de aposentado.

A decisão de se aposentar pode afetar o núcleo familiar e dificultar o convívio conjugal, principalmente quando o aposentado não possui atividades de ocupação ou de lazer externas ao convívio familiar (Zanelli, 2012). A permanência contínua no lar pode causar estresse no companheiro e nos filhos. É possível que o aumento no tempo de convivência com a família faça o trabalhador perceber situações que antes não conseguia 
enxergar, seja por falta de tempo ou por se esquivar do problema. Ao tentar modificar as situações familiares que julga serem inadequadas, especialmente se for por meio de comportamentos autoritários e de imposição, o servidor lidará com conflitos que talvez dificultem a dinâmica familiar consolidada ao longo dos anos.

Quanto ao convívio conjugal com o(a) companheiro(a), a aposentadoria pode se tornar um fator de estresse, especialmente se a relação já não estava bem. É possível que a convivência diária agrave a crise no casamento e acentue as diferenças entre os parceiros (França, 2002), principalmente se não ocorreu um planejamento compartilhado para a aposentadoria. Por exemplo, decidir onde morar quando aposentados é uma questão que angustia muitos casais. São comuns relatos de um querer morar na praia, para não se afastar da vida urbana, e o outro preferir residir em um sítio ou uma chácara, por gostar mais da vida rural e para evitar o tumulto das cidades. Desta forma, a fim de que a aposentadoria não afete a relação marital, é fundamental que o casal reflita sobre as vantagens e desvantagens dessa decisão, compartilhe dúvidas e medos, realize um planejamento em conjunto e estabeleça objetivos convergentes (Soares \& Costa, 2011) para uma convivência com harmonia.

As questões emocionais, como depressão e ansiedade, que podem ocorrer com a proximidade da aposentadoria ou como consequência de algum transtorno psíquico adquirido no decorrer da vida são consideradas agravantes nesse processo. São comuns, nessa fase de transição, sentimentos de tristeza, medo do futuro e insegurança na tomada de decisão quanto a se aposentar. Com o passar do tempo, é esperado que os trabalhadores adaptem-se ao novo contexto e tracem novos projetos de vida. Entretanto, algumas pessoas podem não atingir essa adaptação e, consequentemente, desenvolver um quadro depressivo crônico. Vale salientar que, na aposentadoria, depressão, isolamento social, perda do prestígio, conflitos conjugais e solidão são fatores de risco para o suicídio entre os idosos 
(Minayo, Cavalcante, Mangas, \& Souza, 2012). Deste modo, profissionais que trabalham com ações de educação para aposentadoria devem ficar atentos a estes sinais e procurar conhecer a história de vida do indivíduo, dentro e fora da organização, de forma a orientálo no planejamento e em uma decisão segura.

Com relação às diferenças de gênero, há evidências de que os homens possuem mais dificuldades em se adaptar à aposentadoria do que as mulheres (Santos, 1990). Resultados do estudo realizado por Oliveira, Torres e Albuquerque (2009) demonstram que a facilidade na mobilidade está positivamente associada ao bem-estar psicossocial na aposentadoria do homem. A pesquisa foi realizada na cidade de Goiânia, com 118 homens, média de idade de 65 anos, todos aposentados por tempo de serviço na administração pública direta e indireta. A maioria dos participantes considerou que ter carro próprio e residir em um imóvel bem localizado, em uma cidade com qualidade de vida e com opções de lazer, facilitam o convívio com os amigos e proporcionam o bem-estar na aposentadoria. Tal fato chama a atenção para a importância de se considerar as prioridades do público masculino no planejamento dos programas de educação para aposentadoria. Em resumo, alguns cuidados são essenciais para garantir a motivação e a adesão desse público, por exemplo, ouvi-los antes de planejar a ação e elaborar estratégias de acordo com suas necessidades.

Quanto às mulheres, a facilidade em adaptarem-se à aposentadoria pode estar relacionada aos diversos papéis (mãe, avó, esposa, filha) que elas estão acostumadas a exercer diariamente, além do trabalho formal. Todas essas atribuições tendem a ocupar grande parte do seu tempo, sendo assim, a perda do trabalho assalariado pode não ser tão impactante (França, 2002). 


\section{Condições Associadas à Aposentadoria como Liberdade}

A aposentadoria-liberdade consiste na percepção da aposentadoria como um acontecimento positivo e uma situação de não crise. No estudo de Santos (1990), 59 participantes inclusos nesta categoria possuíam um nível econômico privilegiado, como os da aposentadoria-recusa, mas se diferenciavam desta por não limitar suas identidades apenas à ocupação profissional. Os resultados provenientes da aposentadoria-liberdade foram associados à construção de projetos de vida antes e após a aposentadoria, como, por exemplo, realizar atividades de lazer e intelectuais, e à concepção da aposentadoria como um período de realização, de liberdade, que lhes possibilita dedicar-se a atividades que dão prazer, sem a rigidez de cumprir horários.

Sendo assim, recursos designados como positivos envolvem fatores ou variáveis que reduzem o impacto da crise na aposentadoria. Tais fatores têm potencial para atenuar a magnitude da crise, protegendo o indivíduo das adversidades. Estas variáveis podem estar relacionadas a recursos como autoestima, autoeficácia, autonomia, coesão familiar e rede de apoio social. Além disso, possuir boa saúde física e mental, aposentar para realizar outras atividades, engajar-se em um trabalho formal, em atividades de lazer e de voluntariado e ter uma relação conjugal positiva, assim como uma boa condição financeira, são condições que favorecem a adaptação à aposentadoria (Wang, Henkens, \& van Solinge, 2011). A Figura 2 apresenta algumas condições que auxiliam no processo de adaptação à aposentadoria, de acordo com a literatura especializada (França, L., 2002; França, C., \& Murta, 2014; Wang, Henkens, \& van Solinge, 2011; Zanelli, 2012). 




Figura 2. Aposentadoria como liberdade.

Entre os recursos para uma aposentadoria satisfatória estão a prática de atividade física, o lazer e a ingestão de alimentos saudáveis. Estes são comportamentos preventivos que podem proporcionar uma vida ativa, com saúde e longevidade (Canizares, 2009; Zanelli, 2012). No estudo de Oliveira, Torres e Albuquerque (2009), possuir boa saúde física e psicológica e ter plano de saúde está associado à satisfação e ao bem-estar na aposentadoria. Indivíduos que adotam um estilo de vida saudável (prática de atividade física, consumo de álcool moderado e abandono do cigarro) antes de aposentar tendem a ter mais saúde na aposentadoria (Breslow, Reuben, \& Wallace, 2000).

A ausência do trabalho formal, em consequência da aposentadoria, também pode afetar a saúde do indivíduo é o que revela uma pesquisa realizada pelo centro de estudos Institute of Economics Affairs (IEA), com sede em Londres. Segundo a pesquisa, a aposentadoria pode elevar em $40 \%$ as chances de desenvolver depressão, enquanto a possibilidade do aparecimento de um problema físico aumenta em 60\% (IEA, 2013). 
Sendo assim, cuidados prévios com a saúde e atividades de ocupação representam fatores de proteção para diminuir os possíveis riscos advindos da aposentadoria.

O apoio da família e do parceiro, assim como a companhia dos amigos, é fundamental nessa fase da vida. A reflexão sobre a importância de novos vínculos de amizade deve ser incluída no planejamento para aposentadoria. Com frequência, participantes de programas de educação para aposentadoria relatam experiências de pessoas que se aposentam e deixam de conviver com os colegas de trabalho, e o quanto isto impacta emocionalmente o aposentado. Para prevenir tais dificuldades, a ampliação da rede social fora do contexto do trabalho, antes de se aposentar, é um recurso relevante. A prática de atividade física e de lazer também é um artifício positivo na geração de vínculos sociais, evitando riscos como solidão e isolamento.

Outro fator que promove a adaptação à aposentadoria é a realização de atividades de voluntariado, que funcionam como estratégia de ocupação, distração e inclusão, além de proporcionar bem-estar, altruísmo e compromisso social. A ação voluntária possibilita a continuidade do trabalho formal, útil àqueles trabalhadores que desejam continuar exercendo suas habilidades profissionais, com autonomia sobre suas tarefas e seus horários, e ser reconhecidos por sua experiência e capacidade produtiva (Figueiredo, 2005).

Seidl (2010) realizou uma pesquisa com 74 trabalhadores portugueses de uma indústria em Leiria - sendo que a maioria deles não se encontrava perto da aposentadoria com o objetivo de investigar quais fatores os ajudariam a se adaptar à aposentadoria no futuro e a vivenciá-la como bem-sucedida. Os trabalhadores consideraram que a satisfação com o casamento, uma boa saúde (física e mental) e a prática frequente de atividades físicas os ajudaria a se adaptar a essa fase e a obter uma aposentadoria promissora. 
Além disso, ao serem questionados sobre quais fatores os incentivariam a optar pela aposentadoria após alcançar os critérios exigidos para tal, as respostas mais significativas foram, mais uma vez, estar satisfeito com a vida a dois, de modo a poder dedicar-se ao marido/esposa com mais tempo e qualidade, e, além disso, reconhecer outras fontes de prazer além do trabalho - por exemplo, ter mais tempo para realizar atividades de lazer, como viajar, participar de ações de voluntariado, passar mais tempo com a família e com os amigos e poder se dedicar a interesses pessoais.

Em um estudo realizado por França, Murta, Negreiros, Pedralho e Carvalhedo (2013) sobre as intenções de modificar ou adquirir comportamentos de autocuidado que ajudem na adaptação à aposentadoria, 41 servidores públicos federais, residentes em Brasília, relataram que tencionavam investir, respectivamente, em atividades de ocupação (lazer, hobby, religião, voluntariado e segunda carreira), saúde (check-up médico, alimentação saudável e prática de atividade física), rede social (vínculos de amizade e familiares), planejamento para aposentadoria (sem foco específico) e finanças.

Esses dados mostram que, ao refletir sobre sua aposentadoria, o indivíduo reconhece a importância de investir em diversos dos fatores de proteção apontados pela literatura especializada como importantes para uma aposentadoria vivida como liberdade, e não como crise. Destaca-se, neste estudo, a menor proporção na intenção de cuidar das finanças. Este fato chama atenção, pois era esperado que os trabalhadores pesquisados relatassem esta intenção como prioritária, tendo em vista que a maioria dos servidores de órgãos do Poder Executivo Federal possui uma remuneração inferior em comparação aos servidores de outros poderes federais, por exemplo, os do Legislativo e do Judiciário. Estes resultados podem auxiliar na implantação de ações de educação para aposentadoria em organizações públicas, na medida em que demonstram que tais ações devem englobar 
temas diversificados, de modo a promover a qualidade de vida, e não se restringir apenas aos cuidados com as finanças.

Embora não sejam muito abordadas em ações de educação para aposentadoria, práticas espirituais e religiosas podem funcionar como recursos favoráveis ao enfrentamento dessa fase. Não raro, os participantes de programas de educação para aposentadoria relatam a fé, a conexão com algo maior do que si mesmos, uma força interna, como benéficas ao fortalecimento pessoal e ao enfrentamento das adversidades. Religiosidade e espiritualidade se diferenciam. A primeira está relacionada a um sistema organizado, a um modo de vida, que envolve crenças, rituais e experiência de grupo que compartilha da mesma religião. A segunda está ligada a um sentido para o modo de vida, ou seja, envolve uma experiência transcendente e uma busca pessoal de respostas para o significado da vida (Peres, Simão, \& Nasello, 2007).

Estudos evidenciam que a religiosidade está associada positivamente aos indicadores de saúde mental (satisfação com a vida, felicidade e menos depressão) e física, principalmente em pessoas expostas a situações de estresse, como idosos e indivíduos com deficiências e doenças clínicas (Guimarães \& Avezum, 2007). O crescimento espiritual também pode ser definido como meta terapêutica legítima que independe de experiência religiosa. Portanto, é pertinente a inclusão deste tema, de modo mais amplo, em programas de educação para aposentadoria, evitando conotação apenas religiosa, como forma de promover uma melhor adaptação às mudanças provenientes dessa fase.

Em suma, observa-se que a percepção e a vivência da aposentadoria como crise ou liberdade são influenciadas por aspectos internos e externos, que envolvem condições associadas às situações pessoais, psicossociais e organizacionais. Sendo assim, uma aposentadoria vivenciada mais como liberdade e menos como crise dependerá do desenvolvimento de características que funcionem como fatores de proteção, as quais 
favoreçam uma boa adaptação à aposentadoria e diminuam as vulnerabilidades nessa fase da vida.

\section{Considerações Finais}

Levando em conta os fatores que influenciam a aposentadoria vivenciada com qualidade de vida, enfatiza-se que profissionais que atuam em programas e ações de educação para aposentadoria devem buscar utilizar estratégias que auxiliem os trabalhadores a identificar os fatores individuais, afetivo-sociais e comunitários que resultarão em uma aposentadoria bem-sucedida. Para tanto, a Tabela 1 apresenta recomendações que podem ser adotadas por profissionais que trabalham com esse público. 
Tabela 1. Estratégias que Facilitam a Adaptação e Promovem a Qualidade de Vida na Aposentadoria

\begin{tabular}{|c|c|}
\hline Categorias & Estratégias \\
\hline Atividade física & $\begin{array}{l}\text { Incentive a realização de atividade física no trabalho, em clubes, ao } \\
\text { ar livre e em locais próximos às residências dos participantes. }\end{array}$ \\
\hline Alimentação saudável & $\begin{array}{l}\text { Aconselhe os participantes a realizarem leituras sobre o tema e a } \\
\text { consultarem especialistas, utilizando o plano de saúde ou hospitais } \\
\text { públicos regionais. }\end{array}$ \\
\hline Lazer/hobby & $\begin{array}{l}\text { Oriente os participantes a praticarem atividades de lazer e de hobby } \\
\text { com as quais se identifiquem e que lhes deem prazer. }\end{array}$ \\
\hline Voluntariado & $\begin{array}{l}\text { Motive os participantes a se engajarem em atividades de } \\
\text { voluntariado em escolas, hospitais e casas de repouso e de } \\
\text { recuperação. }\end{array}$ \\
\hline Empreendedorismo & $\begin{array}{l}\text { Estimule a realização de cursos (p. ex., os oferecidos pelo Serviço } \\
\text { Brasileiro de Apoio às Micro e Pequenas Empresas (SEBRAE), pelo } \\
\text { Serviço Nacional de Aprendizagem Industrial (SENAI) e cursos de } \\
\text { extensão de universidades) que desenvolvam competências e } \\
\text { habilidades para a criação de projetos no período pós-carreira. }\end{array}$ \\
\hline Família & $\begin{array}{l}\text { Encoraje a discussão de planos para o futuro com o cônjuge e para a } \\
\text { autonomia e a independência financeira de filhos e netos. }\end{array}$ \\
\hline Apoio social & $\begin{array}{l}\text { Incentive o resgate ou a aquisição de amizades por meio de } \\
\text { telefonemas, internet, encontros e participação em grupos na } \\
\text { comunidade. }\end{array}$ \\
\hline Finanças & $\begin{array}{l}\text { Informe sobre a importância do equilíbrio financeiro, dos } \\
\text { investimentos para o futuro, da previdência privada e da inclusão da } \\
\text { família no manejo das finanças. }\end{array}$ \\
\hline $\begin{array}{l}\text { Religiosidade/ } \\
\text { espiritualidade }\end{array}$ & $\begin{array}{l}\text { Promova atividades que permitam aos participantes refletir sobre } \\
\text { seus valores e sobre o que traz sentido às suas vidas. }\end{array}$ \\
\hline Moradia & $\begin{array}{l}\text { Oriente a negociação com o cônjuge sobre questões relativas à } \\
\text { moradia e mobilidade. }\end{array}$ \\
\hline Planejamento antecipado & $\begin{array}{l}\text { Disponibilize programas para pessoas em início de carreira. Quanto } \\
\text { mais tempo para planejar, melhor! }\end{array}$ \\
\hline
\end{tabular}




\section{Referências}

Breslow, R., Reuben, D., \& Wallace, S. (2000). Introduction to special issue on health promotion among the elderly. American Journal of Health Promotion, 14, 341-342.

Canizares, J. C. (2009). Fatores de risco à senilidade na transição à aposentadoria. Tese de Doutorado, Universidade de São Paulo, São Paulo.

Couto, M. C. (2007). Fatores de risco e proteção na promoção de resiliência no envelhecimento. Dissertação de Mestrado, Curso de Pós-Graduação em Psicologia da Universidade Federal do Rio Grande do Sul e da Faculdade de Psicologia e Ciências da Educação da Universidade de Lisboa. Porto Alegre, RS.

Figueiredo, N. C. (2005). Interfaces do trabalho voluntário na aposentadoria. Dissertação de Mestrado. Programa de Pós-Graduação em Psicologia Social e Institucional, Universidade Federal do Rio Grande do Sul.

França, L. H. (2002). Repensando a aposentadoria com qualidade: um manual para facilitadores em programas de educação para aposentadoria. Rio de Janeiro: CRDE/UnATI/UER.

França, C., \& Murta, S. (2014). Fatores de risco e proteção na adaptação à aposentadoria. Manuscrito submetido para publicação. Psicologia Argumento.

França, C., Murta, S., Negreiros, J. L., Pedralho, M., \& Carvalhedo, R. (2013). Intervenção Breve na Preparação para Aposentadoria. Revista Brasileira de Orientação Profissional, 14, 99-110.

Guimarães, H., \& Avezum, A. (2007). O impacto da espiritualidade na saúde física. Revista de Psiquiatria Clínica, 34, 88-94.

Institute of Economics Affairs - IEA (2013). Acesso em: 02 jun. 2013. Disponível em: <http://www.iea.org.uk/publications/economic-affairs>. 
Menezes, G., \& França. L. H. (2012). Preditores da Decisão da Aposentadoria por Servidores Públicos Federais. Revista Psicologia: Organizações e Trabalho, 12, 315-328.

Minayo, C. M., Cavalcante, F., Mangas, R. M., \& Souza, J. (2012) Autópsias psicológicas sobre suicídio de idosos no Rio de Janeiro. Ciência e Saúde Coletiva, 17, 2.7732.781 .

Oliveira, C., Torres, A. R., \& Albuquerque, S. (2009). Análise do bem-estar psicossocial de aposentados de Goiânia. Psicologia em Estudo, 14, 749-757.

Peres, J. F., Simão, M. J., \& Nasello, A. (2007). Espiritualidade, religiosidade e psicoterapia. Revista de Psiquiatria Clínica, 34, 136-145.

Santos, F. (1990). Identidade e Aposentadoria. São Paulo: E.P.U.

Seidl, J. (2010). Asking about retirement before retiring. Master thesis, European Master on Work, Organizational and Personnel Psychology. Universidade de Coimbra, Portugal.

Soares, D. H., \& Costa, A. (2011). Aposent-Ação: Aposentadoria para Ação. 1. ed. São Paulo: Vetor.

Wang, M., Henkens, K., \& van Solinge, H. (2011). Retirement adjustment: A review of theoretical and empirical advancements. American Psychologist, 66, 204-213.

Yunes, M. A. M., \& Szymanki, H. (2001). Resiliência: noção, conceitos afins e considerações críticas. Em Tavares (Ed.) Resiliência e Educação, 13-42, São Paulo: Cortez.

Zanelli, J. C. (2012). Processos psicossociais, bem-estar e estresse na aposentadoria. Revista Psicologia: Organizações e Trabalho, 12, 329-340. 


\section{CAPÍTULO 4}

Publicado em periódico internacional ${ }^{\mathbf{1 0}}$

\section{Evaluation of Retirement Planning Programs: A Qualitative Analysis of Methodologies and Efficacy}

7. Artigo escrito durante estágio doutoral (doutorado sanduíche) da primeira autora em Netherlands Interdisciplinary Demographic Institute - NIDI, Haia, Holanda, 2015.

Leandro-França, C., Murta. S., Hershey, D. \& Barbosa, L. (2016). Evaluation of retirement planning programs: A qualitative analysis of methodologies and efficacy, Educational Gerontology, 42, 497 - 512. doi: 10.1080/03601277.2016.1156380 


\begin{abstract}
The objective of this integrative literature review was to evaluate the quality of retirement planning programs described in the extant literature. This was accomplished through a qualitative analysis of methodological and efficacy criteria as described by Flay et al. (2005), Kazdin (2010, 2011), and Murta (2005). Several databases were consulted in searching for retirement program articles, including: Academic Search Premier, Medline, PsycInfo, and Web of Science, among others. Retirement planning intervention articles published in English, Portuguese, and Spanish were considered, with a focus on their evaluation methods and results. Eleven studies were identified that described the procedures for both program implementation and intervention evaluation. Results revealed methodological shortcomings in the papers reviewed, with concerns being related to a lack of experimental or quasi-experimental approaches, a failure to use previously validated measurement instruments and longitudinal assessments, and insufficiently robust data analysis procedures. That said, however, there was evidence from multiple investigations that the intervention programs examined led to increases in knowledge, positive changes in attitudes linked to retirement, and an increase in retirement-linked planning and preparation behaviors. Identification of strengths and weaknesses in the methods used and efficacy of these interventions could facilitate the construction of a research agenda aimed at promoting more favorable research designs. Use of more rigorous designs would stand to improve the internal validity of these retirement programs and, consequently, progress in this field.
\end{abstract}

Keywords: Retirement, intervention; program evaluation; efficacy; planning 
In many countries around the world, life expectancy continues to increase. According to the World Health Organization (WHO, 2014), by the year 2020, for first time in history the number of people 60 years of age or older will exceed the number of children under the age of five. Consequently, there has been an increase in the growth rate of chronic diseases and a concomitant decrease in age-related wellbeing, resulting in a major global public health challenge. One implication of these trends is that people will live longer than ever before after entering retirement, and many will be in jeopardy of experiencing a poor quality of life. That being the case, retirement planning intervention programs that actively promote wellbeing and quality of life can play an important role in helping individuals take proactive steps to avoid negative life outcomes (Comish, 1995; Peila-Shuster, 2011).

The purpose of this article is to conduct an integrative review of published empirical studies on retirement intervention programs. In doing so, we focus on two different facets of such programs: (i) methodological aspects of different interventions (e.g., format, duration, delivery context), and (ii) program efficacy considerations (e.g., participant satisfaction with the program, increases in knowledge, increases in adaptive pre-retirement planning behaviors). By adopting these dual foci, our hope is to determine whether some programs are more efficacious than others, with an eye toward understanding possible methodological reasons that distinguish performance outcomes. This study is unique in this regard; we could find no previous comparable reviews that have appeared in the extant retirement literature. We begin with a discussion of methodological dimensions, which is followed by a section that characterizes ways to distinguish intervention efficacy. 


\section{Methodological Aspects of Retirement Programs}

Employer-based retirement preparation programs began in the United States in the early to mid-1950s (Glamser, 1981; Salgado, 1980, as cited in Zanelli, 2000). However, publications that describe such programs did not begin to appear in the literature until the 1970s. Most articles that describe retirement preparation programs suggest they lead to positive results (Beck, 1984; Heather, 1996; Makino, 1994; Marcellini, Sensoli, Barbini, \& Fioravanti, 1997; Wolfe \& Wolfe, 1975; Wotherspoon, 1995), which makes the prospect of the widespread dissemination of preparedness programs promising in light of the aging trends described above. However, most employer-based programs are targeted toward individuals in their mid-50s and older, which, from health and financial planning perspectives may be too late in life to make meaningful lifestyle changes that would result in increased post-employment life satisfaction (Ekerdt, 1989).

According to Hershey, Mowen, and Jacobs-Lawson (2003), retirement programs can be classified as being either limited or comprehensive depending on the range of topics covered. Limited programs typically focus on only one or two aspects of planning for the post-employment period (e.g., financial planning), whereas comprehensive programs address a broader range of topics (e.g., health, leisure, finances, social relations). These authors further distinguish programs that have a planning focus (typically seminars with group discussions) from those with a counseling objective (typically one-on-one sessions) in order to promote behavior change leading to enhanced retirement adjustment.

According Glamser (1981), workplace retirement programs have been marketed under a variety of different names, including those that focus on: retirement adjustment, retirement planning, retirement preparation, planning for late life, retirement education, and pre-retirement counseling (Glamser, 1981). Positive outcomes associated with participation in such programs include improved adaptation to retirement, positive changes 
in attitudes and habits (Ogunbameru \& Sola, 2008), better relations between employees and their employers, and reduced objections to mandatory retirement (Glamser \& DeJong, 1975). Others suggest retirement programs can improve life satisfaction following workplace departures (Glamser, 1981), increased post-employment autonomy, lower levels of anxiety, and the ability to develop projects appropriate for this stage of life (Makino, 1994).

Beyond the United States, significant strides have taken place in the delivery of retirement programs in Brazil since the 1980s. During that decade, one national Brazilian oil company (PETROBRAS) set the stage for the widespread dissemination of employersponsored programs, by offering retirement education for its employees. As a result, studies about Brazilian retirement programs began to appear in the literature in the 1990s (França, 1992; Muniz, 1996; Zanelli, 1994). ${ }^{1}$ Further interest in retirement programs has been spurred on during the last decade by increases in life expectancy, improvements in the socioeconomic conditions of the population, and passage of the Statute of the Elderly law (Law number 10741, October 2003), which recommends the implementation of retirement planning programs in public and private organizations as a way of promoting quality of life and well-being among future cohorts retirees.

Seidl, Leandro-França, and Murta (2014) advanced a tripartite classification of retirement programs on the basis of their duration. Long-term (or continuing) programs typically involve 8-20 weekly sessions using a group-based meeting format. Intensive programs, in contrast, are shorter in duration and they typically involve "immersion meetings" that occur on consecutive days of the week. Brief programs - which in terms of duration are the shortest format-typically involve 1-3 sessions using a group-based meeting format. This distinction based on program duration should be useful in future 
work by helping to classifying qualitatively different approaches to retirement intervention.

In a narrative review chapter that focuses on retirement programs in Brazil, Seidl et al. (2014) suggest that both long and brief interventions can promote cognitive, motivational, and behavioral changes. Cognitive changes can include improvements in retirement decision making (such as deciding when to retire, or where to live after leaving the workforce), as well as the acquisition of new knowledge about factors related to retirement preparation, retirement adjustment and successful aging (França, Murta, Negreiros, Pedralho, \& Carvalhedo, 2013; Murta et al., 2008; Pereira \& Guedes, 2012). Motivational changes are designed to foster the development and clarification of retirement-linked goals, and to heighten interest and involvement in goal-setting and goalachievement activities (França et al., 2013; Murta et al., 2008; Soares, Costa, Rosa, \& Oliveira, 2007). Finally, behavioral changes that may result as a function of involvement in a retirement program include steps that can be taken to strengthen one's social support network, financial autonomy, and health care practices (Murta et al., 2008; Soares \& Costa, 2011; Zanelli, 2000).

Despite the fact that studies suggest advantages are associated with participation in retirement preparation programs (Beck, 1984; Heather, 1996; Makino, 1994; Marcellini et al., 1997; Wolfe \& Wolfe, 1975; Wotherspoon, 1995), only a handful of studies that have evaluated such programs could be found in the literature. In the following section, we turn attention toward ways to evaluate intervention efficacy.

\section{Program Efficacy}

Efficacy in the program evaluation context has been defined as extent to which a specific intervention produces a beneficial effect under ideal implementation conditions (Flay et al., 2005). Writings on best practices in the delivery of intervention programs 
(Creswell, 2007; Flay et al., 2005; Kazdin, 2010, 2011) suggest a series of criteria that can be applied to evaluate the overall quality of a program. One higher-order dimension in this regard involves aspects linked to the methodological quality of the program. A second dimension involves the quality of specific program outcomes (i.e., whether the program had the intended impact on participants). In terms of the former (methodological considerations), one could look to a strong theoretical foundation for the development of the intervention program, the implementation of a pilot study prior to the intervention, use of a control (or comparison) group, and the administration of post-intervention follow-up evaluation(s). These criteria are fairly straightforward and not difficult to identify in published investigations.

In terms of program outcomes, one might seek, for instance, to determine whether the intervention produced more potent effects for those who attended the program relative to members of a control or contrast group (i.e., "statistical significance" criteria). Or, one could ask whether the program produced a meaningful effect, as opposed to a merely statistically significant outcome (i.e., the "clinical significance" of the intervention). Or, one might seek to determine whether the observed effects carry the promise of broad societal significance, with findings that generalize well beyond the sample investigated. The criteria outlined in this paragraph and the preceding paragraph, among others, will be used in this study as a way of evaluating retirement preparation programs.

Previous retirement researchers have argued that methodological weaknesses associated with preparation programs include the lack of a control or contrast group, the lack of follow-up investigations and longitudinal measurement approaches, and sample sizes that are too small to effectively generalize results to broader populations (França et al., 2013; Hershey et al., 2003; Taylor-Carter, Cook, \& Weinberg, 1997). Others have been critical of the use of measurement instruments that lack reasonable psychometric 
properties (e.g., reliability, validity), studies that report outcomes unsupported by statistical analysis (França et al., 2013) and the failure to assess the robustness of effects through the administration of follow-up measures (Glamser \& DeJong, 1975).

\section{Present Investigation}

In sum, this article is a focused, integrative literature review that is designed to assess the quality of retirement preparation programs using both methodological and efficacy evaluation criteria. Our purposes in developing this study were to explore the range of intervention methodologies used, and whether those methodologies hold promise when it comes to shaping individuals' retirement-linked attitudes, beliefs, motives and behaviors. In the following section we describe how articles were selected for inclusion in this review, as well as the specific evaluation criteria that were adopted.

\section{Method}

\section{Article Search and Selection Procedures}

Two inclusionary criteria were adopted in the selection of articles for this review. First, only articles written in Portuguese, Spanish, and English were considered. ${ }^{2}$ This included papers published from the earliest electronic records available (in the databases accessed) through the end of December 2014. Second, articles were only considered if they included detailed information on the following: a description of intervention procedures, evaluation of program procedures, and results. Duplicate articles that appeared in more than one database, articles that involved secondary data analysis, dissertations, theses, and benchmark reports were not considered.

Multiple academic databases were consulted in an effort to identify appropriate articles that may have appeared in a variety of different disciplines, including: psychology, sociology, business, economics, finance, and medicine. Specifically, databases accessed as

part of this literature review included: Academic Search Premier, Business Source 
Premier, Cochrane, EconLit, Lilacs, Medline, PsycInfo, PsycArticles, Scientific Electronic Library Online, Scopus, Sociological Abstracts, Virtual Health Library-BVSPsi, and Web of Science. The Boolean operator "AND" was used to seek out combinations of keywords that would return the desired results. Keywords examined included: "retirement," “intervention," "preretirement," “education," "counseling," "preparation," and "program," as well as their equivalent descriptors in Portuguese and Spanish.

Articles identified through the electronic search process were analyzed by reading their title and abstract to verify that each was consistent with the inclusionary criteria for the study. A secondary search was then performed based on the curriculum vitae of authors initially identified, in an effort to find additional relevant publications by those who have published on the topic. Finally, an email was sent to the primary author for each article identified, requesting other publications they may have on the topic of retirement programs. Once these steps had been performed, a content analysis of the articles was carried out.

\section{Analytic Approach}

Studies were analyzed by focusing on two separate dimensions: (i) methodological criteria (see Table 1) and (ii) efficacy evaluation criteria (see Table 2). Methodological criteria comprised topics including (but not limited to): the use of strong theory in the development of the program, the nature of the research design, program format, the number of individuals who participated in the study, the process evaluation format, and evidence of a data analysis process. Efficacy evaluation criteria, in contrast, focused on: (a) the quality of the evaluation procedures (e.g., use of a control condition; use of multiple measures; use of valid instruments), and (b) evidence of positive outcomes during or following program delivery (e.g., the absence of negative effects; statistical significance testing; conclusions regarding clinical significance). These two sets of intervention 
evaluation criteria were based largely on the recommendations of the Society for

Prevention Research (SPR), which are fully described by Flay and colleagues (2005).

Table 1. Definition of Methodological Criteria used to Evaluate Intervention Studies

\begin{tabular}{|c|c|}
\hline Criteria & Description \\
\hline Theory & Theoretical model or approach that underlies the study or program. \\
\hline Design & $\begin{array}{l}\text { Describe whether the study is non-experimental (defined as lacking a control } \\
\text { group), quasi-experimental (involving a control group but with non-random } \\
\text { assignment), or experimental (involving a control group and random } \\
\text { assignment). }\end{array}$ \\
\hline Context & $\begin{array}{l}\text { Context in which the study was carried out (e.g., public or private } \\
\text { organization, university, factory). }\end{array}$ \\
\hline Program format & $\begin{array}{l}\text { This criteria analyzes program duration, the total number of meetings, and } \\
\text { whether the intervention occurred individually or in groups. Duration is } \\
\text { characterized in terms of long programs (meetings occurring weekly over a } \\
\text { period of months), intensive programs (immersion meetings that occur on } \\
\text { consecutive days of a week), and brief programs (that involve a short time } \\
\text { frame of one to three meetings). }\end{array}$ \\
\hline Content & $\begin{array}{l}\text { Themes and techniques used as part of the intervention (e.g., group } \\
\text { discussion and activities designed to increase self-reflection, awareness } \\
\text { exercises, sharing of experiences, and development of attitudes and positive } \\
\text { emotions). }\end{array}$ \\
\hline Participants & $\begin{array}{l}\text { Number of individuals that participated in the intervention (initial sample } \\
\text { size). }\end{array}$ \\
\hline $\begin{array}{l}\text { Needs } \\
\text { assessments }\end{array}$ & $\begin{array}{l}\text { A priori assessment designed to identify target issues for intervention. } \\
\text { Criteria involved determining whether a needs assessment was carried out. }\end{array}$ \\
\hline $\begin{array}{l}\text { Process } \\
\text { Evaluation }\end{array}$ & $\begin{array}{l}\text { Process evaluation involved evidence of one or more of the following } \\
\text { criteria: (1) recruitment approach - strategies used to invite individuals to } \\
\text { participate in the program, (2) program context-environmental } \\
\text { characteristics that may interfere with implementation and program } \\
\text { execution, (3) interim assessment-investigate whether participants made use } \\
\text { of resources and engaged in planning activities during the course of a long } \\
\text { seminar program, (4) fidelity - examine whether steps or stages of the } \\
\text { intervention were carried out as planned, and (5) satisfaction-assessment } \\
\text { with participants' satisfaction with the quality of the program. }\end{array}$ \\
\hline Instruments & $\begin{array}{l}\text { Evaluation of the type(s) of instruments used to collect data on program } \\
\text { content and effectiveness, as measured by changes in participants' attitudes, } \\
\text { knowledge, behaviors and beliefs. }\end{array}$ \\
\hline Data Analysis & Whether qualitative or quantitative procedures were used to analyze data. \\
\hline Results & $\begin{array}{l}\text { Clear description of the main results of the intervention, focusing on } \\
\text { empirical evidence of program strengths and weaknesses. }\end{array}$ \\
\hline
\end{tabular}

Note: Adapted from "Occupational stress management programs: A systematic literature review,” by Murta (2005). 
Table 2. Definition of Efficacy Criteria used to Evaluate the Intervention Studies

\begin{tabular}{|c|c|c|}
\hline & Criteria & \multirow{2}{*}{$\begin{array}{c}\text { Description } \\
\text { Presence or absence of a control or comparison group. }\end{array}$} \\
\hline & $\begin{array}{l}1.1 \quad \text { Control } \\
\text { condition }\end{array}$ & \\
\hline & 1.2 Study pilot & $\begin{array}{l}\text { Pre-study assessment designed to improve techniques and } \\
\text { measures. }\end{array}$ \\
\hline & $\begin{array}{l}1.3 \text { Multimodal } \\
\text { Measurement }\end{array}$ & $\begin{array}{l}\text { Involving both quantitative and qualitative measurement } \\
\text { approaches as part of study (e.g., scales, interviews, } \\
\text { questionnaires). }\end{array}$ \\
\hline & $\begin{array}{l}1.4 \quad \text { Multiple } \\
\text { informants }\end{array}$ & $\begin{array}{l}\text { Participation of employer, family members, friends, neighbors } \\
\text { as part of program evaluation. }\end{array}$ \\
\hline & \multirow{2}{*}{$\begin{array}{l}\text { 1.5 Exter } \\
\text { evaluation } \\
\text { 1.6 Follow-up }\end{array}$} & $\begin{array}{l}\text { Evaluation done by someone who is not part of the research } \\
\text { team or a study participant. }\end{array}$ \\
\hline.$\tilde{0}$ & & $\begin{array}{l}\text { Periodic evaluation(s) over time following the end of the } \\
\text { intervention. }\end{array}$ \\
\hline$\frac{\partial}{\stackrel{\pi}{\pi}}$ & $\begin{array}{l}1.7 \quad \text { Inter-rater } \\
\text { agreement }\end{array}$ & $\begin{array}{l}\text { Analysis procedures to determine the degree of agreement } \\
\text { between coders when conducting qualitative analyses. }\end{array}$ \\
\hline 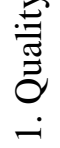 & $\begin{array}{l}1.8 \text { Validity/Rel- } \\
\text { iability of } \\
\text { Instruments }\end{array}$ & $\begin{array}{l}\text { Use of instruments that have demonstrated evidence of validity } \\
\text { and/or reliability. }\end{array}$ \\
\hline \multirow{5}{*}{ 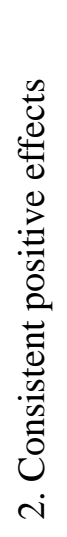 } & $\begin{array}{l}2.1 \text { Consistent } \\
\text { effects }\end{array}$ & $\begin{array}{l}\text { Significant statistical or clinical results observed in groups } \\
\text { exposed to the intervention, and less significant findings in } \\
\text { groups not exposed to the intervention. }\end{array}$ \\
\hline & $\begin{array}{l}2.2 \quad \text { Negative } \\
\text { effects }\end{array}$ & Lack of negative effects reported as part of study findings. \\
\hline & $\begin{array}{l}2.3 \quad \text { Statistical } \\
\text { significance }\end{array}$ & $\begin{array}{l}\text { Analysis of impact as measured by statistical significance } \\
\text { calculations. }\end{array}$ \\
\hline & $\begin{array}{l}2.4 \quad \text { Clinical } \\
\text { significance }\end{array}$ & $\begin{array}{l}\text { Analysis of impact as measured by clinical significance } \\
\text { calculations. }\end{array}$ \\
\hline & 2.5 Social impact & Analysis of impact as measured by social impact. \\
\hline
\end{tabular}

Note: Criteria adapted from Flay et al. (2005) and Kazdin (2010, 2011).

Once the evaluative criteria had been established, two independent coders conducted a full text analysis of each article using a coding protocol that reflected the range of topics identified in Tables 1 and 2. Given the nominal and categorical nature of the data analyzed, inter-rater reliability levels were established using the percentage agreement approach (Gwet, 2014), which was obtained by taking the number of agreements divided by the sum of both agreements and disagreements, multiplied by 100 
(see also Kazdin, 2010). Coding disagreements were resolved with the assistance of a researcher with expertise in the development and delivery of retirement planning programs. Inter-rater agreement for methodological criteria was 90 percent and agreement for efficacy criteria was 81 percent. According to Kazdin (2011) percentage agreement rates equivalent to or greater than 75 percent are considered acceptable.

\section{Results}

A search of the databases identified in the Method section resulted in 178 hits. Duplicate hits were omitted as well as articles in languages other than English, Portuguese, and Spanish. Also omitted were articles that failed to provide sufficient information about program procedures or evaluative criteria. This resulted in 11 full-text articles, six of which were written in English and five of which were written in Portuguese. ${ }^{3}$ The source and a description of the contents of these articles can be found in Table 3. 
Table 3. Analysis of Methodological Criteria

\begin{tabular}{|c|c|c|c|c|c|}
\hline $\begin{array}{l}\text { Author, Year (A) } \\
\text { Language (L) }\end{array}$ & $\begin{array}{l}\text { Theory (T) } \\
\text { Design (D) } \\
\text { Context (CX) } \\
\text { Participants (n) } \\
\end{array}$ & Format (F) & $\begin{array}{l}\text { Content (C) } \\
\text { Techniques (TC) }\end{array}$ & $\begin{array}{l}\text { Need Assessment (NA) } \\
\text { Process Evaluation (PE) } \\
\text { Instruments (I) }\end{array}$ & $\begin{array}{l}\text { Data Analysis (DA) } \\
\text { Results (R) }\end{array}$ \\
\hline $\begin{array}{l}\text { (A) França, Murta, } \\
\text { Negreiros, } \\
\text { Pedralho, \& } \\
\text { Carvalhedo, } 2013 . \\
\text { (L) Portuguese }\end{array}$ & $\begin{array}{l}\text { (T) FRAMES and } \\
\text { Transtheoretical } \\
\text { Model } \\
\text { (D) Non- } \\
\text { experimental, } \\
\text { follow-up at } 11 \\
\text { months } \\
\text { (CX) Public } \\
\text { organization } \\
\text { (n) } 41\end{array}$ & $\begin{array}{l}\text { (F) Brief: one } \\
\text { meeting during } 4 \\
\text { hours and three } \\
\text { follow } \\
\text { meetings }\end{array}$ & $\begin{array}{l}\text { (C) Rapport between participants, } \\
\text { resource assessment and } \\
\text { encouragement of responsibility; } \\
\text { self-assessment of preparation for } \\
\text { retirement behaviors; self-efficacy; } \\
\text { relevant factors in the transition to } \\
\text { retirement; preparation of action } \\
\text { plans. } \\
\text { (TC) Educational and experiential: } \\
\text { activities with discussion group, } \\
\text { illustrative pictures of retirement } \\
\text { resources, retirement planning } \\
\text { guidebook }\end{array}$ & $\begin{array}{l}\text { (NA) Not specified } \\
\text { (PE) Assessment of } \\
\text { process fidelity and group } \\
\text { climate, suitability of } \\
\text { context in which program } \\
\text { takes place, performance } \\
\text { of coordinators and } \\
\text { evaluation of satisfaction. } \\
\text { (I) Interview, protocol } \\
\text { analysis, completion of } \\
\text { sentences, and scale to } \\
\text { assess retirement } \\
\text { resources }\end{array}$ & $\begin{array}{l}\text { (DA) Qualitative content analysis and } \\
\text { descriptive statistics. } \\
\text { (R) Majority of participants judged that their } \\
\text { participation in the intervention motivated } \\
\text { planning for retirement, promoted experiences } \\
\text { of positive emotions in relation to retirement, } \\
\text { change of behavior in health care and increased } \\
\text { knowledge about actions that promote } \\
\text { adjustment to retirement }\end{array}$ \\
\hline
\end{tabular}




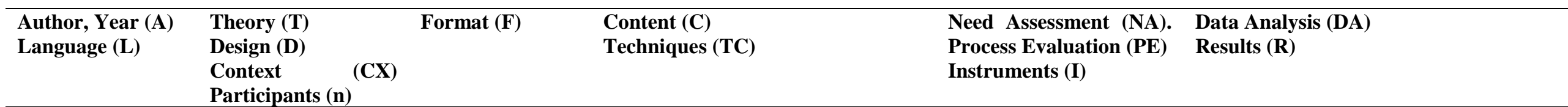

(A) Glamser, F. \& DeJong, 1975.

(L) English
(T) None specified

(D) Experimental, follow-up at 1 month (CX) Factory (n) 132
(F) Long: eight meetings, duration 90 min each. Brief: visit the social security, housing conditions, plant personnel health insurance.

office for an (TC) Educational and experiential: explanation of the Long: group discussions and reading company a book on preparation for retirement. retirement Brief: use of four booklets on benefits-duration retirement adjustment and resources 30 minutes

(A) Glamser, 1981. (T) None specified (L) English
(D) Experimental and longitudinal

(Evaluated six years after interventions ended)

(CX) Factory

(n) 82
(F) Long: eight meetings, duration 90 min each.

\section{Brief: visit the}

plant personnel

office for an

explanation of the

company

retirement

benefits, duration

30 minutes
(NA) None specified

(PE) None specified

(I) Questionnaire measuring knowledge of retirement issues

(C) Meaning of work and retirement, (NA) None specified financial planning, health, leisure, (PE) None specified family and friends, life projects, (I) Questionnaire social security, housing conditions and health insurance.

(TC) Educational and experiential: Long: group discussions and reading a book on preparation for retirement Brief: use of four booklets on retirement adjustment and resources
(DA) Statistical analyses: t-tests and analysis of variance.

(R) Long program was effective when compared to the control group and brief intervention. Significant increase in the number of retirement activities and plans (e.g., saving activities, talking about plans with a partner, healthy eating). Efficacy of brief program compared to long program was relatively minimal

(DA) Statistical analyses: chi-square tests (R) No significant differences between retirement program groups and a control group regarding the expected, level of preparation, life satisfaction and attitudes toward retirement 


\begin{tabular}{|c|c|c|c|c|c|}
\hline $\begin{array}{l}\text { Author, Year (A) } \\
\text { Language (L) }\end{array}$ & $\begin{array}{l}\text { Theory (T) } \\
\text { Design (D) } \\
\text { Context (CX) } \\
\text { Participants (n) }\end{array}$ & Format (F) & $\begin{array}{l}\text { Content (C) } \\
\text { Techniques (TC) }\end{array}$ & $\begin{array}{l}\text { Need Assessment (NA). } \\
\text { Process Evaluation (PE) } \\
\text { Instruments (I) }\end{array}$ & $\begin{array}{l}\text { Data Analysis (DA) } \\
\text { Results (R) }\end{array}$ \\
\hline
\end{tabular}

(A) Hershey, (T) Conceptual model Walsh, Brougham, analysis of the Carter, \& Farrell, retirement (F) Brief: three 1998.

(L) English affordability decision. (D) experimental (CX) NonUniversity

(n) 23

(A) Hershey, (T) Image theory Mowen, \& Jacobs- (D) Experimental, Lawson, 2003. (L) English (D) Experimental,
follow-up one year after intervention.

(CX) Community center (n) 106
(F) Brief: Four groups, financial info and goal-setting

module (90 $\mathrm{min}$ each); financia only; one only, and memory training control group
(C) Financial knowledge, effects of (NA) None specified inflation, longevity, and projected (PE) None specified expenses associated with retirement.

(TC) Educational and experiential: includin use of computer-based financial financial knowledge test, planning program, video and attitudes toward presentation, technical writings and planning for retirement discussions

(C) Financial planning, clarity of (NA) None specified goals for retirement, and memory (PE) None specified improvement (control condition). (TC) Educational and experiential: (I) Questionnaire Lecture with one theme, lecture and planning and retirement discussion group. Comparison group goal clarity scales did exercises to improve memory
(DA) Statistical analyses: descriptives (mean, standard deviation) and $t$-tests (R) Although financial knowledge of participants increased significantly due to the intervention, the quality of financial decisions were not significantly better between pre- and post-intervention

(DA) Statistical analyses: ANCOVA.

(R) Combined seminar (lecture and discussion group) associated with greater impact on financial information and clarity of goals. The other seminars (financial information only; goals only) had a moderate influence on retirement planning behaviors 


\begin{tabular}{|c|c|c|c|c|c|}
\hline $\begin{array}{l}\text { Author, Year (A) } \\
\text { Language (L) }\end{array}$ & $\begin{array}{l}\text { Theory }(T) \\
\text { Design (D) } \\
\text { Context }(\mathbf{C X}) \\
\text { Participants (n) }\end{array}$ & Format (F) & $\begin{array}{l}\text { Content (C) } \\
\text { Techniques (TC) }\end{array}$ & $\begin{array}{l}\text { Need Assessment (NA). } \\
\text { Process Evaluation (PE) } \\
\text { Instruments (I) }\end{array}$ & $\begin{array}{l}\text { Data Analysis (DA) } \\
\text { Results (R) }\end{array}$ \\
\hline
\end{tabular}

(A) Laughlin \& $\quad$ (T) None specified

Cotten, 1994

(L) English
(T) None specified mental health center (n) 30
(F) Intensive, five days, 3 hours per of 3 weeks
(C) Pre-retirement

unspecified issues.

planning (NA) None specified

(PE) None specified

(TC) Educational: experimental group-classes; control groupoccupational training activities, beauty care, leisure and recreation, daily activities

semantic knowledge, preferences

(A) Murta, Abreu, (T) Transtheoretical França, Pedralho, Model.

Seidl, Lira, (D)
(D)

Non-

Carvalhedo,

Conceição,

Gunther, 2014

experimental,

(L) Portuguese
(F) Long: eight meetings, weekly, duration 3 hours each
(CX)
Public

(n) 13
(C) Successful aging, the process of change and resilience, legislation, family and social networks, health, finances, talents, life projects.

(TC) Educational and experiential: lectures, guidebook for participants, interactive activities, homework
(I) Scales: pre-retirement about retirement,

differentia

attitudes about retirement life satisfaction among older adults

(DA) Statistical analysis: ANCOVA.

(R) Intervention had an effect on

knowledge and preferences for retirement.

However, they had no effect on life satisfaction and attitudes toward retirement

(NA) Interview and focal group.

(PE) Suitability of context in which program takes place; interim assessment of planning activities; fidelity of process and quality of social skills group coordinator assessment of
of (1)

intermediate goals

(I) Interview,

questionnaire, process

evaluation protocol
(DA) Content analysis.

(R) The intervention favored the strengthening of social and family networks, planning and control of financial spending, awareness of planning for retirement, health care, development of leisure activities, initiation and maintenance of physical activities, spiritual engagement, healthy eating practices, prospects for a new career 


\begin{tabular}{|c|c|c|c|c|c|}
\hline $\begin{array}{l}\text { Author, Year (A) } \\
\text { Language (L) }\end{array}$ & $\begin{array}{l}\text { Theory (T) } \\
\text { Design (D) } \\
\text { Context (CX) } \\
\text { Participants (n) }\end{array}$ & Format (F) & $\begin{array}{l}\text { Content (C) } \\
\text { Techniques (TC) }\end{array}$ & $\begin{array}{l}\text { Need Assessment (NA). } \\
\text { Process Evaluation (PE) } \\
\text { Instruments (I) }\end{array}$ & $\begin{array}{l}\text { Data Analysis (DA) } \\
\text { Results (R) }\end{array}$ \\
\hline
\end{tabular}

(A) Pereira \& (T) None specified

Guedes, 2012.

(L) Portuguese

(D)

experimental

(CX)

(F) Long: 45

Non- hours, meetings weekly, duration 3

Public hours each

organization

(n) 14

(A) Soares, Costa,

Rosa, \& Oliveira,

2007.

(T) None specified

(D)

(F) Long: nine experimental

(L) Portuguese

(CX) University

(n) 16

duration 2 hours

each
(C) Self-awareness, relationships, project.

(TC) Educational and experiential: dynamics, texts, interactive exhibits, teamwork, lectures and film
(NA) Interview (PE) None specified

(I) Interview

questionaire

(C) Past, present and future choices

career, (PE) None specified

social support, business, finance,

health, sport, search for self, leisure and future projects.

(TC) Educational and experiential:

activities, discussion group, and lectures and (DA) None specified

(R) The intervention helped participants

increase planning conscientiousness and and decide upon and develop a project for their post-career life

(DA) None specified

(R) The intervention promoted sharing of experiences, the development of new friendships, and dispelling myths about retirement 


\begin{tabular}{|c|c|c|c|c|c|}
\hline $\begin{array}{l}\text { Author, Year (A) } \\
\text { Language (L) }\end{array}$ & $\begin{array}{l}\text { Theory (T) } \\
\text { Design (D) } \\
\text { Context(CX) } \\
\text { Participants (n) }\end{array}$ & Format (F) & $\begin{array}{l}\text { Content (C) } \\
\text { Techniques (TC) }\end{array}$ & $\begin{array}{l}\text { Need Assessment (NA). } \\
\text { Process Evaluation (PE) } \\
\text { Instruments (I) }\end{array}$ & $\begin{array}{l}\text { Data Analysis (DA) } \\
\text { Results (R) }\end{array}$ \\
\hline $\begin{array}{l}\text { (A) Soares, Luna, } \\
\& \text { Lima, } 2010 . \\
\text { (L) Portuguese }\end{array}$ & $\begin{array}{l}\text { (T) None specified } \\
\text { (D) } \quad \text { Non- } \\
\text { experimental } \\
\text { (CX) } \\
\text { organization } \\
\text { (n) } 15\end{array}$ & $\begin{array}{l}\text { (F) Intensive: } \\
\text { three meetings, } \\
\text { one every other } \\
\text { week, duration } 8 \\
\text { hours each }\end{array}$ & $\begin{array}{l}\text { (C) Self-knowledge; changes and } \\
\text { choices; family and social dynamics; } \\
\text { health, management of financial and } \\
\text { free time, life projects. } \\
\text { (T) Educational and experiential: } \\
\text { lectures, activities, and group } \\
\text { discussions }\end{array}$ & $\begin{array}{l}\text { (NA) None specified } \\
\text { (PE) None specified } \\
\text { (I) Tool of self- } \\
\text { evaluation }\end{array}$ & $\begin{array}{l}\text { (DA) None specified } \\
\text { (R) Participants reported that the program } \\
\text { helped them to reflect on the past and } \\
\text { future perspectives and provide security } \\
\text { about the decision to retire }\end{array}$ \\
\hline $\begin{array}{l}\text { (A) Taylor-Carter, } \\
\text { Cook, \& Weinberg, } \\
1997 . \\
\text { (L) English }\end{array}$ & $\begin{array}{l}\text { (T) Social Cognitive } \\
\text { Theory } \\
\text { (D) Non- } \\
\text { experimental } \\
\text { (CX) University } \\
\text { (n) } 34\end{array}$ & $\begin{array}{l}\text { (F) Brief: lecture } \\
\text { with rwo } \\
\text { meetings, } 4 \text { hours } \\
\text { each }\end{array}$ & $\begin{array}{l}\text { (C) Social security, financial } \\
\text { planning, leisure, pension law. } \\
\text { (T) Educational: seminar/lecture }\end{array}$ & $\begin{array}{l}\text { (NA) None specified } \\
\text { (PE) None specified } \\
\text { (I) Financial planning and } \\
\text { leisure scales, retirement } \\
\text { self-efficacy scale }\end{array}$ & $\begin{array}{l}\text { (DA) Statistical analyses: Pearson } \\
\text { correlations, multiple regression, } t \text {-tests. } \\
\text { (R) Effect of the seminar increased } \\
\text { anticipated retirement satisfaction and } \\
\text { anticipated financial satisfaction. Pre- } \\
\text { intervention assessment demonstrated } \\
\text { effects of informal leisure planning and } \\
\text { financial planning on retirement } \\
\text { expectations }\end{array}$ \\
\hline
\end{tabular}




\section{Methodological Evaluation Criteria}

The 11 publications that were identified as part of this review appeared in the literature during a four decade period between 1975 and 2014. Five program studies were carried out in Brazil (França et al., 2013; Murta et al., 2014; Pereira \& Guedes, 2012; Soares et al., 2007; Soares, Luna, \& Lima, 2010) and the remaining six were conducted in the United States (Glamser \& DeJong, 1975; Glamser, 1981; Hershey, Walsh, Brougham, Carter, \& Farrell, 1998; Hershey et al., 2003; Laughlin \& Cotten, 1994; Taylor-Carter, Cook, \& Weinberg, 1997).

Four papers mentioned a theoretical foundation for the development of the program or intervention. Specific theories or theoretical frameworks employed included the transtheoretical model of change (Murta et al., 2014); the "FRAMES" approach to intervention, which is an acronym that stands for: feedback, responsibility, advice, menu of options, empathy and self-efficacy (França et al., 2013), image theory (Hershey et al. 2003), and social cognitive theory (Taylor-Carter et al., 1997). The remaining seven studies that did not report a specific theoretical basis appeared to be driven by the empirical goals associated with testing the intervention program.

Four of the publications were found to have adopted an experimental design that used some form of control group (Glamser \& DeJong, 1975; Glamser, 1981; Hershey et al., 2003; Laughlin \& Cotten, 1994). None of the studies examined used a quasiexperimental design.

The interventions programs were implemented in five different settings including: universities (four studies, Hershey et al.,1998; Murta et al., 2014; Soares et al.,2007; Taylor-Carter et al., 1997), public organizations (three studies, França et al., 2013; Pereira \& Guedes, 2012; Soares et al., 2010), factories (two studies, Glamser, \& DeJong, 1975; Glamser, 1981), a community center (one study, Hershey et al., 2003), and a community 
mental health center (one study, Laughlin \& Cotten, 1994). The minimum number of participants reported in a study was 13 (Murta et al., 2014) and the maximum number of individuals who participated in an intervention was 132 (Glamser \& DeJong, 1975).

In terms of program duration, the format used to deliver the interventions varied from one investigation to the next. Three programs adopted a "long duration" approach (Murta et al., 2014; Pereira \& Guedes, 2012; Soares et al., 2007), and four other programs employed a brief format (França et al., 2013; Hershey et al., 1998; Hershey et al., 2003; Taylor-Carter et al., 1997). Two of the programs evaluated used an intensive format (Laughlin \& Cotten, 1994; Soares et al., 2010), whereas two other investigations (Glamser \& DeJong; 1975 and Glamser; 1981) were found to have used a combined (long and brief) format in the development of their intervention approach.

With respect to the intervention procedures, nine studies were found to have used educational activities (e.g., lectures, seminars, brochures, books) in combination with experiential exercises (e.g., group discussions). This hybrid model was clearly the preferred format approach. Only two investigations were found to have exclusively used either educational activities or experiential exercises (Laughlin \& Cotten, 1994; TaylorCarter et al., 1997).

The content discussed during the intervention programs involved a combination of themes about antecedents of retirement adjustment, such as support from family members and members of one's broader social network, physical and mental health, financial planning activities, beliefs about the meaning of work, longevity and aging, the management of free time, post career life projects, leisure activities, social security laws, and retirement-related self- knowledge. Financial planning was the most commonly explored theme; in fact, as a topic finances were discussed in ten of the eleven investigations (França et al., 2013; Glamser \& DeJong, 1975; Glamser, 1981; Hershey et 
al., 1998; Hershey et al., 2003; Murta et al., 2014; Pereira \& Guedes, 2012; Soares et al., 2007; Soares et al., 2010; Taylor-Carter et al., 1997).

With regard to process evaluations of the intervention programs, some form of participant satisfaction was the most commonly used criterion, although fewer than half collected data on this dimension. Perceptions of program satisfaction were a target in five studies (Glamser \& DeJong, 1975; Pereira \& Guedes, 2012; Soares et al., 2007; Soares et al., 2010; Zanelli, 2000). Two other studies (França et al., 2013; Murta et al., 2014) referred to the use of comprehensive process evaluations that tapped multiple aspects of the intervention program including participant satisfaction.

Three studies (Murta et al., 2014; Pereira \& Guedes, 2012; Soares et al., 2007) reported using some type of (pre-intervention) participant needs assessment. These assessments took the form of an interview, a focus group discussion, or questionnaire. The instruments most widely used for data collection purposes included scales (four studies, Hershey et al., 1998; Hershey et al., 2003; Laughin \& Cotten, 1994; Taylor-Carter et al., 1997), a combination of a questionnaire and interview (two studies, Murta et al., 2014; Pereira \& Guedes, 2012), a questionnaire (three studies, Glamser \& DeJong, 1975; Glamser, 1981; Soares et al., 2010), an interview supplemented by the use of a scale (one study, França et al., 2013) and an interview only (one study, Soares et al., 2007).

Three studies (Pereira \& Guedes, 2012; Soares et al., 2007; Soares et al., 2010) failed to report the type of data analyses used to evaluate the interventions. Of the eight remaining studies, one went in a qualitative direction (Murta et al., 2014) describing the use of thematic content analysis, one employed a combination of qualitative and quantitative approaches (França et al., 2013), and six others (Glamser, 1981; Glamser \& DeJong, 1975; Hershey et al., 1998; Hershey et al, 2003; Laughlin \& Cotton, 1994; Taylor-Carter et al., 1997) used some form of quantitative approach to analyze the data. 
These latter investigations typically not only presented descriptive data (e.g., means, standard deviations, counts), but they also reported the results of inferential tests to assess the programs including $t$-tests, chi-square tests, correlations, multiple regression analysis, analysis of variance, and analysis of covariance.

\section{Efficacy Evaluation Criteria}

As described in Table 2, efficacy evaluation criteria focused on two overarching themes: (i) the quality of the evaluation criteria (e.g., external evaluation, use of followups, establishing inter-rater agreement), and (ii) evidence of positive effects of the program. In terms of the former dimension, four studies (Glamser \& DeJong, 1975; Glamser, 1981; Hershey et al., 2003; Laughlin \& Cotten, 1994) used a control or comparison group, three studies (França et al., 2013; Murta et al., 2014; Pereira \& Guedes, 2012) used a multimodal measurement approach, one made use of multiple informants (Murta et al., 2014), and two cited the use of a pilot study to assist in the development of intervention content (França et al., 2013; Murta et al., 2014). None of studies mentioned made use of blind evaluation procedures. It is also noteworthy that five studies described the presence of one or more follow-up evaluations (França et al., 2013; Glamser \& DeJong, 1975; Glamser, 1981; Hershey et al., 2003; Murta el at., 2014). One investigation (Glamser, 1981), in fact, reported data collected from individuals who participated in the Glamser and DeJong (1975) study six years earlier, in order to assess the long-term impact of the 1975 intervention program.

Inasmuch as few investigations relied upon content analysis to evaluate the effect of the intervention, not surprisingly, none reported inter-rater agreement levels. However, four studies reported having used instruments that had previously been demonstrated to 
have evidence of validity and/or reliability (França et al., 2013; Hershey et al., 2003; Laughlin \& Cotten, 1994; Taylor-Carter et al., 1997).

Continuing with the analysis of efficacy criteria, we now turn our attention to the second overarching theme - that is, whether evidence was provided regarding positive intervention effects (i.e., items 2.1 to 2.5 in Tables 2 and 4).

Results regarding the effects of the interventions revealed that long intervention programs (i.e., based on 8-20 weekly meetings, mostly using a group format) led to increases in knowledge of retirement planning (Glamser \& DeJong, 1975), control of financial spending, awareness of the need for retirement planning, health care, the development of leisure activities, the initiation and maintenance of physical activities, spiritual engagement, healthy eating practices, and prospects for a new career (Glamser \& DeJong, 1975; Murta et al., 2014; Soares et al., 2007).

Interventions that used an intensive format (i.e., an immersion approach with multiple meetings that occur on consecutive days) promoted reflection of the past and future, feelings of security about the decision to retire (Soares et al., 2010), and knowledge about resources that would help to ensure a successful retirement (Laughlin \& Cotten, 1994). Brief or limited intervention programs (i.e., a short duration approach of 1-4 group meetings), in contrast, were found to motivate planning for retirement. They promoted the experience of positive emotions in relation to retirement, improved health care practices, and increased knowledge of strategies that could be used to promote retirement adjustment (França et al., 2013). Brief programs were also found to promote increased financial knowledge, increases in retirement goal clarity (Hershey et al., 1998; Hershey et al., 2003), anticipated retirement and financial satisfaction, leisure planning, and realistic future financial planning expectations (Taylor-Carter et al., 1997). 
One experimental study that compared the differential impact of long and brief intervention programs (Glamser \& DeJong, 1975) showed strong results in favor of the long intervention format. Specifically, compared to individuals who were exposed to a brief program or who were in a control group, those who participated in a long intervention program were more likely to be engaged in retirement planning activities. In addition, studies that compared different types of brief interventions found that combined intervention formats (i.e., that used educational seminars in combination with group discussions) had a greater impact on participants than interventions that relied exclusively on an educational program (Hershey et al., 1998; Hershey et al., 2003). However, a longitudinal study carried out by Glamser (1981) failed to find differences in retirement expectations, retirement preparedness, life satisfaction, and attitudes toward retirement when participants from long and brief intervention programs were compared to members of a control group.

Six of the eleven studies relied upon inferential statistics (i.e., $p$-level evidence) to evaluate the effectiveness of the intervention (Glamser \& DeJong, 1975; Glamser, 1981; Hershey et al., 1998; Hershey et al., 2003; Laughlin \& Cotten, 1994; Taylor-Carter et al., 1997). Of the five remaining investigations, either descriptive statistics were reported or no information was provided as to how the intervention was evaluated. What was surprising, however, was the fact that none of the eleven studies specifically commented on the clinical significance or (potential) social impact of the program under scrutiny. From an intervention perspective, this would seem to be a serious omission. 
Table 4. Analysis of Efficacy Criteria

\begin{tabular}{|c|c|c|c|c|c|c|c|c|c|}
\hline Study & & & & & & & & & \\
\hline &  & 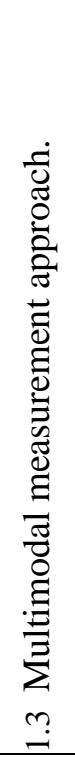 & 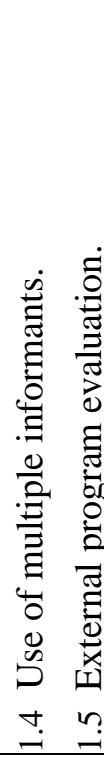 &  & 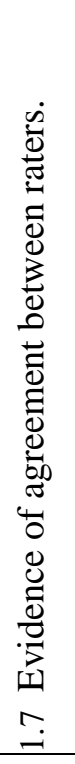 & 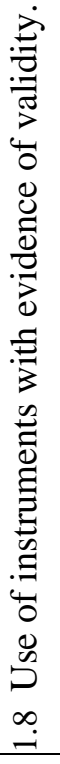 & 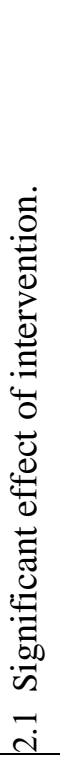 & 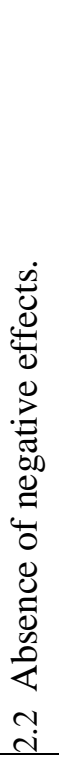 &  \\
\hline França, Murta, Negreiros, Pedralho, \& Carvalhedo (2013) & $\mathrm{x}$ & $\mathrm{x}$ & & $\mathrm{x}$ & & $\mathrm{x}$ & $\mathrm{x}$ & $\mathrm{x}$ & \\
\hline Glamser \& DeJong (1975) & $\mathrm{x}$ & & & $\mathrm{x}$ & & & $\mathrm{x}$ & $\mathrm{x}$ & $\mathrm{x}$ \\
\hline Glamser (1981) & $\mathrm{x}$ & & & $\mathrm{x}$ & & $\mathrm{x}$ & & $\mathrm{x}$ & $\mathrm{x}$ \\
\hline Hershey, Walsh, Brougham, Carter, \& Farrell (1998) & & $\mathrm{x}$ & & & & $\mathrm{x}$ & & $\mathrm{x}$ & $\mathrm{x}$ \\
\hline Hershey, Mowen, \& Jacobs-Lawson (2003) & $\mathrm{x}$ & $\mathrm{x}$ & & $\mathrm{x}$ & & $\mathrm{x}$ & $\mathrm{x}$ & $\mathrm{x}$ & $\mathrm{x}$ \\
\hline Laughlin \& Cotten. (1994) & $\mathrm{x}$ & & & & & $\mathrm{x}$ & $\mathrm{x}$ & $\mathrm{x}$ & $\mathrm{x}$ \\
\hline $\begin{array}{l}\text { Murta, Abreu, França, Pedralho, Seidl, Lira, Carvalhedo, } \\
\text { Conceição, \& Gunther. (2014) }\end{array}$ & $\mathrm{x}$ & $\mathrm{X}$ & $\mathrm{x}$ & $\mathrm{x}$ & & & $\mathrm{x}$ & $\mathrm{x}$ & \\
\hline Pereira \& Guedes (2012) & & $\mathrm{x}$ & & & & & & $\mathrm{x}$ & \\
\hline Soares, Costa, Rosa, \& Oliveira (2007) & & & & & & & & $\mathrm{x}$ & \\
\hline Soares, Luna, \& Lima (2010) & & & & & & & & $\mathrm{x}$ & \\
\hline Taylor-Carter, Cook, \& Weinberg (1997) & & & & & & $\mathrm{x}$ & $\mathrm{x}$ & $\mathrm{x}$ & $\mathrm{x}$ \\
\hline
\end{tabular}




\section{Discussion}

In describing best practices for intervention research, theorists (Flay et al., 2005; Kazdin, 2010, 2011; Murta, 2005) have identified two broad sets of criteria against which real-world intervention programs can be evaluated. Methodological criteria focus on the development and design of intervention programs, and efficacy criteria, in contrast, focus primarily on the effectiveness of the intervention. The evaluative criteria across these two dimensions are not mutually exclusive, as elements of methodologies (e.g., use of a control group; measurement approach) have been specified as key criteria in the evaluation of efficacy.

In this integrative literature review, eleven retirement intervention programs that had been identified in the primary scientific literature were evaluated, to determine their overall quality. While it was found that many of the published studies met recommended standards in terms of their methods and efficacy, the data suggest there exist considerable room for improvement. In fact, no one intervention program could be viewed favorably in terms of all evaluative criteria. The implication of this outcome is important, as the identification of gaps in best practices can provide guidance for program specialists in many economically more developed nations who seek to cultivate retirement interventions in the future.

In terms of methodological criteria, a number of studies were designed and delivered in such a way as to maximize the likelihood of positive effects. Ideally, programs would not only be grounded in strong theory, but also developed in such a way as to meet the unique needs of program participants. That said, however, only four of the eleven articles indicated the use of a specific theoretical framework in the development of the program, and four articles indicated that a pre-program needs assessment had been carried 
out. Future intervention efforts, it would seem, could benefit from more solid (theoretical and empirical) foundations.

Program format (design; duration) is another important dimensions that revealed variability across studies. The stated use of a control group (or appropriate contrast group) was found to be lacking in a majority of investigations, which would seem to be a critical shortcoming. From a design perspective, the gold standard in intervention research is to use a matched control group, so that the magnitude of treatment effects can be unequivocally assessed. Investigators also face choices in terms of selecting an appropriate program format and duration. Certainly, in choosing a program duration, the data from this study suggest there is a trade-off in terms of the time invested and the costs incurred (both financial and personnel costs). Although all three types of program formats/durations (i.e., long, intensive, brief; Seidl et al., 2014) were found to lead to positive effects, at least one investigation found evidence for the superiority of the long format approach (i.e., Glamser \& DeJong, 1975). This approach would seem to more readily lend itself to comprehensive topical programming; single topic interventions (e.g., financial only)—which are indeed more common than comprehensive interventions - are more easily adapted to the brief program format.

We now turn attention to the efficacy of retirement intervention programs. In this regard, the data from the present investigation are unequivocal. The general conclusion reached is that retirement programs foment change. This is evidenced not only by the observation of significant positive effects (found in more than half of the studies surveyed), but also the absence of negative effects (found in all eleven investigations). Broad support for the efficacy of retirement interventions could be overestimated, however, by a publication bias in favor of investigations that demonstrate significant outcomes. That is, it is unknown how many intervention studies failed to produce change 
that have gone unpublished — what researchers refer to as the "file drawer effect" (Scargle, 2000). Despite this fact, there would appear to be sufficient evidence to suggest that a carefully designed and implemented program will lead to desired outcomes; depending on intervention objectives, such programs are likely to result in improvements in retirementlinked knowledge, expectations, attitudes, and planning behaviors.

From a public policy perspective, the findings from this study suggest it would be well worth investing in the further development and dissemination of retirement intervention programs. This endorsement is conditioned upon the premise that future program specialists would consider best practices criteria when designing their research and developing program content. There is every reason to believe that interventions are potentially effective when offered in any one of a number of settings - in community centers, schools, and in the workplace. To that extent, it could be advantageous for proponents of interventions to partner with universities, large corporations, and government agencies when seeking funding and tangible support for their efforts.

This investigation is not without its limitations. One limitation involved the pragmatic decision to focus on program reports published only in English, Portuguese, and Spanish. There may be evaluation studies published in other languages that were not included in this review. On that point, it is interesting to note that the investigations identified were only published in English and Portuguese. Notably, a number of the English reports were older, reflecting the long-standing interest in retirement programs in the U.S. (Ekerdt, 1989), and the Portuguese language reports all appeared in the literature since 2006, following passage of the 2003 Brazilian Statute of the Elderly law mentioned in the introduction.

Perhaps future investigations could focus on articles published in major world languages not examined as part of this study, such as Chinese, Hindi, Arabic, Bengali, 
Russian, and Japanese. Doing so would result in a richer understanding of how retirement preparation programs differ across countries and cultures. Of particular interest would be the way in which programs in Asian and Southeast Asian cultures prepare workers for retirement, in light of differences across countries in sources of financial, family, and instrumental support (Asher, 2002; McCallum, 1992). Beyond understanding differential patterns of support, future retirement program development could benefit from an enhanced understanding of the way in which retirement goals, lifestyles, and leisure pursuits in Eastern nations diverge from that which is typically found in the West.

Another limitation of this study involved the fact that the analytic strategy adopted was restricted to the use of descriptive statistics. A stronger approach would have involved using inferential statistics to examine program outcomes - such as in the form of a metaanalysis - however, the small number of investigations identified made it impossible to adopt a superior quantitative methodology. Perhaps in the coming years as more studies on this topic appear in the literature, with more consistent focal criteria and analysis procedures, it will be possible to revisit the issue of program efficacy using more robust inferential methods.

In closing, we are optimistic that the aging of members of the baby boom generation will spur on further research on the topic of retirement intervention programs. Findings from this review suggest that the widespread dissemination of such programs, whether in the workplace or in other venues, stand to enhance the future wellbeing of program participants in one or more realms of functioning. Balanced against the alternative - that is, a cohort of poorly prepared retirees who can be expected to experience a diminished quality of life-it would seem well worth the cost to develop evidence-based programs that have clearly focused objectives and demonstrable effects. 


\section{References}

Asher, M. G. (2002). The future of retirement protection in Southeast Asia. International Social Security Review, 51, 3-30. doi: 10.1111/1468-246X.00001

Beck, S. (1984). Retirement preparation programs: Differentials in opportunity and use. Journal of Gerontology, 39, 596-602.

Creswell, J.W. (2007). Qualitative inquiry and research design: Choosing among five approaches. Thousand Oaks, CA: Sage.

Comish, S. E. (1995). Changing images of self: The efficacy of retirement preparation programs for women. Doctoral Dissertation in Philosophy, Department of Counselling Psychology, University of British Columbia, Canada.

Ekerdt, D. (1989). Retirement preparation. In M. P. Lawton (Ed.), Annual Review of Gerontology and Geriatrics, (pp. 321-356). New York: Springer.

Estatuto do Idoso [Statute of the Elderly] Brazilian Law 10/741/203 (2003, $1^{\text {o }}$ de outubro). Diário Oficial da União, Brazil. Retrieved from http://www.planalto.gov.br/ccivil_03/leis/2003/L10.741.htm

Flay, B., Biglan, A., Boruch, R., Castro, F., Gottfredson, D., Kellam, S.,... Ji, P. (2005). Standards of evidence: Criteria for efficacy, effectiveness and dissemination. Prevention Science, 6, 151-175. doi: 10.1007/s11121-005-5553-y

França, C. L., Murta, S., Negreiros, J. L., Pedralho, M., \& Carvalhedo, R. (2013). Intervenção breve na preparação para aposentadoria [Brief intervention in preparation for retirement]. Revista Brasileira de Orientação Profissional, 14, 99110.

França, L. H. (1992). Terceira idade: O trabalho social com idosos no SESC e os programas de preparação para aposentadoria nas empresas [Third age: Social work 
with seniors at SESC and preparation programs for retirement in companies]. Revista de Administração Pública, 26, 174-181.

Glamser, F., \& DeJong, G. (1975). The efficacy of preretirement preparation programs for industrial workers. Journal of Gerontology, 30, 595-600.

Glamser, F. (1981). The impact of preretirement programs on the retirement experience. Journal of Gerontology, 36, 244-250.

Gwet, K. L. (2014). Handbook of inter-rater agreement: The definitive guide to measuring agreement among raters $\left(4^{\text {th }}\right.$ Ed.). Gaithersburg, Maryland: Advanced Analytics.

Heather, E. (1996). Do retirement preparation programs improve the retirement experience? Benefits Quarterly, 12, 40-46.

Hershey, D. A., Walsh, D. A., Brougham, R., Carter, S., \& Farrell, A. H. (1998). Challenges of training pre-retirees to make sound financial planning decisions. Educational Gerontology, 24, 447-470.

Hershey, D. A., Mowen, J. C., \& Jacobs-Lawson, J. M. (2003). An experimental comparison of retirement planning intervention seminars. Educational Gerontology, 29, 339-359. doi: $10.1080=03601270390180271$

Kazdin, A. E. (2010). Research designs in clinical psychology ( $4^{\text {th }}$ Ed.). New York: Allyn and Bacon.

Kazdin, A. E. (2011). Single-case research designs: Methods for clinical and applied settings. New York: Oxford University Press.

Laughlin, C., \& Cotten, P.D. (1994). Efficacy of a pre-retirement planning intervention for ageing individuals with mental retardation. Journal of Intellectual Disability Research, 38, 317-328.

Makino, N. (1994). Preretirement education and life planning programs in Japan. Educational Gerontology, 20, 503-510. 
Marcellini, F., Sensoli, C., Barbini, N., \& Fioravanti, P. (1997). Preparation for retirement: Problems and suggestion of retirees. Educational Gerontology, 23, 377-387. doi:10.1080/0360127970230406.

McCallum, J. (1992). Asia Pacific retirement: Models for Australia, Fiji, Malaysia, Philippines and Republic of Korea. Journal of Cross-Cultural Gerontology, 7, 2543.

Murta, S. G. (2005). Programas de manejo de estresse ocupacional: Uma revisão sistemática da literatura [Occupational stress management programs: A systematic literature review]. Revista Brasileira de Terapia Comportamental e Cognitiva, 7, 159-177. doi:10.1590/S0102-79722007000200016

Murta, S. G., Caixeta, T. D., Souza, K. L., \& Ribeiro, D. C. (2008). Avaliação de um programa de preparo para a aposentadoria e envelhecimento bem sucedido. In S.G Murta (Ed.), Grupos Psicoeducativas: Aplicações em múltiplos contextos, (pp. 181196). Goiânia: Porã Cultural.

Murta, S., Abreu, S., França, C.L., Pedralho, M., Seidl, J., Lira, N., ... Gunther, I. (2014). A preparação para a aposentadoria: Implantação e avaliação do programa Viva Mais! [Preparing for retirement: Implementation and evaluation of the "Live More" program]. Psicologia: Reflexão e Crítica, 27, 1-9. doi:10.1590/S010279722014000100001

Muniz, J. A. (1996). PPA: Programa de preparação para o amanhã [PPA: Program of preparation for tomorrow]. Estudos de Psicologia, 2, 198-204.

Ogunbameru, O., \& Sola, A. (2008). Transition to retirement: Effect of participation in preretirement education in Nigeria. Educational Gerontology, 34, 418-427. doi: $10.1080 / 03601270600850867$ 
Peila-Shuster, J. (2011). Retirement self-efficacy: The effects of a pre-retirement strengthsbased intervention on retirement self-efficacy and an exploration of relationships between positive affect and retirement self-efficacy (UMI No. 3468973). Doctoral Dissertation in Philosophy, Colorado State University, Fort Collins, USA.

Pereira, T., \& Guedes, S. (2012). Novo Tempo: A experiência de implantação do programa de preparação para o pós-carreira no IFRN [New time: The experience of implementing preparation programs for the Post-Career at IFRN]. Hollos, 4, 158177.

Scargle, J. D. (2000). Publication bias: The "file-drawer problem" in scientific inference. Journal of Scientific Exploration, 14, 91-106. doi: 0892-3310/00

Seidl, J., Leandro-França, C., \& Murta, S. (2014) Formatos de programas de educação para aposentadoria [Format of retirement education programs]. In S. Murta, C. LeandroFrança \& J. Seidl. (Eds.). Programas de educação para aposentadoria: Como planejar, implementar e avaliar [Retirement education programs: How to plan, implement and evaluate] (pp. 84-113). Novo Hamburgo: Sinopsys.

Soares, D. H., Costa, A., Rosa, A., \& Oliveira, M. L (2007). Aposenta-ação: Programa de preparação para aposentadoria [Aposenta-Ação: Retirement preparation program]. Estudos interdisciplinares sobre o envelhecimento, 12, 143-161.

Soares, D. H., \& Costa, A.(2011). Aposenta-Ação: Aposentadoria para ação [AposentaAção: Retirement to action]. São Paulo: Vetor.

Soares, D. H., Luna, I., \& Lima, M. (2010). A arte de aposentar-se: Programa de preparação para aposentadoria com policiais federais [The art of retirement: Retirement preparation program for policeman]. Estudos interdisciplinares sobre o envelhecimento, 15, 293-313. 
Taylor-Carter, M.A., Cook, K., \& Weinberg, C. (1997). Planning and expectations of the retirement experience. Educational Gerontology, 23, 273-288.

Wolfe, B., \& Wolfe, G. (1975). Exploring retirement in a small group. Social Work, 20, 481-484.

World Health Organization, WHO. (2014). "Ageing well" must be a global priority. Retrieved from http://www.who.int/mediacentre/news/releases/2014/lancet-ageingseries/en/

Wotherspoon, C. (1995). Plan now, enjoy later? A study of the use and effectiveness of formal retirement planning programs. Benefits Quarterly, 11, 53-57.

Zanelli, J. C. (1994). Aposentadoria: percepções dos servidores da Universidade Federal de Santa Catarina [Retirement: Perceptions of employees of the Federal University of Santa Catarina]. Anais do ENANPAD, 10, 26-45.

Zanelli, J. C. (2000). O Programa de preparação para aposentadoria como um processo de intervenção ao final de uma carreira [The retirement preparation program as intervention process at the end of a career]. Revista de Ciências Humanas, edição especial temática, 157-176. 


\section{Footnotes}

${ }^{1}$ These three papers were not analyzed as part of the present investigation because they failed to meet the specified inclusionary criteria.

${ }^{2}$ Members of the author team were proficient in these three languages.

${ }^{3}$ Of the 167 publications that were not included in this review, 90 papers $(53.8 \%)$ were omitted because they failed to have a primary focus on retirement preparation programs, $38(22.8 \%)$ were duplicate articles that appeared in more than one database, 28 papers $(16.8 \%)$ failed to adequately describe either program content, procedures, or results, 10 articles (6.0\%) involved secondary data analysis, dissertations, theses or benchmark reports, and 1 paper (0.6\%) was written in an excluded language (German). 


\section{CAPÍTULO 5}

\section{Escala de Perspectiva de Tempo Futuro relativa à Aposentadoria: Evidências de Validade $^{11}$}

${ }^{11}$ As autoras agradecem ao Prof. Dr. Fábio Iglesias pela colaboração neste estudo 


\section{Resumo}

Planejar o futuro com clareza de objetivos pode facilitar o ajustamento à aposentadoria. Este estudo examina evidências de validade de um instrumento que investiga perspectiva de tempo futuro relativa à aposentadoria, no contexto de pessoas em planejamento da aposentadoria. O instrumento foi respondido on-line por 141 trabalhadores, homens e mulheres, com 25 a 66 anos $(\mathrm{M}=44)$. A análise fatorial exploratória revelou estrutura unifatorial que explica 20,94\% da variância do construto. As cargas fatoriais dos itens permaneceram estáveis e o valor do alpha de Cronbach de 0,74 sugere a confiabilidade do instrumento, indicando propriedades psicométricas satisfatórias. As boas cargas fatoriais dos itens indicam a possibilidade dos participantes possuírem elevada perspectiva de tempo futuro relativo à aposentadoria.

Palavras-chave: validade do teste; perspectiva de tempo; aposentadoria. 
O aumento na expectativa de vida da população tem estimulado estudos na área de envelhecimento em todo mundo, especialmente em relação a um fenômeno marcante nessa fase da vida: a aposentadoria. Aposentadoria pode ser definida como um processo de adaptação a uma nova etapa da vida que engloba dois períodos: (a) transição para aposentadoria (fase de empregado para aposentado) e (b) trajetória pós-aposentadoria (fase do desenvolvimento da vida na aposentadoria). Com base nesse conceito, aposentadoria é amplamente reconhecida pela ciência social e psicológica como uma transição desenvolvimental que requer planejamento ao longo do curso da vida para a ocorrência de uma boa adaptação (Wang \& Shi, 2014; Noone, Sthepens, \& Alpass, 2010).

Nas últimas três décadas, pesquisadores investigaram os fatores psicológicos, socioeconômicos e pessoais das pessoas que planejam e não planejam a aposentadoria (Noone et al., 2010). Na esfera psicológica, compreender e avaliar a Perspectiva de Tempo Futuro (PTF) mostra-se útil na elaboração de planos sobre o que fazer na aposentadoria. Indivíduos que possuem objetivos claros para o futuro, próximo ou distante, podem experimentar maiores níveis de satisfação pessoal nessa fase da vida. Metas claras e específicas proporcionam o estabelecimento de intenções futuras e orientam a realização de comportamentos desejados (Stawski, Hershey, \& Jacobs-Lawson, 2007). Com base nesses conceitos, nota-se que ter clareza de objetivos para o futuro integra o constructo PTF.

PTF é conceituada como uma dimensão cognitiva motivacional da personalidade que resulta em estabelecimento de objetivos e metas e depende de atitudes motivacionais. Além disso, pode ser definida como o grau e a maneira na qual o futuro é antecipado e integrado na vida psicológica atual do indivíduo (Nuttin \& Lens, 1985; Lens, Paixão, Herrera \& Grobler, 2012). Para esses autores, PTF pode ser explicada em dois níveis: PTF restrita (elaboração de objetivos a serem alcançados em um futuro próximo) e PTF extensa 
ou aprofundada (elaboração de objetivos a serem alcançados em um futuro distante). Indivíduos com PTF extensa ou aprofundada que possuem objetivos claros para o futuro em longo prazo (ex. cinco anos a partir do presente) percebem a distância do tempo como mais curta, demonstram mais motivação e perseverança para alcançar os objetivos e elaboram planos ou projetos com estruturas comportamentais sólidas, duradouras e equilibradas. Pode-se dizer que pessoas com PTF extensa são mais capazes de transformar seus objetivos ou intenções comportamentais em ações do que os que possuem uma PTF restrita (Lens et al., 2012).

Apesar de não existir um consenso sobre as dimensões que compõem o construto PTF, a literatura indica evidências de sua unidimensionalidade. Estudos iniciais sobre esse constructo, realizados por Aunque Daltrey e Langer, em 1984, revelaram que PTF é composta por um conjunto de cinco dimensões (extensão, coerência, direcionalidade, densidade e atitude). Entretanto, a matriz de correlação das 5 subescalas mostrou que elas não são tão ortogonal como esperado, o que levou os pesquisadores a hipótese de que, embora a PTF seja conceituada em termos de dimensões discretas, elas estão psicometricamente relacionadas. Desse modo, os autores concluíram que, "apesar da utilidade de uma construção multifatorial em termos de aplicação e de diagnóstico para certas áreas, pesquisadores devem considerar a unifatorialidade como melhor forma de explicar esse constructo" (Río-González \& Herrera, 2006, p.49).

Apesar desses achados, a maioria das pesquisas ainda considera PTF como um constructo multidimensional. Três dimensões são utilizadas com maior frequência em pesquisas com esse constructo: extensão temporal, atitude em relação ao tempo e preferência de tempo. A primeira refere-se à capacidade de projeção no futuro, que pode ser relativamente baixa, quando relacionada ao futuro próximo, ou elevada, quando direcionada ao futuro distante. A segunda é uma dimensão mais afetiva e motivacional e 
diz respeito a um sentimento otimista e promissor ou pessimista e ameaçador com relação ao futuro. Por fim, a terceira dimensão refere-se à orientação ou propensão que uma pessoa tem em valorizar e preferir um determinado período de tempo (passado, presente ou futuro). Uma orientação temporal equilibrada e consciente sobre o tempo motiva o indivíduo a enfrentar os desafios do presente, a valorizar as experiências vividas no passado e a ter expectativas e objetivos em relação ao seu futuro (Lens et al., 2012; RíoGonzález \& Herrera, 2006).

Ao examinar a literatura, nota-se que o construto PTF é amplamente analisado em amostras de público jovem, como, por exemplo, no ambiente escolar, para examinar a valorização que estudantes universitários atribuem as diversas áreas da formação acadêmica (Schmitt, 2010) e para entender a motivação dos estudantes na elaboração de planos para prática de exercício físico (Vansteenkiste, Simons, Soenens, \& Lens, 2004). Além disso, instrumentos que investigam esse constructo são escassos, predominando o uso de técnicas projetivas e métodos qualitativos como a entrevista (Río-González \& Herrera, 2006).

Observa-se também que avaliações sobre PTF são pouco exploradas na área de envelhecimento e planejamento da aposentadoria. Exceções a isso são os trabalhos de França e Hershey (2010), Hershey, Jacobs-Lawson, McArdle e Hamagami (2007), Hershey, Henkens e van Dalen (2010) e Rafalski e Andrade (no prelo).

Os conceitos sobre clareza de objetivos para aposentadoria e PTF têm sido utilizados por França e Hershey (2010), Hershey et al. (2007) e Hershey et al. (2010) em medidas que avaliam os determinantes que influenciam o comportamento de poupar e planejar o futuro financeiro. O modelo interdisciplinar de planejamento financeiro é base teórica adotada nesses estudos. Este modelo, testado originalmente na Holanda e nos Estados Unidos, foi desenvolvido por Hershey e colaboradores $(2007 ; 2010)$ e é composto 
por um conjunto de dimensões (psicológica, econômica, financeira, sócio-demográfica e planejamento social), apontadas como fundamentais nas práticas de planejamento para aposentadoria e percepção da adequação de poupar para o futuro (França, 2012).

No estudo de Hershey et al. (2007), o modelo interdisciplinar de planejamento financeiro foi testado em 265 trabalhadores americanos (115 homens e 150 mulheres), com idade entre 25 a 45 anos e investigaram-se as dimensões psicológicas perspectiva de tempo futuro, clareza de objetivo para aposentadoria, autoavaliação de conhecimento financeiro e a mediação entre indicadores demográficos (ex. idade, gênero, renda) e poupança. Nesse estudo, o alfa de Cronbach para o fator clareza de objetivos para aposentadoria foi 0,87 , com $25 \%$ da variância explicada. Já o fator perspectiva de tempo futuro teve um alfa de 0,76 e, embora considerado um índice de consistência interna aceitável, a variância explicada foi relativamente inexpressiva (8\%).

França e Hershey (2010) replicaram o modelo interdisciplinar de planejamento financeiro, utilizado no estudo de Hershey et al. (2010), numa amostra de trabalhadores brasileiros $(n=167)$, casados ou em união estável, com idade entre 21-69 anos $(\mathrm{M}=51)$. Os resultados apontaram que "a perspectiva de tempo futuro e a clareza de objetivos para aposentadoria se apresentaram como principais preditores de percepção da adequação da poupança para o futuro" (França, 2012, p. 39).

O estudo de Rafalski e Andrade (no prelo) teve como objetivo desenvolver e apresentar evidências de validade da Escala de Percepção de Futuro da Aposentadoria (EPFA), aplicada em trabalhadores brasileiros $(\mathrm{N}=982)$, de ambos os sexos, com idade média de 40,1 anos. Resultados psicométricos extraíram cinco dimensões: percepções de saúde, desligamento do trabalho, finanças, relacionamentos interpessoais e perdas na aposentadoria. A escala mostrou-se útil para investigar as impressões dos participantes 
quanto à transição para aposentadoria nos aspectos: saúde, centralidade do trabalho e motivos para aposentar.

Considerando a escassez e a lacuna na literatura brasileira sobre instrumentos que investigam o constructo PTF relativo à aposentadoria com foco em dimensões cognitivas e motivacionais, decidiu-se por adaptar itens de um instrumento desenvolvido por Hershey et al. $(2007 ; 2010)$ e verificar evidências de validade dessa medida. Para tanto, foram utilizadas itens desse estudo que compõem os fatores clareza de objetivos para aposentadoria e perspectiva de tempo futuro.

O instrumento adaptado e avaliado no presente estudo difere de outros métodos de avaliação citados na literatura brasileira em planejamento para aposentadoria como a escala de Mudança de Comportamento em Planejamento para Aposentadoria - EMCPA (Leandro-França, Murta, \& Iglesias, 2014), Escala de Fatores-Chaves no Planejamento da Aposentadoria ou Factors on Retirement Planning - KFRP (França \& Carneiro, 2009), a Escala de Percepção de Futuro da Aposentadoria - EPFA (Rafalski \& Andrade, no prelo) e a Escala de Planejamento da Aposentadoria: Adaptação Brasileira da PRePS (Rafalski \& Andrade, no prelo). De modo geral, essas escalas buscam investigar a influência de fatores ou domínios no planejamento da aposentadoria (saúde, finanças, ocupação, relacionamentos sociais, familiares, fatores de risco) e mudanças de comportamentos favoráveis à adaptação à aposentadoria. Ademais, são averiguadas as percepções sobre o futuro, com foco nos preditores de adaptação a esse período da vida, e estilos de tomada de decisão no planejamento da aposentadoria.

Por outro lado, a proposta do presente instrumento é focar em dimensões cognitivas e motivacionais de PTF como: reflexão sobre o futuro e qualidade de vida na aposentadoria, clareza de objetivos para aposentadoria, capacidade de projeção para o futuro e estabelecimento de metas para o futuro. Nesta investigação, adotam-se os 
conceitos de PTF restrita e aprofundada (Lens et al., 2012) para analisar a perspectiva de tempo futuro relativa à aposentadoria dos participantes .

O objetivo principal deste estudo é investigar evidências de validade desse instrumento. Em adição, com base nos valores das cargas fatoriais dos itens e resultados da estatística descritiva, será discutida a possibilidade de os participantes possuírem ou não uma perspectiva de tempo futuro relativo à aposentadoria de forma restrita ou aprofundada.

\section{Método}

\section{Participantes}

O estudo consiste em uma amostra final composta por 141 respondentes das regiões brasileiras Norte, Nordeste, Sul, Sudeste e Centro Oeste, todos servidores públicos do poder executivo, que participaram de um treinamento a distância sobre planejamento, implementação e avaliação de programas de preparação para aposentadoria. Doze por cento eram homens e $88 \%$ mulheres, de 25 a 66 anos (média $=44$ anos; DP $=10,87$ ) Quanto à escolaridade, 2\% possuíam ensino superior incompleto, 20\% ensino superior completo, $8 \%$ pós-graduação incompleta e $70 \%$ pós-graduação completa. Além disso, $55 \%$ eram casados, $26 \%$ solteiros, $9 \%$ separados, $8 \%$ possuíam união estável e $2 \%$ eram viúvos.

\section{Instrumento}

A construção da Escala foi realizada em três etapas: (1) adaptação do instrumento, (2) análise semântica dos itens e (3) validação por juízes. Primeiro, o instrumento original (Hershey et al., 2007) foi traduzido para a língua portuguesa e adaptado ao contexto brasileiro. Após a tradução dos itens escolhidos, o instrumento foi finalizado e iniciou-se a segunda etapa: análise semântica dos itens. A proposta desta etapa foi identificar e corrigir as possíveis ambiguidades quanto à clareza e objetividade dos itens. Para essa finalidade, a escala foi aplicada de forma individual em oito servidores da administração pública 
federal, de órgãos distintos, com escolaridade entre ensino médio à pós-graduação. Por ser uma medida curta, com poucos itens de avaliação, ela foi considerada de fácil compreensão pelos respondentes. A terceira etapa, validação por juízes, ocorreu por meio da análise independente de dois pesquisadores da área de planejamento para aposentadoria.

Na montagem do instrumento para o presente estudo optou-se por uma seleção de sete itens dos estudos de Hershey et al. $(2007 ; 2010)$ referentes a dois fatores psicológicos: (1) clareza de objetivos para aposentadoria (três itens) e (2) perspectivas de tempo futuro (quatro itens). Os itens escolhidos para o fator clareza de objetivos foram: "Eu tenho pensado muito sobre a qualidade de vida na aposentadoria; Eu tenho estabelecido metas de quanto economizar para a aposentadoria; Eu tenho uma visão clara de como será a minha vida na aposentadoria".

$\mathrm{O}$ fator perspectiva de tempo futuro é composto pelos itens "O futuro distante me parece vago e incerto; Eu gosto de pensar sobre como eu viverei de hoje em diante; Eu vivo muito mais para o presente do que para o futuro; Eu sigo as orientações de economizar para os momentos difíceis". Esses itens foram associados a uma escala tipo Likert contendo 5 pontos, na qual 1 representa a total discordância; 2 discordo, 3 neutro, 4 concordo e 5 a total concordância com os itens.

\section{Coleta de Dados}

Após a análise semântica e por juízes, foram enviadas cartas, por email, a aproximadamente 350 servidores públicos federais, de todas as regiões do Brasil, que participaram de um curso a distância sobre planejamento, implementação e avaliação de programas de preparação para aposentadoria, provido pela plataforma Moodle. A cartaconvite online encaminhada aos servidores (Anexo D) continha o termo de consentimento para participação do estudo, explicações sobre o anonimato dos dados coletados, os objetivos e os procedimentos da pesquisa. Os servidores que concordaram em participar 
responderam ao instrumento, indicado em link específico, que foi disponibilizado utilizando-se a ferramenta "Formulários" do Google Forms. As respostas foram automaticamente armazenadas via web, durante um mês, e após esse prazo inseridas em um banco de dados utilizando-se o software a ferramenta SPSS.

\section{Análise de Dados}

Os dados coletados foram submetidos a uma análise fatorial exploratória com o objetivo de avaliar a validade de construto da escala. Os procedimentos adotados seguiram as recomendações Tabachnick e Fidell (2001). A fatorabilidade da matriz foi avaliada pelo índice Kaiser-Meyer-Olson (KMO) e pelo teste de esfericidade de Bartlett.

Para definição da quantidade de fatores que poderiam ser extraídos foi utilizado a analise de componentes principais. Tal análise obedeceu ao critério dos eigenvalues (valores próprios) para a retenção do fator que tivesse maior variância do que um item isolado (Autovalor $(\mathrm{\gamma})>1,0$ ) e que sua variância não pudesse ser explicada pela aleatoriedade (Análise paralela) (Pasquali, 2012).

Para extração e rotação dos fatores foi empregado o método Principal Axis Factoring como critério de pertencimento, foram mantidos apenas os itens que possuíam cargas fatoriais iguais ou superiores a 0,40. Para avaliar a fidedignidade e precisão da escala foi utilizado o coeficiente Alfa de Cronbach.

\section{Resultados}

Os índices de fatorabilidade demonstraram que sua matriz é favorável e que as correlações foram relativamente bem concentradas $(\mathrm{KMO}=.736$ e teste de esfericidade de Bartlett, $\chi 2=213,44 ; \mathrm{gl}=21 ; \mathrm{p}<0,001)$.

Por meio da análise dos componentes principais (PAC) e mediante o critério de autovalores $(\mathrm{\gamma}<1,00)$ poderiam ser retidos até 02 fatores que explicaram $56,75 \%$ da 
variância da matriz de correlação. Porém, a análise paralela demonstrou que apenas um fator atendia o critério de não aleatoriedade. Sendo que a estrutura unifatorial foi confirmada pela análise de consistência interna do segundo fator $(\alpha=0,64)$. Dessa forma, para solução fatorial foi mantido apena 01 fator que explica $40,10 \%$ de variância $(\mathrm{\gamma}=$ 2,08). Além disso, decidiu-se por uma solução unifatorial pela sua robustez e adequação a critérios teóricos. A extração do fator se deu por meio da análise fatorial. Todos os itens foram mantidos, pois suas cargas variaram entre 0,43 e 0,66 (ver Tabela 1), e não houve itens que sua retirada melhoraria a consistência interna do fator.

Os itens 06 (O futuro distante me parece vago e incerto) e 07 (Vivo muito mais para o presente do que para o futuro) apresentaram cargas negativas, por isso foram invertidos para manter o escore da escala positivo (quanto maior melhor a perspectiva de tempo futuro relativo à aposentadoria). $\mathrm{O}$ índice de consistência interna foi de $\alpha=0,74$.

Para nomear o fator extraído foi mantido o nome da escala "Perspectiva de Tempo Futuro relativo à Aposentadoria- EPersTFA. Na amostra de validação, a média do fator foi de $25,85(\mathrm{DP}=4,58)$ com coeficiente de variância de $17,70 \%$ o que demonstra uma homogeneidade na amostra em relação a perspectiva de tempo futuro relativa a aposentadoria.

\section{Discussão}

O objetivo central deste estudo foi examinar as propriedades psicométricas e reunir evidências de validade da Escala Perspectiva de Tempo Futuro relativo à Aposentadoria EPersTFA. Os resultados revelam que a estrutura unifatorial encontrada mostra-se adequada para investigar PTF não somente em jovens, como frequentemente investigado na literatura especializada (Schmitt, 2010; Vansteenkiste et al., 2004), mas também em trabalhadores de meia idade e mais velhos. 
A estrutura unifatorial para esse constructo corrobora achados de Aunque Daltrey e Langer (citado por Río-González \& Herrera, 2006). Estes pesquisadores consideraram a unifatorialidade como melhor forma de explicar a PTF. Ademais, ao comparar os dados deste estudo com os encontrados no estudo de Hershey et al. (2007) observam-se características psicométricas equivalentes no que se refere ao índice de consistência interna dos itens clareza de objetivos para a aposentadoria e perspectiva de tempo futuro.

Ainda com relação aos resultados, as cargas fatoriais elevadas para os itens "Gosto de pensar sobre como eu viverei de hoje em diante" e "Tenho pensado muito sobre a minha qualidade de vida na aposentadoria" e menor carga fatorial para o item "Vivo muito mais para o presente do que para o futuro" indica a possibilidade de grande parte dos participantes possuírem uma extensão temporal elevada (capacidade de fazer projeções para o futuro), atitude otimista em relação ao futuro e orientação temporal (visão equilibrada e consciente sobre o futuro).

Logo, ao demonstrarem interesse sobre o futuro e sobre a qualidade de vida na aposentadoria, é provável que os participantes possuam PTF extensa ou aprofundada. Tais pensamentos evidenciam a capacidade em transformar seus objetivos ou intenções comportamentais em ações (Lens et al., 2012), podendo impactar em uma aposentadoria bem-sucedida. Estima-se ainda que tal resultado tenha ocorrido em função da participação dos respondentes no treinamento sobre planejamento, implementação e avaliação de programas de preparação para aposentadoria. Porém, para que se seja possível fazer inferências e/ou discussões mais precisas sobre isso são necessários estudos longitudinais que acompanhem os participantes antes e durante a aposentadoria.

Uma limitação deste estudo é a impossibilidade de generalização dos resultados. Embora a amostra represente trabalhadores de várias regiões brasileiras, o público avaliado se restringe à população de servidores do poder executivo e com alto nível de escolaridade. 
Pessoas com maior escolaridade têm mais acesso à informação (Petkoska \& Earl, 2009), propensão a fazer planos para o futuro, viabilizando uma melhor preparação para o póscarreira (Leandro-França \& Murta, 2014). Assim, para verificar se a consistência do instrumento é mantida, sugere-se a aplicação desta escala em contexto privado, em outros poderes da administração pública e em amostras com níveis de escolaridade diversificados.

Numa perspectiva aplicada, os resultados deste estudo indicam que programas de preparação para aposentadoria podem utilizar este instrumento e o conceito de PTF para aprimorar estratégias, elaborar materiais para intervenção e conhecer a perspectiva de tempo futuro relativo à aposentadoria dos participantes. Tal proposta visa potencializar os programas e promover a aquisição de PTF elevada. Além disso, por se tratar de um instrumento com poucos itens, mas, com boas cargas fatoriais e rápida aplicabilidade, sua utilização pode ser profícua se aliada a outros instrumentos que avaliam, por exemplo, comportamentos e preditores de planejamento para aposentadoria.

No presente estudo, optou-se por incluir na amostra os trabalhadores de diversas idades e não apenas àqueles próximos à aposentadoria, haja vista que o planejamento para aposentadoria é percebido como um processo permanente de aprendizagem e de desenvolvimento ao longo da vida profissional (Seidl, Leandro-França, \& Murta, 2014). Contudo, como proposta para estudos futuros, sugere-se a aplicação deste instrumento em amostras com participantes mais próximos à aposentadoria, com idade e tempo de contribuição para aposentar, com o intuito de investigar especificamente os trabalhadores nessa fase da vida. Estudos futuros poderão ainda examinar PTF e associá-la às variáveis como idade, gênero, renda, tipo e condições de trabalho, como realizado por Hershey et al. (2007; 2010). 


\section{Referências}

França, L.H., \& Hershey, D. (2010). Interdisciplinary influences on personal financial planning in Brazil. Poster presented at the 63rd Annual Meeting of the Gerontological Society of America. New Orleans, 19-23, November.

França, L. H. (2012). Envelhecimento dos trabalhadores nas organizações. In L. França \& D. Stepansky (Eds.). Propostas multidisciplinares para o bem-estar na aposentadoria (pp. 25-52). Rio de Janeiro: Quartet.

França, L. H., \& Carneiro, V. L. (2009). Programas de preparação para a aposentadoria: Um estudo com trabalhadores mais velhos em Resende (RJ). Revista Brasileira de Geriatria e Gerontologia, 12, 429-447.

Hershey, D. A., Jacobs-Lawson, J. M., McArdle, J. J., Hamagami, A. (2007). Psychological foundations of financial planning for retirement. Journal of Adult Development, 14, 26-36.

Hershey, D. A., Henkens, K., \& van Dalen, H. (2010). Aging and financial planning for retirement: Interdisciplinary influences viewed through a cross-cultural lens. International Journal of Aging and Human Development, 70, 1-38. doi: 10.2190/AG.70.1.a

Leandro-França, C., \& Murta, S. (2014). Fatores de risco e de proteção na adaptação à aposentadoria. Revista Psicologia Argumento, 32, 33-43. doi:10.7213/psicol.argum.32.076.DS03.

Leandro-França, C., Murta, S., \& Iglesias, F. (2014). Planejamento da aposentadoria: uma Escala de Mudança de Comportamento. Revista Brasileira de Orientação Profissional, 15, 75-84.

Lens, W., Paixão, M. P., Herrera, D., \& Grobler, A. (2012). Future time perspective as a motivational variable: Content and extension of future goals affect the quantity and 
quality of motivation. Japanese Psychological Research, 54, 321-333. doi:10.1111/j.1468-5884.2012.00520.x

Noone, J. H., Stephens, C., \& Alpass, F. (2010). The Process of Retirement Planning Scale (PRePS): Development and validation. Psychological Assessment, 22, 520-531. doi: 10.1037/a0019512.

Nuttins, J. \& Lens, W. (1985). Future time perspective and motivation: Theory and research method. Louvain: Presses Universitaires de Louvain.

Pasquali, L. (2012). Análise fatorial para pesquisadores. 2ª Ed. Brasília: LabPAM.

Petkoska, J. \& Earl, J. (2009). Understanding the influence of demographic and psychological variables on retirement planning. Psychology and Aging, 24, 24551. doi: $10.1037 / \mathrm{a} 0014096$

Rafalski, J.C. \& de Andrade, A. L. (no prelo). Desenvolvimento da Escala de Percepção de Futuro da Aposentadoria (EPFA) e correlatos psicossociais [Manuscrito aceito para publicação]. Psico-USF, 22 (1).

Río-González, A. M., \& Herrera, A. N. (2006). Desarrollo de un instrumento para evaluar perspectiva de tiempo futuro en adolescentes. Avances en Medición, 4, 47-60.

Seidl, J., Leandro-França, C., \& Murta, S. (2014) Formatos de programas de educação para aposentadoria. In S. Murta, C. Leandro-França \& J. Seidl. (Eds.). Programas de educação para aposentadoria: Como planejar, implementar e avaliar (pp. 84-113). Novo Hamburgo: Sinopsys.

Schmitt, R. E. (2010). Teoria da perspectiva de tempo futuro: Aplicações preliminares e reflexões voltadas à pesquisa no ensino superior. Revista Educação por Escrito, $1,5-16$. 
Stawski, R. S., Hershey, D. A., \& Jacobs-Lawson, J. M. (2007). Goal clarity and financial planning activities as determinants of retirement savings contributions. International Journal of Aging and Human Development, 64, 13-32.

Tabachnick, B., \& Fidell, L. (2001). Using multivariate statistics. San Francisco: Allyn \& Bacon.

Vansteenkiste, M., Simons, J., Soenens, B., \& Lens, W. (2004). How to become a persevering exerciser? Providing a clear, future intrinsic goal in an autonomy supportive way. Journal of Sport and Exercise Psychology, 26, 232-249.

Wang, M., \& Shi, J. (2014). Psychological research on retirement. Annual Review of Psychology, 65, 209-233. 
Tabela 1. Média e Desvio Padrão e Matriz Unifatorial dos Itens da Escala Perspectiva de Tempo Futuro Relativo à Aposentadoria

\begin{tabular}{llccc} 
Item & Descrição & M & DP & Carga do fator \\
\hline 5 & $\begin{array}{l}\text { Gosto de pensar sobre como eu viverei de } \\
\text { hoje em diante }\end{array}$ & 4.15 & .83 & .66 \\
2 & $\begin{array}{l}\text { Tenho estabelecido metas de quanto } \\
\text { economizar para a aposentadoria }\end{array}$ & 3.34 & 1.15 & .58 \\
1 & $\begin{array}{l}\text { Tenho pensado muito sobre a minha } \\
\text { qualidade de vida na aposentadoria }\end{array}$ & 4.41 & .80 & .57 \\
3 & $\begin{array}{l}\text { Tenho uma visão clara de como será a } \\
\text { minha vida na aposentadoria }\end{array}$ & 3.26 & 1.06 & .55 \\
& $\begin{array}{l}\text { Sigo as orientações de economizar para } \\
\text { os momentos difíceis }\end{array}$ & 3.76 & 1.12 & .53 \\
6 & $\begin{array}{l}\text { O futuro distante me parece vago e incerto } \\
7\end{array}$ & 3.80 & 1.11 & -.49 \\
Vivo muito mais para o presente do que & 3.11 & 1.17 & -.43 \\
para o futuro
\end{tabular}

Nota: Método de extração oblíqua. 


\section{CAPítULO 6}

\section{Evidências de Eficácia e Validade Social de Programas de Preparação para Aposentadoria: Um Estudo Experimental ${ }^{12}$}

\footnotetext{
${ }^{12}$ As autoras agradecem a Joyce Santos, Karen Weizenmann da Matta e Soraya Waquim pelo auxílio na coleta de dados deste estudo.
} 


\section{Resumo}

Este estudo avalia a eficácia de três programas de preparação para aposentadoria (longo, breve e testemunho), em uma amostra de servidores públicos $(n=30)$, compara resultados entre essas modalidades e um grupo controle antes e seis meses após suas realizações e investiga a validade social desses programas. Os programas longo e breve adotaram estratégias dialogadas, informativas e vivenciais, e o programa testemunho contou com depoimento de uma servidora aposentada. Os instrumentos aplicados foram questionário demográfico, escalas de mudança em comportamentos de planejamento para aposentadoria, de bem-estar subjetivo e de perspectiva de tempo futuro relativa à aposentadoria, questionário de satisfação do cliente e entrevistas. Os dados foram analisados por estatística não paramétrica e descritiva e pela análise de conteúdo. Não houve diferença estatisticamente significativa entre os grupos. No entanto, resultados da estatística descritiva demonstraram efeitos positivos das três intervenções, no follow-up, quanto ao bem-estar subjetivo, em comparação ao grupo controle. Os dados revelam ainda validade social elevada, com destaque para os programas longo e breve. São discutidas limitações para o poder estatístico decorrentes do tamanho pequeno da amostra e indicadas sugestões para fomentar uma agenda de pesquisa na área.

Palavras-Chave: aposentadoria; estudos de intervenção; eficácia. 
A passagem para aposentadoria e a ausência do trabalho formal é, para muitos, um período de incertezas e mudanças que exige adequações a esse novo estágio da vida. A transição para aposentadoria implica para grande parte dos trabalhadores brasileiros uma queda no padrão de consumo e na qualidade de vida (Zanelli, 2012). Assim, planejar a aposentadoria é uma forma de prevenir a ocorrência de uma aposentadoria insatisfatória e mal sucedida e promover bem-estar nessa etapa da vida.

O planejamento para aposentadoria pode ser conceituado como um processo composto por fases que englobam (i) representações mentais, consciência ou conhecimento prévio sobre aposentadoria, comparando o presente e o futuro desejado, (ii) objetivos para aposentadoria (iii) decisão de se preparar para aposentadoria, e (iv) preparação (Noone, Stephens, \& Alpass, 2009).

O estágio de preparação inclui formulação de planos para a aposentadoria, implementação e revisão desses planos. Quando o trabalhador tem consciência da importância de planejar sua aposentadoria e decide implementar ações que favoreçam o bem-estar na aposentadoria, construir planos promove a transformação de objetivos em comportamentos proativos (Leandro-França, Seidl, \& Murta, 2016).

Algumas estratégias de suporte com foco no planejamento para aposentadoria como, por exemplo, os programas de preparação para aposentadoria, de curta ou longa duração, podem ser úteis para promover a percepção de bem-estar (Kim \& Moen, 2002), mudanças em comportamento de planejamento para aposentadoria (Leandro-França, van Solinge, Hénkens, \& Murta, 2016), clareza de metas para aposentadoria e perspectiva de tempo futuro (Hershey, Henkens, \& van Dalen, 2010).

As intervenções com foco no planejamento para aposentadoria apresentam diferenças quanto aos objetivos, número de encontros, duração, temas abordados e técnicas utilizadas. Os programas longo ou continuado têm, em geral, duração de oito a 20 
encontros, com periodicidade semanal, quinzenal ou mensal. Os programas breves têm duração de um a três encontros, uma vez por semana (Seidl, Leandro-França, \& Murta, 2014). Usualmente, esses programas incorporam módulos informativos, com encontros que apresentam conteúdos em forma de palestras, e módulos vivenciais, que utilizam estratégias dialogadas e atividades interativas. Essas estratégias têm o intuito de facilitar a adaptação do indivíduo à aposentadoria e amenizar o impacto causado pelas mudanças decorrentes desse processo (Leandro-França et al., 2016; Glamser, 1981).

Nessa perspectiva, o presente estudo tem como objetivo principal avaliar a eficácia de três intervenções ou programas (longo, breve e testemunho) de preparação para aposentadoria, em uma amostra de servidores públicos federais brasileiros, e comparar resultados entre essas modalidades e um grupo controle, antes e seis meses após suas realizações. Como pergunta central desta investigação, procura-se compreender em que extensão três diferentes programas de preparação para a aposentadoria promovem maior bem-estar subjetivo, melhor perspectiva de tempo futuro relativo à aposentadoria e mudanças em comportamento de planejamento para aposentadoria?

Como objetivo secundário, busca-se verificar a validade social desses programas, considerando critérios de relevância dos objetivos, aceitabilidade dos procedimentos e importância social de seus efeitos. No campo da saúde pública e da psicologia comportamental, existe uma rica literatura sobre a história e conceitos de validade social (Francisco \& Butterfoss, 2007; Lane \& Beebe-Frankenberger, 2004). No entanto, esse tipo de avaliação é desconhecido na literatura sobre programas de preparação para aposentadoria. O principal objetivo de investigar a validade social é conhecer como a intervenção pode afetar a vida dos participantes e se a qualidade de vida foi melhorada em função da intervenção. Busca-se por meio da avaliação de validade social verificar principalmente a aceitabilidade dos procedimentos e efeitos das intervenções entre clientes 
e consumidores (Bowen et al., 2009; Kazdin, 1977; Francisco \& Butterfoss, 2007). Desse modo, a pergunta a ser respondida neste estudo sobre a validade social das intervenções é se os programas são percebidos como úteis para aqueles que os receberam. Um método usual para avaliar o grau de aceitabilidade dos procedimentos do programa é perguntar àqueles que os receberam, desenvolveram ou implementaram, qual a opinião deles sobre o programa (Carter, 2010).

Em resumo, existem muitas razões importantes para investigar a validade social dos programas em planejamento para aposentadoria. Primeiro, verificar a validade social dessas intervenções suprirá a lacuna na literatura da área no que se refere a esse tipo de avaliação. Segundo, acessar a validade social dessas intervenções utilizando métodos mistos de análises, como recomendado na literatura (Francisco \& Butterfoss, 2007), ampliará a possibilidade de efeitos além dos resultados de significância estatística. Para Francisco e Butterfoss (2007), nos estudos sobre saúde pública e pesquisas com a participação da comunidade, basear-se somente no teste de significância estatística pode resultar perder importantes dimensões sociais como, por exemplo, o impacto da intervenção na vida dos participantes e efeitos na comunidade.

Terceira razão, elevados níveis de aceitabilidade desses programas podem ajudar gestores e profissionais a escolher a intervenção mais adequada, considerando a carga horária, complexidade da implementação, os recursos necessários para implementá-las e outras características do contexto que influenciam a viabilidade dos programas (Bowen et al., 2009). Além disso, as sugestões dos participantes serão relevantes para aprimoramento e adaptação das estratégias utilizadas e fortalecimento dessas ações.

Por fim, para facilitar a elaboração de "relações causais hipotetizadas entre os componentes dos programas e os resultados esperados" (Murta \& Santos, 2015, p. 175), 
foi elaborado o modelo lógico dos três Programas de Preparação para Aposentadoria investigados neste estudo.

\section{Modelo Lógico}

Modelo lógico é uma ferramenta ou esquema gráfico utilizado para apresentar resumidamente os componentes de programas, contexto, mecanismos de funcionamento, procedimentos adotados, as causas do problema e resultados esperados ao longo do tempo, que podem ser proximais (curto prazo) e distais (médio e longo prazo). O modelo lógico auxilia o pesquisador a focar nos elementos importantes dos programas, identificar as variáveis investigadas, formular perguntas e hipóteses do estudo e escolher medidas fundamentais para avaliar as variáveis do estudo (Wholey, Hatry, \& Newcomer, 2010). Logo, é proposta do presente estudo atingir as metas proximais ou de curto prazo descritas no modelo lógico na Figura 1. 


\section{Modelo Lógico: Programas de Preparação para Aposentadoria}

Programas/Componentes

Descrição dos programas longo, breve e

testemunho, formato grupal, com foco

no planejamento/educação para

aposentadorias de servidores públicos federais.

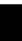

Programa Longo

Composta por 13 sessões em grupo, duração cada sessão frequência semanal, 180 minutos de

\section{Modalidades dos Programas \\ Estratégias e etapas realizadas para atingir as metas dos programas. \\ Técnicas Informativas (educativas, \\ Fatores de Risco e de \\ Proteção \\ Fatores que dificultam (risco) ou facilitam (proteção) a adaptação à aposentadoria

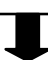
coma participação de palestrantes convidados) e Vivenciais (dirigidas à reflexão, sensibilização e expressão das emoções como discussão em grupo, trocas de experiências).

Temas centrais: saúde física e emocional, finanças, ocupação, póscarreira, apoio familiar e social.

\section{Rapport - Descontração} aproximação entre participantes e facilitadores

Responsabilidade - Histórias de

pessoas aposentadas

Feedback - Devolução dos resultados da EMCPA Sessão única, em grupo, duração de 180 minutos

Autoeficácia - Diagrama de

Recursos com uso de figuras

ilustrativas

Menu de opções - Guia de preparação para aposentadoria

Aconselhamento - Plano de ação escrito

Empatia - postura empática e escuta responsiva pelo facilitador

Testemunho - Depoimento de um servidor aposentado

Programa Testemunh Sessão única, em grupo, duração de 180 minutos

Técnica: Discussão dos fatores de risco e de proteção para adaptação à aposentadoria.

Fatores de Risco

Declínio de saúde física e mental

Depressão e ansiedade

Dificuldades na relação conjugal

Possuir poucos recursos financeiros

Aposentar de forma abrupta e involuntária

\section{Fatores de Proteção}

Saúde física e psicológica

Boa relação conjugal

Laços familiares e de amizade

Autoeficácia

Segurança financeira

Práticas de atividade física e de voluntariado

Planejamento da aposentadoria

Aposentaria gradual e voluntária

\section{Metas Proximais}

Resultados de curto prazo em bemestar subjetivo, perspectivas de tempo

futuro e mudanças cognitivas, motivacionais e comportamentais para a adaptação à aposentadoria.

Bem Estar Subjetivo

Maior satisfação com a vida, vivência de afetos positivos e diminuição de afetos negativos.

Perspectivas de Tempo Futuro Maior clareza de objetivos para aposentadoria e percepção de tempo futuro.

\section{Mudança Cognitiva}

Reflexão ou consciência sobre a importância do planejamento para a aposentadoria, mudança em crenças sobre aposentadoria, aquisição de novas informações sobre o assunto.

\section{Mudança Motivaciona} Desejo de mudar, determinação para adquirir um comportamento que ajudará na adaptação à aposentadoria e tomada de decisão segura quanto aposentar.

\section{Mudança Comportamental}

(1) Mudança física - cuidados com a saúde, alimentação e atividade física.

(2) Mudança financeira - poupança, investimentos e controle de despesas

(3) Atividades produtivas e de lazer

(4) Mudança sócio-emocional investimentos em relacionamentos sociais e familiares.
Metas Distais

Resultados esperados a médio e longo prazo (meses e anos) após término dos programas

Prevenção de Riscos

Redução no surgimento de transtornos psico-afetivos que antecedem e sucedem a aposentadoria como depressão, ansiedade, estresse, alcoolismo e suicídio.

\section{Prevenção de Danos}

Redução no surgimento de doenças como hipertensão, diabetes e obesidade.

Promoção da Saúde, BemEstar e Qualidade de Vida

Aumento na qualidade de vida e bem-estar durante a aposentadoria considerando os fatores de proteção (sociais, físicos, financeiros e ocupacionais) abordados nos três tipos de programa.

Aumento da longevidade obtenção de um envelhecimento ativo com participação autônoma nas questões sociais, econômicas, culturais, espirituais e civis. 


\section{Teoria e Hipóteses}

Este estudo tem como principal fundamentação teórica o modelo Perspectiva Dinâmica de Recursos (Wang, Hénkens, \& van Solinge, 2011). A partir desse modelo, pesquisadores argumentam que uma boa adaptação à aposentadoria está aliada ao investimento em mudanças comportamentais, respaldadas em recursos cognitivos, motivacionais, emocionais, ocupacional-social, autonomia e bem-estar (Barbosa, Monteiro, \& Murta, 2016; Leandro-França \& Murta, 2014; Leandro-França, Murta, \& Villa, 2014; van Solinge \& Hénkens, 2008; Wang et al., 2011).

Recurso "é a capacidade total que um indivíduo tem em satisfazer as necessidades que ele mais valoriza" (Wang et al., 2011, p. 3). São exemplos de recursos que promovem uma aposentadoria satisfatória, ter saúde e estabilidade financeira (Kim \& Moen, 2002; Richardson \& Kilty, 1991), possuir uma boa relação conjugal (Price \& Joo, 2005), ter vínculos conscientes, valorosos e prazerosos com a família, comunidade e amigos (van Solinge \& Hénkens, 2008), possuir autoestima e autoeficácia (Reitzes \& Mutran, 2004; van Solinge \& Henkens, 2008). Na perspectiva desse modelo, as pessoas que possuem recursos valorizados por elas e que atendem suas necessidades terão menos dificuldade em se adaptar à aposentadoria. Em contrapartida, a diminuição de tais recursos provocarão efeitos adversos sobre a adaptação à aposentadoria (Wang et al., 2011).

Existem ainda evidências na literatura de que ter clareza de objetivos para aposentadoria e perspectiva de tempo futuro prediz uma boa adaptação e bem-estar na aposentadoria, especialmente como preditor da percepção da adequação da poupança para o futuro (França \& Hershey, 2010; Hershey, Henkens, \& van Dalen, 2010). Perspectiva de Tempo Futuro (PTF) é caracterizada como um recurso cognitivo e motivacional da personalidade, um fator de proteção que promove resiliência (Nuttin \& Lens, 1985) e está 
associada às dimensões positivas do bem-estar subjetivo (Nuttin \& Lens, 1985; RíoGonzález \& Herrera, 2006).

Pessoas com PTF aprofundada, que possuem objetivos claros, a serem alcançados no futuro em longo prazo (ex. pessoas que planejam aposentar e se preparam de forma contínua e equilibrada cinco anos antes da aposentadoria), estão mais propensas a alcançar seus objetivos e realizar seus projetos do que as que possuem uma PTF restrita. Pessoas com PTF restrita são aquelas que têm objetivos e elaboram projetos a serem alcançados em um futuro próximo (Nuttin \& Lens, 1985; Río-González \& Herrera, 2006).

O construto bem-estar subjetivo, também investigado neste estudo tem se destacado nos últimos anos em pesquisas de diversas áreas do conhecimento por envolver dimensões como felicidade, satisfação, estado de espírito e afeto positivo (Giacomoni, 2004). O conceito de bem-estar subjetivo está relacionado a três categorias: (1) satisfação com a vida ou julgamentos que fazemos em relação à própria vida, (2) afetos positivos ou vivências de emoções agradáveis e (3) afetos negativos ou vivências de emoções desprazerosas (Diener, 2000).

Ao examinar a relação entre bem-estar subjetivo, aposentadoria e o modelo perspectiva de recursos, o bem-estar subjetivo pode ser considerado como um recurso emocional, uma vez que a aposentadoria pode aumentar o bem-estar, reduzir o estresse, aumentar o tempo livre e representar um marco importante de realização (afetos positivos). Por outro lado, a aposentadoria pode diminuir o bem-estar pela redução do contato social e mudança em componentes da identidade (Kim \& Moen, 2002). Tais características podem ser classificadas como afetos negativos ou desprazerosos.

Assim, os efeitos da aposentadoria sobre o bem-estar subjetivo são heterogêneos e podem ser afetados por diversas variáveis como, por exemplo, idade de aposentadoria, importância de possuir um trabalho para afirmação da identidade e características 
psicológicas individuais (Michinov, Fouquereau, \& Fernandez, 2008; Reitzes \& Mutran, 2004). Posto isso, o presente estudo intenciona contribuir para a literatura em planejamento para aposentadoria de seis maneiras:

Primeiro, a literatura destaca que os programas longos produzem resultados benéficos aos participantes como, por exemplo, aquisição de conhecimento sobre planejamento para aposentadoria, fortalecimento da rede social e familiar, controle dos gastos financeiros, cuidados com a saúde, valorização do lazer, perspectiva para uma nova carreira e auxílio na tomada de decisão para aposentadoria (Murta et al., 2014; Pereira \& Guedes, 2012; Soares, Costa, Rosa \& Oliveira, 2007). Entretanto, a literatura da área não faz referência sobre o efeito desse tipo de programa sobre a promoção de perspectiva de tempo futuro relativa à aposentadoria e em que extensão esses programas afetam o bemestar subjetivo dos participantes. Assim, este estudo tem a proposta de suprir essa lacuna ao comparar resultados de um programa longo com outras modalidades de intervenção (breve e testemunho) e um grupo controle. Para que isso seja possível, a seguinte hipótese foi elaborada:

H1: Os participantes do programa longo demonstrarão maior bem-estar subjetivo, melhor perspectiva de tempo futuro relativa à aposentadoria e mudanças em planejamento para aposentadoria, no follow-up, em comparação aos participantes do programa breve, testemunho e grupo controle.

Segundo, o programa breve e testemunho também têm apresentado resultados promissores quanto às mudanças no planejamento para aposentadoria. Ainda que recente, a literatura indica que esses tipos de ações favorecem mudanças cognitivas e motivacionais (Leandro-França et al., 2016) como o aumento do conhecimento sobre o processo de 
aposentadoria, consciência sobre a importância de planejar essa fase da vida e auxílio dos programas na tomada de decisão para aposentar. Ademais, o programa breve foi capaz de promover mudanças comportamentais em ajustamento financeiro, atenção à saúde, convivência familiar e conjugal (França, 2012; França, Murta, Negreiros, Pedralho, \& Carvalhedo, 2013; Leandro-França et al., 2014; Leandro-França et al., 2016).

Desse modo, a próxima hipótese visa corroborar os achados da área sobre mudanças motivacionais, cognitivas e comportamentais decorrentes dos programas breve e testemunho e preencher lacunas existentes quanto à avaliação da variável bem-estar subjetivo e perspectiva de tempo futuro. Em suma, espera-se que o programa breve e testemunho apresentem resultados equivalentes, tendo em vista similaridades em duração e estratégias (Leandro-França et al., 2016). Para essa finalidade, foi formulada a seguinte hipótese:

H2: Os participantes do programa breve e testemunho apresentarão resultados similares, no follow-up, em bem-estar subjetivo, perspectiva de tempo futuro relativa à aposentadoria e mudanças em comportamentos de planejamento para aposentadoria.

Terceiro, é apresentado neste estudo o programa testemunho, prática usual sobre planejamento da aposentadoria nas organizações, mas apenas recentemente abordado na literatura sobre planejamento para aposentadoria por Leandro-França et al. (2016). O programa testemunho foi adaptado de estudos na área da saúde que utilizam comunicação narrativa ou depoimentos (testemunho) como estratégia para promoção de comportamentos de prevenção de câncer (Janssen, van Osch, De Vries, \& Lechner, 2012; Lemal \& van den Bulck, 2010) e atribuições de responsabilidade sobre as causas da obesidade (Niederdeppe, Sahpiro, \& Porticella, 2011). O testemunho ou depoimento 
favorece a percepção de risco quando a pessoa (a) identifica-se com a situação-problema por meio da empatia, (b) perceber-se em situação similar, (c) percebe a história como uma representação realista do mundo e (d) é absorvido ou transportado para dentro da narrativa (Busselle \& Bilandzic, 2008).

Para o presente estudo, estima-se que o programa testemunho alcançará resultados favoráveis como os encontrados na área de saúde (Janssen et al., 2012; Lemal \& van den Bulck, 2010; Niederdeppe et al, 2011) e equivalentes ao programa breve quanto à mudanças em comportamentos de planejamento para aposentadoria, conforme pesquisas de França et al. (2013) e Leandro-França et al. (2014). São esperados ainda melhores resultados nas variáveis dependentes deste estudo para os programas breve e testemunho em comparação ao grupo controle como especificado na hipótese abaixo:

H3: Os participantes do programa breve e testemunho demonstrarão um maior bem-estar subjetivo, melhor perspectiva de tempo futuro relativa à aposentadoria e mudanças em comportamentos de planejamento para aposentadoria, no follow-up, em comparação aos participantes do grupo controle.

Por fim, nota-se que a eficácia de programas de planejamento para aposentadoria tem sido difícil de alcançar em razão da não especificação dos métodos de amostragem, da ausência de medidas pré e pós-intervenção e de follow-up, da falta de grupos controle, da escassez de instrumentos validados, de múltiplos informantes e de múltiplas medidas (Murta, Leandro-França, \& Barbosa, 2014; Leandro-França et al., 2016; Hershey, Mowen, \& Jacobs-Lawson, 2003). Eficácia está associada à validade interna da intervenção ou aos "efeitos benéficos de um determinado programa, projeto ou política sob condições ideais 
de implementação e está relacionado ao alcance dos objetivos e metas propostas por essas ações" (Murta et al., 2014, p. 298).

Desse modo, como quarta contribuição, estima-se que ao fazer uso de um delineamento experimental, mais robusto quanto às ameaças à validade interna e ao utilizar critérios relevantes na avaliação da eficácia dos programas (ex. randomização, grupo controle, instrumentos validados, medidas pré-intervenção e de follow-up, múltiplas medidas e métodos mistos de análises), o presente estudo ofereça evidências relativas à eficácia, à validade social ou às limitações de intervenções em planejamento para aposentadoria.

\section{Método}

\section{Delineamento}

Trata-se de um estudo clínico randomizado com participantes alocados aleatoriamente, por sorteio, para uma das quatro condições experimentais, sendo um grupo controle e três programas/intervenções de preparação para aposentadoria. Foram realizadas medidas pré-programa (T1) e follow-up (T2) aos seis meses, como descrito na Figura 2. O tipo de programa (longo, breve e testemunho) é a variável independente. As variáveis dependentes são: (a) promoção de bem-estar subjetivo; (b) promoção de perspectiva de tempo futuro relativa à aposentadoria e (c) mudanças cognitiva, motivacional e comportamental de planejamento para aposentadoria. 


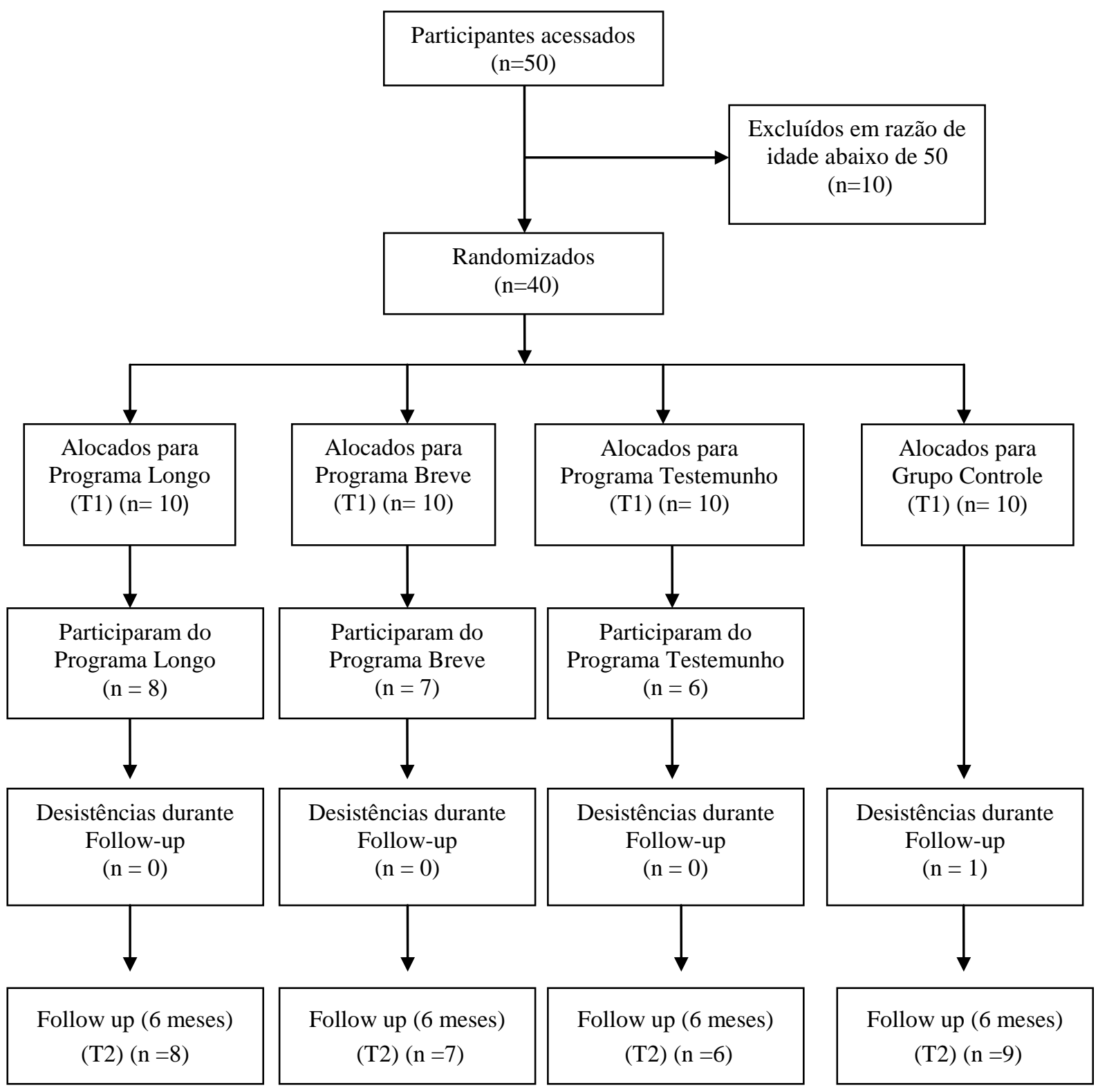

Figura 2. Fluxograma de participantes, randomização e desistências.

\section{Amostra do Estudo}

Servidores de quatro organizações públicas federais brasileiras $(N=40)$ foram alocados por randomização em três programas de preparação para aposentadoria (longo, breve e testemunho) e um grupo controle (não intervenção). Os participantes foram submetidos às medidas pré-programa e avaliação de follow-up seis meses após realização dos programas. A amostra final $(n=30)$ foi composta por maioria mulheres $(56,7 \%)$. A idade dos participantes variava de 51 a 67 anos (Média $=58.00 \pm 5,01 ; \mathrm{C}_{v}=0.09$ ). Além disso, a maioria dos participantes disse ter ensino médio completo $(56,7 \%)$, trabalhar 40 
horas por semana (90,0\%), possuir renda acima de $\mathrm{R} \$ 10.000$ (Dez mil reais) e $50 \%$ relatou ser casado. Todos os participantes eram servidores efetivos da administração pública federal (Poder executivo) e ingressaram nas organizações por meio de concurso público. Destaca-se que a renda da maioria dos participantes (80\%) é considerada bem acima dos rendimentos médios (04 salários mínimos) recebidos pelos servidores efetivos do setor público, de acordo com dados do IBGE (2016). As informações completas da amostra encontram-se na Tabela 1.

Tabela 1. Características Demográficas da Amostra

\begin{tabular}{|c|c|c|c|}
\hline & & Frequência Absoluta & $\%$ \\
\hline \multirow{4}{*}{$\begin{array}{l}\text { Experimental } \\
\text { Condição }\end{array}$} & Programa Longo & 8 & 26,7 \\
\hline & Programa Breve & 7 & 23,3 \\
\hline & Testemunho Programa & 6 & 20,0 \\
\hline & Grupo Controle & 9 & 30,0 \\
\hline \multirow{2}{*}{ Sexo } & Homens & 13 & 43,3 \\
\hline & Mulheres & 17 & 56,7 \\
\hline \multirow{3}{*}{ Escolaridade } & Ensino médio completo & 5 & 16,7 \\
\hline & $\begin{array}{l}\text { Ensino superior } \\
\text { completo }\end{array}$ & 17 & 56,7 \\
\hline & $\begin{array}{l}\text { Pós-graduação } \\
\text { completa }\end{array}$ & 8 & 26,7 \\
\hline \multirow{5}{*}{ Estado Civil } & Solteiro & 5 & 16,7 \\
\hline & Casado & 15 & 50,0 \\
\hline & Divorciado & 5 & 16,7 \\
\hline & Viúvo & 1 & 3,3 \\
\hline & União Estável & 4 & 13,3 \\
\hline \multirow{2}{*}{$\begin{array}{l}\text { Horas de Trabalho } \\
\text { Semanal }\end{array}$} & $30 \mathrm{~h}$ & 3 & 10 \\
\hline & $40 \mathrm{~h}$ & 27 & 90 \\
\hline \multirow{4}{*}{ Renda } & $\mathrm{R} \$ 2.000$ até $\mathrm{R} \$ 5.000$ & 6 & 20,0 \\
\hline & $\mathrm{R} \$ 5.001$ até $\mathrm{R} \$ 7.000$ & 3 & 10,0 \\
\hline & $\mathrm{R} \$ 7.001$ até $\mathrm{R} \$ 10.000$ & 6 & 20,0 \\
\hline & Acima de $\mathrm{R} \$ 10.000$ & 15 & 50,0 \\
\hline
\end{tabular}




\section{Instrumentos}

\section{Variáveis Dependentes}

\section{Escala de Bem Estar Subjetivo - BES}

Para avaliar o bem estar subjetivo foi utilizado um instrumento construído por Albuquerque e Tróccoli (2004) composto por 62 itens divididos em duas partes. Os itens da primeira parte da escala, 1 a 47, descrevem os afetos positivos (ex: agradável, animado, seguro, alegre) e negativos (ex: preocupado, nervoso, tenso, triste) e o participante é convidado a responder como ele tem se sentido ultimamente, com relação à vivência de sentimentos positivos e negativos em uma escala em que 1 significa não muito e 5 significa extremamente. A segunda parte da escala, 1 a 15, descreve julgamentos relativos à avaliação de satisfação (ex: estou satisfeito com minha vida) ou insatisfação (ex: minha vida está ruim) com a vida. Esses itens são respondidos em uma escala em que 1 significa discordo totalmente e 5 significa concordo totalmente. A análise fatorial por extração dos eixos principais e rotação oblimin revelaram três fatores: afeto positivo (21 itens, explicando 24,3\% da variância, $\alpha=0,95$ ); afeto negativo (26 itens, 24,9\% da variância, $\alpha=$ $0,95)$ e satisfação com a vida (15 itens, $21,9 \%$ da variância, $\alpha=0,90)$. Juntos, os três fatores explicaram 44,1 \% da variância total do construto.

\section{Escala de Perspectiva de Tempo Futuro relativa à Aposentadoria- EpersTFA}

Para investigar esta variável dependente foi utilizada a Escala de Perspectiva de Tempo Futuro relativa à Aposentadoria- EPersTFA, medida de autoavaliação adaptada do modelo interdisciplinar de planejamento financeiro desenvolvido por Hershey et al. (2010). Este modelo consiste em um conjunto de fatores (psicológico, econômico, financeiro, sociodemográfico e planejamento social) apontados como determinantes 
fundamentais das práticas de planejamento para aposentadoria e preditores da percepção de poupar para o futuro.

$\mathrm{Na}$ construção da escala para o presente estudo, optou-se por uma seleção de sete itens dos estudos de Hershey, Jacobs-Lawson, McArdle e Hamagami, (2007) referentes a dois fatores psicológicos: (a) clareza de metas para a aposentadoria (ex. eu tenho pensado muito sobre a qualidade de vida na aposentadoria) e (b) perspectiva de tempo futuro (ex. futuro distante parece vago e incerto). Os entrevistados responderam a uma escala likert de cinco pontos que variavam de 1 (discordo plenamente) a 5 (concordo plenamente). A análise fatorial exploratória resultou em uma solução unifatorial, "perspectiva de tempo futuro relativo à aposentadoria" (Autovalor = 2,08; Variância Explicada = 40,10\%), que agrupou os sete itens e apresentou nível de consistência interna aceitável $(\alpha=0,74)$ com cargas fatoriais variando de 0,43 a 0,66 .

\section{Escala de Mudança em Comportamento de Planejamento para Aposentadoria}

O instrumento Escala de Mudança em Comportamentos de Planejamento para Aposentadoria - EMCPA, utilizado neste estudo, foi construído por Leandro-França, Murta e Iglesias (2014) com objetivo de avaliar estágios de mudanças (cognitivas, motivacionais e comportamentais) referentes à preditores de adaptação à aposentadoria. A escala é organizada em 15 itens, com categorias de resposta que variam de 1 a 6 , ancorada nos estágios de mudança: (1) não estou interessado nisso (pré-contemplação); (2) venho pensando em fazer algo sobre isso (contemplação); (3) estou decidido a fazer algo nesse sentido (preparação); (4) comecei a fazer, mas parei (recaída); (5) comecei a fazer há pouco tempo (ação); e (6) já faço isso há bastante tempo (manutenção).

A escala é composta por dois fatores: (a) investimento ocupacional-social, com oito itens tais como: participar de grupos na comunidade; investir em projetos que podem ser 
executados a partir da aposentadoria; fazer cursos para aperfeiçoamento em outra área com objetivo de uma segunda carreira; fazer trabalho voluntário na comunidade; dedicar-me a práticas espirituais ou religiosas; ter um hobby; fazer cursos de formação na minha área de trabalho atual; cultivar minhas amizades $(\alpha=0,71$; cargas fatoriais variando de 0,32 a $0,73)$ e (b) investimento em autonomia e bem-estar, com sete itens como: realizar atividade física regularmente; ter tempo para investir na vida familiar; possuir investimentos financeiros para o futuro; praticar atividades de lazer; dedicar-me à relação com o meu parceiro; ter uma dieta saudável; fazer exames médicos para check-up $(\alpha=0,63$; cargas fatoriais variando de 0,39 a 0,70$)$.

\section{Validade Social}

Questionário de Satisfação do Cliente

Para avaliar a validade social dos programas foi utilizado o Questionário de Satisfação do Cliente, elaborado com base no instrumento Client Satisfctaion Questionnaire - CQS-8 de Clifford Attkisson (Corcoran \& Fischer, 2000). Este instrumento foi usado em estudo prévio no contexto de pesquisa sobre planejamento da aposentadoria por França et al. (2013). O instrumento inclui cinco perguntas fechadas e quatro perguntas abertas. As perguntas fechadas são: (1) Como você avalia a qualidade da intervenção que recebeu? (2) Em que proporção o programa atendeu suas necessidades? (3) Se um familiar ou amigo seu necessitar de ajuda similar, você recomendaria o programa a ele ou a ela? (4) Quão satisfeito você está com a quantidade de horas do programa que recebeu? (5) Sua participação no programa te ajudou a lidar melhor com o planejamento da sua aposentadoria?

As respostas estão ancoradas em uma escala que varia de 1 (ruim, não definitivamente, nenhum dos meus interesses foi atendido, muito insatisfeito, não ajudou 
em nada) a 4 (excelente, sim definitivamente, todos os meus interesses foram atendidos, muito satisfeito, sim ajudou muito). As questões abertas investigam o que os participantes mais gostaram e menos gostaram nas intervenções e solicitam sugestões para aprimoramento das intervenções sobre o que deve ser mantido e o que deve ser modificado.

Ainda como instrumentos deste estudo, utilizou-se um roteiro de entrevista para avaliar qualitativamente o processo de mudança dos participantes, após o follow-up de seis meses:

\section{Roteiro de Entrevista para Avaliação de Processo de Mudança}

Este roteiro guiou as entrevistas semiestruturadas realizadas com os participantes dos programas e grupo controle, em follow-up de seis meses (Anexo M). O objetivo central da entrevista foi averiguar as mudanças cognitivas, motivacionais e comportamentais de planejamento para aposentadoria que ocorreram nesse intervalo de tempo, após participação ou não participação nos programas. Cada entrevista durou aproximadamente quarenta minutos. Neste estudo, serão explorados apenas os relatos dos participantes do grupo controle direcionados às mudanças comportamentais de planejamento para aposentadoria. Logo, buscou-se saber o que de fato os participantes conseguiram implementar nesse intervalo de seis meses de follow-up. Os relatos dos participantes dos programas longo, breve e testemunho foram analisados no estudo de Leandro-França et al. (2016), capítulo 7 desta tese.

\section{Variável Independente}

\section{Programa Longo}

O programa longo teve duração de 13 encontros, informativo-vivenciais, com periodicidade semanal, de 3 horas de duração cada encontro, e seguiu os procedimentos adotados no estudo de Murta et al. (2014). Os encontros ocorreram em grupo e os temas 
abordados foram: (1) apresentação e preditores de uma aposentadoria e envelhecimento bem sucedido, (2) resiliência, processo de mudança e aposentadoria, (3) legislação previdenciária, (4) autonomia financeira e aposentadoria, (5) saúde e alimentação saudável, (6) saúde e atividade física, (7) saúde e sexualidade, (8) família e aposentadoria, (9) pós-carreira e empreendedorismo, (10) rede social e aposentadoria, (11) espiritualidade, (12) projeto de vida pós-carreira, e (13) encerramento.

Os primeiros 90 minutos do encontro foram dedicados aos módulos vivenciais, enquanto os 90 minutos finais foram utilizados para os módulos informativos. Os módulos informativos englobaram a participação de convidados externos, incluindo médico, educador físico, nutricionista, psicólogo, enfermeiro, administrador, especialista em legislação previdenciária e economista. Esta parte do encontro foi executada em forma de palestras. Os módulos vivenciais fizeram uso de atividades interativas como, por exemplo, dinâmicas escritas, verbais, filmes e músicas, como proposto em estudos de Murta, Caixeta, Souza e Ribeiro (2008) e Murta et al. (2014). A Tabela 2 apresenta os temas, objetivos e principais técnicas utilizadas na realização deste programa. No Anexo L, as técnicas utilizadas neste programa são descritas detalhadamente. 
Tabela 2. Descrição de Temas, Objetivos e Técnicas utilizadas no Programa Longo

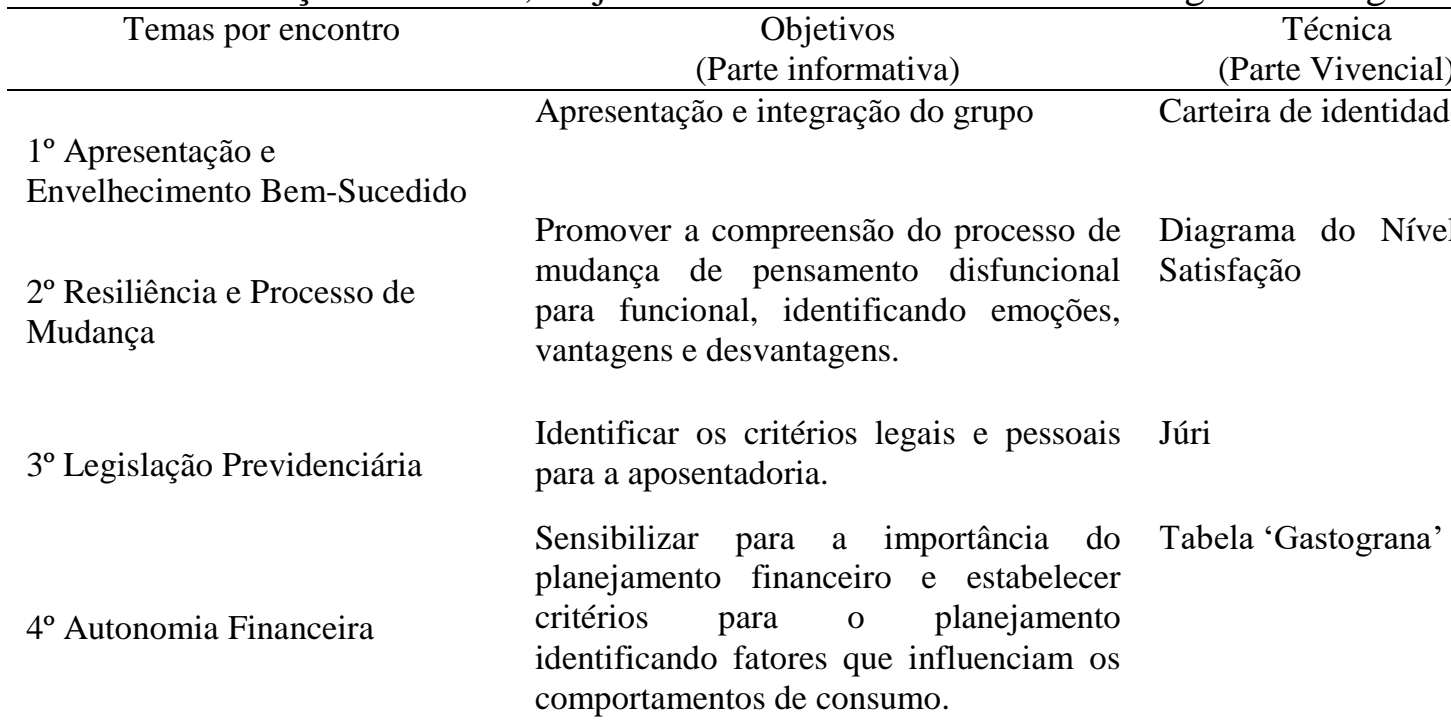

Promover a compreensão da importância

$5^{\circ}$ Saúde e Alimentação Saudável de uma alimentação saudável para a qualidade de vida e envelhecimento ativo

Lista de supermercado

Proporcionar consciência corporal e sensibilizar para o interesse na prática de atividade física.

Atividade da linha do tempo sobre hábitos de atividade e exercício físico

Ampliar o conceito de sexualidade, apresentar a importância de cuidar deste aspecto da vida e relacioná-lo com a aposentadoria.

Promover a compreensão da importância dos vínculos familiares no processo de aposentadoria.

Sensibilizar para a importância de investir em atividades de ocupação do tempo na aposentadoria e identificar interesses e valores pessoais relacionados a atividades de ocupação do tempo.

$9^{\circ}$ Pós-carreira e

Empreendedorismo

Promover a reflexão da importância da rede social de apoio e apresentar recursos para criar e manter uma rede.

$10^{\circ}$ Rede Social e Aposentadoria

Explorar a espiritualidade dos participantes, promovendo a percepção da importância dos valores na construção do

$11^{\circ}$ Espiritualidade projeto de vida.

Estimular a construção de um projeto de vida e o estabelecimento de planos e metas para o futuro como fator de proteção para uma aposentadoria bem sucedida.

Avaliando Heranças

Familiares

Imagem guiada

Mapeando as relações sociais

Dinâmica do "Sentido da Vida"

Instrumento "Projeto de Vida para Aposentadoria”

Analisar os benéficos da intervenção e a Instrumento de satisfação dos participantes com o "Avaliação por Pares" programa. 


\section{Programa Breve}

O programa breve aplicado neste estudo seguiu a fundamentação teórica e os procedimentos utilizados no estudo de França et al. (2013). Logo, foi realizado encontro único, informativo-vivencial, com duração de 3 horas, composto pelo modelo FRAMES (Feedback, Responsabilidade, Aconselhamento, Menu de opções, Empatia e Autoeficácia/Self-efficacy), princípios ativos da intervenção breve (Miller \& Rolnick, 2001). A Tabela 3 apresenta as etapas e atividades realizadas nesta ação.

Tabela 3. Descrição das Etapas, Objetivos e Atividades Realizadas na Intervenção Breve

\begin{tabular}{|c|c|c|c|}
\hline & Etapas/FRAMES & Objetivos & Atividades \\
\hline \multirow[b]{3}{*}{ E } & Rapport & $\begin{array}{l}\text { Apresentação, } \\
\begin{array}{l}\text { descontrair, } \\
\text { integrar e enhecer } \\
\text { percepções }\end{array}\end{array}$ & $\begin{array}{l}\text { Relatar sonhos para a aposentadoria, } \\
\text { aplicar questionário sociodemográfico } \\
\text { e TCLE }\end{array}$ \\
\hline & Responsabilidade & $\begin{array}{l}\text { Autoconhecimento sobre } \\
\text { fatores para a aposentadoria } \\
\text { bem-sucedida }\end{array}$ & $\begin{array}{l}\text { Relatar histórias positivas ou } \\
\text { negativas de pessoas aposentadas e } \\
\text { conhecer os recursos utilizados por } \\
\text { elas para permanecerem bem }\end{array}$ \\
\hline & Feedback & $\begin{array}{l}\text { Devolver resultados obtidos } \\
\text { na EMCPA }\end{array}$ & $\begin{array}{l}\text { Responder EMCPA } \\
\text { resultados }\end{array}$ \\
\hline $\begin{array}{l}\mathrm{A} \\
\mathrm{T}\end{array}$ & Autoeficácia & $\begin{array}{ll}\text { Promover a confiança nos } \\
\text { próprios recursos } & \text { e } \\
\text { capacidade de sucesso }\end{array}$ & $\begin{array}{l}\text { Escrever em um diagrama os recursos } \\
\text { necessários para uma aposentadoria } \\
\text { promissora. Compartilhar com o } \\
\text { grupo (Anexo J). }\end{array}$ \\
\hline A & Мenu de opções & $\begin{array}{l}\text { Fornecer alternativas sobre } \\
\text { atividades que beneficiem a } \\
\text { adaptação na aposentadoria }\end{array}$ & $\begin{array}{l}\text { Distribuir e ler um guia de preparação } \\
\text { para a aposentadoria (Murta et al., } \\
\text { 2010). }\end{array}$ \\
\hline & Aconselhamento & $\begin{array}{l}\text { Orientar a realização de } \\
\text { metas viáveis } \\
\text { autocuidado e preparo para a } \\
\text { aposentadoria }\end{array}$ & $\begin{array}{l}\text { Definir plano de ação: para ter uma } \\
\text { aposentadoria promissora tenho que } \\
\text { parar de..., continuar a... e começar } \\
\text { a... (Anexo K) }\end{array}$ \\
\hline & Avaliação de satisfação & $\begin{array}{l}\text { Avaliar reações sobre a } \\
\text { proposta da intervenção }\end{array}$ & $\begin{array}{l}\text { Aplicar o Questionário de Satisfação } \\
\text { do Cliente (Corcoran \& Fischer, } \\
\text { 2000) ao final da intervenção. }\end{array}$ \\
\hline
\end{tabular}

Nota: Leandro-França, Murta, \& Villa (2013).

\section{Programa Testemunho}

A ação consistiu em encontro único, informativo-vivencial, com duração de 3 horas e teve como técnica principal o depoimento de uma servidora, com um ano de aposentadoria, que trabalhou em uma organização pública, na cidade de Brasília- Distrito 
Federal. O relato continha informações detalhadas com o objetivo de evocar imagens sobre

o período antes e depois da aposentadoria, questões emocionais que envolveram essa transição, a vivência atual da aposentada e estratégias utilizadas para lidar com as dificuldades e riscos nessa fase. O programa testemunho realizado no presente estudo seguiu as etapas apresentadas na Tabela 4.

Tabela 4. Descrição e Objetivos das Etapas da Intervenção Testemunho

\begin{tabular}{|c|c|c|}
\hline Atividades & Objetivos & Descrição \\
\hline Apresentação & $\begin{array}{l}\text { Integração dos } \\
\text { participantes e } \\
\text { facilitador }\end{array}$ & $\begin{array}{l}\text { Solicitar aos participantes que informem nome, } \\
\text { tempo de serviço no órgão e expectativas sobre o } \\
\text { encontro. }\end{array}$ \\
\hline $\begin{array}{l}\text { Sentenças } \\
\text { Incompletas }\end{array}$ & $\begin{array}{l}\text { Conhecer o que os } \\
\text { participantes já realizam } \\
\text { com relação ao } \\
\text { planejamento para } \\
\text { aposentadoria }\end{array}$ & $\begin{array}{l}\text { Solicitar aos participantes que peguem uma das } \\
\text { frases, dentro de uma pequena caixa, relativas a } \\
\text { comportamentos, sentimentos e determinantes de } \\
\text { uma aposentadoria bem sucedida. Em seguida, } \\
\text { pedir que eles leiam a frase em voz alta e } \\
\text { completem a sentença respondendo-a de acordo } \\
\text { com o que já realizam (Anexo I). }\end{array}$ \\
\hline Testemunho & $\begin{array}{l}\text { Conhecer a experiência } \\
\text { sobre o processo de } \\
\text { aposentadoria de um(a) } \\
\text { servidor(a) } \\
\text { aposentado(a) }\end{array}$ & $\begin{array}{l}\text { Convidar uma servidora que se aposentou e que } \\
\text { trabalhe na administração pública federal. A } \\
\text { servidora narrará com detalhes como foi o } \\
\text { processo de sua aposentadoria. A narrativa deve } \\
\text { conter informações reais, emocionais e evocar } \\
\text { imagens sobre o período antes e depois da } \\
\text { aposentadoria. }\end{array}$ \\
\hline Discussão & $\begin{array}{l}\text { Identificar fatores de } \\
\text { risco e proteção na } \\
\text { preparação para } \\
\text { aposentadoria }\end{array}$ & $\begin{array}{l}\text { Convidar os participantes a esclarecerem suas } \\
\text { dúvidas perguntando a aposentada sobre os } \\
\text { principais riscos ocorridos nessa fase e quais } \\
\text { recursos a ajudaram a enfrentar esses riscos }\end{array}$ \\
\hline Avaliação & $\begin{array}{l}\text { Avaliar a satisfação dos } \\
\text { participantes com a } \\
\text { intervenção }\end{array}$ & $\begin{array}{l}\text { Aplicar o Questionário de satisfação do Cliente } \\
\text { (Corcoran \& Fischer, 2000) ao final da } \\
\text { intervenção. }\end{array}$ \\
\hline Fechamento & $\begin{array}{l}\text { Encerrar o encontro e } \\
\text { agradecer a participação } \\
\text { de todos envolvidos }\end{array}$ & $\begin{array}{l}\text { Agradecer a participação dos envolvidos e } \\
\text { perguntar o que eles estão levando daquela } \\
\text { experiência quanto aos desejos, planos, } \\
\text { descobertas, percepções, ideias, intenções e } \\
\text { constatações sobre a aposentadoria. }\end{array}$ \\
\hline
\end{tabular}


A escolha da servidora convidada contou com o auxílio da equipe de um programa de preparação para aposentadoria de uma universidade local. Essa equipe sugeriu o nome da servidora que fez o depoimento por ela ter enfrentando problemas e riscos que poderiam impactar na aposentadoria dela como, por exemplo, a perda de seu único filho durante o processo de transição para aposentadoria. Apesar da perda do filho ter alterado seus planos para aposentadoria, o qual incluía morar com o filho em outra cidade, a servidora conseguiu lidar com esse impacto afetivo em sua vida ao utilizar recursos como espiritualidade, rede de apoio social e familiar, prática de voluntariado e outras atividades de ocupação e fonte de renda como artesanato.

Foi previsto a realização de um estudo piloto para esta modalidade de intervenção, com a finalidade de aprimorar a técnica e ajustes de tempo na aplicação dos procedimentos, mas o piloto foi cancelado tendo em vista a impossibilidade de participação da servidora que daria o depoimento. Assim, foi realizado um encontro prévio com a convidada para obter sua anuência na participação do projeto, bem como, investigar seu estado emocional e como ela estava se sentido na condição de aposentada e para instruí-la quanto aos procedimentos da intervenção. Após essa conversa inicial, verificouse que a servidora tinha o perfil adequado para o depoimento.

\section{Procedimentos de Coleta de Dados}

Como procedimentos de coleta de dados, realizou-se inicialmente a capacitação da equipe executora composta por duas psicólogas e uma enfermeira com conhecimento na condução de programas de preparação para aposentadoria. Para uniformização dos procedimentos, foi elaborado um texto-guia contendo as etapas a serem executadas. Em seguida, foi enviado um convite, por email, aos departamentos de recursos humanos de cinco organizações públicas federais, da cidade de Brasília - Distrito Federal. 
Quatro instituições concordaram em participar do estudo e o divulgaram via email institucional aos servidores em ativa com tempo de contribuição para aposentar. Inicialmente, um total de 50 participantes concordou em participar deste estudo. Dentre os interessados, foram selecionados os que possuíam $(\mathrm{N}=40)$ tempo de contribuição para aposentar (30 anos/ mulheres e 35 anos/ homens) e idade entre 50 a 70 anos. Após essa etapa, entrevistas com aplicação dos instrumentos foram realizadas na avaliação de préteste e, posteriormente, os participantes foram aleatoriamente alocados para os programas (longo, breve e testemunho) e grupo controle. Optou-se por não realizar avaliações pósteste, imediatamente ao término das intervenções, pois as mudanças investigadas necessitavam de um tempo maior para se manifestarem, no caso da intervenção breve e testemunho.

Decorrido seis meses após o término da intervenção, realizou-se avaliação de follow-up e os instrumentos foram reaplicados em trinta pessoas (amostra final), incluindo participantes do grupo controle. Por fim, logo após a realização dos programas e follow-up, os participantes que abandonaram o estudo $(n=10)$, antes de participarem das intervenções e durante follow-up, foram contatados via telefone e perguntados sobre os motivos de desistência nessas etapas. As principais razões relatadas por esses participantes foram problemas de saúde, férias e mudança para outra cidade por motivo de aposentadoria.

A aprovação ética para esta pesquisa foi concedida pelo Comitê de Ética do Instituto de Ciências Humanas da Universidade de Brasília (Registro 707.387).

\section{Procedimentos de Análise de Dados}

As análises estatísticas foram realizadas por meio do pacote estatístico SPSS 22. Considerando que os dados não satisfizeram as condições de normalidade exigidas para o uso da estatística paramétrica além da limitação do tamanho da amostra, foram utilizadas 
estatísticas inferenciais não paramétricas (Field, 2013). Para comparação entre os grupos, das diversas condições experimentais, foi realizado o teste Kruskal-Wallis, nos dois tempos diferentes, pré-teste e follow-up. Para a comparação intragrupos na mesma condição experimental, foi utilizado o teste dos Ranks de Wilcoxon comparando o préteste com o follow-up. Para análise dos testes inferenciais foi considerado estatisticamente significativo o valor de $\mathrm{p}<0,05$. A análise dos dados qualitativos foi realizada por meio técnica de Análise de Conteúdo do tipo Temática e Estrutural (Bardin, 2011).

\section{Resultados}

Os resultados deste estudo são apresentados de acordo com os objetivos e hipóteses investigadas, considerando primeiro as análises da estatística descritiva, em seguida as análises inferenciais e, por fim, os resultados de avaliação da validade social das intervenções.

A primeira hipótese (H1) predisse maior bem-estar subjetivo, melhor perspectiva de tempo futuro relativo à aposentadoria e mudanças em comportamentos de planejamento para aposentadoria para os participantes do programa longo, quando comparados aos participantes do programa breve, testemunho e grupo controle. A segunda hipótese (H2) afirmava que os participantes do programa breve e testemunho, por razões de similaridades em duração e estratégias, apresentariam resultados equivalentes nessas variáveis dependentes. A terceira hipótese (H3) previa maior efeito do programa breve e testemunho em melhores resultados nessas variáveis dependentes em comparação ao grupo controle.

A Tabela 5 apresenta os valores de estatísticas descritivas intragrupos e entregrupos para as variáveis dependentes, comparando resultados do pré-teste e follow-up. 
Tabela 5. Valores de Estatísticas Descritivas Intra e Entre Grupos para as Variáveis Dependentes, comparando Resultados do Pré-Teste e Follow-up.

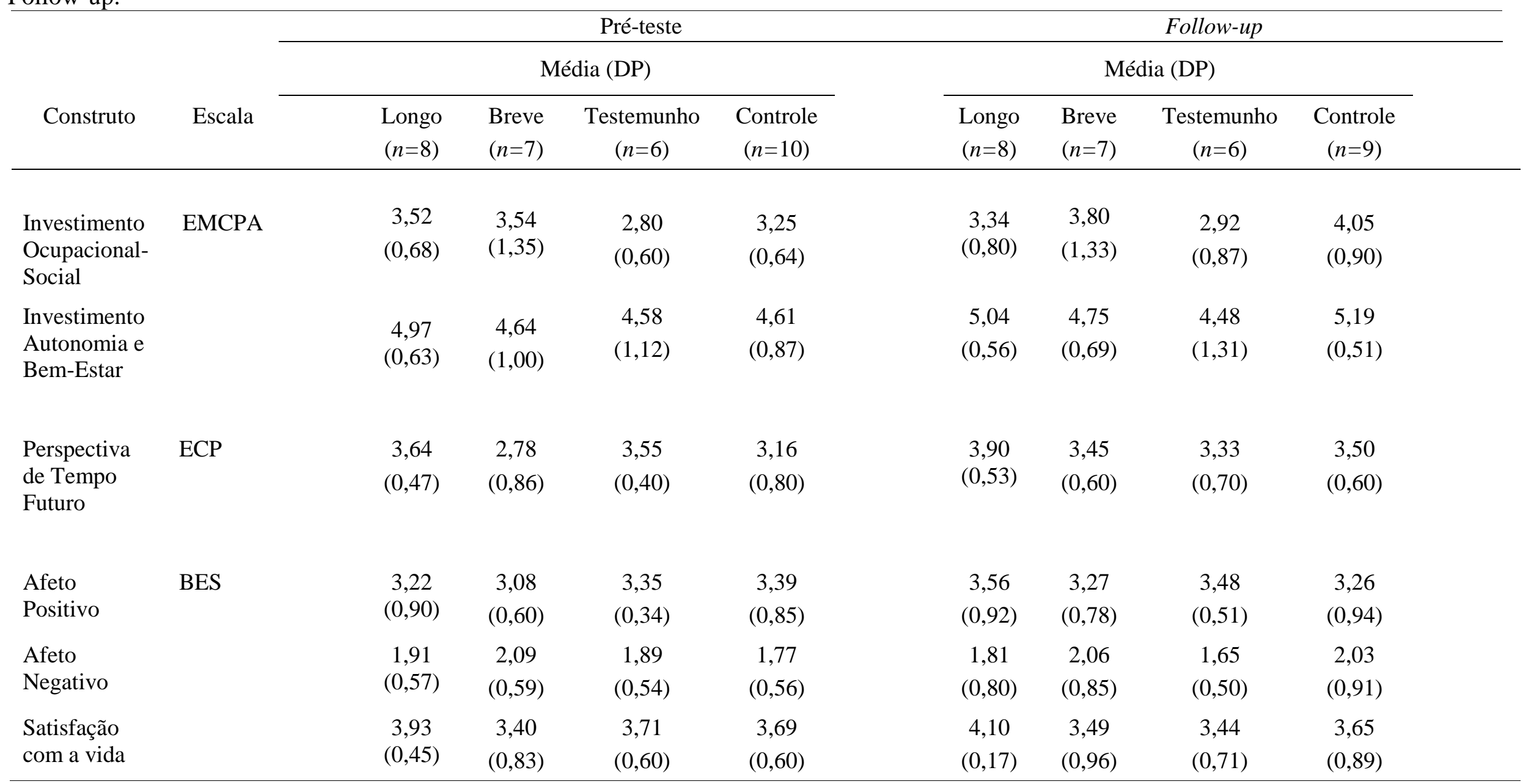


Embora não acentuadas, notam-se diferenças intragrupos e entre grupos nas médias dos escores dos participantes no follow-up quando comparadas às médias do pré-teste. $\mathrm{Na}$ comparação intragrupos, os trabalhadores que participaram do programa longo apresentaram, nos resultados da avaliação de follow-up, maiores médias no fator investimento em autonomia e bem-estar $(\mathrm{M}=5,04 ; \mathrm{DP}=0,56)$, perspectiva de tempo futuro, afeto positivo e satisfação com a vida, com diminuição da média em afeto negativo $(\mathrm{M}=1,81 ; \mathrm{DP}=0,80)$.

Participantes do programa breve apresentaram ocorrência de aumento nas médias dos escores, no follow-up, em todos os fatores (ocupacional-social, autonomia e bem-estar, perspectiva de tempo futuro, afeto positivo e satisfação com a vida), sendo a maior média em autonomia e bem-estar $(\mathrm{M}=4,75 ; \mathrm{DP}=0,69)$, com diminuição do afeto negativo $(\mathrm{M}=$ 2,06; $\mathrm{DP}=0,85)$. $\mathrm{O}$ aumento nas médias dos escores para os participantes do grupo testemunho, no follow-up, ocorreu apenas em afeto positivo $(\mathrm{M}=3,48$; $\mathrm{DP}=0,51) \mathrm{e}$ investimento ocupacional-social, com diminuição do afeto negativo $(\mathrm{M}=1,65 ; \mathrm{DP}=0,50)$.

A amostra do grupo controle apresentou aumento nas médias dos escores em investimento ocupacional-social, perspectiva de tempo futuro, autonomia e bem-estar $(\mathrm{M}=$ $5,19 ; \mathrm{DP}=0,51)$ e afeto negativo $(\mathrm{M}=2,03 ; \mathrm{DP}=0,91)$, com diminuição das médias no afeto positivo $(M=3.26 ; \mathrm{DP}=0,94)$ e satisfação com a vida $(\mathrm{M}=3,65 ; \mathrm{DP}=0,89)$. As diferenças das médias entre os grupos quanto aos resultados das variáveis dependentes deste estudo, no pré-teste e follow-up, são ilustradas nos gráficos apresentados na Figura 3. 


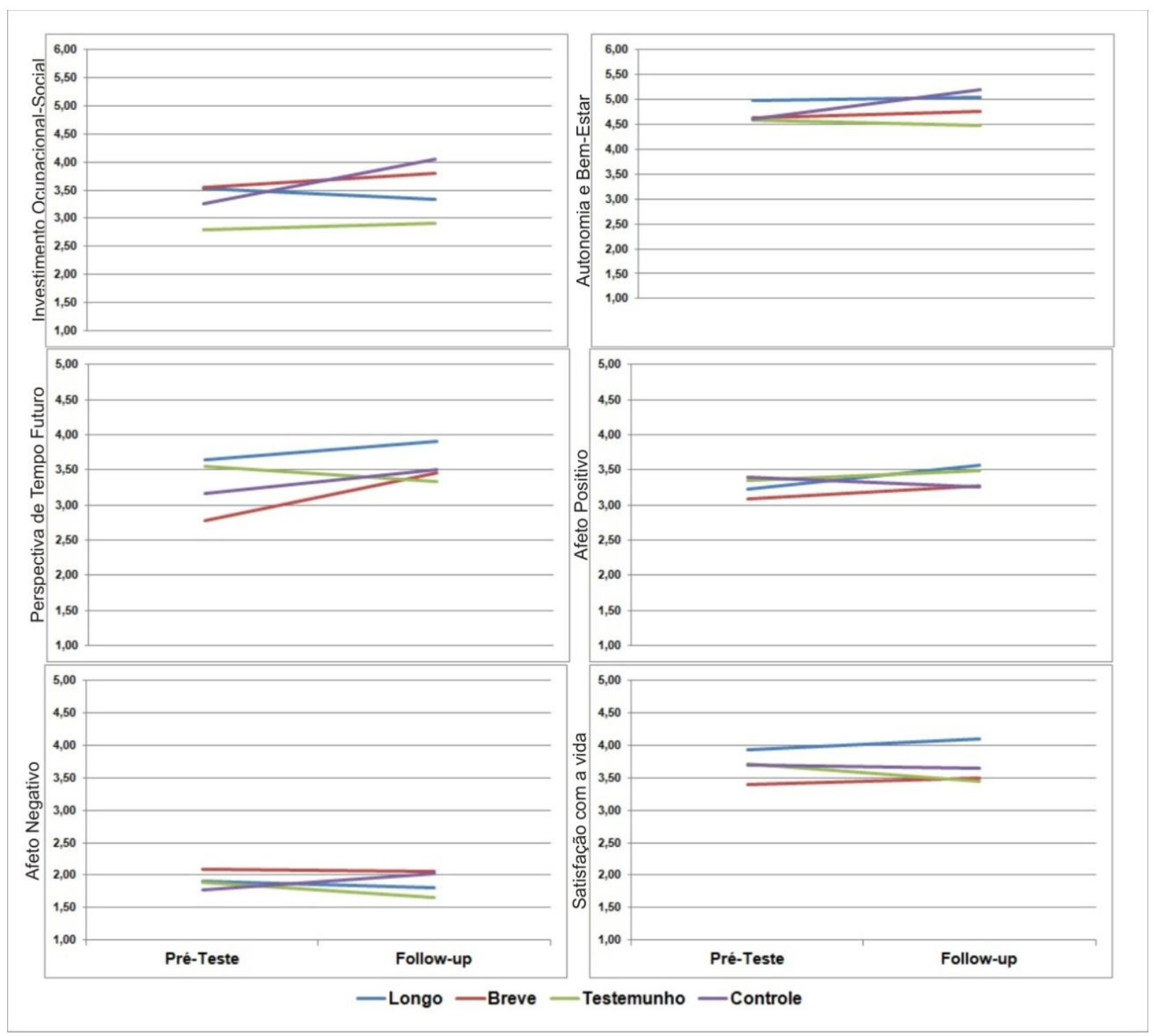

Figura 3. Média dos fatores que compõem as variáveis dependentes deste estudo, em cada condição experimental, nas avaliações de pré-teste e follow-up.

De acordo com a Figura 3, resultados da variável dependente "mudanças em comportamentos de planejamento para aposentadoria", no fator investimento ocupacionalsocial, mostram que ao comparar as quatro condições experimentais, por ordem, os aumentos nessa variável foram mais acentuados no grupo controle, intervenção breve e intervenção testemunho e leve decréscimo na intervenção longa. No que se refere ao fator investimento em autonomia e bem-estar, comparando-se os resultados das quatro condições experimentais, o grupo controle teve aumento mais evidente. Ocorreu ainda um 
leve aumento na intervenção longa e na intervenção breve e discreta diminuição na intervenção testemunho.

Dados sobre a variável dependente "perspectiva de tempo futuro relativo à aposentadoria" indicam resultados contraditórios ao comparar as quatro condições experimentais. A intervenção longa e breve tiveram resultados melhores, mas a intervenção breve teve média mais acentuada do que a intervenção longa. A intervenção testemunho teve o pior resultado nesta variável, enquanto o grupo controle mostrou bons resultados. Em suma, os dados são inconclusivos nesta variável.

Quanto aos dados sobre a variável dependente "bem-estar subjetivo" no que se refere aos fatores afeto positivo e afeto negativo, comparando-se os resultados das quatro condições experimentais, os dados das três intervenções geraram resultados melhores nesses fatores do que o grupo controle. No entanto, o dado não é robusto para afirmar a superioridade da intervenção longa sobre as outras modalidades. Quanto ao fator satisfação com a vida, os resultados das médias são maiores para a intervenção longa e intervenção breve quando comparados às outras condições experimentais. Além disso, ocorreu um decréscimo para a intervenção testemunho e condição controle.

Análises não paramétricas foram aplicadas visto que os dados da amostra são assimétricos e a quantidade de participantes é pequena. Para testar as hipóteses H1, H2 e H3, utilizou-se o teste Kruskal-Wallis, na comparação entre grupos, como ilustrados na Tabela 6. 
Tabela 6. Valores de Significância Entre Grupos para as Variáveis Dependentes, conforme Condição Experimental, do Pré-Teste e Follow-up.

\begin{tabular}{|c|c|c|c|c|c|c|}
\hline \multirow{2}{*}{ Fatores } & \multicolumn{3}{|c|}{ Pré-teste } & \multicolumn{3}{|c|}{ Follow up } \\
\hline & Qui $^{2}$ & $\mathrm{gl}$ & p-valor & Qui $^{2}$ & $\mathrm{gl}$ & p-valor \\
\hline Ocupacional-Social & 3,57 & 3 & 0,312 & 4,92 & 3 & 0,177 \\
\hline Autonomia e Bem-Estar & 0,70 & 3 & 0,874 & 1,93 & 3 & 0,588 \\
\hline $\begin{array}{l}\text { Perspectiva de Tempo Futuro } \\
\text { relativo à Aposentadoria }\end{array}$ & 5,31 & 3 & 0,150 & 3,19 & 3 & 0,363 \\
\hline Afeto Positivo & 1,85 & 3 & 0,603 & 0,87 & 3 & 0,834 \\
\hline Afeto Negativo & 1,28 & 3 & 0,733 & 0,51 & 3 & 0,916 \\
\hline Satisfação com a Vida & 2,17 & 3 & 0,538 & 3,03 & 3 & 0,387 \\
\hline
\end{tabular}

Nota: Qui² - Teste Kruskal Wallis

Os dados da Tabela 6 apontam que não existem diferenças estatisticamente significativas $(\mathrm{p}<0,05)$, entre os grupos, no que se refere aos fatores que compõem às variáveis dependentes: bem-estar subjetivo, perspectiva de tempo futuro relativo à aposentadoria e mudanças em comportamentos de planejamento para aposentadoria.

Para verificar as diferenças intragrupos utilizou-se o teste Wilcoxon como apresentados na Tabela 7. 
Tabela 7. Valores de Significância Intragrupos para as Variáveis Dependentes, conforme Condição Experimental, comparando Resultados do Pré-Teste e Follow-up.

\begin{tabular}{|c|c|c|c|c|c|c|c|c|}
\hline & & ngo & $\mathrm{Br}$ & eve & Teste & munho & $\mathrm{Co}$ & atrole \\
\hline & $\mathrm{Z}$ & p-valor & $\mathrm{Z}$ & $\begin{array}{c}\mathrm{p}- \\
\text { valor }\end{array}$ & $\mathrm{Z}$ & $\begin{array}{c}\text { p- } \\
\text { valor }\end{array}$ & $\mathrm{Z}$ & p-valor \\
\hline Ocupacional-Social & 1,781 & 0,075 & 1,183 & 0,237 & 0,315 & 0,752 & 1,965 & 0,049 \\
\hline Autonomia e Bem estar & 0,946 & 0,344 & 0,508 & 0,611 & 0,526 & 0,599 & 1,682 & 0,092 \\
\hline $\begin{array}{l}\text { Perspectiva de Tempo } \\
\text { Futuro relativo à } \\
\text { Aposentadoria }\end{array}$ & 1,219 & 0,223 & 1,511 & 0,131 & 1,054 & 0,292 & 0,135 & 0,892 \\
\hline Afeto Positivo & 1,014 & 0,310 & 1,101 & 0,271 & 0,316 & 0,752 & 1,260 & 0,208 \\
\hline Afeto negativo & 0,135 & 0,893 & 0,105 & 0,917 & 1,051 & 0,293 & 1,540 & 0,123 \\
\hline Satisfação com a Vida & 0,946 & 0,344 & 0,681 & 0,496 & 1,153 & 0,249 & 0,491 & 0,624 \\
\hline
\end{tabular}

Nota: $\mathrm{z}$ - Test dos Ranks de Wilcoxon

As diferenças intragrupos de cada condição experimental revelam que houve uma diferença significativa $(\mathrm{p}<0,05)$ na amostra do grupo controle quanto ao fator investimento ocupacional-social. As atividades que compõem esse fator estão associadas à participação em grupos na comunidade, investir em projetos que podem ser executados a partir da aposentadoria, fazer cursos para aperfeiçoamento em outra área com objetivo de uma segunda carreira, práticas de voluntariado espirituais ou religiosas, investir em hobby e no cultivo de amizades. Não houve diferenças estatisticamente significativas intraparticipantes nos programas de formato longo, breve e testemunho.

Em vista dos resultados positivos alcançados pelos participantes do grupo controle, análises de seus relatos, obtidos durante as entrevistas de follow-up, foram realizadas. Dentre os nove participantes do grupo controle, apenas um integrante não foi entrevistado no follow-up, pois estava aposentado e morando em outra cidade. As análises dos relatos verbais produziram quatro categorias (saúde, finanças, ocupação e social) acerca de mudança ou manutenção de comportamentos em planejamento para aposentadoria. A 
Tabela 8 apresenta a definição das categorias, frequências e algumas falas dos participantes.

Tabela 8. Categorias, Frequência (F) e Relatos dos Participantes do Grupo Controle.

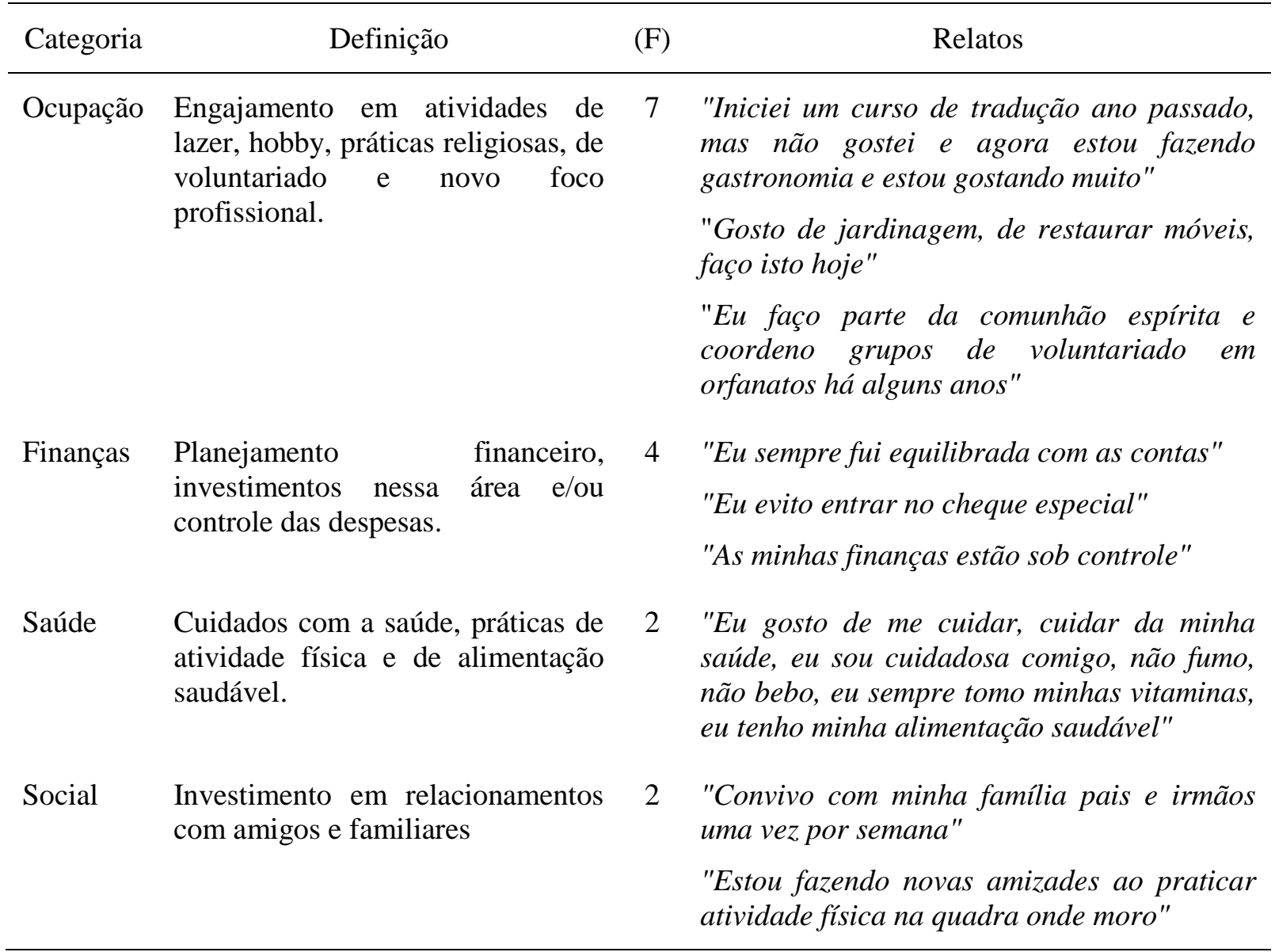

Nota-se que a maioria dos participantes da condição controle declarou investir em comportamentos preditores de uma boa aposentadoria associados às atividades de ocupação produtiva e de lazer $(\mathrm{F}=7)$, seguido, em menor frequência, por gerenciamento das finanças $(\mathrm{F}=4)$, práticas de saúde $(\mathrm{F}=2)$ e engajamento social $(\mathrm{F}=2)$. De acordo com resultados das frequências e relatos, percebe-se que alguns dos participantes do grupo controle estão engajados em uma ou mais mudanças de comportamentos nessas categorias e que alguns desses comportamentos tem sido realizados antes da participação neste estudo. 


\section{Dados de Validade Social}

Os resultados do Questionário de Satisfação do Cliente foram utilizados para investigar a validade social das intervenções. Nesta seção, inicialmente, serão apresentados os resultados das cinco questões fechadas e em seguida serão descritos os dados das três questões abertas desse questionário.

A Tabela 9 apresenta resultados das frequências e percentuais de respostas dos participantes nos programas (longo, breve e testemunho) às perguntas fechadas. Foram excluídos dessa tabela itens que os respondentes não marcaram como: regular; ruim $\left(1^{\mathrm{a}}\right.$ pergunta) nenhum dos meus interesses foi atendido ( $2^{\mathrm{a}}$ pergunta), não definitivamente; não eu penso que não ( $3^{\mathrm{a}}$ pergunta), um pouco insatisfeito ( $4^{\mathrm{a}}$ pergunta), não praticamente não ajudou; não ajudou em nada ( $5^{\text {a }}$ pergunta). As respostas dos participantes mostram elevada relevância quanto aos objetivos, aceitabilidade dos procedimentos e importância social dos efeitos das três intervenções, a julgar pelas respostas aos itens da escala que indicam conotação mais positiva do que negativa.

De acordo com os resultados da Tabela 9, a intervenção testemunho foi a que teve um percentual mais alto sobre o critério qualidade do programa. Todos os participantes desse programa $(\mathrm{F}=6)$ declaram essa intervenção como excelente. Também avaliados pela maioria dos seus participantes com qualidade excelente, o programa longo teve $75 \%$ de respostas $(\mathrm{F}=6)$, seguido do programa breve com $57 \%(\mathrm{~F}=4)$.

Respostas à segunda pergunta do questionário "Em que proporção o programa atendeu suas necessidades?" ficaram acima da média para o programa breve (57\%) no item "A maioria dos meus interesses foi atendida". O programa longo e testemunho tiveram resultados equivalentes nesta pergunta, com 50\% da amostra de cada programa demonstrando que a maioria dos seus interesses foi atendida. Apenas um participante 
(12\%) do programa longo marcou a resposta "um pouco dos meus interesses foram atendidos".

Tabela 9. Frequência (F) e Percentual (\%) de Respostas ao Questionário de Satisfação.

\begin{tabular}{|c|c|c|c|c|c|c|c|}
\hline Questão & Resposta & & & Tipo de & ogram & $\mathrm{N}=21)$ & \\
\hline \multirow{3}{*}{$\begin{array}{l}\text { 1. Como você } \\
\text { avalia a qualidade } \\
\text { do programa que } \\
\text { recebeu? }\end{array}$} & & $\begin{array}{c}\text { Longo } \\
\mathrm{N}=8 \\
\text { (F) }\end{array}$ & $\%$ & $\begin{array}{c}\text { Breve } \\
\mathrm{N}=7 \\
\text { (F) }\end{array}$ & $\%$ & $\begin{array}{l}\text { Testemunho } \\
\mathrm{N}=6 \\
\text { (F) }\end{array}$ & $\%$ \\
\hline & Boa & 2 & $25 \%$ & 3 & $43 \%$ & & \\
\hline & Excelente & 6 & $75 \%$ & 4 & $57 \%$ & 6 & $100 \%$ \\
\hline \multirow{3}{*}{$\begin{array}{l}\text { 2. Em que } \\
\text { proporção o } \\
\text { programa atendeu } \\
\text { suas necessidades }\end{array}$} & $\begin{array}{l}\text { Um pouco dos } \\
\text { meus interesses } \\
\text { foram atendidos }\end{array}$ & 1 & $12 \%$ & & & 2 & $33 \%$ \\
\hline & $\begin{array}{l}\text { A maioria dos } \\
\text { meus interesses } \\
\text { foi atendida }\end{array}$ & 4 & $50 \%$ & 4 & $57 \%$ & 3 & $50 \%$ \\
\hline & $\begin{array}{l}\text { Todos os meus } \\
\text { interesses foram } \\
\text { atendidos }\end{array}$ & 3 & $38 \%$ & 3 & $43 \%$ & 1 & $17 \%$ \\
\hline \multirow{2}{*}{$\begin{array}{l}\text { 3. Se um familiar } \\
\text { ou amigo seu } \\
\text { necessitar de ajuda } \\
\text { similar você } \\
\text { recomendaria o } \\
\text { programa a ela/ela? }\end{array}$} & $\begin{array}{c}\text { Sim, eu acho } \\
\text { que sim }\end{array}$ & 1 & $12 \%$ & & & 2 & $33 \%$ \\
\hline & $\begin{array}{c}\text { Sim, } \\
\text { definitivamente }\end{array}$ & 7 & $88 \%$ & 7 & $100 \%$ & 4 & $67 \%$ \\
\hline \multirow{3}{*}{$\begin{array}{l}\text { 4. Quão satisfeito } \\
\text { você está com a } \\
\text { quantidade de } \\
\text { horas do programa } \\
\text { que recebeu? }\end{array}$} & $\begin{array}{c}\text { Muito } \\
\text { insatisfeito }\end{array}$ & & & & & 1 & $16 \%$ \\
\hline & $\begin{array}{l}\text { Um pouco } \\
\text { satisfeito }\end{array}$ & 4 & $50 \%$ & 1 & $14 \%$ & 1 & $16 \%$ \\
\hline & Muito satisfeito & 4 & $50 \%$ & 6 & $86 \%$ & 4 & $68 \%$ \\
\hline \multirow{2}{*}{$\begin{array}{l}\text { 5. Sua participação } \\
\text { no programa te } \\
\text { ajudou a lidar } \\
\text { melhor com o } \\
\text { planejamento da } \\
\text { sua aposentadoria? }\end{array}$} & $\begin{array}{l}\text { Sim, ajudou um } \\
\text { pouco. }\end{array}$ & 1 & $12 \%$ & 1 & $14 \%$ & 3 & $50 \%$ \\
\hline & $\begin{array}{l}\text { Sim, ajudou } \\
\text { muito. }\end{array}$ & 7 & $88 \%$ & 6 & $86 \%$ & 3 & $50 \%$ \\
\hline
\end{tabular}

Quando questionados se indicariam à intervenção a um familiar ou amigo, todos participantes do programa breve $(\mathrm{F}=7)$ responderam "sim, definitivamente". Resposta 
similar a essa pergunta foi emitida pela maioria dos participantes do programa longo $(\mathrm{F}=$ 7) e programa testemunho $(\mathrm{F}=4)$. Quanto à quarta pergunta "Quão satisfeito você está com a quantidade de horas do programa", maior parte dos participantes do programa breve $(\mathrm{F}=6)$ ficou satisfeita com a quantidade de horas oferecida por esse programa. No programa testemunho, embora a maioria tenha declarado estar muito satisfeito com a quantidade de horas do programa $(\mathrm{F}=4)$, um participante disse estar um pouco satisfeito e outro declarou estar muito insatisfeito. Ademais, 50\% dos participantes do programa longo relataram estar um pouco satisfeito e $50 \%$ disseram estar muito satisfeito.

Ainda com relação aos resultados, a maioria dos participantes do programa longo $(F=7)$ e breve $(F=6)$ relatou que sua participação nessa ação os ajudou a lidar melhor com o planejamento da aposentadoria. Os participantes da intervenção testemunho se dividiram quanto às respostas a essa pergunta, a julgar que 50\% declararam "sim, ajudou um роисо" е 50\% respondeu "sim, ajudou muito". Mas, não foram atribuídas respostas de "não ajuda" para esta pergunta em nenhum dos programas.

As Tabelas 10 e 11 apresentam resultados das análises de conteúdo sobre duas perguntas abertas do Questionário de Satisfação ao Cliente referente à aceitabilidade dos procedimentos das intervenções. Os participantes dos três programas (longo, breve e testemunho) foram questionados sobre (1) o que mais gostaram nos programas (Tabela 10) e (2) o que menos gostaram (Tabela 11). 
Tabela 10. Frequência (F) e Categorias das Perguntas "O Que Você Mais Gostou no Programa?"

\begin{tabular}{|c|c|c|c|}
\hline Programa & Mais Gostou & $(\mathrm{F})$ & Relato dos Participantes \\
\hline \multirow[t]{4}{*}{ Longo } & $\begin{array}{c}\text { Troca de } \\
\text { experiências }\end{array}$ & 6 & $\begin{array}{l}\text { "Interação com os colegas, a troca e } \\
\text { compartilhamento das experiências e } \\
\text { preocupações relacionadas ao tema." }\end{array}$ \\
\hline & Palestras & 5 & "Palestras e temas abordados" \\
\hline & Procedimentos & 2 & $\begin{array}{l}\text { "Formato do curso, que deu oportunidade de } \\
\text { trocar experiência com os colegas... Gostei dos } \\
\text { trabalhos com a equipe." }\end{array}$ \\
\hline & $\begin{array}{c}\text { Troca de } \\
\text { experiências }\end{array}$ & 9 & $\begin{array}{l}\text { "Troca entre as pessoas e de escutar } \\
\text { depoimentos acerca do modo de pensar dos } \\
\text { demais participantes." }\end{array}$ \\
\hline \multirow[t]{3}{*}{ Breve } & Tudo & 2 & "Gostei de tudo" \\
\hline & $\begin{array}{l}\text { Manejo do } \\
\text { tempo }\end{array}$ & 1 & "Eficácia de tempo da metodologia aplicada" \\
\hline & $\begin{array}{l}\text { Perspectiva } \\
\text { positiva }\end{array}$ & 1 & $\begin{array}{l}\text { "Ver a aposentadoria sob uma perspectiva } \\
\text { positiva, mas com preocupação com o } \\
\text { planejamento" }\end{array}$ \\
\hline \multirow[t]{2}{*}{ Testemunho } & $\begin{array}{l}\text { Troca de } \\
\text { experiências }\end{array}$ & 7 & $\begin{array}{l}\text { "Relatos de experiências, trocas, interação e } \\
\text { vivência dos participantes" }\end{array}$ \\
\hline & Depoimento & 1 & "Ouvir o depoimento da convidada" \\
\hline
\end{tabular}

Os dados da Tabela 10 revelam que no programa longo a categoria "troca de experiência" referente à interação, compartilhamento de informações, ideias e experiências sobre o planejamento da aposentadoria foi relatada com maior frequência pelos participantes $(F=6)$, seguido da categoria "palestras" $(F=5)$. O conteúdo das palestras oferecidas pelo programa longo envolviam temas como: preditores para uma aposentadoria e envelhecimento bem-sucedido, legislação, finanças, saúde física e psicológica, relacionamentos social e familiar, empreendedorismo, espiritualidade e projeto de vida pós-carreira. A categoria troca de experiências foi também a mais relatada pelos participantes do programa breve $(\mathrm{F}=9)$ e testemunho $(\mathrm{F}=7)$. 
Tabela 11. Frequência (F) e Categorias da Pergunta "O Que Você Menos Gostou no Programa?"

\begin{tabular}{|c|c|c|c|}
\hline Programa & Menos Gostou & $(\mathrm{F})$ & Relato dos Participantes \\
\hline \multirow[t]{3}{*}{ Longo } & Carga horária & 4 & $\begin{array}{l}\text { "O tempo de cada encontro foi curto e muitas } \\
\text { vezes não permitiu abordar melhor os temas" }\end{array}$ \\
\hline & Palestras & 2 & "Palestras sobre economia e nutrição" \\
\hline & $\begin{array}{l}\text { Nenhuma } \\
\text { Insatisfação }\end{array}$ & 2 & $\begin{array}{l}\text { "Não teve pontos negativos. Tudo que foi dado } \\
\text { no programa foi importante" }\end{array}$ \\
\hline \multirow[t]{2}{*}{ Breve } & $\begin{array}{l}\text { Nenhuma } \\
\text { insatisfação }\end{array}$ & 5 & "Não teve nada que eu não gostasse" \\
\hline & Carga horária & 1 & $\begin{array}{l}\text { "Tempo curto para a formação de vínculos e } \\
\text { para maior entrosamento entre facilitadores e } \\
\text { participantes" }\end{array}$ \\
\hline \multirow[t]{3}{*}{ Testemunho } & $\begin{array}{l}\text { Nenhuma } \\
\text { insatisfação }\end{array}$ & 3 & "Não teve itens dos quais não gostei" \\
\hline & Carga horária & 1 & $\begin{array}{l}\text { "Do tempo de duração, acho que eu ouviria e } \\
\text { falaria por mais } 10 \text { horas seguidas" }\end{array}$ \\
\hline & Não respondeu & 1 & \\
\hline
\end{tabular}

Na Tabela 11, nota-se que participantes do programa longo emitiram mais relatos negativos com relação à categoria "carga horária" $(\mathrm{F}=4)$. Esta categoria refere-se à insatisfação com relação ao tempo de duração (3 horas para cada encontro) do programa longo. Alguns participantes gostariam de mais tempo para aprofundar a discussão no tema de cada encontro. Ainda para dois participantes deste programa, as palestras sobre finanças e nutrição foram as que eles menos gostaram. Os principais motivos foram, respectivamente, dificuldade em acompanhar o conteúdo sobre tipos de investimentos financeiros e previdência complementar e metodologia adotada.

Quanto ao programa breve, a maioria dos participantes disse não ter nenhuma insatisfação a relatar sobre este programa $(F=5)$, com apenas um relato de insatisfação com relação à carga horária reduzida (3 horas de duração no programa breve). Equivalente aos resultados do programa breve, no programa testemunho percebe-se uma maior 
frequência de relatos $(F=3)$ na categoria "nenhuma insatisfação" e um relato negativo com relação à carga horária reduzida (3 horas de duração no programa testemunho).

A última pergunta do questionário de satisfação do cliente refere-se à solicitação para aprimoramento da qualidade dos programas, especificamente: (a) sugestões de mudanças e (b) o que manter nos programas. A Figura 4 apresenta tais resultados:

\begin{tabular}{|c|c|c|c|c|}
\hline Programa & Mudar & $(\mathrm{F})$ & Manter & $(\mathbf{F})$ \\
\hline Longo & $\begin{array}{l}\text { "Não responderam" } \\
\text { "Aumentar a carga horária do } \\
\text { programa" } \\
\text { "Aumentar o tempo das palestras, } \\
\text { possibilitando o debate ao final" } \\
\text { "Inserir atividades ao ar livre" } \\
\text { "Incluir pessoas mais jovens no } \\
\text { programa" }\end{array}$ & $\begin{array}{l}2 \\
2 \\
2 \\
1 \\
1\end{array}$ & $\begin{array}{l}\text { "Não responderam" } \\
\text { "Manter as dinâmicas iniciais e } \\
\text { demais técnicas utilizadas" } \\
\text { "Manter os temas das palestras" } \\
\text { "Manter os debates em grupo sobre } \\
\text { os temas apresentados" }\end{array}$ & $\begin{array}{l}2 \\
2\end{array}$ \\
\hline Breve & $\begin{array}{l}\text { "Não responderam" } \\
\text { "Realizar mais um ou dois } \\
\text { encontros" } \\
\text { "Incluir informação sobre impacto } \\
\text { da aposentadoria na redução da } \\
\text { remuneração" }\end{array}$ & $\begin{array}{l}4 \\
2\end{array}$ & $\begin{array}{l}\text { "Não responderam" } \\
\text { "Manter como se encontra" } \\
\text { "Manter o ambiente acolhedor e } \\
\text { escuta empática por parte dos } \\
\text { facilitadores" } \\
\text { "Manter a dinâmica de discussão e } \\
\text { metodologia" } \\
\text { "Manter o tempo da intervenção" }\end{array}$ & $\begin{array}{l}2 \\
2\end{array}$ \\
\hline Testemunho & $\begin{array}{l}\text { "Não mudar nada" } \\
\text { "Aumentar a divulgação desta } \\
\text { ação" } \\
\text { "Mais tempo de duração" } \\
\text { "Disponibilizar/compartilhar } \\
\text { contatos dos participantes" } \\
\text { "Sem sugestões" }\end{array}$ & $\begin{array}{l}2 \\
1 \\
1 \\
1 \\
1\end{array}$ & $\begin{array}{l}\text { "Sem sugestões" } \\
\text { "Está ótimo assim" } \\
\text { "Manter os temas dos encontros" } \\
\text { "Manter as dinâmicas de } \\
\text { interação" }\end{array}$ & $\begin{array}{l}2 \\
2\end{array}$ \\
\hline
\end{tabular}

Figura 4. Relatos dos participantes e frequência de respostas (F) para aprimoramento da qualidade dos programas

De acordo com a Figura 4, sugestões de mudanças para o programa longo estão associadas ao aumento do tempo para cada encontro $(\mathrm{F}=2)$ a fim de possibilitar o debate ao final das palestras $(\mathrm{F}=2)$. Outra sugestão foi inserir atividades ao ar livre $(\mathrm{F}=2)$. Essas 
atividades foram recomendadas nos encontros que envolvem atenção à saúde e elaboração de projeto de vida pós-carreira. Tais práticas foram relacionadas à realização de atividade física em parques, com acompanhamento de um educador físico, e visitas às organizações que proporcionam atividades de voluntariado. Os participantes desse programa sugeriram ainda a inclusão de pessoas mais jovens, que não estivessem próximas à aposentadoria (F =1). Para os participantes, quanto mais cedo os trabalhadores se prepararem para essa fase da vida, melhor e mais adequado será o planejamento.

No programa breve, a maioria dos servidores não fez sugestão de mudanças $(\mathrm{F}=$ 4). Entretanto, houve a necessidade de seguimento da ação quando participantes sugeriram a inclusão de mais um ou dois encontros $(\mathrm{F}=2)$ e de abordar perdas salariais decorrentes da aposentadoria $(F=1)$. Quanto ao que mudar no programa testemunho, ocorreram relatos de aumentar a divulgação da ação, tempo da intervenção, compartilhar contatos dos participantes $(\mathrm{F}=3)$, relatos de não mudança e sem sugestão $(\mathrm{F}=3)$.

Considerando a categoria sobre o que manter, no programa longo, os participantes demonstraram boa aceitabilidade dos procedimentos como, por exemplo, as estratégias dialogadas, dinâmicas vivenciais, informativas e temas abordados $(F=4)$. No programa breve e testemunho as sugestões são similares sobre o que manter em cada intervenção. Foi sugerido manter todos os procedimentos realizados nas intervenções $(F=4)$ incluindo as estratégias dialogadas e de interação e o conteúdo $(F=4)$. Além disso, a postura empática e acolhedora dos facilitadores é algo que deve ser mantido $(\mathrm{F}=1)$, assim como o tempo de duração da intervenção $(\mathrm{F}=1)$, segundo participantes do programa breve.

\section{Discussão}

Este estudo teve como objetivo principal avaliar a eficácia de três programas (longo, breve e testemunho) de preparação para aposentadoria e comparar resultados entre 
essas modalidades e um grupo controle, antes e seis meses após suas realizações. Buscouse compreender em que extensão três diferentes programas de preparação para a aposentadoria promovem mudanças em comportamento de planejamento para aposentadoria, maior bem-estar subjetivo e perspectiva de tempo futuro relativo à aposentadoria. Para responder essas questões, três hipóteses foram elaboradas.

Com base nas análises não paramétricas, não foi possível corroborar a $\mathrm{H} 1$ a qual afirmava que participantes do programa longo apresentariam maior bem-estar subjetivo, melhor perspectiva de tempo futuro relativo à aposentadoria e mudanças em planejamento para aposentadoria, em comparação aos participantes do programa breve, testemunho e grupo controle. De modo similar, não foi confirmada a $\mathrm{H} 2$ a qual previa que os participantes do programa breve e testemunho, por razões de similaridades em duração e estratégias, apresentariam resultados equivalentes nessas variáveis dependentes. Também não se observou efeito do programa breve e testemunho em melhores resultados nessas variáveis dependentes em comparação ao grupo controle. Logo, a H3 não foi corroborada.

Por outro lado, resultados da estatística descritiva das análises entre grupos revelam achados favoráveis, no follow-up, quanto à variável bem-estar subjetivo para as três modalidades de intervenção em comparação ao grupo controle. Estes são indícios sugestivos de que os três programas tiveram efeitos positivos para promover maior bemestar subjetivo do que o grupo controle. Estima-se que se a amostra selecionada fosse maior, dados significativos poderiam ter sido encontrados. No entanto, embora não sejam estatisticamente significativos, os bons resultados em afeto positivo e a diminuição do afeto negativo pelos participantes dos três programas revelam a vivência de emoções prazerosas e sentimentos de felicidade com a vida. A satisfação com a vida também foi um fator preponderante para os participantes do programa longo e breve. Ao associar o modelo perspectiva dinâmica de recursos (Wang et al, 2011) ao bem-estar subjetivo, pode- 
se inferir que o bem-estar subjetivo atua como um recurso emocional que ajuda os participantes a vivenciarem a aposentadoria como um marco importante de realização e com maior sentimento de bem-estar, como referenciado em estudos de Santos (1990) e Leandro-França (2014).

Em contrapartida, os participantes da condição controle tiveram diminuição do afeto positivo e em satisfação com a vida com aumento do afeto negativo, ao término do estudo, demonstrando a vivência de emoções desprazerosas. Estima-se que a redução do bem-estar subjetivo para essa população é um fator de risco à vivência da aposentadoria como crise (Santos,1990; Leandro-França, 2014). Todavia, para se confirmar tais hipóteses seria necessário um acompanhamento desses participantes no período de suas aposentadorias.

Análises intragrupos revelaram que mudanças em comportamentos de planejamento para aposentadoria para os participantes do programa longo ocorreram no fator investimento em autonomia e bem-estar. Essas mudanças estão associadas à realização de atividade física regular; tempo para investir na vida familiar; investimentos financeiros para o futuro; práticas de atividades de lazer; dedicar-se à relação com o parceiro; ter uma dieta saudável e fazer exames médicos para check-up. A literatura corrobora esses efeitos, ao destacar que os programas longos promovem o fortalecimento da rede social e familiar, autonomia financeira, cuidados com a saúde, engajamento em atividade física, valorização do lazer e mudanças nos hábitos alimentares (Glamser \& DeJong, 1975; Murta et al., 2008; Murta et al., 2014; Pereira \& Guedes, 2012; Soares et al., 2007; Zanelli, 2000).

Ainda com relação às análises intragrupos, as mudanças em comportamento de planejamento para aposentadoria provenientes do programa breve, ocorreram nos dois fatores dessa variável: investimento ocupacional-social e em autonomia e bem-estar. Esses 
achados estão em consonância com as investigações já realizadas na literatura com o uso dessa modalidade de intervenção e seu potencial em promover mudanças no convívio social, familiar e conjugal, nos cuidados com a saúde, no estilo de vida e ajustamento financeiro (França 2012; França et al., 2013; Leandro-França et al., 2014). Embora com escores não tão acentuados, participantes do programa breve foram os que apresentaram mudanças em todos os fatores que compõem as variáveis dependentes deste estudo.

Na comparação intragrupos, as mudanças resultantes do programa testemunho não foram tão acentuadas quanto às observadas pelo programa longo e breve. Contudo, nota-se que essa modalidade foi útil aos participantes desta intervenção pelo potencial em promover mudanças em investimento ocupacional-social e afeto positivo. Ademais, esses resultados ultrapassam expectativas com relação ao uso dessa estratégia de intervenção ao comparar dados desse estudo e os achados na área da saúde, haja vista que os resultados dessa intervenção em estudos da área de saúde produziram efeitos apenas em mudanças de crenças (Niederdeppe et al., 2011) e em percepção de risco como, por exemplo, na prevenção ao câncer de pele (Janssen et al., 2012; Lemal \& van den Bulck, 2010). Logo, por se tratar de uma intervenção testada pela primeira vez na população de trabalhadores em preparação para aposentadoria, ainda que frequentemente conduzida nas organizações, e não ter apresentado danos iatrogênicos aos participantes, consideram-se esses achados promissores.

Em seguimento às analises intragrupos, com exceção da intervenção testemunho, os programas longo e breve promoveram perspectiva de tempo futuro relativo à aposentadoria. Este resultado sugere que seis meses após a realização das intervenções, os participantes demonstraram ter clareza de metas para a aposentadoria ou conhecimento sobre o que fazer nessa fase da vida. De acordo com o modelo teórico PTF (Lens, Paixão, Herrera, \& Grobler, 2012; Schmitt, 2010), pessoas que possuem objetivos claros para o 
futuro podem experimentar maiores níveis de satisfação pessoal e de vida. Esse dado está em consonância com os resultados de bem-estar subjetivo e satisfação com a vida apresentados neste estudo pelos participantes dos programas longo e breve. Assim, esperase que a elaboração de metas claras oriente os servidores quanto à realização de comportamentos desejados para uma aposentadoria bem-sucedida (Stawski, Hershey, \& Jacobs-Lawson, 2007).

No que se refere ao grupo controle, percebem-se mudanças não esperadas para este grupo, tendo em vista sua natureza de não intervenção. As mudanças ocorreram em fatores de investimento ocupacional-social, autonomia e bem-estar e perspectiva de tempo futuro relativo à aposentadoria, com mudança estatisticamente significativa intraparticipantes no fator investimento ocupacional-social. Entretanto, a ocorrência desses resultados pode ser explicada por meio dos dados coletados nas entrevistas com os participantes desse grupo após follow-up. Dados dessas entrevistas demonstram que o grupo controle estava altamente engajado em comportamento de planejamento para aposentadoria relacionado às atividades de ocupação, autonomia financeira, atenção à saúde, vínculos sociais e familiares, nos seis meses de follow-up e antes mesmo de participação no estudo. Estes comportamentos contemplam as características dos fatores investimento ocupacionalsocial e autonomia e bem-estar os quais os participantes demonstraram maior engajamento nas avaliações de follow-up.

Além disso, ao considerar que os participantes do grupo controle estavam próximos à aposentadoria e motivados a planejarem-se para essa fase da vida, existe a possibilidade dessas pessoas terem acessado essas informações sobre planejamento da aposentadoria em outros contextos. Questiona-se também se os participantes dessa condição se sentiram desvalorizados por não terem sido contemplados para as intervenções (Creswell, 2010; 
Nezu \& Nezu, 2008), impulsionando assim à procura desse conhecimento por outros meios.

Estima-se ainda a ocorrência de difusão ao tratamento, considerando que participantes do grupo controle e dos grupos experimentais trabalham nas mesmas instituições (Creswell, 2010; Nezu \& Nezu, 2008). Em outras palavras, os trabalhadores do grupo experimental podem ter fornecido informações e compartilhado experiências vivenciadas nos programas, com o grupo controle, e ter influenciado os resultados desse grupo. Desse modo, os resultados obtidos na avaliação de follow-up podem não refletir o que se espera para a condição não intervenção (Nezu \& Nezu, 2008).

Acrescenta-se nessa discussão, as análises quanto aos efeitos devido ao teste (Nezu \& Nezu, 2008). Os participantes do estudo podem reagir de formas diferentes do que deveriam ao saber que eles estão sendo avaliados. Isto é nomeado pela literatura como "vieses de autorrelato", ou seja, os respondentes tendem a apresentar respostas mais favoráveis antes da intervenção (Kazdin, 2010). Observa-se que isto pode ter ocorrido no pré-teste com relação às respostas dos participantes dos três programas, especialmente quanto aos resultados da EMCPA. Tal fenômeno pode explicar a razão das diferenças nos escores do follow-up dos participantes dos programas e o grupo controle, no que diz respeito ao investimento ocupacional-social, autonomia e bem-estar. A julgar pelos resultados, é provável que após participação nos programas (longo, breve e testemunho), providos de conhecimento e informações necessárias para a obtenção de uma aposentadoria bem-sucedida, integrantes desses grupos se autoavaliaram de forma mais fidedigna quanto às mudanças de comportamento necessárias no planejamento da aposentadoria em comparação as avaliações do pré-teste.

Esses aspectos são descritos na literatura (Creswell, 2010; Nezu \& Nezu, 2008) como ameaças à validade interna e externa do estudo. Portanto, mesmo com a 
randomização entre os grupos e uso de grupo controle, isso não garante que este estudo esteja livre dessas ameaças. Destaca-se ainda como possíveis ameaças à validade interna, o abandono ou perdas (attrition) dos participantes ao longo do estudo, o que ocasionou uma diminuição da amostra que já na avaliação de pré-teste mostrava-se reduzida. O pequeno tamanho da amostra reduz o poder estatístico, isto é, "a probabilidade de rejeitar a hipótese nula (que não existem diferenças) quando, de fato, a hipótese é falsa e alternativamente, detectar a diferença entre grupos quando, de fato, uma diferença verdadeira existe" (Kazdin, 2010, p. 580). Além disto, o pequeno tamanho da amostra impossibilita o uso de métodos estatísticos mais robustos e, consequentemente, afeta a obtenção de um resultado significativo. Para Dancey e Reidy (2013), "mostrar que a significância estatística depende do tamanho da amostra é importante, pois indica que a significância estatística não é igual à importância prática ou psicológica" (p. 259).

Embora considerada uma amostra pequena para uso de análises estatísticas robustas, o tamanho da amostra atende os pressupostos de uma avaliação qualitativa quanto à validade social, objetivo secundário deste estudo. Resultados de validade social das intervenções estão associados à relevância dos objetivos, aceitabilidade dos procedimentos e importância social dos efeitos das intervenções sobre a mudança de comportamento (Carter, 2010; Francisco \& Butterfoss, 2007; Lane \& BeebeFrankenberger, 2004).

De acordo com os métodos qualitativos e quantitativos que acessaram a validação social das intervenções, estas foram avaliadas pela maioria dos servidores como excelentes. Esse dado revela alta aceitabilidade e satisfação dos participantes com os procedimentos dos programas. Além disso, grande parte dos servidores afirmou que a maioria dos procedimentos deveria ser mantida como: temas das palestras, dinâmicas de interação e discussão, metodologia utilizada, ambiente acolhedor e empatia dos 
facilitadores. Estes aspectos estão relacionados aos que eles mais gostaram nos programas com destaque para a troca de experiência e interação entre as pessoas. Segundo Yalom e Leszcz (2006) o compartilhamento de informações, a coesão grupal, o pertencimento ao grupo, a identificação com os pares ou a universalidade são fatores terapêuticos que atuam como mecanismos de mudanças nas práticas psicoterapêuticas grupais. Logo, facilitadores dos programas de preparação para aposentadoria devem favorecer a ocorrência desses fatores como forma de potencializar os benefícios dessas ações.

Mesmo que a maioria dos participantes tenha declarado satisfação com a metodologia utilizada nas intervenções, os resultados da validade social forneceram informações para aprimoramento nos procedimentos dessas modalidades. Opiniões contraditórias foram observadas com relação à carga horária das intervenções. Ocorreu uma maior variabilidade de respostas quanto a essa categoria no programa longo. Este dado não era esperado tendo em vista que essa intervenção ofereceu maior quantidade de horas. Contudo, detectou-se por meio dos relatos dos servidores desse grupo a necessidade de ajustes na carga horária de cada encontro de forma a possibilitar um maior debate ao final das palestras. Ainda como orientações de mudanças no programa longo, vale ressaltar a sugestão sobre a inserção de trabalhadores mais jovens. Esta heterogeneidade entre gerações precisa ser considerada nos programas de preparação para aposentadoria, pois poderá trazer benefícios como fortalecer vínculos entre as diferentes gerações, reconstruir crenças sobre envelhecimento e, por conseguinte, diminuir o ageísmo nas organizações (França, Bendassolli, \& Menzes, 2013; Silva \& França, 2015). Aos participantes dos programas de curta duração (breve e testemunho) que demonstraram insatisfação com relação ao tempo da intervenção foi sugerido que eles participassem do programa longo, após finalização da pesquisa. 
Além da aceitabilidade dos procedimentos, foram investigados outros componentes da validade social como relevância dos objetivos e importância social dos efeitos das intervenções. Estes elementos avaliam em que proporção os participantes visualizam os programas como tendo potencial para produzir mudanças de comportamentos e resultados socialmente relevantes (Francisco \& Butterfoss, 2007; Lane \& Beebe-Frankenberger, 2004). Os dados deste estudo apontam o alcance desses efeitos, especialmente para as intervenções longa e breve, ao considerar que grande parte dos participantes relatou que a maioria de seus interesses foi atendida, que os programas os ajudaram a lidar melhor com o planejamento de suas aposentadorias e que os recomendaria a um amigo ou familiar caso eles necessitassem de ajudar similar.

Vale salientar a ocorrência de variabilidade nas respostas dos participantes do programa testemunho quanto ao auxílio dessa intervenção para o planejamento de suas aposentadorias. Percebe-se que metade da amostra desse grupo se beneficiou com a intervenção e que outros não se sentiram completamente satisfeitos com essa abordagem no que se refere ao planejamento de suas aposentadorias. Desse modo, novas pesquisas com esta modalidade de intervenção são necessárias para esclarecer esses resultados contraditórios.

Este estudo apresenta algumas limitações. Uma das limitações diz respeito ao reduzido tamanho da amostra, o que restringiu o poder estatístico e impossibilitou o uso de métodos estatísticos mais robustos para explorar a variável independente e as dependentes e realizar correlações entre elas e as variáveis demográficas como idade, gênero, escolaridade e estado civil. Ao analisar os resultados encontrados no presente estudo observa-se que embora os participantes tenham sido alocados aleatoriamente, o pequeno tamanho da amostra pode ter prejudicado a randomização e falhado em fornecer, por exemplo, amostras estratificadas por gênero, a julgar que no programa breve a amostra foi 
composta apenas por mulheres. Portanto, pode-se inferir que o pequeno tamanho da amostra limitou a validade de conclusão estatística. Esta forma de validade refere-se aos "aspectos da avaliação quantitativa que podem afetar os resultados alcançados no estudo quanto à presença e a força de relações de causa-efeito entre o tratamento e os resultados" (Nezu \& Nezu, 2008, p. 17).

Em adição às limitações, nota-se que os dados não permitem generalizar resultados à população como um todo, uma vez que a amostra utilizada é altamente qualificada com relação à escolaridade, possui homogeneidade em renda, ou seja, recebe rendimentos bem acima da média dos servidores públicos do poder executivo e contempla apenas quatro organizações públicas de um estado brasileiro. Ainda com relação à limitação à validade externa, o programa testemunho apresentou apenas o depoimento de uma trabalhadora aposentada. No entanto, a literatura aponta diferenças entre homens e as mulheres no que diz respeito ao planejamento, adaptação e satisfação na aposentadoria (Barbosa et al., 2016; Kim \& Moen, 2002; Leandro-França et al., 2014; Petkoska \& Earl, 2009). Sendo assim, tal fato diminui o poder de generalização dos resultados dessa intervenção para o sexo masculino como também para pessoas de renda inferior as investigadas neste estudo.

Destacam-se como principais contribuições deste estudo a adoção do delineamento experimental como forma de suprir a escassez, especialmente na literatura brasileira, quanto ao uso desse tipo de método para investigar a eficácia dos programas de preparação para aposentadoria. Mesmo se revelando como área em ascenção, as ações com foco no planejamento da aposentadoria são pouco avaliadas, a julgar pela escassez de publicações (Murta et al., 2014, p. 288). A eficácia de programas de planejamento para aposentadoria tem sido difícil de alcançar nessa área tendo em vista a não especificação dos métodos de amostragem, de amostras randomizadas, da ausência de medidas pré e pós-intervenção e de follow-up, de estudos piloto, da falta de grupo controle e da escassez de instrumentos 
validados a essa população (Leandro-França, Murta, Hershey, \& Barbosa, 2016; Murta et al., 2014).

Assim, dentre os cuidados realizados neste estudo quanto ao cumprimento dos critérios metodológicos e de eficácia das intervenções (Flay et al.,2005; Leandro-França et al., 2016; Murta et al, 2014), enfatiza-se a descrição detalhada dos procedimentos adotados nos programas, intervenções fundamentadas em teorias, uso de amostras randomizadas, grupo controle, múltiplas medidas, instrumentos validados, avaliações pré-teste e de follow-up e uso de métodos mistos na avaliação. A inclusão desses critérios como métodos de avaliação de eficácia dos programas de preparação para aposentadoria mostra-se importante para oferecer à sociedade práticas baseadas em evidências.

A avaliação e divulgação de resultados comparativos de três modalidades de intervenção aplicadas à população em transição para aposentadoria poderá encorajar a implementação de ações similares em organizações públicas e privadas, como previsto na legislação brasileira. Embora recentes na administração pública brasileira, avaliações de programas públicos realizadas de forma sistemática e contínua são essenciais para se alcançar resultados eficazes, possibilitar um melhor uso e controle dos recursos públicos, fornecer dados importantes para implementar políticas mais consistentes e auxiliar os gestores de programas na tomada de decisão, resultando em uma gestão pública eficiente (Costa \& Castanhar, 2003).

Ademais, a avaliação de uma intervenção (programa testemunho), já utilizada em organizações públicas brasileiras, mas ainda não testada neste público, surge como alternativa viável aos gestores e facilitadores desses programas bem como aos trabalhadores no auxílio ao planejamento dessa fase da vida. De acordo com estudo de L. França et al. (2014) apesar de serem considerados importantes pelos gestores e recomendados pela legislação brasileira, os programas de preparação para a aposentadoria 
não são práticas amplamente utilizadas nas organizações. Por este motivo, modalidades de curta duração e de baixo custo econômico, como intervenção breve e testemunho, são opções a serem consideradas como práticas de gestão de pessoas.

Ainda como contribuição deste estudo, ressalta-se a investigação de validade social desses programas e sua relevância científica, tendo em vista que dados semelhantes ainda não foram publicados na literatura sobre programas de preparação para aposentadoria. Os componentes da validação social foram originalmente desenvolvidos para investigar a aceitabilidade dos procedimentos e efeitos das intervenções comportamentais entre clientes e consumidores (Francisco \& Butterfoss, 2007). Para acessar essas informações, métodos mistos de análises, quantitativos e qualitativos, foram empregados neste estudo, seguindo recomendações de Francisco e Butterfoss (2007). Segundo esses autores, nos estudos de saúde pública e pesquisas com a participação da comunidade, basear-se somente no teste de significância estatística pode resultar perder importantes dimensões sociais como, por exemplo, o impacto da intervenção na vida dos participantes e efeitos na comunidade. Logo, a verificação da validade social dos programas realizados nesta pesquisa supriu a lacuna na literatura da área, no que se refere a esse tipo de avaliação, como também acessou efeitos dessas intervenções ampliando a análise dos resultados além da significância estatística.

Como recomendações para estudos futuros, orienta-se a utilização de um delineamento experimental em uma amostra maior, estratificada quanto ao gênero, que contemple diversos níveis de escolaridade, renda, idade e categorias profissionais. Enfatiza-se a atenção aos potenciais cuidados que previnem ameaças à validade interna como, por exemplo, a difusão do tratamento e o sentimento de desvalorização (Creswel, 2010; Nezu \& Nezu, 2008). Como proposta para evitar a difusão do tratamento, sugere-se incluir mais organizações e selecionar poucos participantes em cada uma delas ou ainda 
recrutar participantes da mesma organização, mas em setores diferenciados. Uma forma de evitar o sentimento de desvalorização dos participantes do grupo controle é oferecer um tratamento mínimo (Kazdin, 2010) como, por exemplo, uma orientação individual por meio de uma cartilha como apresentada na etapa "Menu de Opções" da intervenção breve.

Outros pontos a serem acrescentados na agenda de pesquisa referem-se (1) à exploração de variáveis mediadoras como atitudes frente à aposentadoria numa perspectiva individual, social, familiar, política, econômica e organizacional (França, 2004), suporte social, coesão grupal e demais fatores terapêuticos dos grupos (Yalom \& Leszcz, 2006), (2) seus efeitos sobre a variável independente (3) à inclusão de depoimentos de homens e mulheres no programa testemunho como forma de possibilitar a generalização dos resultados dessa intervenção e (4) realizar avaliações longitudinais com o intuito de acompanhar os participantes por vários anos durante a aposentadoria. Por fim, espera-se que os resultados deste estudo sensibilizem os gestores sobre a importância dessas práticas nas organizações, fortaleçam as reflexões acerca de uma agenda de pesquisa nesta área e estimulem a implementação de ações desta natureza, como recomendado pela legislação brasileira. 


\section{Referências}

Albuquerque, A. \& Tróccoli, B. (2004) Desenvolvimento de uma escala de bem-estar subjetivo. Psicologia: Teoria e Pesquisa, 20, 153-164.

Barbosa, L., Monteiro, B., \& Murta, S. (2016). Retirement adjustment predictors: A systematic review. Work, Aging and Retirement, 2, 262-280, doi:10.1093/workar/waw008.

Bardin, L. (2011). Análise de conteúdo. São Paulo: Edições 70.

Bowen, D. J., Kreuter, M., Spring, B., Cofta-Woerpel, L., Linnan, L., Weiner, C... \& Fernandez, M. (2009). How we design feasibility studies. American Journal of Preventive Medicine, 36, 452-457

Busselle, R., \& Bilandzic, H. (2008). Fictionality and perceived realism in experiencing stories: A model of narrative comprehension and engagement. Communication Theory, 18, 255-280.

Carter, S. L. (2010). The social validity manual: A guide to subjective evaluation of behavior interventions in applied behavior analysis. London, UK: Academic Press

Corcoran, K. \& Fischer, J. (2000). Measures for clinical practice: A sourcebook. New York:The Free Press, 3a edição.

Costa, F., \& Castanhar, J. C. (2003). Avaliação de programas públicos: Desafios conceituais e metodológicos. Revista de Administração Pública, 37, 969- 992.

Creswell, J. (2010). Projeto de pesquisa: Métodos qualitativo, quantitativo e misto. Porto Alegre: Bookman.

Dancey, C. \& Reidy, J. (2013). Questões de significância. In Dancey, C. \& Reidy, J (Eds.). Estatística sem matemática para a psicologia (pp. 250-268). Porto Alegre: Penso. 
Diener, E. (2000). Subjective well-being: The science of happiness and a proposal for a national index. American, Psychologist, 55, 34-43. doi:10.1037/0003-066X.55.1.34

Field A. (2013). Discovering statistics using IBM SPSS statistics. New York: Sage.

Flay, B., Biglan, A., Boruch, R., Castro, F., Gottfredson, D., Kellam, S.,... Ji, P. (2005). Standards of evidence: Criteria for efficacy, effectiveness and dissemination. Prevention Science, 6, 151-175. doi: 10.1007/s11121-005-5553-y

Francisco, V., \& Butterfoss, F. (2007) Social validation of goals, procedures, and effects in public health. Health Promotion Practice, 8, 128-133.

França, L.H. (2004). Attitudes towards retirement: A cross-cultural study between New Zealand and Brazilian executives. PhD Thesis. Department of Psychology. The University of Auckland, New Zealand.

França, C. (2012). Modelo de uma intervenção breve para planejamento da aposentadoria: desenvolvimento e avaliação. Dissertação de Mestrado, Universidade de Brasília, Brasília, DF.

França, C., Murta, S., Negreiros, J., Pedralho, M., \& Carvalhedo, R. (2013). Intervenção breve na prepração para aposentadoria. Revista Brasileira de Orientação Profissional, $14,99-110$.

França, L. H., \& Hershey, D. (2010). Interdisciplinary influences on personal financial planning in Brazil. Poster presented at the 63rd Annual Meeting of the Gerontological Society of America. New Orleans, 19-23, November.

França, L. H., Menezes, G., Bendassolli, P., \& Macedo, L. (2013). Aposentar-se ou continuar trabalhando? O que influencia essa decisão? Psicologia: Ciência $e$ Profissão, 33, $548-563$.

França, L. H., Nalin, C., Siqueira-Brito, A., Amorim, S., Rangel, T., \& Ekman, N.C. (2014). A percepção dos gestores brasileiros sobre os programas de preparação 
para aposentadoria. Estudos interdisciplinares sobre o envelhecimento, 19, 879898.

Giacomoni, C. (2004). Bem-estar subjetivo: Em busca da qualidade de vida. Temas em Psicologia, 12, 43-50.

Glamser, F., \& DeJong, G. (1975). The efficacy of pre-retirement preparation programs for industrial workers. Journal of Gerontology, 30, 595-600.

Glamser, F. (1981). The impact of preretirement programs on the retirement experience. Journal of Gerontology, 36, 244-250.

Hershey, D. A., Mowen, J. C., \& Jacobs-Lawson, J. M. (2003). An experimental comparison of retirement planning intervention seminars. Educational Gerontology, 29, 339-359. doi: 10.1080=03601270390180271

Hershey, D. A., Jacobs-Lawson, J. M., McArdle, J. J., \& Hamagami, A. (2007). Psychological foundations of financial planning for retirement. Journal of Adult Development, 14, 26-36.

Hershey, D. A., Henkens, K., \& van Dalen, H. (2010). Aging and financial planning for retirement: Interdisciplinary influences viewed through a cross-cultural lens. International Journal of Aging and Human Development, 70, 1-38.

Instituto Brasileiro de Geografia e Estatística - IBGE (2016). Retirado de http://www.sidra.ibge.gov.br/bda/emprego/

Janssen, E., van Osch, L., De Vries, H., \& Lechner, L. (2012). The influence of narrative risk communication on feelings of cancer risk. British Journal of Health Psychology, 18, 407-419. doi: 10.1111/j.2044-8287.2012.02098.x

Kazdin, A. E. (1977). Assessing the clinical or applied importance of behavior change through social validation. Behavior Modification, 1, 427-452.

Kazdin, A. (2010). Research design in clinical psychology. Boston: Allyn \& Bacon. 
Kim, J. E., \& Moen, P. (2002). Retirement transitions, gender and psychological wellbeing: A life course ecological model. Journal of Gerontology, 57B, 212-222. doi: $10.1348 / 096317905 \times 68204$

Lane, K. L., \& Beebe-Frankenberger, M. (2004). School-based interventions: The tools you need to succeed. Boston : Pearson

Leandro-França, C., \& Murta, S. (2014). Fatores de risco e de proteção na adaptação à aposentadoria. Revista Psicologia Argumento, 32, 33-43. doi:10.7213/psicol.argum.32.076.DS03.

Leandro-França, C., Murta, S., \& Iglesias, F. (2014). Planejamento da aposentadoria: Uma escala de mudança de comportamento. Revista Brasileira de Orientação Profissional, 15, 75-84.

Leandro-França, C. (2014). Aposentadoria: Crise ou liberdade. In Murta, S., LeandroFrança, C., \& Seidl. J. (Eds.). Programas de educação para aposentadoria: Como planejar, implementar e avaliar (pp. 54-65). Novo Hamburgo: Sinopsys.

Leandro-França, C., Murta, S., \& Villa, M. (2014). Efeitos de uma intervenção breve no planejamento da aposentadoria. Revista Psicologia: Organizações e Trabalho, 14, 257-270.

Leandro-França, C., Murta, S., Hershey, D., \& Barbosa, L. (2016). Evaluation of retirement planning programs: A qualitative analysis of methodologies and efficacy. Educational Gerontology, 42, 497-512.

doi: $10.1080 / 03601277.2016 .1156380$

Leandro-França, C., van Solinge, H., Henkens, K., \& Murta, S. (2016). Effects of three types of retirement preparation program: A qualitative study of civil servants in Brazil. Educational Gerontology, 42, 388-400.

doi:10.1080/03601277.2016.1139969 
Leandro-França, C., Seidl, J., \& Murta, S. (2016). Intervenção Breve como Estratégia de Planejamento para Aposentadoria: Transformando Intenções em Ações, Psicologia em Estudos, 20, 543-553. doi: 10.4025/psicolestud.v20i4.27413.

Lemal, M., \& van den Bulck, J. (2010). Testing the effectiveness of a skin cancer narrative in promoting positive health behavior: A pilot study. Preventive Medicine, 51, 178181. doi: 10.1016/j.ypmed.2010.04.019

Lens, W., Paixão, M. P., Herrera, D., \& Grobler, A. (2012). Future time perspective as a motivational variable: Content and extension of future goals affect the quantity and quality of motivation. Japanese Psychological Research, 54, 321-333. doi:10.1111/j.1468-5884.2012.00520.x

Michinov, E., Fouquereau, E., \& Fernandez, A. (2008). Retirees' social identity and satisfaction with retirement. International Journal of Aging and Human Development, 66, 175-194.

Miller, W., \& Rollnick, S. (2001). Motivational interviewing: Preparing people to change addictive behavior (2nd ed.). New York, NY: Guilford Press.

Murta, S. G., Caixeta, T. D., Souza, K. L., \& Ribeiro, D. C. (2008). Avaliação de um programa de preparo para a aposentadoria e envelhecimento bem sucedido. In S.G Murta (Ed.), Grupos psicoeducativas: Aplicações em múltiplos contextos, (pp. 181196). Goiânia: Porã Cultural.

Murta, S., Oliveira, S., Siqueira, A.L., Carvalhedo, R., Gunther, I., Lira, N,...Naves, M. (2010). Viva Mais! Programa de preparação para aposentadoria: Guia para participantes. Universidade de Brasília, Brasil.

Murta, S., Leandro-França, C., \& Barbosa, L. (2014). Pesquisa em avaliação de programas de educação para aposentadoria. In Murta, S. Leandro-França, C. $\quad$ \& 
Seidl, J. (Eds.). Programas de Educação para Aposentadoria: Como planejar, implementar e avaliar (288-311). Novo Hamburgo: Sinopsys.

Murta, S., Abreu, S., França, C.L., Pedralho, M., Seidl, J., Lira, N., ... Gunther, I. (2014). A preparação para a aposentadoria: Implantação e avaliação do programa Viva Mais!. Psicologia: Reflexão e Crítica, 27, 1-9. doi:10.1590/S010279722014000100001

Murta, S., \& Santos, K. (2015). Desenvolvimento de programas preventivos e de promoção de saúde mental. In S., Murta, C., Leandro-França, K., Santos, \& L., Polejack (Eds.). Prevenção e promoção em saúde mental: Fundamentos, planejamento e estratégias de intervenção (pp. 168-191). Novo Hamburgo: Sinopsys.

Niederdeppe, J. Sahpiro, M., \& Porticella, N. (2011). Attributions of responsability for obesity: Narrative communication reduces reactive counterarguing among liberals. Human Communication Research, 37, 295-323.

Nezu, A., \& Nezu, C. (2008). Evidence-based outcome research: A practical guide to conducting randomized controlled trials for psychosocial interventions. New York: Oxford University Press.

Nezu, A., \& Nezu, C. (2008). The "Devil is in the Details": Recognizing and dealing with threats to validity in randomized controlled trials. In Nezu, A. \& Nezu, C. (Eds). Evidence- based outcome research: A practical guide to conducting randomized controlled trials for psychosocial interventions. (pp. 324). New York: Oxford University Press.

Noone, J., Stephens, C., \& Alpass, F. (2009). Pre-retirement planning and well-being in later life: A prospective study. Research on Aging, 31, 295-317. doi:10.1177/0164027508330718 
Nuttins, J. \& Lens, W. (1985). Future time perspective and motivation: Theory and research method. Louvain: Presses Universitaires de Louvain.

Pasquali, L. (2012). Análise fatorial para pesquisadores. 2ª Ed. Brasília: LabPAM.

Pereira, T. \& Guedes, S. (2012). Novo tempo: A experiência de implantação do programa de preparação para o pós-carreira no IFRN, Holos, 4, 158-177.

Petkoska, J. \& Earl, J. (2009). Understanding the influence of demographic and psychological variables on retirement planning. Psychology and Aging, 24, 24551. doi: $10.1037 / \mathrm{a} 0014096$

Price, C. A., \& Joo, E. (2005). Exploring the relationship between marital status and women's retirement satisfaction. International Journal of Aging and Human Development, 61, 37-55.

Reitzes, D. C., \& Mutran, E. J., (2004). The transition to retirement: Stages and factors that influence retirement adjustment. International Journal of Aging and Human Development, 59, 63-84.

Richardson, V., \& Kilty, K. M. (1991). Adjustment to retirement: Continuity vs. discontinuity. International Journal of Aging and Human Development, 33, $151-169$.

Río-González, A. M., \& Herrera, A. N. (2006). Desarrollo de un instrumento para evaluar perspectiva de tiempo futuro en adolescentes. Avances en Medición, 4, 47-60.

Santos, F. (1990). Identidade e Aposentadoria. São Paulo: E.P.U.

Schmitt, R. E. (2010). Teoria da perspectiva de tempo futuro: Aplicações preliminares e reflexões voltadas à pesquisa no ensino superior. Revista Educação por Escrito, $1,5-16$. 
Seidl, J., Leandro-França, C., \& Murta, S. (2014) Formatos de programas de educação para aposentadoria. In Murta, S. Leandro-França, C. \& Seidl, J. (Eds.). Programas de Educação para Aposentadoria: como planejar, implementar e avaliar (pp. 84-113). Novo Hamburgo: Sinopsys.

Soares, D. H., Costa, A., Rosa, A., \& Oliveira, M. L (2007). Aposenta-ação: Programa de preparação para aposentadoria. Estudos interdisciplinares sobre o envelhecimento, $12,143-161$.

Stawski, R. S., Hershey, D. A., \& Jacobs-Lawson, J. M. (2007). Goal clarity and financial planning activities as determinants of retirement savings contributions. International Journal of Aging and Human Development, 64, 13-32.

van Solinge, H., \& Henkens, K. (2008). Adjustment to and satisfaction with retirement: Two of a kind? Psychology and Aging, 23, 422-434. doi: 10.1037/08827974.23.2.422

Wang, M., Henkens, K., \& van Solinge, H. (2011). Retirement adjustment: A review of theoretical and empirical advancements. American Psychologist, 66, 204-213. doi: $10.1037 / \mathrm{a} 0022414$

Wholey, J., Hatry, H., \& Newcomer, K. (2010). Handbook of practical program evaluation. 3. ed. Hoboken: John Wiley \& Sons.

Yalom. I., \& Leszcz, M. (2006). Psicoterapia de grupo: Teoria e prática. Porto Alegre: Artmed.

Zanelli, J. C. (2000). O Programa de preparação para aposentadoria como um processo de intervenção ao final de uma carreira. Revista de Ciências Humanas, edição especial temática, 157-176.

Zanelli, J. C. (2012). Processos psicossociais, bem-estar e estresse na aposentadoria. Revista Psicologia: Organizações e Trabalho, 12, 329-340. 


\section{CAPÍTULO 7}

Publicado em periódico internacional ${ }^{13}$

\section{Effects of Three Types of Retirement Preparation Program: A Qualitative Study of Civil Servants in Brazil}

${ }^{13}$ Artigo escrito durante estágio doutoral (doutorado sanduíche) da primeira autora em Netherlands Interdisciplinary Demographic Institute - NIDI, Haia, Holanda, 2015.

Leandro-França, C., van Solinge, H., Henkens, K. \& Murta. S.G., (2016). Effects of Three Types of Retirement Preparation Program: A Qualitative Study of Civil Servants in Brazil, Educational Gerontology Journal, 42, 388-400.doi:10.1080/03601277.2016.1139969 


\begin{abstract}
Studies on the effectiveness of retirement planning programs are relatively scarce. Retirement preparation and planning programs may assist individuals to smooth the transition to retirement and subsequent adjustment. This qualitative study examines the effects of three retirement preparation programs on civil servants in Brazil. Theoretically, the study builds on the transtheoretical model (TTM), also called the stages of change model. Twenty civil servants (aged 53-67) working for the Brazilian Government were randomly assigned to one of the three retirement planning programs entitled testimony, short, and extensive. The results of qualitative interviews, conducted 6 months after completion of the programs, show that participants on the extensive program presented a broader array of changes in retirement planning and had progressed through more stages of the TTM than participants who took part in the short and testimony programs.
\end{abstract}

Keywords: retirement planning programs, retirement adjustment, older workers, aging, transtheoretical model 
Retirement is an important life-course event that marks the start of a new life stage in which work is no longer dominant. Employees have to adjust to the significant life changes that accompany the transition and to try to achieve psychological comfort with their retirement life. Managing retirement is a central developmental task in late adult life involving two developmental challenges. The first challenge involves the social and psychological detachment from work (Damman, Henkens, \& Kalmijn, 2015). The second involves the development of a satisfactory post-retirement lifestyle (Havighurst, Munnichs, Neugarten, \& Thomae, 1969). Dealing with loss is a central aspect of the first developmental task. This is a complex and individual psychological process of adjustment (Harvey \& Miller, 1998). The second developmental challenge - establishing a postretirement lifestyle - is closely related to the individual's access to resources. The development of a satisfactory post-retirement lifestyle may be seriously constrained by shortages of or loss of relevant resources (van Solinge \& Henkens, 2008).

For many people, retirement is a period of uncertainty and change. Retirement preparation and planning programs may assist individuals to smooth their transition to retirement and their subsequent adjustment. Cross-sectional research on the use of a variety of planning measures suggests that financial planning is predictive of later life satisfaction in retirees (Noone, Stephens, \& Alpass, 2009). This planning may take several forms, including informal preparation through discussions with partners, friends, or retired persons and reading about retirement, as well as formal preparation in retirement seminars (Kim \& Moen, 2002; Lee \& Law, 2004; Noone et al., 2009; Taylor, Carter, Cook, \& Weinberg, 1997).

Retirement planning and preparation programs to prepare older workers for life after a working career have been developed since the early 1960s (Brady, Leighton, Fortinsky, Crocker, \& Fowler, 1996; Petkoska \& Earl, 2009). Yet, despite the extensive 
array of retirement preparation programs offered by employers and private organizations, scientific research on the effect of these programs is relatively scarce. Many of the previous studies were conducted in the 1970s and 1980s in the United States (Glamser \& DeJong, 1975, 1981) and their focus is primarily on a narrow set of behaviors related to financial retirement planning (Brady et al., 1996; Lee \& Lau, 2004; Noone et al., 2009). Financial planning is, however, only one - albeit important - aspect of older adults' preparation for retirement. Planning and preparation is also deemed important with respect to achieving social and psychological detachment from work and the development of a post-retirement lifestyle. The latter is not only related to financial resources, but also to health and to social participation.

The aim of the current study is to investigate the impact of three different forms of retirement planning program in Brazilian public organizations. The central research question is: to what extent do three different forms of retirement preparation program facilitate the individual's planning and preparation for retirement? These programs vary in terms of duration, coverage of the issue, and didactical method. The 1-day ( 3 hours) is a 'testimony' program, where participants listen to and interact with individuals who have already made the transition to retirement. The impact of two more elaborate programs that have been named the 'short' program and the 'extensive' program - are compared with the testimony program.

The purpose of this paper is to advance the existing knowledge on retirement planning and preparation in three ways. First, although retirement adjustment and preparation is increasingly viewed as a multidimensional process, most theoretical research, as well as practical interventions, has focused on financial planning and preparation for retirement. Other aspects, such as health, (psycho-) social issues, and leisure planning have received relatively little attention (Petkoska \& Earl, 2009; Wong \& 
Earl, 2009). Therefore, the current research explicitly acknowledges the multidimensional character of the retirement process.

Second, the present study applies a theoretical model widely used in health research to the field of retirement preparation. To investigate the impact of the various retirement preparation programs, this study uses the transtheoretical model (TTM). The model has been widely applied in health psychology to assess an individual's readiness to act on a new health behavior, such as no longer smoking (DiClemente, Prochaska, \& Gibertini, 1985; Prochaska \& DiClemente, 1983), and to adopt a healthier lifestyle through, for instance, exercise regimens, weight control, safer sex, condom use, sunscreen use, and mammography (Prochaska et al., 1994).

The TTM assumes that individuals move through several stages of change before a particular behavior (e.g., stopping smoking) is carried out. How people progress through these stages can be inferred from their covert and overt activities and self-reporting of these activities. This study is one of the first to apply this model in retirement planning research.

Third, the current study is among the first to examine retirement preparation among older workers in an emerging economy. As such, we follow the suggestion of Wang (2012), who advocates research in other sociocultural contexts, such as countries where the social institution of retirement is very different from that in the United States. Current knowledge on retirement preparation programs is primarily based on North American samples (e.g., Glamser \& DeJong, 1975, 1981) and may not represent the social and economic conditions of other societies. Therefore, this research focuses on the experience of a sample of civil servants in Brazil.

The present paper describes a qualitative study on the effects of retirement planning programs on 20 civil servants (aged 53-67) working for the Brazilian Government. These 
civil servants were randomly assigned to one of the three aforementioned retirement preparation programs. Qualitative interviews were conducted 6 months after completion of the programs.

\section{Retirement Context in Brazil}

Brazil is a country with a predominantly young population, but has the pension expenditure of a country with an aging population. For every one hundred 15- to 64-yearolds, it has just 10 over-65s, fewer than anywhere in the G7. Yet it spends $13 \%$ of gross domestic product (GDP) on pensions, more than any G7 member except Italy, where the share of old people is three times higher than in Brazil (The Economist, 2012). With a high replacement rate (replacing $70-80 \%$ of average income) and relaxed contribution requirements, Brazil's pensions are among the world's most generous. Moreover, Brazil is set to witness a rapid increase in the proportion of its aging population in the coming years, so the demands on its public pension system will increase.

To ensure the sustainability of the public pension system in the light of the rapid aging of the population, the public pension system has been the subject of a series of ongoing reforms since the late 1990s. In the past, in order to retire on full pay most Brazilians needed to make contributions for only 15 years and work until the age of 65 for men and 60 for women. Early retirement, on a smaller but still generous budget, was possible after 35 years (men) and 30 years (women) of contribution. Brazil's pension system currently uses a formula known as 85/95 under which a woman can request her retirement pension when her age and years of contribution to the system total 85 , while a man can retire when that number reaches 95 . The Government wants to change this calculation to 90/100, with this change phased in gradually from 2015 to 2020 . 
The fast changing retirement context in Brazil may seriously challenge the retirement choices and opportunities of older workers in the country with potentially adverse consequences for their wellbeing. This has been acknowledged by the Government in their Elderly Statute (Brazilian Law 10/741/2003). This law underlines the importance of making informed choices regarding retirement in order to maintain quality of life before and after leaving the workforce. Given that current cohorts of older workers may still retire at a relatively young age, the law motivates Brazilian organizations to implement activities to promote active aging, thereby enabling people to realize their potential in terms of their physical, social, and mental wellbeing throughout their life course and to participate as fully as possible in society. Inspired by this law, many public and private organizations currently offer their older employees programs to help them make meaningful and informed choices about their lives and to plan their future based on their individual retirement needs, whether that be replacing work with new activities or continuing to work.

\section{Theoretical Background}

In order to evaluate the impact of three different forms of retirement preparation program, this study focuses on the reports made by individual participants about the processes and activities undertaken with respect to retirement planning and preparation. Theoretically, this study builds on the TTM (also called the stages of change model) developed by Prochaska and DiClemente (Prochaska \& DiClemente, 1983; Prochaska et al., 1994). The TTM focuses on the decision-making process of the individual. The idea of stages of change lies at the heart of the TTM. The model postulates that people move through a series of stages when modifying their behavior. While the time a person stays in 
each stage is variable, the tasks required to move to the next stage are not (Prochaska \& DiClemente; 1983, 1992). These stages are:

- Pre-contemplation: no awareness of the problem and resistance to change;

- Contemplation: being aware of the problem and thinking about taking action;

- Preparation: getting emotionally ready, intending to act;

- Action: taking the necessary actions;

- Maintenance: keeping up the necessary actions, not backing out or slowing down.

The model has been widely applied in health psychology to assess an individual's readiness to act on a new health behavior, such as reducing alcohol consumption and quitting smoking (DiClemente et al., 1985; Scott \& Wolfe, 2003). Leandro-França, Murta, and Villa (2014) have suggested that the TTM may be also useful for studying retirement planning and preparation. Like the process of behavioral change in the health field, a successful process of change in retirement planning is characterized, first, by increasing awareness of the advantages of planning and the risks of not preparing for this life transition. Second, decision making, goal setting, and initial preparation steps cohere with personal values. Third, intentions and plans become actions in order to strengthen the resources that will make retirement projects feasible (such as financial investment, talent development, leisure activities, and physical exercise).

This study supposes that older workers in their process of planning and preparation for retirement move through the various stages of change as described in the TTM and that retirement preparation programs may support them in this process. Many older workers are not aware of, have resistance to, or lack interest in retirement planning (characteristic of the pre-contemplation stage). Following the TTM, we assume that older workers who 
participate in programs of planning for retirement will move through the several stages of the model and that their progress can be inferred from their covert and overt activities and self-reporting of these activities (see Table 1).

Table 1. Transtheoretical Model Applied to the Retirement Preparation Process

\begin{tabular}{|c|c|c|}
\hline Stage & Characteristics & Changes in Characteristic \\
\hline Pre-contemplation & $\begin{array}{l}\text { Individuals are not aware of or have } \\
\text { resistance to or a lack of interest in } \\
\text { retirement planning, so there is no } \\
\text { intention to change behaviors or to } \\
\text { participate in programs focused on this } \\
\text { issue. }\end{array}$ & \\
\hline Contemplation & $\begin{array}{l}\text { This is a period of ambivalence in } \\
\text { which the desire to change coexists } \\
\text { with the desire to remain the same. }\end{array}$ & $\begin{array}{l}\text { Reports of cognitive changes: } \\
\text { reflection and awareness } \\
\text { about the importance of } \\
\text { planning for retirement, } \\
\text { beliefs about retirement and } \\
\text { acquisition of new } \\
\text { information about this issue. }\end{array}$ \\
\hline Preparation & $\begin{array}{l}\text { Individuals make plans about when to } \\
\text { retire, how to deal with loss of income } \\
\text { and changes in social contacts and } \\
\text { their relationship with their partner. } \\
\text { For the development of their post- } \\
\text { retirement lifestyle they show } \\
\text { determination and optimism to } \\
\text { implement these plans. However, at } \\
\text { this stage the plans are not put it into } \\
\text { practice yet. }\end{array}$ & $\begin{array}{l}\text { Reports of motivational } \\
\text { changes: desire to change, } \\
\text { determination to acquire } \\
\text { behavior that will aid } \\
\text { adjustment to retirement and } \\
\text { decision-making } \\
\text { retirement. }\end{array}$ \\
\hline Action & $\begin{array}{l}\text { Plans for retirement are put into } \\
\text { practice. In this stage, individuals } \\
\text { engage in specific activities to adjust } \\
\text { to retirement, such as participation in } \\
\text { actions to promote health, retirement } \\
\text { preparation programs, physical } \\
\text { activity, leisure and financial } \\
\text { management. }\end{array}$ & $\begin{array}{l}\text { Reports of behavioral } \\
\text { changes: } \\
\text { activities that help to adjust to } \\
\text { retirement. }\end{array}$ \\
\hline Maintenance & $\begin{array}{l}\text { Individuals work to prevent a relapse } \\
\text { into pre-retirement behaviors/habits } \\
\text { and to solidify the gains obtained in } \\
\text { the action stage. }\end{array}$ & \\
\hline
\end{tabular}

The central research question in this study is: to what extent do three different forms of retirement preparation program facilitate the individual's planning for retirement? 
These programs vary in terms of their duration, coverage of the issue and didactical methods (see Table 2). The shortest program, the testimony program, takes place on one day in the form of a meeting that lasts 3 hours during which participants listen to and interact with a retired individual who have already made the transition to retirement. This program is unstructured and bears a resemblance to informal preparation activities with friends and family members. The other two programs are formal preparation activities guided by professionals. The short formal program also takes place on one day and lasts for 3 hours, while the extensive formal program consists of 13 weekly meetings, each lasting 3 hours. Both of the formal programs cover a broad array of issues relevant to the retirement planning and preparation process. The didactical methods vary between and within meetings, to include lectures, group discussions and psycho-educative activities.

Table 2. Characteristics of the Programs for Retirement Planning

\begin{tabular}{|c|c|c|c|}
\hline & Testimony & Short & Extensive \\
\hline Structure & Unstructured & Structured & Structured \\
\hline Duration & $\begin{array}{l}1 \text { meeting, } 3 \\
\text { hours }\end{array}$ & 1 meeting, 3 hours & $\begin{array}{l}13 \text { meetings, weekly, } 3 \\
\text { hours each }\end{array}$ \\
\hline Topics covered & $\begin{array}{l}\text { Retirement } \\
\text { experience }\end{array}$ & $\begin{array}{l}\text { Physical health, } \\
\text { financial planning, } \\
\text { productive and } \\
\text { leisure activities, } \\
\text { family and social } \\
\text { network, volunteer } \\
\text { work, and active } \\
\text { aging }\end{array}$ & $\begin{array}{l}\text { Physical health, financial } \\
\text { planning and retirement } \\
\text { income, productive and } \\
\text { leisure activities, family } \\
\text { and social network, social } \\
\text { security laws, volunteer } \\
\text { work, and.active aging }\end{array}$ \\
\hline Speaker & $\begin{array}{l}\text { Experienced civil } \\
\text { servant, retired }\end{array}$ & Professional expert & Professional experts \\
\hline Didactic & Group discussion & $\begin{array}{lr}\text { Group } & \text { discussion } \\
\text { and } & \text { educational } \\
\text { activities } & \text { (e.g., } \\
\text { booklet) } & \end{array}$ & $\begin{array}{ll}\text { Group discussion and } \\
\text { educational activities } \\
\text { (e.g., lectures) }\end{array}$ \\
\hline
\end{tabular}

The scientific literature on changes in health behaviors has shown that brief interventions are more effective than no counseling or no intervention (Bien, Miller, \& 
Tonigan, 1993; Wilk, Jensen, Tomas, \& Havighurst, 1997) and that the impact (in terms of behavioral changes with regard to alcohol consumption or the use of other addictive substances) of extensive and brief interventions are similar (Bien et al., 1993; Miller \& Rollnick, 2002). Based on these assumptions, our expectation is that participants in the extensive as well as in the short program will show a broader array of changes, and that they will have progressed through more stages of the TTM, than participants in the testimony program during the 6 months of the follow-up period after the program.

\section{Method}

This study on the impact of three different forms of retirement planning program in Brazilian public organizations is based on a qualitative study of civil servants all working for the Brazilian Government.

\section{Design and Study Population}

For this study, researchers of the Post-Graduation Program in Clinical Psychology and Culture, University of Brasíl contacted the HR managers of five public organizations, four of which agreed to participate. Participation implied that the researchers received access to the internal e-mail system and web pages of the organizations in order to invite older employees to enroll in a retirement preparation program. From those who were interested, the researchers selected individuals aged 50 years and older. A total of 30 participants - all civil servants of these four public organizations - agreed to participate in this study. The participants were randomly allocated to either the extensive, short, or testimony programs described in Table 2. Participants allocated to the short and testimony programs were also informed that at the end of the study (i.e., after the final interview) they could choose to participate in the extensive program as well if they so wished. A total 
of 21 workers participated in one of the programs. Twenty individuals were interviewed after they had participated in the allocated program. The main reasons that participants dropped out of this study before the start and during programs were health problems, vacation, and migration (see Figure 1).

The final analytical sample consists of fourteen females and six males, whose age ranged from 53 to 67 years. Fourteen were married or living in a consensual union, three were single, and three were divorced or widowed. With respect to education level, six participants were postgraduates, eleven had a university degree, and three had finished high school.

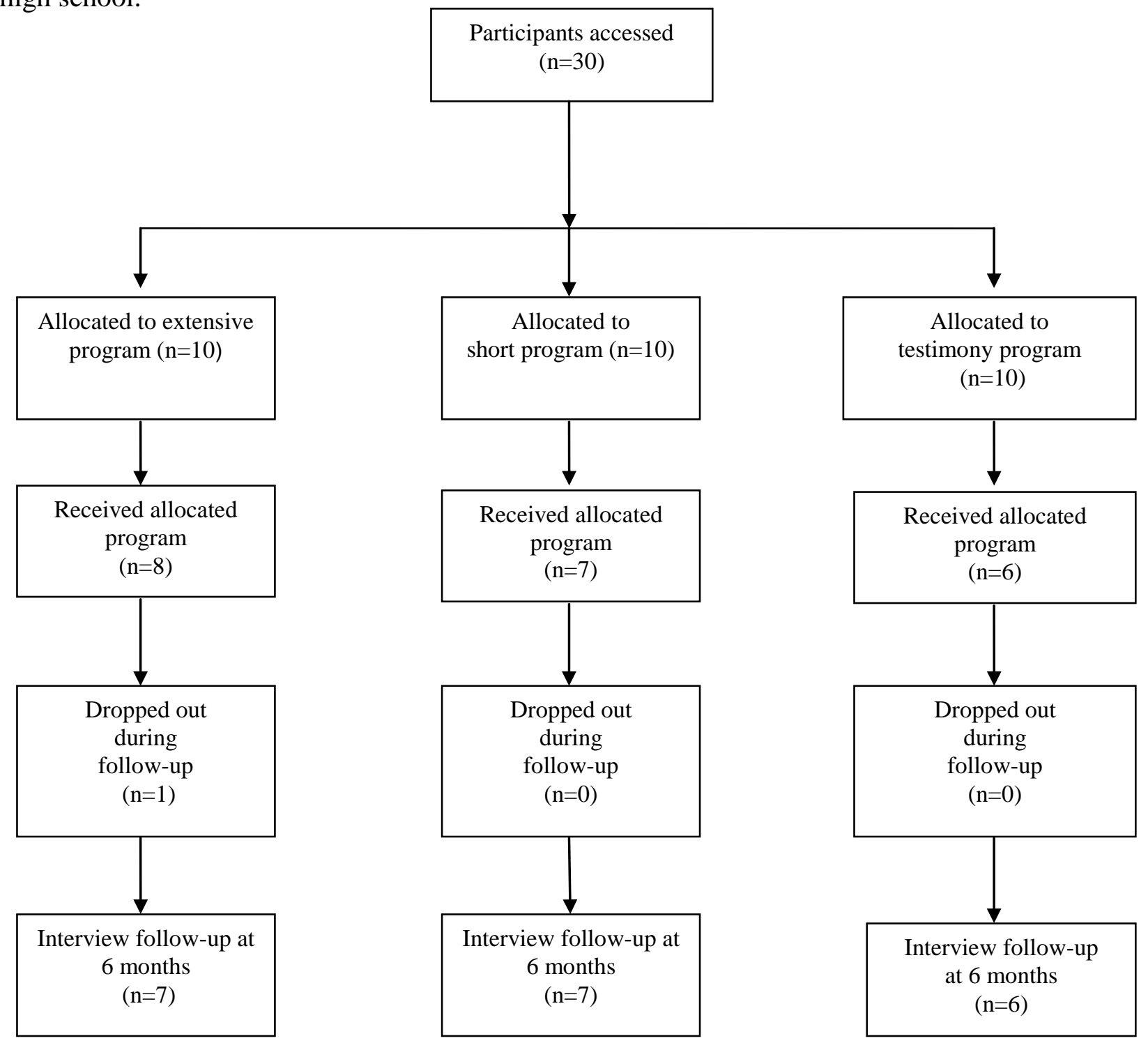

Figure 1. Flow Chart of Participants and Dropouts 


\section{Analysis}

The analysis is based on qualitative data from individual follow-up evaluation interviews with the participants who took part in one of the three retirement preparation programs. Interviews were conducted 6 months after the completion of the program. The interviews were recorded and transcribed. The transcripts of the interviews were imported into a software package for data storage retrieval and analysis (WeftQDA). The coding categories were operationalized using the definitions based on Wang, Henkens, and van Solinge (2011). The focus of the analysis was to establish whether the participants referred to cognitive, emotional, and/or behavioral changes in the period following the program and to what extent the results differed for the various programs. In line with the theoretical framework, the changes are labeled as follows:

- Cognitive: When the participant reported a reflection on or awareness about the importance of planning for retirement, beliefs about retirement, and the acquisition of new information about the issue.

- Motivational: When the participant reported a desire to change their behavior regarding aspects relevant to retirement and/or the start of a decision-making process about retirement.

- Behavioral: When the participants reported changes in overt behavior that may contribute to successful retirement. Four subcategories are distinguished in this respect: 1) physical change - related to healthcare, physical activity, and healthy eating; 2) financial change,- in relation to planning, investment, and control of spending; 3 ) productive and leisure activities change - with regard to bridge employment, volunteer work, new professional focus, engaging in leisure activities, hobbies, religious activities; and 4) socio-emotional change covering investments in relationships with friends and family. 


\section{Results}

The transcripts of the interviews with all 20 participants were analyzed. Table 3 shows an overview of the results of the coding of the individual interviews in terms of reported types of change. The results clearly demonstrate that the participants in the extensive program reported more changes, as well as a broader variety of changes than the participants in the other programs. Participants in the testimony program reported the fewest changes. Participants in the short program had an intermediate position in this respect. In the following, we look more closely at the process of change that the participants of the various programs may or may not have experienced.

Table 3. Descriptive Results of the Coding of the Interviews ( $=20)$

\begin{tabular}{|c|c|c|c|c|c|c|c|}
\hline & \multirow[t]{2}{*}{$\mathrm{ID}^{1}$} & \multirow{2}{*}{$\begin{array}{c}\text { Cognitive } \\
\text { Change }\end{array}$} & \multirow{2}{*}{$\begin{array}{c}\text { Motivational } \\
\text { Change }\end{array}$} & \multicolumn{4}{|c|}{ Behavioral Change } \\
\hline & & & & Physical & Financial & Activity $^{2}$ & Social \\
\hline \multicolumn{8}{|l|}{ Testimony } \\
\hline Female / 61 years & $\mathrm{T} 1$ & . & . & . & . & . & . \\
\hline Female / 59 years & $\mathrm{T} 2$ & $\mathrm{x}$ & . & . & . & . & . \\
\hline Female / 62 years & $\mathrm{T} 3$ & $\mathrm{xx}$ & . & . & . & . & . \\
\hline Male / 60 years & $\mathrm{T} 4$ & $\mathrm{xx}$ & . & . & . & . & . \\
\hline Female / 53 years & $\mathrm{T} 5$ & . & . & . & . & . & . \\
\hline Male / 67 years & T6 & $\mathrm{x}$ & . & . & . & . & . \\
\hline \multicolumn{8}{|l|}{ Short } \\
\hline Female / 56 years & $\mathrm{S} 1$ & . & . & . & . & . & . \\
\hline Female / 67 years & $\mathrm{S} 2$ & . & $\mathrm{X}$ & . & . & . & . \\
\hline Female / 55 years & S3 & $\mathrm{x}$ & . & . & . & . & . \\
\hline Female / 53 years & $\mathrm{S} 4$ & $\mathrm{xx}$ & $X$ & . & . & . & . \\
\hline Female / 58 years & S5 & $\mathrm{xx}$ & $X x$ & . & . & . & . \\
\hline Female / 56 years & S6 & $\mathrm{xx}$ & $\mathrm{Xx}$ & . & . & . & . \\
\hline Female / 53 years & S7 & $\mathrm{x}$ & . & . & . & . & . \\
\hline \multicolumn{8}{|l|}{ Extensive } \\
\hline Female / 65 years & E1 & . & $\mathrm{X}$ & $\mathrm{x}$ & $\mathrm{X}$ & $\mathrm{x}$ & . \\
\hline Male / 56 years & E2 & . & $X x$ & $\mathrm{x}$ & $\mathrm{X}$ & . & . \\
\hline Male / 55 years & E3 & $\mathrm{x}$ & $\mathrm{X}$ & $\mathrm{x}$ & . & . & . \\
\hline Male / 56 years & E4 & $\mathrm{xx}$ & $\mathrm{X}$ & . & . & $\mathrm{x}$ & . \\
\hline Male / 63 years & E5 & $\mathrm{xx}$ & $X x$ & . & $\mathrm{X}$ & . & . \\
\hline Female / 57 years & E6 & $\mathrm{x}$ & $\mathrm{Xx}$ & . & . & $\mathrm{x}$ & $\mathrm{x}$ \\
\hline Female / 57 years & E7 & $\mathrm{xx}$ & $X x$ & . & . & $\mathrm{x}$ & . \\
\hline
\end{tabular}


We start with the results for the testimony program. This program consisted of one 3-hour meeting in which a retiree shared her experiences with the participants of the program. The results of the interviews, carried out 6 months after the testimony meeting, suggest that the impact of the program is quite limited. In fact, two out of the six participants declared that it had no impact at all, stating:

"The workshop did not help me to plan for retirement as, for example, I already wanted to do it and now I will do it. I think the meeting was a bit superficial" (T1, female, age 61).

"I liked some of the experiences of retired life reported by the group and a testimony of a retired person. But it did not change anything for now on my way to prepare for retirement because I do not have time to practice what was discussed about investing in the important factors for a good retirement. I work eight hours a day” (T5, female, age 53).

However, some participants in this program reported increase in awareness (indicative of cognitive change). A change in awareness about the importance of health was reported by a 62-year-old woman, who stated that:

"The meeting made me think more about my health. Because with age, a person becomes more vulnerable and I have this concern because when I cannot do my daily activities, who is going to do to them for me? How will they be done?" (T3, female, age 62).

Another participant remarked that he had started to think about post-retirement activities:

"The workshop helped me think about some activities that will help me to keep busy when I retire, for example, I can set up a business or start voluntary work, because I like to help people” (T6, male, age 67). 
Moreover, the program stimulated a 60-year-old male worker to reconsider his negative beliefs and concepts in relation to the retired condition:

"Retirement is a word that no one likes to say. 'I'm retired.' I would not want to say to anyone that I am retired, because for many people it sounds synonymous with unoccupied, idle. I was curious to talk to people who have retired. The meeting gave me this opportunity. To listen to someone already retired... to her experience... what was positive or negative. It changed my beliefs about this phase of life" (T4, male, age 60).

From these narratives, we argue that the participants in this program remained in the contemplation stage as described in the TTM. The impact of this program was thus limited. So, an important question arises as to whether a more extensive program yields more results in terms of cognitive and motivational changes, or even behavioral changes with respect to retirement preparation.

We now turn to the results for the short program, which was also a single meeting of 3 hours duration. However, this program differed from the testimony program in the sense that the meeting was structured, covered a wide array of topics, and was led by a professional expert. Table 3 reveals that six out of seven of participants reported cognitive or motivational changes or both with respect to retirement planning, as exemplified by a 53-year-old woman, who said that the program had made her think about financial issues:

"Another thing I heard in the workshop, and I did not think of before, was about the importance of financial planning, maintaining capital, some savings for the future. I had not thought about it. A country like ours with an unstable economy and thinking of the future wasn't something that was part of my life” (S4, female, age 53).

Several workers declared that the short program stimulated them to reflect on the meaning of work in their life as well as on their wishes with regard to post-retirement (paid) work. Participants also reported a growing awareness of the importance of investing in family relationships or financial planning. 
Four out of seven participants also reported motivational change. Changes are labeled as motivational whenever the participant expresses an intention to take action and/or engage in a decision-making process with regard to retirement. Indeed, participants reported that the program helped in decision making for retirement and that sharing experiences with other workers in transition stimulated their own personal planning. For instance, a 53-year-old woman stated:

"The main change in my life as result of having participated in this intervention was the decision I made to retire without fear, because before participating in this intervention I felt insecure about decisions about retirement"'(S4, female, age 53).

The opportunity to share experiences and concerns with other pre-retirees was considered helpful in this respect:

"A significant issue for me was to talk to others who are in the same situation that I am, near retirement, who have some concerns that are my concerns. Therefore, the possibility to share experiences, to listen to other people, helped me in thinking about my own plans for retirement" (S6, female, age 56).

Only one participant reported no apparent change:

"I liked several things in the meeting. I think it was cool, interesting, but it did not change the way I am preparing for retirement"'(S1, female, age 56).

In sum, the short program promoted cognitive and motivational changes in most of the participants. However, no behavioral change was reported. Therefore, on the basis of the TTM, this result indicates that the participants in this program stagnated between the contemplation and preparation stage. The program presumably did not trigger actual changes in their behavior in the observed domains (i.e., they did not reach the action stage).

In contrast to the above two programs, the extensive program consisted of a large number of meetings over a 3-month period. The results of the interviews suggest that the 
impact of this extensive program was substantial when compared to the testimony and short program. The majority of participants in the extensive program (five out of seven) stated that they were more involved in thinking about retirement as a new phase of life and also had a more positive view about it. For example, this 57 -year-old woman stated:

"I might have already retired seven years ago. I knew that retirement would someday come, but I avoided thinking or speaking about it. But after my participation in the retirement planning program I started to think about this process as an acquired right and a set of opportunities" (E6, female, age 57).

A 63-year-old man evaluated the program in a similar way:

"The program covered all the important factors of adaptation to retirement. So, it went beyond my expectations, I have to be thankful. I have spoken with my wife and my children that this program helped me to reflect on what I'll do when I retire. I'm thinking about getting involved in a second professional career when I retire such as building my own business with my son" (E5, male, age 63).

The study's expectation was that extensive program would result in cognitive changes among the participants. This indeed turned out to be the case. On the basis of the reports, we can say that the participant quoted first above - who previously avoided thinking or talking about retirement - was in the pre-contemplation stage before the program. However, after participating in the program she progressed to the contemplation stage because she somewhat altered her beliefs about retirement and started to recognize the importance of planning for retirement. With respect to the second quoted participant, as a result of the program he was developing plans for retirement and was aware of the importance of retirement planning, but had not yet made a commitment to take action. So, we can say that he showed features in accordance with the contemplation stage. 
All the participants in the extensive program reported motivational changes, as illustrated by the report below:

"The major benefit that the program gave me was that I made a decision about retiring and seeing myself retired. When I started to participate in the meetings I was undecided about retiring. When the program ended I was secure in the decision to retire and felt happy about that" (E1, female, age 65).

The fact that the participants demonstrated motivational change indicates that they moved from the contemplation to the preparation stage according to TTM. They increased their commitment and determination to change by exploring and clarifying their plans and making decisions with regard to retirement.

Reports of behavioral changes indicate that the next stage - action - was also reached. Behavioral changes are overt modifications in behavior within 6 months (followup) after the program end. Indeed, all participants in the extensive program reported behavioral changes in one or more of the following domains: physical health, finances, activity and socio-emotional. Examples of the different types of behavioral change are provided below:

"During the program I began to take better care of my health through physical activity" (E1, female, aged 65, physical health change).

"One thing that the program helped me with was to manage my finances. Today I have extra money that I didn't have before. I want to continue like this to be comfortable in my retirement" (E2, male, age 56, financial change).

"My main change after participating in the program was related to the spiritual feature. My wife and I are working with a religious community. We are participating in some of the religious study groups and doing volunteer work with the poor community" (E4, male, age 56, leisure activity change) 
"The program helped me to invest more in family relationships and bond with my partner. The opportunity to dedicate myself more to my family and my partner as we discussed in the meetings is a positive factor about being retired" (E6, female, age 57, socio-emotional change).

"After participating in the program I had a great desire to take courses and study other areas of knowledge. I'm participating in a distance course that is totally different from my current work. So, I'm starting to prepare myself for another reality, that of retirement. I have a desire to seek and undertake work that I do not know; to seek and learn new things" (E7, female, age 57, productive activity change).

Additionally, some workers reported that the extensive program strengthened the behavior they had acquired before their participation in the program which is indicative for the maintenance stage. This is illustrated by report of a 55-year- old male:

"The program helped me to maintain the activities that I already performed such as the practices of regular exercise and healthy eating, by showing me additional technical and scientific knowledge on this subject. This was very important to me” (E3, male, age 55).

To summarize, the participants in the extensive program reported a combination of cognitive, motivational, and behavioral changes. In other words, they acquired new information about retirement, expressed a desire to learn or a motivation to invest in new (post-career) activities and to prepare for this phase of life (cognitive and motivational changes). In several cases, this even resulted in engagement in courses or other preparatory activities (behavioral change). The interviews suggested that participants in the extensive program went through several stages of change with regard to retirement planning contemplation (cognitive change) through preparation (motivational change) to action (behavioral change) and maintenance. 


\section{Discussion}

Retirement from work is an important transition in a person's late career. Planning and preparation for retirement increases the likelihood of a smooth transition into post-retirement life and success in developing a post-retirement lifestyle. The central research question in this study was to what extent different forms of retirement preparation program facilitate the individual's planning for retirement. Three different retirement preparation programs were developed and used by older Brazilian civil servants, who were randomly assigned to one of the three programs. The first program was a brief testimony program, where a retiree shared her experiences with the participants on the program. The second program was a short structured program where under supervision of an expert many issues related to retirement were discussed. The third program involved an extensive series of meetings in which in depth information was given about the different facets of retirement. Our expectation was that participants in the extensive as well as in the short program would show a broader array of changes and that they would progress through more stages of the TTM than participants in the testimony program during the 6-month follow-up period after the program.

We found partial support for this expectation. The interviews revealed that, in particular, the extensive program had a substantial impact on the participants. They progressed through more stages of the TTM (pre-contemplation, contemplation, preparation, action, and maintenance) than the participants on the short program. However, the participants on the short program progressed through more stages of the TTM than those on the testimony program.

The extensive program provided access to new information about the retirement process and showed some success in raising awareness about the importance of 
planning for retirement and in assisting in retirement decision making through the sharing of experiences by the participants. The cognitive, motivational, and behavioral changes were not only in relation to the financial aspects of retirement, but also to participants' physical activity, healthy eating practices, voluntary work, religious activities in the community, leisure activities, networks with friends and family, and post-career investment activities. The short program promoted changes in knowledge about the retirement process, awareness about the importance of planning for retirement, and assisted in retirement decision making (cognitive and motivational changes), while the testimony intervention promoted only change in knowledge and awareness about the importance of planning for retirement (cognitive change).

According to the literature, psychosocial programs such as the programs investigated in the present study seek to promote the action and maintenance stages in the TTM. Progress from the pre-contemplation to the contemplation stage or from the contemplation stage to the preparation stage is also considered relevant. Increasing awareness, motivation, and the decision to adopt relevant behavior are important precursors of the action and maintenance stage (Norcross, Krebs, \& Prochaska, 2011).

As such, although the effects of the short and the testimony programs were relatively minimal, short structured programs are not without some merit for workers in the process of transition to retirement. Shorter programs may be used by organizations: (a) when access to an extensive program is limited or impossible due to lack of time and/or budgetary constraints; (b) to make the workers aware of the relevance of retirement planning; and (c) to strengthen the perception of the risk factors of not planning for retirement and not preparing to make adjustments (Janssen, van Osch, De Vries, \& Lechner, 2012; Lemal \& van den Bulck, 2010). 
It should be noted that the present study has some limitations. First, concerning external validity, we used a small sample of highly educated older workers in Brazilian public organizations. The findings may not be generalizable to the population as a whole. Second, although the participants were randomly allocated to a program, the short program was a female-only sample. Future research studies should pay particular attention to the gender composition of the sample. Third, the testimony program investigated in this study presented only the perspectives (report) of a retired female worker. There is, however, evidence in the literature that men and women differ with regard to retirement planning, adjustment, and satisfaction in retirement (Kim \& Moen, 2002; Petkoska \& Earl, 2009). Future research should therefore examine the impact of the testimony of a male retiree in a composite sample of both genders.

We recommend that future research should use a combination of qualitative and quantitative methods and a longitudinal design to follow participants for several years after retirement. Furthermore, to evaluate the efficacy of these retirement planning programs, we suggest that the experimental design should incorporate the use of a comparison or control group. Finally, we suggest that this study be replicated on a variety of representative samples, in public and private organizations and include workers from different cultures.

The main contribution of this study is that we have analyzed the impact (in terms of behavioral change) of three retirement preparation programs by using the ideas expressed in the TTM. The TTM provides insights on the stages of change in behavior and about how the process of change occurs. Knowledge of this process may be useful to counselers in assisting older workers in managing the latter years of their career and their process of preparing and planning for retirement. 


\section{Ethics Committee Approval}

Ethical approval for this research was granted from the Ethical Committee of the Institute of Humanities at the University of Brasília (Registration 707.387). To protect the anonymity and privacy of participants, usernames and other identifying details were excluded from the analysis. 


\section{References}

Bien, T. H., Miller, W. R., \& Tonigan, J. S. (1993). Brief interventions for alcohol problems: A review. Addiction, 88, 315-336.

Brady, M., Leighton, A., Fortinsky, R., Crocker, E., \& Fowler, E. (1996). Pre-retirement education models and content: A New England study. Educational Gerontology, 22, 329-339.

Damman, M., Henkens, K. \& Kalmijn, M. (2015), Missing work after retirement: the role of life histories in the retirement adjustment process. The Gerontologist 55 (5): 802813.

DiClemente, C., Prochaska, J., \& Gibertini, M. (1985). Self-efficacy and the stages of self-change in smoking. Cognitive Therapy and Research, 9, 181-200.

Estatuto do Idoso [Statute of the Elderly] Brazilian Law 10/741/203 (2003, $1^{\text {o }}$ de outubro). Diário Oficial da União, Brazil. $\quad$ Retrieved from http://www.planalto.gov.br/ccivil_03/leis/2003/L10.741.htm

Glamser, F., \& DeJong, G. (1975). The efficacy of pre-retirement preparation programs for industrial workers. Journal of Gerontology, 30, 595-600.

Glamser, F. (1981). The impact of preretirement programs on the retirement experience. Journal of Gerontology, 36, 244-250.

Harvey, J. H., \& Miller, E. D. (1998). Toward a psychology of loss. Psychological Science, 9, 429-434.

Havighurst, R. J., Munnichs, J. M. A., Neugarten, B., \& Thomae, H. (1969). Adjustment to retirement: A cross-national study. New York: Humanities Press.

Janssen, E., van Osch, L., De Vries, H., \& Lechner, L. (2012). The influence of narrative risk communication on feelings of cancer risk. British Journal of Health Psychology, 18, 407-419. doi: 10.1111/j.2044-8287.2012.02098.x 
Kim, J. E., \& Moen, P. (2002). Retirement transitions, gender and psychological wellbeing: A life course ecological model. Journal of Gerontology, 57B, 212-222. doi: $10.1348 / 096317905 \times 68204$

Leandro-França, C., Murta, S., \& Villa, M. (2014). Efeitos de uma intervenção breve no planejamento da aposentadoria [Effects of a brief intervention in retirement planning] Revista Psicologia: Organizações e Trabalho, 14, 257-270.

Lee, W. K. M., \& Law, K. W. K. (2004). Retirement planning and retirement satisfaction: The need for a national retirement program and policy in Hong Kong. Journal of Applied Gerontology, 23, 212-233. doi: 10.1177/0733464804268591

Lemal, M., \& van den Bulck, J. (2010). Testing the effectiveness of a skin cancer narrative in promoting positive health behavior: A pilot study. Preventive Medicine, 51, 178181. doi: 10.1016/j.ypmed.2010.04.019

Miller, W., \& Rollnick, S. (2002). Motivational interviewing: Preparing people to change addictive behavior (2nd ed.). New York, NY: Guilford Press.

Noone, J., Stephens, C., \& Alpass, F. (2009). Pre-retirement planning and well-being in later life: A prospective study. Research on Aging, 31, 295-317. doi:10.1177/0164027508330718

Norcross, J., Krebs, P., \& Prochaska, J. (2011). Stages of changes. Journal of Clinical Psychology: In Session, 2, 143-154. doi: 10.1002/jclp.20758

Petkoska, J., \& Earl, J. (2009). Understanding the influence of demographic and psychological variables on Retirement Planning. Psychology and Aging, 24, 245251. doi: $10.1037 / \mathrm{a} 0014096$

Prochaska, J., \& DiClemente, C. (1983). Stages and processes of self-change of smoking: Toward an integrative model of change. Journal of Consulting and Clinical Psychology, 51, 390-395. 
Prochaska, J., \& DiClemente, C. (1992). Stages of change in the modification of problem behaviors. Em M. Hersen, M. Eiser \& W. Miller (Orgs.), Progress in behavior modification (pp.184-214). Sycamore: Sycamore Press.

Prochaska, J. O., Velicer, W. F., Rossi, J. S., Goldstein, M. G., Marcus, B. H., Rakowski, ... Rossi, S. R. (1994). Stages of change and decisional balance for twelve problem behaviors. Health Psychology, 13, 39-46.

Scott, K., \& Wolfe, D. (2003). Readiness to change as a predictor of outcome in batterer treatment. Journal of Consulting and Clinical Psychology, 71, 879-889.

Taylor-Carter, M.A., Cook, K., \& Weinberg, C. (1997). Planning and expectations of the retirement experience. Educational Gerontology, 23, 273-288.

The Economist. Brazil's pension system: Tick, tock (March, 24th, 2012). Retrieved from http://www.economist.com/node/21551093

van Solinge, H., \& Henkens, K. (2008). Adjustment to and satisfaction with retirement: Two of a kind? Psychology and Aging, 23, 422-434. doi: 10.1037/08827974.23.2.422

Wang, M. (2012). Retirement research: Concluding observations and strategies to move forward. In M. Wang (Ed.), The Oxford handbook of retirement (pp. 603-615). New York: Oxford University Press.

Wang, M., Henkens, K., \& van Solinge, H. (2011). Retirement Adjustment: A Review of Theoretical and Empirical Advancements. American Psychologist, 66, 204-213. doi: $10.1037 / \mathrm{a} 0022414$

Wilk, A. I., Jensen, N. M., Tomas, M.S., \& Havighurst, T. C. (1997). Meta-analysis of randomized control trials addressing brief interventions in heavy alcohol drinkers. Journal of General Internal Medicine,12, 274 -283. 
Wong, J., \& Earl, J. (2009). Towards an integrated model of individual, psychosocial, and organizational predictors of retirement adjustment. Journal of Vocational Behavior, 75, 1-13. doi:10.1016/j.jvb.2008.12.010 


\section{CAPíTULO 8}

\section{Conclusões}


O aumento na longevidade da população brasileira e sua consequência para a sociedade têm inserido a aposentadoria e envelhecimento como uma das principais pautas de agendas políticas e científicas atuais. É consenso na literatura especializada que a aposentadoria não é um evento isolado no ciclo de desenvolvimento humano, mas, um processo o qual as pessoas percorrem no decorrer dos anos de suas vidas (Shultz \& Wang, 2011). Para esses autores, o processo de aposentadoria pode ser descrito em três etapas: preparação pré-aposentadoria ou planejamento para aposentadoria, processo de tomada de decisão para aposentadoria e ajustamento ou adaptação à aposentadoria. Ao compreender a aposentadoria como um processo nota-se a importância de se investir no planejamento da aposentadoria ao longo da vida.

Desse modo, os programas de preparação mostram-se como alternativas viáveis a essa finalidade, a julgar pelos seus benefícios no que se refere ao auxílio na preparação, tomada de decisão e adaptação à aposentadoria (França, Menezes, Bendassolli, \& Macedo, 2013; Leandro-França, Murta, Hershey, \& Barbosa, 2016; Seidl, Leandro-França, \& Murta, 2014a). Entretanto, evidências sobre a eficácia desses programas são escassas. Para suprir essa lacuna, o principal objetivo desta tese foi avaliar o efeito de três programas (longo, breve e testemunho) de planejamento ou preparação para aposentadoria. Buscouse, especificamente, responder a seguinte questão de pesquisa:

Em que extensão três diferentes programas ou intervenções de preparação para a aposentadoria promovem maior bem-estar subjetivo, perspectiva de tempo futuro relativo à aposentadoria e mudanças em comportamento de planejamento para aposentadoria? Como objetivo secundário, verificou-se a validade social desses programas, considerando a relevância dos objetivos, aceitabilidade dos procedimentos e importância social desses programas. 
Para responder a essas questões de pesquisa, foi realizado um estudo experimental, com amostras randomizadas, e avaliações pré-intervenções e de follow-up, seis meses após a finalização dos programas. A pesquisa contou com a participação de trinta servidores, de quatro organizações públicas brasileiras, com idade de 51 a 67 anos, e comparou resultados entre os programas (longo, breve e testemunho) e um grupo controle, explorando ainda a validade social desses programas. Métodos mistos, qualitativos e quantitativos, foram utilizados na coleta e análises dos dados.

Em suma, os capítulos desta tese consistem de duas revisões narrativas, sendo uma sobre o envelhecimento e modalidades de intervenções na prevenção e promoção à saúde mental da pessoa idosa (Capítulo 2), e outra sobre as situações associadas à percepção e à vivência da aposentadoria como favorecedora de crise ou bem-estar (Capítulo 3) e de uma revisão integrativa sobre a qualidade dos programas de planejamento para aposentadoria, considerando critérios metodológicos e de eficácia (Capítulo 4). Adicionalmente, realizouse um estudo para testar evidências de uma escala sobre perspectiva de tempo futuro relativo à aposentadoria (Capítulo 5) e dois estudos empíricos, um com métodos mistos, para investigar a eficácia de três programas (longo, breve e testemunho) de planejamento para aposentadoria e a validade social dessas intervenções (Capítulo 6), e outro qualitativo, para averiguar os efeitos de três programas de preparação aposentadoria (longo, breve e testemunho), examinando as mudanças cognitivas, motivacionais e comportamentais e o progresso dos participantes através dos estágios do Modelo Transteórico de Mudança (Capítulo 7).

No presente capítulo, os principais achados desses estudos serão sumarizados com base na questão de pesquisa, objetivo principal e secundário e hipóteses desta tese. Em seguida, será discutida a relevância social e científica dos resultados, apontadas as 
limitações do estudo, descritas as considerações para uma agenda de pesquisa e, por fim, apresentadas as implicações para a prática profissional.

\section{Sumário dos Resultados}

Os principais achados desta tese são sumarizados abaixo conforme os estudos realizados:

No Capítulo 2 foram descritos os aspectos históricos, conceituais e intervenções sobre prevenção e promoção à saúde mental da pessoa idosa. Políticas nacionais que preveem direitos a uma velhice saudável foram abordadas como a Constituição de 1988, a Política Nacional do Idoso (Lei $\left.n^{0} 8.842 / 1994\right)$ Estatuto do Idoso (Lei $n^{0} 10.741 / 2003$ ). Dentre as políticas internacionais, destaca-se o Plano Internacional de Ação sobre o Envelhecimento - PIAE (WHO, 2002). As discussões desse plano possibilitaram à Organização Mundial da Saúde adotar, em 2002, o termo "Envelhecimento Ativo" para promover a visão da velhice como um processo natural do ciclo de vida que deve ser vivenciado com autonomia, independência, reconhecimento de direitos, segurança, dignidade, bem-estar e saúde. Em geral, as intervenções de prevenção e promoção da saúde mental das pessoas idosas são pautadas nos pilares da política sobre envelhecimento ativo. Essas intervenções são estratégias potenciais na promoção do empoderamento, saúde e cidadania, adaptação à aposentadoria, redução dos sintomas de depressão, ansiedade e na prevenção do suícidio.

O Capítulo 3 identificou as condições pessoais, psicológicas, sociais e organizacionais associadas à percepção e à vivência da aposentadoria como favorecedora de "crise ou liberdade". A vivência da aposentadoria como crise ou liberdade foi definida por Santos (1990) como uma dualidade de sentimentos, ou seja, de um lado estão os que vivenciam a aposentadoria como algo negativo e com sentimentos de desprazer e, do 
outro, estão os que percebem aposentadoria como uma oportunidade de mudança para uma vida com mais autonomia e bem-estar. As principais variáveis associadas à vivência da aposentadoria como "crise" envolvem o declínio da saúde física, problemas de saúde na família, escassez financeira, ausência de objetivos e projetos de vida, não aceitação da condição de aposentado, depressão, dificuldade no convívio conjugal, associar à aposentadoria à velhice, morte, fracasso e inutilidade e aposentadoria abrupta e involuntária. Por outro lado, a vivência da aposentadoria como bem-estar e "liberdade" é associada a ter boa relação conjugal, saúde física e psicológica, estilo de vida mais saudável, realizar práticas de lazer, religiosas e espirituais, de voluntariado e de atividade física, possuir moradia, segurança financeira, apoio social e familiar, planejar a aposentadoria com antecedência, aposentar de forma voluntária e gradual. A obtenção de uma aposentadoria bem sucedida dependerá dos recursos que cada pessoa possui e da aquisição e mudanças desses recursos ao longo da vida (Wang, Henkens, \& van Solinge, 2011). Com base nesses recursos e sua aplicabilidade, ao final deste capítulo foram apresentadas estratégias que favorecem a adaptação e a qualidade de vida na aposentadoria e que podem ser adotadas por profissionais que trabalham com esse público como forma de orientar trabalhadores que se encontram nesse processo.

O Capítulo 4 avaliou a qualidade dos programas de planejamento para aposentadoria, descritos na literatura da área, considerando critérios metodológicos e de eficácia dos programas. Os resultados revelaram fragilidades nos critérios metodológicos e de eficácia nos estudos analisados apontando escassez de delineamentos experimentais ou quase-experimental, grupo controle, falta de instrumentos previamente validados, de avaliações longitudinais dos programas e de procedimentos mais robustos para análise de dados. Resultados dos estudos analisados mostram que os programas investigados promoveram o aumento do conhecimento, mudanças positivas nas atitudes relacionadas à 
aposentadoria e um aumento em comportamentos de planejamento e preparação para aposentadoria. Entretanto, em função das deficiências metodológicas e de eficácia apresentadas em grande parte desses estudos, não existem evidências suficientes para confirmar os resultados desses achados.

O Capítulo 5 testou evidências de validade de uma escala que investiga perspectiva de tempo futuro relativa à aposentadoria. A análise fatorial da escala revelou estrutura unifatorial, índice de consistência interna aceitável $(\alpha=0,74)$, com cargas que variaram entre .43 e .66 e propriedades psicométricas satisfatórias. Para nomear o fator extraído foi mantido o nome da escala "Perspectiva de Tempo Futuro relativo à Aposentadoria- EPersTFA". Decidiu-se por uma solução unifatorial pela sua robustez e adequação a critérios teóricos. Os resultados revelaram que a estrutura unifatorial encontrada mostrou-se adequada para investigar PTF não somente em jovens, como frequentemente investigado na literatura especializada (Schmitt, 2010; Vansteenkiste, Simons, Soenens, \& Lens, 2004), mas também em trabalhadores de meia idade e mais velhos.

O Capítulo 6 avaliou a eficácia de três programas (variável independente) de preparação para aposentadoria (longo, breve e testemunho), comparou resultados entre essas modalidades e um grupo controle, antes e seis meses após suas realizações, quanto ao maior bem-estar subjetivo, melhor perspectiva de tempo futuro relativa à aposentadoria e mudanças de comportamentos em planejamento para aposentadoria (variáveis dependentes). Ademais, investigou a validade social desses programas.

Em resposta à pergunta de pesquisa deste estudo "Em que extensão três diferentes programas de preparação para aposentadoria promovem maior bem estar subjetivo melhor perspectiva de tempo futuro relativa à aposentadoria e mudanças de comportamentos em planejamento para aposentadoria?", os dados da estatística descritiva apontam 
superioridade das três intervenções sobre o grupo controle quanto à promoção de maior bem-estar subjetivo. Acrescenta-se que os achados são inconclusivos quanto o potencial da intervenção longa sobre as demais intervenções. Adicionalmente, não se pode afirmar a superioridade das três intervenções sobre o grupo controle nas demais variáveis. Por fim, os dados das análises inferenciais indicam ausência de diferença entre as condições experimentais. Estes achados não podem ser generalizados para a população em virtude das limitações da amostra.

Os dados revelaram ainda alta aceitabilidade e satisfação dos participantes com os procedimentos dos programas com destaque para temas das palestras, dinâmicas de interação, metodologia utilizada, ambiente acolhedor e empatia dos facilitadores. Eles também elegeram a troca de experiências entre os participantes como algo que mais gostaram nos programas. A relevância dos objetivos e importância social dos efeitos das intervenções foi evidenciada, especialmente para as intervenções longa e breve, a julgar que grande parte dos participantes relatou que a maioria de seus interesses foi atendida, que os programas os ajudaram a lidar melhor com o planejamento de suas aposentadorias e que os recomendaria a um amigo ou familiar caso eles necessitassem de ajudar similar.

O Capítulo 7 apresentou os efeitos dos três programas (longo, breve e testemunho) de preparação para aposentadoria. O foco da análise deste estudo foi estabelecer se os participantes apresentaram alterações cognitivas, motivacionais e/ou comportamentais e verificar o progresso dos participantes através dos estágios do Modelo Transteórico de Mudança durante o período de follow-up de seis meses após finalização dos programas. Do ponto de vista das análises qualitativas, os dados apontam superioridade da intervenção longa sobre a intervenção breve e desta sobre a intervenção testemunho na promoção de mudanças comportamentais, motivacionais e cognitivas em planejamento para a aposentadoria e nos estágios de mudança, conforme o Modelo Transteórico. Estes dados 
qualitativos contradizem os achados quantitativos relatados no Capítulo 6, especialmente quanto à variável "mudanças em comportamentos de planejamento para aposentadoria", tendo em vista que neste estudo os três diferentes programas promoveram mudanças cognitivas, motivacionais e comportamentais (mudanças em saúde, finanças, atividades sociais, produtivas e de lazer). Esses dados se mostram alinhados aos resultados sobre a validade social das intervenções quanto à importância dos seus efeitos, apresentados no Capítulo 6, a julgar que a qualidade de vida dos participantes, principalmente do programa longo, foi melhorada em função da intervenção (Francisco \& Butterfoss, 2007). Além disso, os resultados respondem à pergunta de pesquisa deste estudo ao apontar que essas intervenções facilitam o planejamento da aposentadoria e auxiliam os trabalhaores a se prepararem para essa fase da vida. Todavia, é clara a necessidade de novos estudos longitudinais com amostras maiores, mais representativas e randômicas, com junção de medidas quantitativas e qualitativas para esclarecer, confirmar ou refutar esses achados.

\section{Relevância Científica}

A principal contribuição científica deste estudo é ampliar o campo de pesquisa sobre planejamento e intervenções de preparação para aposentadoria e preencher lacunas na literatura quanto ao uso de delineamento experimental para investigar os efeitos desses

programas. A avaliação pode ser definida como um processo sistemático que tem por finalidade averiguar o mérito e relevância de um determinado programa ou política, contemplando seu desenho, implementação e resultados com base nos seus objetivos, visando eficiência e efetividade desses programas (Costa \& Castanhar, 2003; Wholey, Hatry, \& Newcomer, 2010).

Estudos em planejamento para aposentadoria têm focado em revisões teóricas, narrativas e análises exploratórias sobre preditores de ajustamento à aposentadoria, com 
atenção voltada ao planejamento financeiro (Leandro-França, van Solinge, Henkens, \& Murta, 2016). Ainda que reduzida, percebe-se que vem crescendo o interesse de pesquisadores em testar evidências de instrumentos que investiguem esse fenômeno. Em particular, os estudos sobre programas de preparação para aposentadoria, no Brasil, concentram-se, em sua maioria, em descrever os procedimentos e experiências dos profissionais com esses programas. Embora relevantes, a julgar pelos resultados promissores dessas experiências, os delineamentos adotados em grande parte desses estudos são frágeis quanto aos efeitos, eficácia e efetividade dessas ações. A revisão integrativa desta tese (Capítulo 4) apresenta as fragilidades metodológicas e de eficácia em estudos que descrevem e avaliam essas intervenções, em todo o mundo. Para suprir e carência da área, nessas questões metodológicas e de eficácia, o presente estudo fez uso de amostras randomizadas, grupo controle, instrumentos validados, medidas pré-intervenção e de follow-up e múltiplas medidas buscando oferecer evidências relativas à eficácia e limitações de intervenções em planejamento para aposentadoria.

Segundo Murta e Santos (2015), no contexto brasileiro, o estudo de desenvolvimento de intervenções para prevenir diferentes problemas e para promover saúde mental em ambientes diversos é deficiente quanto à avaliação de eficácia e efetividade. O desenvolvimento de intervenções deve percorrer etapas ou uma cadeia de produção de conhecimento como: 1. Estudos epidemiológicos (descrição do problema, prevalência e incidência), 2. Estudos etiológicos (fatores de risco e proteção), 3. Estudos de desenvolvimento (piloto da intervenção), 4. Estudos de eficácia (efeitos da intervenção), 5. Estudos de efetividade (generalização dos resultados), 6. Estudos de difusão (disseminação da intervenção) e 7. Estudos de adaptação cultural (adaptação da intervenção para novas culturas). 
Considerando que os programas de preparação são práticas de prevenção de doenças e de promoção à saúde mental dos trabalhadores, percebe-se que os estudos sobre planejamento para aposentadoria englobam as três etapas iniciais (epidemiológica, etiológica e de desenvolvimento) do ciclo da pesquisa em prevenção em saúde mental (Mrazek \& Haggerty, citado em Murta \& Santos, 2015). Nessa perspectiva, estudos de eficácia como o realizado na presente tese são relevantes, necessitam ser aprimorados em suas limitações e replicados em outros contextos para o avanço da pesquisa na área, rumo ao alcance das etapas de disseminação e adaptação cultural dessas intervenções.

Uma segunda contribuição científica deste estudo para a área de planejamento para aposentadoria foi investigar a modalidade de intervenção (programa testemunho), usual em organizações brasileiras, mas escassa na literatura especializada. Embora tenha apresentado efeito limitado quando comparada à intervenção longa e breve, a intervenção testemunho teve uma elevada aceitabilidade pela maioria dos participantes, que avaliaram sua qualidade como excelente, destacando como pontos positivos a troca de experiências, interação, procedimentos e estratégias utilizadas.

A terceira contribuição está relacionada à investigação da validade social das três intervenções. Averiguar a validade social preenche a lacuna na literatura da área no que se refere ao uso desse tipo de avaliação. Os achados dessa pesquisa fortalecem a validade social dessas intervenções por meio dos altos índices de relevância dos objetivos, aceitabilidade dos procedimentos e importância social detectados nos resultados. Portanto, os dados corroboram a literatura (Francisco \& Butterfoss, 2007) ao demonstrarem que estudos sobre saúde pública e pesquisas com a participação da comunidade, não devem basear suas análises apenas nos resultados do teste de significância estatística, para não perder a essência das dimensões sociais como o impacto da intervenção na vida dos participantes e efeitos na comunidade. Assim, o uso de multimétodos de avaliação e 
análises é recomendado em estudos sobre avaliação de intervenções ou programas de planejamento para aposentadoria.

Por fim, outra colaboração científica deste estudo são os resultados de impacto (em termos de mudança comportamental) de três programas de preparação para a aposentadoria usando os estágios do Modelo Transteórico de Mudança. Este modelo fornece insights sobre os estágios de mudança de comportamento e sobre como o processo de mudança ocorre. O conhecimento deste processo pode ser útil aos facilitadores de programas de preparação para aposentadoria no auxílio aos trabalhadores quanto à gestão dos últimos anos de suas carreiras.

\section{Relevância Social}

Um dos principais desafios em saúde pública no mundo atual é conter o crescente índice de doenças crônicas e a diminuição do bem-estar na velhice, pois embora a expectativa de vida tenha aumentado, não significa que as pessoas estejam vivendo melhor (WHO, 2014). Desse modo, planejar e investir em programas eficientes que promovam qualidade de vida e bem-estar na velhice é estratégia útil e em conformidade com as políticas nacionais e internacionais de promoção ao envelhecimento ativo.

Mediante o aumento na expectativa de vida, estima-se que as pessoas viverão mais tempo na condição de $\operatorname{aposentado(a).~A~maneira~como~as~pessoas~vivenciarão~suas~}$ aposentadorias, se em situações de crise ou bem-estar, dependerá dos recursos internos ou externos que elas possuem (Leandro-França, 2014; Leandro-França \& Murta, 2014a; Santos, 1990). A instabilidade política-econômica no Brasil atual e as possíveis mudanças em leis previdenciárias provavelmente afetarão a percepção, sentimentos e a vivência dos trabalhadores sobre essa fase da vida. Posto isso, as intervenções de planejamento para aposentadoria mostram-se pertinentes como espaço terapêutico de acolhimento, reflexão e 
escuta quanto às crises psicológicas, à insegurança na tomada de decisão, às perdas salariais, à elaboração de planos de ocupação pós-carreira, entre outras questões. Em adição, tais ações serão úteis na promoção da resiliência, da autoeficácia, de investimentos em mudanças cognitivas, motivacionais e comportamentais que favoreçam esse período da vida.

Ademais, como contribuição social, as informações apresentadas nesta tese podem ajudar os diversos atores (stakeholders) ou envolvidos no desenvolvimento, implantação, avaliação, adoção e recepção de programas de preparação para aposentadoria, incluindo aqueles que legislam sobre o assunto, os que financiam esses programas, os profissionais que os executam como também os que recebem tais ações (Wholey et al., 2010).

As modalidades analisadas no presente estudo, de longa e curta duração, poderão ainda subsidiar organizações, públicas ou privadas, quanto à escolha de um programa compatível com suas necessidades, considerando, por exemplo, a viabilidade econômica e potencial de cada ação. Práticas de baixo custo como a intervenção breve e testemunho, podem ser alternativas viáveis no contexto econômico brasileiro atual, tendo em vista a vulnerabilidade aos cortes no orçamento público. Logo, esses programas são eficientes para obter uma dose mínima de informações sobre planejamento para aposentadoria considerando o baixo custo para implantá-los. Por fim, espera-se que os resultados dos estudos apresentados nesta tese fomentem uma agenda de pesquisa em serviços de promoção de saúde e qualidade de vida dos trabalhadores em transição para a aposentadoria. 


\section{Limitações do Estudo}

A principal limitação refere-se ao pequeno tamanho da amostra. $\mathrm{O}$ reduzido número de participantes neste estudo impossibilitou análises aprofundadas entre a variável independente, as dependentes e análises de correlações entre variáveis como idade, escolaridade, sexo e estado civil. Ao analisar os resultados encontrados no presente estudo observa-se que embora os participantes tenham sido alocados aleatoriamente, o pequeno tamanho da amostra $(n=30)$ pode ter prejudicado a randomização e falhado em fornecer, por exemplo, amostras estratificadas por gênero, a julgar que no programa breve a amostra foi composta apenas por mulheres. Convém ressaltar que o pequeno tamanho da amostra reduz o poder estatístico e ameaça a validade de conclusão estatística (Kazdin, 2010; Dancey \& Reidy, 2013). Portanto, os dados de não significância apresentados em um dos estudos empírico desta tese (Capítulo 6) devem ser analisados com cautela e considerar essa limitação.

Por outro lado, embora considerada uma amostra pequena para uso de análises estatísticas robustas, o tamanho da amostra atende os pressupostos de uma avaliação qualitativa. Isto favoreceu a exploração de relatos dos participantes quanto aos efeitos das intervenções em relação às mudanças de comportamentos em planejamento para aposentadoria apresentadas no capítulo 7 e as análises de validade social descritas no capítulo 6. Destaca-se ainda que por meio dos métodos e análises qualitativas utilizadas nesta pesquisa foi possível compreender e esclarecer os resultados do grupo controle, no follow-up, algo que não seria acessado apenas com a utilização de instrumentos quantitativos.

A segunda limitação está relacionada à validade externa ou generalização dos resultados. O fato de ter sido utilizada uma amostra de trabalhadores altamente qualificados, com bom poder aquisitivo, de apenas quatro organizações públicas brasileiras 
e de uma unidade federativa, não permite generalização dos dados para a população como um todo.

Em terceiro lugar, o programa testemunho investigado neste estudo apresentou apenas as experiências (relato) de uma trabalhadora aposentada. Há, no entanto, evidências na literatura que os homens e as mulheres diferem no que diz respeito ao planejamento, adaptação e satisfação na aposentadoria (Barbosa, Monteiro, \& Murta, 2016; Kim \& Moen, 2002; Leandro-França \& Murta, 2014a; Petkoska \& Earl, 2009). Pesquisas futuras devem, portanto, examinar o impacto do testemunho de um aposentado do sexo masculino em uma amostra composta de ambos os sexos e comparar seus resultados com os deste estudo.

\section{Agenda de Pesquisa}

A partir dos resultados obtidos e limitações deste estudo são apontadas outras questões que poderão ser esclarecidos em estudos futuros. Assim, como direções para futuras pesquisas, sugere-se a aplicação de um delineamento experimental numa amostra maior, que possibilite métodos inferenciais mais robustos. Para essa finalidade, recomenda-se o cálculo de tamanho de amostra com o objetivo de ter uma estimativa do número suficiente de participantes que o pesquisador precisará para explorar vários tipos de análises, o tamanho do efeito e o poder do teste (Field, 2013).

Considerando as restrições em recursos financeiros e equipes de coleta, sugere-se a replicação deste estudo utilizando apenas um tipo de intervenção (longo, breve ou testemunho) e um grupo controle. Esta sugestão viabiliza a ampliação da amostra e exploração de métodos estatísticos inferenciais. Uma amostra maior permitirá análises de variáveis mediadoras ou moderadora dos efeitos das intervenções, incluindo variáveis como gênero, idade, tempo de contribuição, estado civil, atitudes frente à aposentadoria 
numa perspectiva individual, social, familiar, política, econômica e organizacional (França, 2004) e fatores terapêuticos de grupos como suporte social e coesão grupo (Yalom \& Leszcz, 2006). Variáveis sócio-organizacionais também podem ser investigadas como ageísmo (França, Bendassolli, \& Menzes, 2013; Silva \& França, 2015) e práticas de gestão de pessoas que auxiliem os trabalhadores mais velhos na transição para aposentadoria. Essas práticas estão associadas à redução da carga horária de trabalho, flexibilidade da jornada de trabalho, teletrabalho, redefinição do cargo em função da experiência, atuação como mentor de trabalhadores menos experientes, treinamentos para adquirir e/ou desenvolver novas competências, práticas de reconhecimento e valorização pelo legado deixado à organização (Armstrong-Stassen, 2008; França et al. 2014; Menezes \& França, 2012).

Para fins de generalização dos resultados, propõem-se incluir na amostra os trabalhadores de organizações privadas, de outras categorias profissionais da administração pública, de outras unidades federativas brasileiras, com níveis de escolaridade diversos, de várias classes sociais e diferentes culturas. Recomenda-se ainda que estudos futuros invistam em avaliações econômicas (custo-benefício versus custoefetividade) desses programas. O objetivo da avaliação econômica é verificar a viabilidade econômica dos programas, se o benefício gerado por eles é maior que seus custos e ajudar os gestores na tomada de decisão na escolha do programa mais eficiente (Wholey et al., 2010).

Por fim, orienta-se que sejam realizados estudos com delineamento longitudinal para acompanhar os participantes durante os anos da aposentadoria e verificar o alcance das metas distais apresentadas no modelo lógico desta tese. No acompanhamento longitudinal, a variável bridge employment (trabalho remunerado realizado na transição para aposentadoria ou após o indivíduo se aposentar e começar a receber a aposentadoria) 
pode ser investigada (Dingemans, 2016; Menezes \& França, 2012). A longevidade da população brasileira, aliada às contínuas mudanças na legislação previdenciária e à instabilidade econômica, pode aumentar o número de pessoas aposentadas que necessitam ou desejam continuar trabalhando seja em razão da sustentação financeira individual e de suas famílias ou por se sentirem ativas e saudáveis para continuarem suas atividades laborais. Dessa forma, investigar a relação entre bridge employment e bem-estar ajudará a definir novas formas de planejar a aposentadoria e de promover o envelhecimento ativo.

\section{Implicações para a Prática Profissional}

No contexto prático, acredita-se que este estudo trará benefícios aos profissionais que desenvolvem e executam os programas de preparação para aposentadoria a julgar pelos dados aqui apresentados como a descrição detalhada dos procedimentos adotados nos programas de longa e de curta duração e o potencial de cada intervenção.

Os profissionais que coordenam e executam essas ações, nomeados como facilitadores, devem ficar atentos especialmente aos resultados da validação social dessas intervenções. Como em geral os programas de preparação para aposentadoria em seu formato longo adotam características informativas e vivenciais semelhantes às realizadas nos estudos empíricos desta tese, sugere-se que os facilitadores direcionem sua atenção aos relatos dos participantes, sobre o que mudar e o que manter nos programas e com relação ao que menos gostaram e o que mais gostaram, pois esses dados podem ser úteis no aprimoramento das técnicas e procedimentos usualmente realizados nessas ações.

Dados deste estudo revelam ainda que a troca de experiência e interação entre os participantes são importantes fatores terapêuticos que atuam como mecanismos de mudanças nas práticas psicoterapêuticas grupais (Yalom \& Leszcz, 2006). Aliado a esses fatores terapêuticos, o ambiente acolhedor e uma escuta empática por parte do facilitador 
do grupo, mostram-se como padrões comportamentais ou habilidades que também propiciam à mudança e o fortalecimento de vínculos entre os participantes do grupo. Desse modo, recomenda-se que facilitadores dos programas de preparação para aposentadoria favoreçam a ocorrência desses fatores como forma de potencializar os benefícios dessas ações. 


\section{Referências}

Armstrong-Stassen, M. (2008). Organizational practices and the post-retirement employment experience of older workers. Human Resource Management Journal, 18, 36-53. doi: 10.1111/j.1748-8583.2007.00057.x

Barbosa, L., Monteiro, B., \& Murta, S. (2016). Retirement adjustment predictors: A systematic review. Work, Aging and Retirement, 2, 262-280, doi:10.1093/workar/waw008.

Constituição da República Federativa do Brasil (1988). Brasília, Brasil. Retirado de http://www.planalto.gov.br/ccivil_03/constituicao/constituicao.htm

Costa, F., \& Castanhar, J. C. (2003). Avaliação de programas públicos: Desafios conceituais e metodológicos. RAP - Revista de Administração Pública, 37, 969992.

Dancey, C. \& Reidy, J. (2013). Questões de significância. In Dancey, C. \& Reidy, J (Eds.). Estatística sem matemática para a psicologia (pp. 250-268). Porto Alegre: Penso.

Dingemans, E.A.A. (2016). Working after retirement; determinants and consequences of bridge employment. Doctoral dissertation. University of Groningen, Holanda. doi:10.1093/workar/waw008

Field A. (2013). Discovering statistics using IBM SPSS statistics. New York: Sage.

Francisco, V., \& Butterfoss, F. (2007) Social validation of goals, procedures, and effects in public health. Health Promotion Practice, 8, 128-133.

França, L.H. (2004). Attitudes towards retirement: A cross-cultural study between New Zealand and Brazilian executives. PhD Thesis. Department of Psychology. The University of Auckland, New Zealand. 
França, L. H., Menezes, G., Bendassolli, P., \& Macedo, L. (2013). Aposentar-se ou continuar trabalhando? O que influencia essa decisão? Psicologia: Ciência $e$ Profissão, 33, $548-563$.

França, L. H., Nalin, C., Siqueira-Brito, A., Amorim, S., Rangel, T., \& Ekman, N.C. (2014). A percepção dos gestores brasileiros sobre os programas de preparação para aposentadoria. Estudos interdisciplinares sobre o envelhecimento, 19, 879898.

Kazdin, A. E. (2010). Research designs in clinical psychology ( $4^{\text {th }}$ Ed.). New York: Allyn and Bacon.

Kim, J. E., \& Moen, P. (2002). Retirement transitions, gender and psychological wellbeing: A life course ecological model. Journal of Gerontology, 57B, 212-222. doi: $10.1348 / 096317905 \times 68204$

Leandro-França, C. (2014). Aposentadoria: Crise ou liberdade. In Murta, S., LeandroFrança, C., \& Seidl. J. (Eds.). Programas de educação para aposentadoria: Como planejar, implementar e avaliar (pp. 54-65). Novo Hamburgo: Sinopsys.

Leandro-França, C., \& Murta, S. (2014a). Fatores de risco e de proteção na adaptação à aposentadoria. Revista Psicologia Argumento, 32, 33-43. doi:10.7213/psicol.argum.32.076.DS03.

Leandro-França, C., Murta, S., Hershey, D., \& Barbosa, L. (2016). Evaluation of retirement planning programs: A qualitative analysis of methodologies and Efficacy. Educational Gerontology, 42, 497-512.

doi: $10.1080 / 03601277.2016 .1156380$

Leandro-França, C.,van Solinge, H., Henkens, K., \& Murta, S. (2016). Effects of three types of retirement preparation program: A qualitative study of civil servants in Brazil. Educational Gerontology, 42, 388-400. doi:10.1080/03601277.2016.1139969 
Lei $\mathrm{n}^{\circ}$ 10.741. (2003, $1^{\circ}$ de outubro). Estatuto do Idoso, Diário Oficial da União, Brasil. Retirado de http://www.planalto.gov.br/ccivil_03/leis/2003/L10.741.htm

Lei $n^{\circ} .8 .842$, de 04 de janeiro de 1994 (1994). Dispõe sobre a Política Nacional do Idoso. Retirado de http://www.planalto.gov.br/ccivil_03/leis/L8842.htm

Menezes, G., \& França, L. H. (2012). Preditores da decisão da aposentadoria por servidores públicos federais. Revista Psicologia, Organizações e Trabalho, 12, 315-328.

Murta, S., \& Santos, K. (2015). Desenvolvimento de programas preventivos e de promoção de saúde mental. In S., Murta, C., Leandro-França, K., Santos, \& L., Polejack (Eds.). Prevenção e promoção em saúde mental: Fundamentos, planejamento e estratégias de intervenção (pp. 168-191). Novo Hamburgo: Sinopsys.

Petkoska, J. \& Earl, J. (2009). Understanding the influence of demographic and psychological variables on retirement planning. Psychology and Aging, 24, 24551. doi: $10.1037 / \mathrm{a} 0014096$

Santos, F. (1990). Identidade e Aposentadoria. São Paulo: E.P.U.

Schmitt, R. E. (2010). Teoria da perspectiva de tempo futuro: Aplicações preliminares e reflexões voltadas à pesquisa no ensino superior. Revista Educação por Escrito, 1, 516.

Seidl, J., Leandro-França, C., \& Murta, S. (2014) Formatos de programas de educação para aposentadoria. In S. Murta, C. Leandro-França \& J. Seidl. (Eds.). Programas de educação para aposentadoria: Como planejar, implementar e avaliar (pp. 84-113). Novo Hamburgo: Sinopsys.

Shultz, K. S., \& Wang, M. (2011). Psychological perspectives on the changing nature of retirement. American Psychologist, 66, 170-179. 
Silva, E.A., \& França, L. H. (2015). Violência contra idosos na cidade do Rio de Janeiro. Estudos e Pesquisas em Psicologia, 15, 155-177.

Vansteenkiste, M., Simons, J., Soenens, B., \& Lens, W. (2004). How to become a persevering exerciser? Providing a clear, future intrinsic goal in an autonomy supportive way. Journal of Sport and Exercise Psychology, 26, 232-249.

Wang, M., Henkens, K., \& van Solinge, H. (2011). Retirement adjustment: A review of theoretical and empirical advancements. American Psychologist, 66, 204-213. doi: $10.1037 / \mathrm{a} 0022414$

Wholey, J., Hatry, H., \& Newcomer, K. (2010). Handbook of practical program evaluation. 3. ed. Hoboken: John Wiley \& Sons.

World Health Organization - WHO. (2002). Active ageing: A policy framework. Madrid: World Health Organization.

World Health Organization, WHO. (2014). "Ageing well" must be a global priority. Retirado de http://www.who.int/mediacentre/news/releases/2014/lancet-ageingseries/en/

Yalom. I., \& Leszcz, M. (2006). Psicoterapia de grupo: Teoria e prática. Porto Alegre: Artmed. 


\section{Curriculum Vitae}

Cristineide Leandro-França é psicóloga, natural de Princesa Isabel, Paraíba, e reside em Brasília-DF desde 1995. Ela obteve o grau de Licenciatura (1992) e Bacharelado (1993) em Psicologia, pelo Centro Universitário de João Pessoa (UNIPÊ). Em 2012, obteve o grau de Mestra (2010-2012) em Psicologia Clínica pela Universidade de Brasília e nesse mesmo ano deu seguimento a sua carreira como pesquisadora, ingressando no Doutorado no Programa de Pós-Graduação em Psicologia Clínica e Cultura da UnB (20122016).

A motivação em estudar o planejamento para aposentadoria e as diversas modalidades de intervenção que favorecem tal processo é oriunda da atuação profissional da pesquisadora como psicóloga da Universidade de Brasília e sua participação no desenvolvimento, implantação e acompanhamento de ações de prevenção e promoção da saúde mental como o programa de preparação para aposentadoria dessa instituição, intitulado Programa Viva Mais! (Murta et al., 2010).

A carência e necessidade de outras modalidades de intervenção com esse público, além dos programas usuais de preparação para aposentadoria de longa duração, foram determinantes para estimular o interesse da pesquisadora em investigar, no mestrado (França, 2012), programas de curta duração como intervenção breve com foco no planejamento para aposentadoria. Como resultado do mestrado, cinco estudos foram publicados: França, Murta, Negreiros, Pedralho e Carvalhedo (2013); Leandro-França e Murta (2014a); Leandro-França, Murta e Iglesias (2014); Leandro-França, Murta e Villa, (2014); Leandro-França, Seidl e Murta (2016).

Ainda que no seu estudo de mestrado tenha sido utilizado um delineamento de seguimento (medidas aos dois, quatro e onze meses após o término da intervenção) e métodos mistos para análise do processo e resultados da intervenção, o delineamento não 
contou com uma amostra randomizada e um grupo controle, portanto, sendo considerado um estudo pré-experimental. Haja vista a escassez nessa área sobre estudos mais robustos quanto ao delineamento, ocorreu o interesse em avaliar no doutorado a eficácia de três intervenções com foco no planejamento para aposentadoria, por meio de um delineamento experimental, comparando resultados de um programa longo (modalidade usualmente realizada em organizações brasileiras), breve (modalidade desenvolvida no estudo de mestrado da pesquisadora), testemunho (modalidade inovadora criada para este estudo) e um grupo controle, antes e 06 meses após a finalização das intervenções.

Durante o período de estudo no Doutorado, a pesquisadora participou de congressos na área de aposentadoria e afins e da supervisão pedagógica do curso "Educação para Aposentadoria: Promoção de Saúde e Desenvolvimento na Administração Pública Federal", oferecido na modalidade a distância, a servidores públicos, pelo Centro de Educação a Distância - CEAD/UnB em parceria com o Ministério do Planejamento. Na ocasião, foram coletados dados para análise de evidência de validade da Escala Perspectiva de Tempo Futuro relativa à Aposentadoria - EPersTFA (capítulo 5). Além disso, o material didático e técnico utilizado no curso resultou na co-organização do livro "Programas de Educação para Aposentadoria: Como Planejar, Implementar e Avaliar" (Murta, LeandroFrança, \& Seidl, 2014). Um dos capítulos deste livro intitulado "Aposentadoria: Crise e Liberdade" compõe esta tese (capítulo 3).

Ademais, como aquisição de conhecimento no doutorado, a pesquisadora participou da coorganização do livro "Prevenção e Promoção em Saúde Mental: Fundamentos, Planejamento e Estratégias de Intervenção" (Murta, Leandro-França, Santos, \& Polejack, 2015), com coautoria em dois capítulos, sendo um deles um relato de experiência sobre intervenção de planejamento para aposentadoria em um grupo de homens de meia idade (Leandro-França, Santos, \& Pedralho, 2015). 
Ainda como produto do doutorado, no segundo semestre de 2015, ela realizou um estágio doutoral (doutorado sanduíche) em Netherlands Interdisciplinary Demographic Institute - NIDI (http://www.nidi.nl/en), vinculado à University of Groninghen, Holanda, o que originou a escrita e a publicação de dois artigos na língua inglesa, que integram esta tese. Estes artigos foram produzidos em coautoria com os pesquisadores holandeses Prof. Dr Kéne Henkéns e Dra. Hanna van Solinge (capítulo 7), o pesquisador Prof. Dr. Douglas Hershey, de Oklahoma State University (capítulo 6), sua orientadora Prof ${ }^{a}$. Dra. Sheila Giardini Murta e MSc. Leonardo Barbosa, colega do Grupo de Estudos em Prevenção e Promoção da Saúde no Ciclo da Vida- GEPPSVida-UnB (http://www.geppsvida.com.br/). 


\section{Referências}

França, C. (2012). Modelo de uma intervenção breve para planejamento da aposentadoria: Desenvolvimento e avaliação. Dissertação de Mestrado, Universidade de Brasília, Brasília, DF.

França, C., Murta, S., Negreiros, J., Pedralho, M., \& Carvalhedo, R. (2013). Intervenção breve na prepração para aposentadoria. Revista Brasileira de Orientação Profissional, 14, 99-110.

Leandro-França, C., \& Murta, S. (2014). Fatores de risco e de proteção na adaptação à aposentadoria. Revista Psicologia Argumento, 32, 33-43. doi:10.7213/psicol.argum.32.076.DS03.

Leandro-França, C., Murta, S., \& Iglesias, F. (2014). Planejamento da aposentadoria: Uma escala de mudança de comportamento. Revista Brasileira de Orientação Profissional, 15, 75-84.

Leandro-França, C., Murta, S., \& Villa, M. (2014). Efeitos de uma intervenção breve no planejamento da aposentadoria. Revista Psicologia: Organizações e Trabalho, 14, 257-270.

Leandro-França, C., Santos, J., \& Pedralho, M. (2015). Planejamento para aposentadoria: Relato de intervenção em um grupo de homens de meia-idade. In S., Murta, C., Leandro-França, K., Santos, \& L., Polejack (Eds.). Prevenção e promoção em saúde mental: Fundamentos, planejamento e estratégias de intervenção (pp. 823843). Novo Hamburgo: Sinopsys.

Leandro-França, C., Seidl, J., \& Murta, S. (2016). Intervenção breve como estratégia de planejamento para aposentadoria: Transformando intenções em ações, Psicologia em Estudos, 20, 543-553. doi: 10.4025/psicolestud.v20i4.27413. 
Murta, S., Oliveira, S., Siqueira, A. L., Carvalhedo, R., Gunther, I., Lira, N., \& Naves, M. (2010). Viva Mais! Programa de preparação para aposentadoria: Guia para participantes. Universidade de Brasília, Brasil.

Murta, S., Leandro-França, C., \& Seidl, J. (2014). Programas de educação para aposentadoria: Como planejar, implementar e avaliar. Novo Hamburgo: Sinopsys.

Murta, S., Leandro-França, C., Santos, K., \& Polejack, L. (2015). Prevenção e promoção em saúde mental: Fundamentos, planejamento e estratégias de intervenção. Novo Hamburgo: Sinopsys. 


\section{ANEXOS}


Anexo A. Autorização do Comitê de Ética

\section{INSTITUTO DE CIENCIAS HUMANAS / UNIVERSIDADE DE BRASÍLIA / CAMPUS}

\section{PARECER CONSUBSTANCIADO DO CEP}

\section{DADOS DO PROJETO DE PESQUISA}

Título da Pesquisa: PROGRAMA DE EDUCAÇÃO PARA APOSENTADORIA: AVALIAÇÃO DE EFICÁCIA

Pesquisador: Cristineide Leandro França

Área Temática:

Versäo: 1

CAAE: 30563814.6 .0000 .5540

Instituição Proponente: Instituto de Psicologia -UNB

Patrocinador Principal: Financiamento Próprio

DADOS DO PARECER

Número do Parecer: 707.387

Data da Relatoria: 30/05/2014

\section{Apresentação do Projeto:}

Trata-se de projeto de tese de doutorado que tem por objetivo avaliar a eficácia do programa de preparação para aposentadoria - Viva Mais, da Universidade de Brasília-UnB, considerando os estágios de mudança em comportamentos de planejamento da aposentadoria, bem-estar subjetivo e qualidade de vida.

Instrumentos para coleta de dados: Questionário Sociodemográfico, Escala de Bem-Estar Subjetivo (BES), Escala de Mudança de Comportamento para Planejamento da Aposentadoria (EMCPA), e Instrumento de Avaliação de Qualidade de Vida (WHOQOL-Bref). O tratamento estatístico dos dados, será realizado por meio do Statistical Package for the Social Sciences - SPSS.

O delineamento adotado nessa pesquisa será quase experimental com grupo controle (comparação) não equivalente e uma medida de follow-up a ser realizada 06 meses após a aplicação do pós-teste. Serão incluídos 90 participantes divididos em três grupos: 1) Grupo Experimental (GE) que receberá uma intervenção no formato continuado, 2) Grupo Breve (GB) que receberá uma intervenção no formato de oficina breve; e 3) Grupo Controle (GC) que não receberá nenhuma intervenção.

A variável independente é o Programa de Preparação para Aposentadoria Viva Mais que é

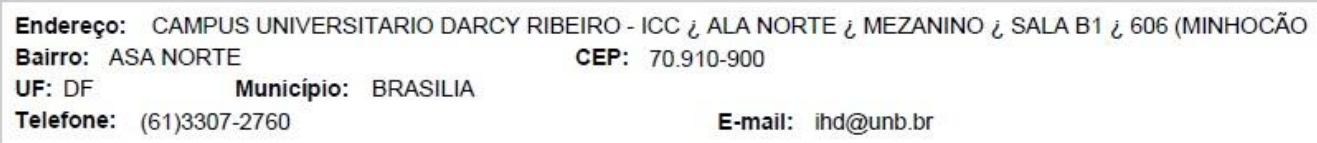




\section{INSTITUTO DE CIENCIAS HUMANAS / UNIVERSIDADE DE BRASÍLIA / CAMPUS}

Continuação do Parecer: 707.387

composto por dois formatos: breve ( 3 horas de duração) e continuado (03 meses de duração). As variáveis dependentes desse estudo são fundamentadas nos principais objetivos do Programa: (a) estágios de mudança em comportamentos de planejamento da aposentadoria (b) promoção de bem-estar subjetivo e (c) promoção de saúde e qualidade de vida.

\section{Objetivo da Pesquisa:}

Objetivo Geral:

Avaliar a eficácia do Programa de preparação para aposentadoria - Viva Mais,

comparando os formatos que o compõe (breve e continuado) e nenhuma intervenção.

Objetivos Especificos:

1) Analisar a transição entre os estágios de mudança em comportamentos de planejamento da aposentadoria, adotados pelos sujeitos que participaram das intervenções continuada, breve e condição controle.

2) Avaliar se o Programa Viva Mais afeta o bem-estar subjetivo dos sujeitos que participaram da intervenção continuada em comparação com formato breve e condição controle.

3) Avaliar se o Programa Viva Mais promove qualidade de vida nos sujeitos que participaram da intervenção continuada comparando os resultados com o formato breve e condição controle. 
Avaliação dos Riscos e Benefícios:

Riscos: de acordo com a pesquisadora, o desenho da pesquisa não ocasionará potenciais riscos, individuais ou coletivos, decorrentes da participação dos servidores no estudo. Além disso, está explicitado o compromisso de proteger os dados dos participantes e manter sigilo sobre sua origem.

Benefícios: a realização do estudo poderá trazer benefícios para os servidores conforme explicitado a seguir:

a) Auxiliar os servidores, participantes do estudo, na tomada de decisão quanto ao melhor momento para aposentar, considerando os preditores de uma aposentadoria bem-sucedida e envelhecimento ativo, como previsto nos objetivos do Viva Mais.

b) Promover bem-estar e qualidade de vida aos participantes desse estudo.

c) Contribuir para o fortalecimento de ações direcionadas à preparação para aposentadoria

conforme previstas em políticas dirigidas a esse público como, por exemplo, Política Nacional do

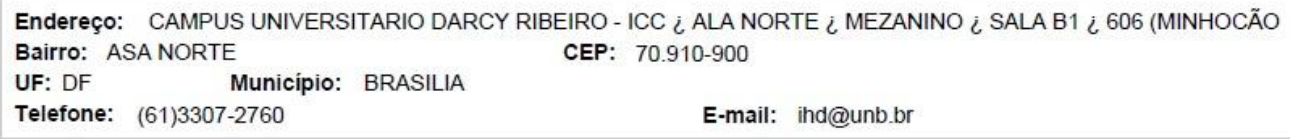

Página 02 de 04

\section{INSTITUTO DE CIENCIAS HUMANAS / UNIVERSIDADE DE BRASÍLIA / CAMPUS}

Continuação do Parecer: 707.387

Idoso,Estatuto do Idoso e Política de Atenção à Saúde do Servidor.

d) Contribuir para avaliação de programas de preparação para aposentadoria, possibilitando resultados eficientes e eficazes.

e) Gerar conhecimento para a área de programas de educação, preparação e/ou planejamento para aposentadoria.

\section{Comentários e Consideraçōes sobre a Pesquisa:}

1) Folha de Rosto: foi atualizada.

2) Carta de revisão ética: foi atualizada, incluindo a referência à Resolução N.466/20112.

3) Cronograma: Foi atualizado com a indicação que a pesquisa será iniciada após a conclusão da revisão ética.

\section{Consideraçōes sobre os Termos de apresentação obrigatória:}

1) Aceite institucional: assinado pela Sra Miriam Aparecida mesquita Oliveira, Diretora de Saúde, Segurança e Qualidade de Vida no Trabalho (DSQVT) da UnB.

2) Termos de Consentimento Livre e Esclarecido: forma anexados três documentos dirigidos aos grupos:Grupo experimental (GE); Grupo Breve (GB), e Grupo Controle (GC). Os documentos estão redigidos em conformidade com a Resolução 466/2012.

\section{Recomendaçōes:}

Conclusões ou Pendências e Lista de Inadequações:

As recomendações do parecer inicial foram atendidas.

\section{Situação do Parecer:}

Aprovado 


\section{Anexo B. Termo de Consentimento Livre e Esclarecido}

\section{Termo de Consentimento Livre e Esclarecido - TCLE}

Você está sendo convidado a participar da pesquisa "Avaliação de eficácia de intervenções de preparação para aposentadoria: um estudo comparativo", de responsabilidade de Cristineide Leandro França, aluna de doutorado da Universidade de Brasília. O objetivo desta pesquisa é avaliar a eficácia de intervenções longa e de curta duração de preparação Para Aposentadoria. Assim, gostaria de consultá-lo(a) sobre seu interesse e disponibilidade de cooperar com a pesquisa. Você receberá todos os esclarecimentos necessários antes, durante e após a finalização da pesquisa, e lhe asseguro que o seu nome não será divulgado, sendo mantido o mais rigoroso sigilo mediante a omissão total de informações que permitam identificá-lo(a). Os dados provenientes de sua participação na pesquisa, tais como questionários, entrevistas e fitas de gravação ficarão sob a guarda do pesquisador responsável pela pesquisa. A coleta de dados será realizada por meio de questionários, escalas, técnicas escritas e relatos de sua participação e interação nas intervenções. É para estes procedimentos que você está sendo convidado a participar. Sua participação na pesquisa não implica em nenhum risco.

Espera-se com esta pesquisa ajudá-lo no enfrentamento das vulnerabilidades decorrentes da transição para a aposentadoria, com a promoção do seu bem-estar e qualidade de vida, possibilitando assim uma decisão segura e a aquisição de uma aposentadoria bem-sucedida. Sua participação é voluntária e livre de qualquer remuneração ou benefício. Você é livre para recusarse a participar, retirar seu consentimento ou interromper sua participação a qualquer momento. A recusa em participar não irá acarretar qualquer penalidade ou perda de benefícios. Se você tiver qualquer dúvida em relação à pesquisa, você pode me contatar através do telefone 61.9216.4611 ou pelo e-mail cristineidel@unb.br. A equipe de pesquisa garante que os resultados do estudo serão devolvidos aos participantes por meio de emails pessoais, email institucional (InfoUnB) e página web da UnB, podendo ser publicados posteriormente na comunidade científica. Este projeto foi revisado e aprovado pelo Comitê de Ética em Pesquisa do Instituto de Ciências Humanas da Universidade de Brasília - CEP/IH. As informações com relação à assinatura do TCLE ou os direitos do sujeito da pesquisa podem ser obtidos através do e-mail do CEP/IH cep_ih@unb.br. Este documento foi elaborado em duas vias, uma ficará com o(a) pesquisador(a) responsável pela pesquisa e a outra com o senhor(a).

Assinatura do (a) participante

Assinatura do (a) pesquisador (a)

Brasília, de de 


\section{Termo de Consentimento Livre e Esclarecido - GRUPO CONTROLE (GC)}

Você está sendo convidado a participar da pesquisa "Avaliação de eficácia de intervenções de preparação para aposentadoria: um estudo comparativo", de responsabilidade de Cristineide Leandro França, aluna de doutorado da Universidade de Brasília. O objetivo desta pesquisa é avaliar a eficácia e avaliar a eficácia de intervenções de preparação Para Aposentadoria. Assim, gostaria de consultá-lo(a) sobre seu interesse e disponibilidade de cooperar com a pesquisa.

Você receberá todos os esclarecimentos necessários antes, durante e após a finalização da pesquisa, e lhe asseguro que o seu nome não será divulgado, sendo mantido o mais rigoroso sigilo mediante a omissão total de informações que permitam identificá-lo(a). Os dados provenientes de sua participação na pesquisa, tais como escalas e questionários, ficarão sob a guarda do pesquisador responsável pela pesquisa. Na coleta de dados, a sua participação consiste no preenchimento de escalas e um questionário em três momentos distintos. A princípio, é para estes procedimentos que você está sendo convidado a participar. Você integrará um Grupo de lista de espera e quando a pesquisa finalizar poderá participar do programa Viva Mais, no formato continuado (13 encontros), se desejar. Sua participação na pesquisa não implica em nenhum risco. Espera-se com esta pesquisa ajudar os trabalhadores no enfrentamento das vulnerabilidades decorrentes da transição para a aposentadoria, com a promoção do bem-estar e qualidade de vida, possibilitando assim uma decisão segura e a aquisição de uma aposentadoria bem-sucedida. Sua participação é voluntária e livre de qualquer remuneração ou benefício. Você é livre para recusar-se a participar, retirar seu consentimento ou interromper sua participação a qualquer momento. A recusa em participar não irá acarretar qualquer penalidade ou perda de benefícios. Se você tiver qualquer dúvida em relação à pesquisa, você pode me contatar através do telefone 61.9216.4611 ou pelo email cristineidel@unb.br. A equipe de pesquisa garante que os resultados do estudo serão devolvidos aos participantes por meio de emails pessoais, email institucional (InfoUnB) e página web da $U n B$, podendo ser publicados posteriormente na comunidade científica.

Este projeto foi revisado e aprovado pelo Comitê de Ética em Pesquisa do Instituto de Ciências Humanas da Universidade de Brasília - CEP/IH. As informações com relação à assinatura do TCLE ou os direitos do sujeito da pesquisa podem ser obtidos através do e-mail do CEP/IH cep_ih@unb.br. Este documento foi elaborado em duas vias, uma ficará com o(a) pesquisador(a) responsável pela pesquisa e a outra com o senhor(a). de de 


\section{Anexo C. Escala de Mudança em Comportamento de Planejamento para Aposentadoria}

No questionário abaixo listamos uma série de atividades que você talvez realize. Sabemos, no entanto, que as pessoas têm diferentes níveis de envolvimento com essas atividades. Por favor, marque com um "X" a opção que melhor representa o seu envolvimento com elas.

\begin{tabular}{|c|c|c|c|c|c|c|c|}
\hline & Atividades & $\begin{array}{c}\text { Não estou } \\
\text { interessado } \\
\text { nisto }\end{array}$ & $\begin{array}{c}\text { Venho pensando } \\
\text { em fazer algo } \\
\text { sobre isto }\end{array}$ & $\begin{array}{l}\text { Estou decidido a } \\
\text { fazer algo neste } \\
\text { sentido }\end{array}$ & $\begin{array}{c}\text { Comecei a } \\
\text { fazer, mas parei }\end{array}$ & $\begin{array}{c}\text { Comecei a } \\
\text { fazer há pouco } \\
\text { tempo }\end{array}$ & $\begin{array}{l}\text { Já faço isto há } \\
\text { bastante tempo }\end{array}$ \\
\hline 1 & Praticar atividade física regularmente & & & & & & \\
\hline 2 & Ter uma alimentação mais saudável & & & & & & \\
\hline 3 & Fazer consultas e exames médicos de check-up & & & & & & \\
\hline 4 & $\begin{array}{l}\text { Ter investimentos financeiros para o futuro (exemplos: previdência privada, } \\
\text { imóveis, ações etc). }\end{array}$ & & & & & & \\
\hline 5 & $\begin{array}{l}\begin{array}{l}\text { Investir tempo na convivência familiar (exemplos: com pais, filhos, irmãos, } \\
\text { sobrinhos ou outros) }\end{array} \\
\end{array}$ & & & & & & \\
\hline 6 & Dedicar-me à relação com o/a meu/minha parceiro/a & & & & & & \\
\hline 7 & Cultivar minhas amizades & & & & & & \\
\hline 8 & $\begin{array}{l}\text { Dedicar-me a práticas espirituais ou religiosas (exemplos: oração, meditação, } \\
\text { cultos, missas, rituais em grupo, etc) }\end{array}$ & & & & & & \\
\hline 9 & $\begin{array}{l}\text { Participar de grupos na comunidade (exemplos: artísticos, políticos, esportivos, } \\
\text { clubes, associações etc). }\end{array}$ & & & & & & \\
\hline 10 & $\begin{array}{l}\text { Praticar atividades de lazer (exemplos: futebol, cinema, vôlei, academia, } \\
\text { viagens, leitura) }\end{array}$ & & & & & & \\
\hline 11 & Ter um hobby (exemplos: pintura, fotografia, pescaria, coleção) & & & & & & \\
\hline 12 & Fazer cursos de aperfeiçoamento em minha área & & & & & & \\
\hline 13 & $\begin{array}{l}\text { Investir em projetos que podem ser adaptados /executados a partir da } \\
\text { aposentadoria }\end{array}$ & & & & & & \\
\hline 14 & Fazer cursos de aprimoramento em outra área com vistas a uma segunda carreira & & & & & & \\
\hline 15 & Realizar trabalhos voluntários na comunidade & & & & & & \\
\hline
\end{tabular}


Anexo D. Carta Convite - Validação da Escala Perspectiva de Tempo Futuro relativa à Aposentadoria - EPersTFA (enviada via email)

\section{Caro(a) Servidor(a),}

Convidamos Vossa Senhoria para participar de uma pesquisa do Programa de PósGraduação em Psicologia Clínica e Cultura da Universidade de Brasília, como requisito parcial à obtenção do título de Doutor. Esta pesquisa esta sendo desenvolvida por Cristineide Leandro- França com orientação da prof ${ }^{\text {a }}$. Sheila Giardini Murta e tem por finalidade investigar a eficácia de intervenções de educação para aposentadoria, considerando, entre outras variáveis, a clareza de metas para aposentadoria e perspectivas para o tempo futuro.

Ao participar deste estudo você deve preencher um questionário, com apenas sete questões, que levará no máximo 2 minutos, sem qualquer prejuízo para você, podendo desistir de participar a qualquer momento. $\mathrm{O}$ seu consentimento livre e esclarecido será representado pelo preenchimento da pesquisa através do Link

Caso não concorde, basta desconsiderar este convite e não retornar o questionário, contudo agradecemos se o preencher completamente. Você não terá nenhum benefício direto, como também não terá nenhum tipo de despesa. Os dados coletados são confidenciais e serão utilizados somente para a realização desta pesquisa, não sendo divulgados para outra finalidade. Sua participação contribuirá para fortalecer o campo de pesquisas e ações em educação para aposentadoria.

Este projeto foi revisado e aprovado pelo Comitê de Ética em Pesquisa do Instituto de Ciências Humanas da Universidade de Brasília - CEP/IH (CAAE. 30563814.6.0000.5540).

Sempre que você quiser poderá pedir mais informações sobre a pesquisa através do email cristineide@unb.br

Atenciosamente,

Cristineide Leandro-França e Sheila Giardini Murta 
Anexo E. Escala Perspectiva de Tempo Futuro Relativa à Aposentadoria - EPersTFA

Na tabela abaixo, insira um X no espaço referente ao número que corresponda ao seu grau de concordância em cada item. É muito importante que o(a) senhor(a) responda a todos os itens.

\begin{tabular}{|l|l|l|l|c|c|c|c|}
\hline 1- DISCORDO PLENAMENTE & 2- DISCORDO & $\mathbf{3}$ - NEUTRO & 4- CONCORDO & \multicolumn{1}{l|}{ 5- CONCORDO PLENAMENTE } \\
\hline 1 & EU TENHO PENSADO MUITO SOBRE A QUALIDADE DE VIDA NA APOSENTADORIA & 1 & 2 & 3 & 4 & 5 \\
\hline 2 & EU TENHO ESTABELECIDO METAS DE QUANTO ECONOMIZAR PARA A APOSENTADORIA & 1 & 2 & 3 & 4 & 5 \\
\hline 3 & O FUTURO DISTANTE ME PARECE VAGO E INCERTO & 1 & 2 & 3 & 4 & 5 \\
\hline 4 & EU GOSTO DE PENSAR SOBRE COMO EU VIVEREI DE HOJE EM DIANTE & 1 & 2 & 3 & 4 & 5 \\
\hline 5 & EU TENHO UMA VISÃO CLARA DE COMO SERÁ A MINHA VIDA NA APOSENTADORIA & 1 & 2 & 3 & 4 & 5 \\
\hline 6 & EU VIVO MUITO MAIS PARA O PRESENTE DO QUE PARA O FUTURO & 1 & 2 & 3 & 4 & 5 \\
\hline 7 & EU SIGO AS ORIENTAÇÕES DE ECONOMIZAR PARA OS MOMENTOS DIFÍCEIS & 1 & 2 & 3 & 4 & 5 \\
\hline
\end{tabular}

Nome 
Anexo F. Questionário Sociodemográfico

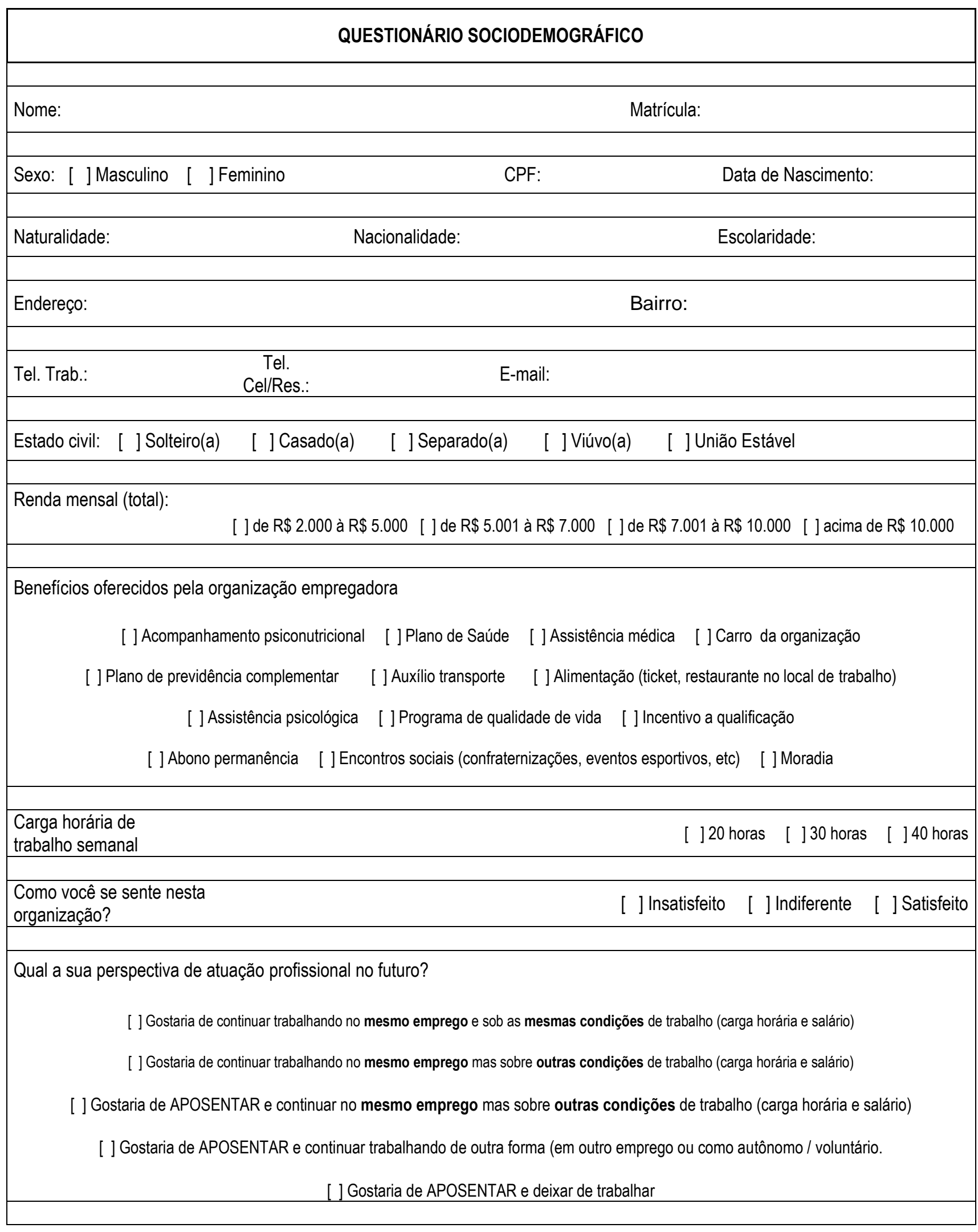


Anexo G. Escala de Bem - Estar Subjetivo (EBES)

\section{Subescala 1}

\section{Escala de Bem-Estar Subjetivo (EBES)}

Gostaria de saber como você tem se sentido ultimamente. Esta escala consiste de algumas palavras que descrevem diferentes sentimentos e emoções. Não há respostas certas ou erradas. O importante é que você seja o mais sincero possível. Leia cada item e depois escreva o número que expressa sua resposta no espaço ao lado da palavra, de acordo com a seguinte escala.

\begin{tabular}{|c|c|c|c|c|}
\hline 1 & 2 & 3 & 4 & 5 \\
Nem um pouco & Um pouco & Moderadamente & Bastante & Extremamente \\
\hline
\end{tabular}

Ultimamente tenho me sentido ...

1) aflito

2) alarmado

3) amável

4) ativo

5) angustiado

6) agradável

7) alegre

8) apreensivo

9) preocupado

10) disposto

11) contente

12) irritado

13) deprimido

14) interessado

15) entediado

16) atento
17) transtornado

18) animado

19) determinado

20) chateado

21) decidido

22) seguro

23) assustado

24) dinâmico

25) engajado

26) produtivo

27) impaciente

28) receoso

29) entusiasmado

30) desanimado

31) ansioso

32) indeciso
33) abatido

34) amedrontado

35) aborrecido

36) agressivo

37) estimulado

38) incomodado

39) bem

40) nervoso

41) empolgado

42) vigoroso

43) inspirado

44) tenso

45) triste

46) agitado

47) envergonhado 


\section{Subescala 2}

Agora você encontrará algumas frases que podem identificar opiniões que você tem sobre a sua própria vida. Por favor, para cada afirmação, marque com um $\mathrm{X}$ o número que expressa o mais fielmente possível sua opinião sobre sua vida atual. Não existe resposta certa ou errada, o que importa é a sua sinceridade.

1

Discordo

Plenamente

48. Estou satisfeito com minha vida

49. Tenho aproveitado as oportunidades da vida

50. Avalio minha vida de forma positiva

51. Sob quase todos os aspectos minha vida está longe do meu ideal de vida

52. Mudaria meu passado se eu pudesse

53.Tenho conseguido tudo o que esperava da vida

54. A minha vida está de acordo com o que desejo para mim

55. Gosto da minha vida

56. Minha vida está ruim

57. Estou insatisfeito com minha vida

58. Minha vida poderia estar melhor

59. Tenho mais momentos de tristeza do que de alegria na minha vida

60. Minha vida é "sem graça"

61. Minhas condições de vida são muito boas

62. Considero-me uma pessoa feliz
3

Não sei

4

5

Concordo

Concordo

Plenamente

|_1_|_2_|_3_|_4_|_5_|

|_1_|_2_|_3_|_4_|_5_|

|_1_|_2_|_3_|_4_|_5_|

|_1_|_2_|_3_|_4_|_5_|

|_1_|_2_|_3_|_4_|_5_|

|_1_|_2_|_3_|_4_|_5_|

|_1_|_2_|_3_|_4_|_5_

|_1_|_2_|_3_|_4_|_5_|

|_1_|_2_|_3_|_4_|_5_|

|_1_|_2_|_3_|_4_|_5_|

|_1_|_2_|_3_|_4_|_5_|

|_1_|_2_|_3_|_4_|_5_|

|_1_|_2_|_3_|_4_|_5_|

|_1_|_2_|_3_|_4_|_5_|

|_1_|_2_|_3_|_4_|_5_| 


\section{Anexo H. Questionário de Satisfação do Cliente}

Caro (a) servidor (a),

Gostaríamos de saber sua opinião sobre a intervenção de preparação para aposentadoria a qual participou. Estamos interessados em sua opinião, seja ela positiva ou negativa. Suas respostas serão sigilosas. Não é necessário se identificar. Sua avaliação será de extrema importância no planejamento de futuras ações para promoção de uma aposentadoria bem-sucedida de servidores públicos federais, deste e de outros órgãos no país.

\section{Muito obrigada por colaborar!}

\section{Circule sua resposta:}

1. Como você avalia a qualidade do Programa/Curso que recebeu?

$\begin{array}{cccc}4 & 3 & 2 & 1 \\ \text { Excelente } & \text { Boa } & \text { Regular } & \text { Ruim }\end{array}$

2. Em que proporção o Programa/Curso atendeu às suas necessidades?

\begin{tabular}{|c|c|c|c|}
\hline 4 & 3 & 2 & 1 \\
\hline $\begin{array}{l}\text { Todos os meus interesses } \\
\text { foram atendidos }\end{array}$ & $\begin{array}{c}\text { A maioria dos meus } \\
\text { interesses foi } \\
\text { atendida }\end{array}$ & $\begin{array}{l}\text { Um pouco dos meus } \\
\text { interesses foi atendido }\end{array}$ & $\begin{array}{c}\text { Nenhum dos meus } \\
\text { interesses foi atendido }\end{array}$ \\
\hline
\end{tabular}

3. Se um familiar ou amigo seu necessitar de ajuda similar, você recomendaria o Programa/Curso a ele ou ela?

\begin{tabular}{|c|c|c|c|}
\hline 1 & 2 & 3 & 4 \\
\hline Não, definitivamente & $\begin{array}{c}\text { Não, eu penso que } \\
\text { não }\end{array}$ & Sim, eu acho que sim & Sim, definitivamente \\
\hline
\end{tabular}

4. Quão satisfeito você está com a quantidade de horas do Programa/Curso que recebeu?

\begin{tabular}{cccc}
1 & 2 & 3 & 4 \\
\hline Muito insatisfeito & Um pouco & Um pouco & Muito satisfeito
\end{tabular}

5. Sua participação no Programa/Curso lhe ajudou a lidar melhor com o planejamento da sua aposentadoria?

\begin{tabular}{cccc}
4 & 3 & 2 & 1 \\
\hline $\begin{array}{c}\text { Sim, ajudou } \\
\text { muito }\end{array}$ & Sim, ajudou & Não, praticamente & Não ajudou \\
um pouco & não ajudou nada
\end{tabular}

6. O que você mais gostou no Programa/Curso?

7. O que você menos gostou no Programa/Curso?

8. Por favor, aponte sugestões para aprimoramento da qualidade do Programa/Curso de preparação para aposentadoria.

(a) Sugiro mudar:

(b) Sugiro manter: 
Anexo I. Sentenças Incompletas

1. Quando penso na aposentadoria eu...

2. Praticar atividade física regularmente para mim é ....

3. Para mim, deixar de comer doces, frituras e refrigerante é...

4. Quando tenho que ir ao médico eu ...

5. Quando penso na minha situação financeira eu...

6. Ter tempo para os amigos é...

7. Meu lazer favorito é...

8. Dedicar-me a práticas espirituais ou religiosas é algo que...

9. Participar de atividades de voluntariado para mim é ...

10. Investir em projetos para aposentadoria para mim é...

11. Quando me aposentar eu pretendo ocupar meu tempo livre com... 
Anexo J. Diagrama de Recursos

Que recursos eu tenho para uma aposentadoria bem-sucedida?

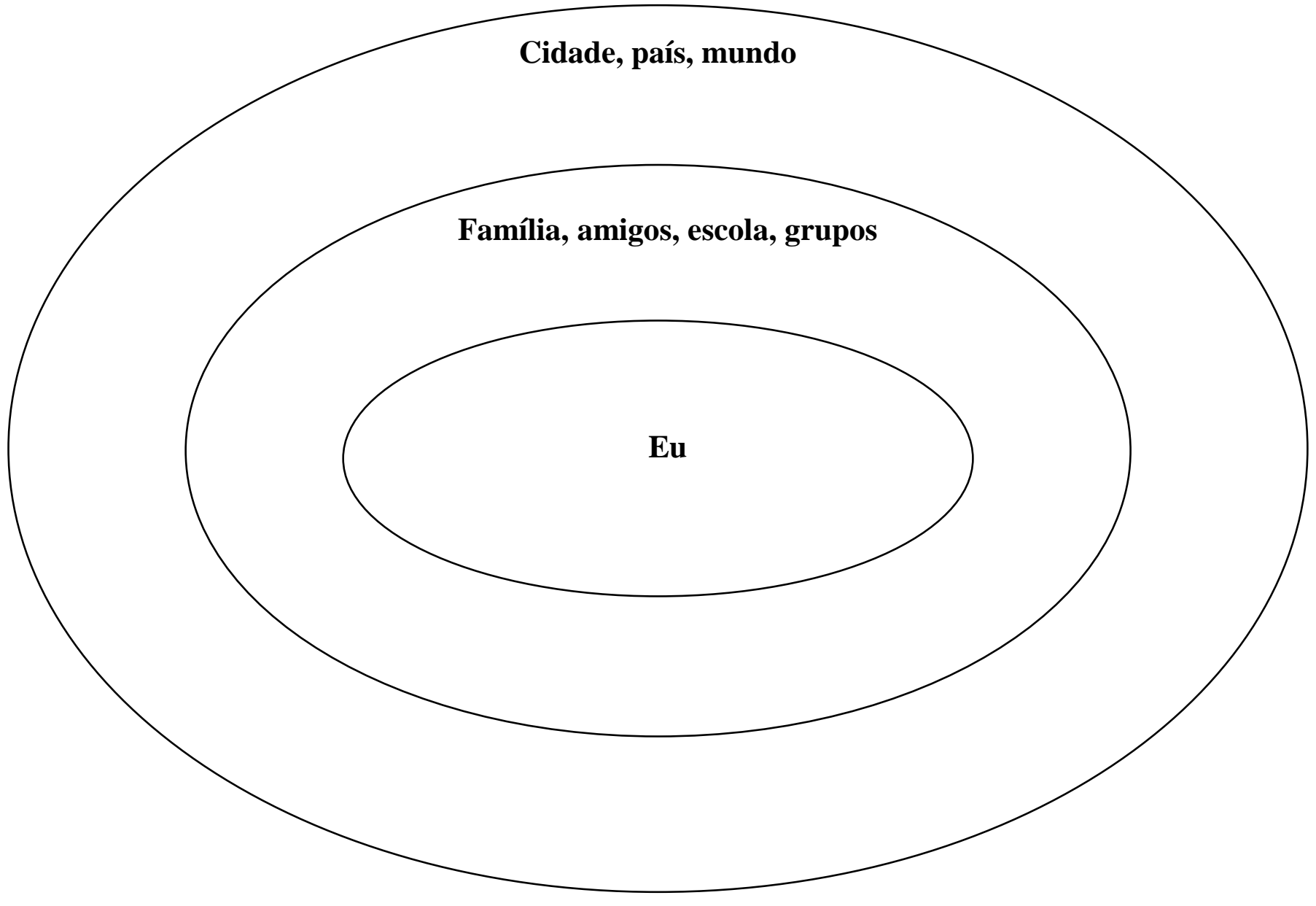


Anexo K. Técnica de Completamento de Frases

Este encontro me fez...

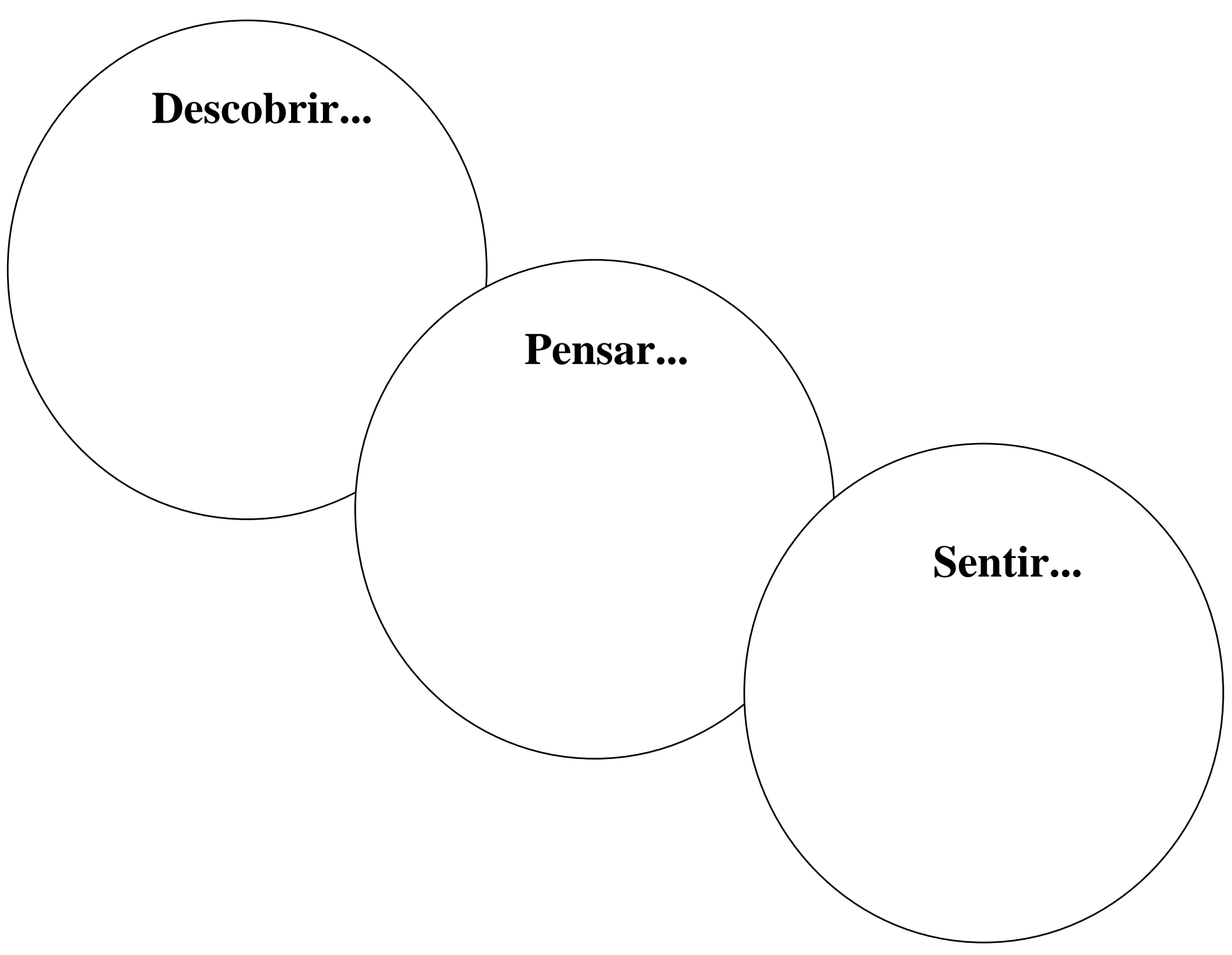


Anexo L. Apresentação de objetivos e principais técnicas aplicadas na intervenção longa

\begin{tabular}{|c|c|c|c|}
\hline Temas por encontro & $\begin{array}{c}\text { Objetivos } \\
\text { (Parte informativa) }\end{array}$ & $\begin{array}{c}\text { Técnica } \\
\text { (Parte Vivencial) }\end{array}$ & Descrição \\
\hline $\begin{array}{l}1^{\circ} \text { Apresentação e } \\
\text { Envelhecimento } \\
\text { Bem-Sucedido }\end{array}$ & $\begin{array}{l}\text { Apresentação e } \\
\text { integração do grupo }\end{array}$ & $\begin{array}{ll}\text { Carteira } & \text { de } \\
\text { identidade } & \end{array}$ & $\begin{array}{l}\text { Preencher a técnica proposta e, em seguida, se } \\
\text { apresentar. Comentar afinidades e interesses em } \\
\text { comum. }\end{array}$ \\
\hline $\begin{array}{l}2^{\circ} \text { Resiliência e } \\
\text { Processo de } \\
\text { Mudança }\end{array}$ & $\begin{array}{lr}\text { Promover } & \text { a } \\
\text { compreensão do } \\
\text { processo de mudança } \\
\text { de pensamento } \\
\text { disfuncional para } \\
\text { funcional, } \\
\text { identificando } \\
\text { emoções, vantagens } \\
\text { e desvantagens. } \\
\end{array}$ & $\begin{array}{l}\text { Diagrama do Nível } \\
\text { de Satisfação }\end{array}$ & $\begin{array}{l}\text { Solicitar aos participantes que marque com } \\
\text { caneta o nível de satisfação em cada uma das } \\
\text { áreas apresentadas no diagrama. Em seguida, } \\
\text { comentar com todos os colegas qual área eles } \\
\text { avaliam que precisa receber maior atenção. } \\
\text { Discutir sobre o que seria necessário para efetuar } \\
\text { mudanças, assim como dificuldades, obstáculos } \\
\text { e recursos. }\end{array}$ \\
\hline $\begin{array}{l}3^{\circ} \text { Legislação } \\
\text { Previdenciária }\end{array}$ & $\begin{array}{lrr}\text { Identificar } & \text { os } \\
\text { critérios legais } & \text { e } \\
\text { pessoais para } & \text { a } \\
\text { aposentadoria. } & \end{array}$ & Júri & $\begin{array}{l}\text { Escolher um participante para ser o juiz, } \\
\text { preferencialmente que esteja indeciso quanto à } \\
\text { aposentadoria. Dividem-se os participantes em } \\
\text { dois grupos que deverão escolher um } \\
\text { representante-"advogado". Apresenta-se um } \\
\text { caso hipotético de um servidor com tempo e } \\
\text { idade para se aposentar. Um grupo deverá } \\
\text { apresentar argumentos à favor da aposentadoria, } \\
\text { enquanto o outro, argumentos contra a } \\
\text { aposentadoria. O advogado deverá apresentar os } \\
\text { argumentos do grupo e o juiz dará o veredicto } \\
\text { final, a favor ou contra a aposentadoria. Ao } \\
\text { final, deixar claro para os participantes que por } \\
\text { mais que hajam argumentos a favor ou contra a } \\
\text { aposentadoria, a decisão deve ser da própria } \\
\text { pessoa. }\end{array}$ \\
\hline $\begin{array}{l}4^{\circ} \text { Autonomia } \\
\text { Financeira }\end{array}$ & $\begin{array}{lr}\text { Sensibilizar } & \text { para } \\
\text { importância } & \text { do } \\
\text { planejamento } & \\
\text { financeiro rrios } & \\
\text { estabelecer critérios } \\
\text { para o planejamento } \\
\text { identificando fatores } \\
\text { que influenciam os } \\
\text { comportamentos de } \\
\text { consumo. }\end{array}$ & $\begin{array}{l}\text { Tabela } \\
\text { 'Gastograna' }\end{array}$ & $\begin{array}{l}\text { Solicitar aos participantes que preencham o } \\
\text { 'gastograna', identificando os gastos pessoais de } \\
\text { acordo com cada opção: "gosto e gasto"; gosto, } \\
\text { mas não gasto"; "não gosto, mas gasto"; "não } \\
\text { gosto e não gasto". Logo após, listar os gastos } \\
\text { mensais dos participantes, identificando o que é } \\
\text { necessidade e desejo. Discutir em grupo, } \\
\text { enfatizando a importância de manter um } \\
\text { equilíbrio entre necessidades e desejos e falar } \\
\text { sobre a relatividade destes termos. }\end{array}$ \\
\hline $\begin{array}{l}5^{\circ} \text { Saúde e } \\
\text { Alimentação } \\
\text { Saudável }\end{array}$ & $\begin{array}{lr}\text { Promover } & \text { a } \\
\text { compreensão } & \text { da } \\
\text { importância de uma } \\
\text { alimentação saudável } \\
\text { para a qualidade de } \\
\text { vida } \\
\text { envelhecimento ativo }\end{array}$ & $\begin{array}{l}\text { Lista } \\
\text { supermercado }\end{array}$ & $\begin{array}{l}\text { Dividir os participantes em grupos de } 3 \text { ou } 4 \text { e } \\
\text { entregar a cada grupo uma cartolina e encartes } \\
\text { de supermercado. Solicitar ao grupo que } \\
\text { preencham a cartolina com figuras de alimentos } \\
\text { "mais consumidos", "menos consumidos" e } \\
\text { consumidos moderadamente". Cada grupo irá } \\
\text { apresentar sua "lista de supermercado" e discutir } \\
\text { sobre a qualidade dos hábitos alimentares. }\end{array}$ \\
\hline $\begin{array}{l}6^{0} \text { Saúde e Atividade } \\
\text { Física }\end{array}$ & $\begin{array}{l}\text { Proporcionar } \\
\text { consciência corporal } \\
\text { e sensibilizar para o } \\
\text { interesse na prática } \\
\text { de atividade física. }\end{array}$ & $\begin{array}{l}\text { Atividade da linha } \\
\text { do tempo sobre } \\
\text { hábitos de atividade } \\
\text { e exercício físico }\end{array}$ & $\begin{array}{l}\text { Preencher a linha do tempo e levar os } \\
\text { participantes a refletirem sobre os benefícios do } \\
\text { exercício físico, obstáculos para a prática de } \\
\text { atividades físicas e estratégias para superá-los. }\end{array}$ \\
\hline
\end{tabular}




\begin{tabular}{|c|c|c|c|}
\hline $\begin{array}{l}7^{\circ} \text { Saúde e } \\
\text { Sexualidade }\end{array}$ & $\begin{array}{l}\text { Ampliar } \text { o r conceito } \\
\text { de } \quad \text { sexualidade, } \\
\text { apresentar } r \\
\text { importância } \quad \text { de } \\
\text { cuidar deste } \\
\text { da vida e relacioná-lo } \\
\text { com a aposentadoria. }\end{array}$ & Discutindo conceito & $\begin{array}{l}\text { Solicitar que cada um diga, em uma palavra, o } \\
\text { significado de sexo e depois sexualidade. Anotar } \\
\text { cada palavra em local visível a todos e discutir } \\
\text { em grupo as diferenças entre os dois termos, } \\
\text { abordando preconceitos, valores, mitos e } \\
\text { aspectos de saúde }\end{array}$ \\
\hline $\begin{array}{l}8^{\circ} \text { Família e } \\
\text { Aposentadoria }\end{array}$ & $\begin{array}{lr}\text { Promover } & \mathrm{a} \\
\text { compreensão } & \text { da } \\
\text { importância } & \text { dos } \\
\text { vínculos familiares } \\
\text { no processo de } \\
\text { aposentadoria. }\end{array}$ & $\begin{array}{l}\text { Avaliando } \\
\text { Heranças } \\
\text { Familiares }\end{array}$ & $\begin{array}{l}\text { Pedir que os participantes reflitam sobre suas } \\
\text { famílias e os valores, sentimentos, pensamentos } \\
\text { atitudes que foram deixadas como "heranças". } \\
\text { Refletir sobre aspectos a melhorar e as heranças } \\
\text { a se preservar. }\end{array}$ \\
\hline $\begin{array}{l}9^{\circ} \text { Pós-carreira e } \\
\text { Empreendedorismo }\end{array}$ & $\begin{array}{lr}\text { Sensibilizar } & \text { para } \\
\text { importância } & \text { de } \\
\text { investir } & \text { em } \\
\text { atividades } & \text { de } \\
\text { ocupação do tempo } \\
\text { na aposentadoria } & \text { e } \\
\text { identificar interesses } \\
\text { e valores pessoais } \\
\text { relacionados } \\
\text { atividades } & \text { de } \\
\text { ocupação do tempo. }\end{array}$ & Imagem guiada & $\begin{array}{l}\text { Colocar uma música tranquila. Pedir que os } \\
\text { participantes fechem os olhos. O facilitador } \\
\text { guiará os participantes, levando-os a pensarem e } \\
\text { imaginarem situações cotidianas ao longo do } \\
\text { tempo (5 ou } 10 \text { anos), avançando cada vez mais } \\
\text { no futuro. Questioná-los como estará sua rotina, } \\
\text { seus planos, alimentação, atividades ao longo do } \\
\text { dia, relações, etc } \\
\text { Pedir que os participantes abram os olhos e } \\
\text { visualizem as figuras espalhadas no chão. } \\
\text { Solicitar que eles peguem } 4 \text { figuras, pensando } \\
\text { em coisas com as quais se identificam e querem } \\
\text { fazer neste momento (momento em que a } \\
\text { imagem guiada parou). Cada um deve falar } \\
\text { sobre as imagens escolhidas e discutir sobre a } \\
\text { necessidade de planejamento e investimento em } \\
\text { novas atividades para aposentadoria. }\end{array}$ \\
\hline $\begin{array}{l}10^{\circ} \text { Rede Social e } \\
\text { Aposentadoria }\end{array}$ & $\begin{array}{l}\text { Promover a reflexão } \\
\text { da importância da } \\
\text { rede social de apoio e } \\
\text { apresentar recursos } \\
\text { para criar e manter } \\
\text { uma rede. }\end{array}$ & $\begin{array}{ll}\text { Mapeando } & \text { as } \\
\text { relações sociais }\end{array}$ & $\begin{array}{l}\text { Colocar música (A lista-Oswaldo Montenegro; } \\
\text { Fotografia-Leoni) enquanto eles montam o mapa } \\
\text { Distribuir folhas com círculos aos participantes e } \\
\text { pedir a eles que escrevam o nome das pessoas } \\
\text { que passaram por suas vidas desde a infância, } \\
\text { ressaltando as amizades e pessoas importantes. } \\
\text { Ao terminarem, pedir para que eles avaliem o } \\
\text { próprio mapa e circulem pessoas que foram/são } \\
\text { especiais, aqueles que gostariam de reatar os } \\
\text { laços. Perguntar o que eles podem fazer para se } \\
\text { reaproximar. Explorar a atividade, verificando a } \\
\text { percepção e os sentimentos dos participantes } \\
\text { diante de seus mapas. Também questionar sobre } \\
\text { como acreditam que essas pessoas percebem o } \\
\text { momento de sua aposentadoria e se acreditam } \\
\text { que haverá mudanças nessas relações quando se } \\
\text { aposentarem. }\end{array}$ \\
\hline $11^{\circ}$ Espiritualidade & $\begin{array}{lr}\begin{array}{lr}\text { Explorar } \\
\text { espiritualidade }\end{array} & \text { dos } \\
\text { participantes, } & \\
\text { promovendo } & \text { a } \\
\text { percepção } & \text { da } \\
\text { importância } & \text { dos } \\
\text { valores na construção } \\
\text { do projeto de vida. }\end{array}$ & $\begin{array}{l}\text { Dinâmica do } \\
\text { "Sentido da Vida" }\end{array}$ & $\begin{array}{l}\text { Distribuir uma folha em branco e pedir que, no } \\
\text { ritmo da música, cada participante dobre sua } \\
\text { folha ao meio, marcando bem o vinco/dobradura } \\
\text { até obter } 8 \text { quadrados. Após, orientar os } \\
\text { participantes, ainda em silêncio, a destacar cada } \\
\text { quadrado. Em cada um dos pedaços, pedir que } \\
\text { escrevam uma palavra que represente um valor, } \\
\text { um sonho ou projeto. "Algo que seja muito } \\
\text { significativo sem o qual a vida perderia o } \\
\text { sentido". Esperar o grupo escrever. Ao terminar, } \\
\text { pedir que eles "deixem pra trás" dois destes }\end{array}$ \\
\hline
\end{tabular}




\begin{tabular}{|c|c|c|c|}
\hline & & & $\begin{array}{l}\text { projetos. Depois abram mão de mais dois, depois } \\
\text { mais um e assim sucessivamente, até sobrar uma } \\
\text { única palavra. Explorar os sentimentos dos } \\
\text { participantes e encerrar a técnica com a reflexão } \\
\text { sobre a necessidade de estarmos conscientes do } \\
\text { que move a nossa vida. }\end{array}$ \\
\hline $12^{\circ}$ Projeto de Vida & $\begin{array}{lr}\text { Estimular } & \text { a } \\
\text { construção de um } \\
\text { projeto de vida e o } \\
\text { estabelecimento de } \\
\text { planos e metas para o } \\
\text { futuro como fator de } \\
\text { proteção para uma } \\
\text { aposentadoria bem } \\
\text { sucedida. }\end{array}$ & $\begin{array}{l}\text { Instrumento } \\
\text { "Projeto de Vida } \\
\text { para } \\
\text { Aposentadoria" }\end{array}$ & $\begin{array}{l}\text { Pedir aos participantes que reflitam e escrevam } \\
\text { sobre seus projetos para após a aposentadoria. } \\
\text { Discutir sobre os planos e metas como fatores de } \\
\text { proteção para a aposentadoria. }\end{array}$ \\
\hline $13^{\circ}$ Encerramento & $\begin{array}{l}\text { Analisar os benéficos } \\
\text { da intervenção e a } \\
\text { satisfação } \quad \text { dos } \\
\text { participantes com o } \\
\text { programa. }\end{array}$ & $\begin{array}{l}\text { Instrumento de } \\
\text { "Avaliação por } \\
\text { Pares" }\end{array}$ & $\begin{array}{l}\text { Solicitar que cada um compartilhe com o grupo } \\
\text { suas respostas sobre as três pessoas (podendo } \\
\text { incluir-se) que mais se beneficiaram com o } \\
\text { programa. } \\
\text { Levar sucatas e materiais diversos e solicitar } \\
\text { que, em grupos de } 3 \text {, os participantes construam } \\
\text { algo que represente o impacto do programa no } \\
\text { seu planejamento de vida e para a aposentadoria. } \\
\text { Aplicar o Questionário de Satisfação do Cliente } \\
\text { adaptado (Corcoran \& Fischer, 2000). }\end{array}$ \\
\hline
\end{tabular}


Anexo M. Roteiro de Entrevista para Avaliação de Processo de Mudança

Este roteiro de entrevista foi desenvolvido para o presente estudo e foi aplicado em participantes das intervenções longa, breve e testemunho após follow-up de seis meses. O objetivo central da entrevista foi averiguar as mudanças motivacionais, cognitivas e comportamentais que ocorreram nesse intervalo de tempo, após participação nas intervenções. A entrevista foi semiestruturada, realizada individualmente e durou cerca de quarenta minutos.

O roteiro da entrevista compreende as seguintes perguntas:

(1) Quais eram seus planos para aposentadoria antes de você participar da intervenção?

(2) Quais são seus planos atuais, após sua participação na intervenção?

(3) Você se sente motivado(a) e/ou decidido(a) a implementar esses planos?

(5) O que de fato você conseguiu implementar após participação ou não participação nas intervenções? 